\title{
Innovation in radiotherapy
}

Citation for published version (APA):

Jacobs, M. J. G. (2017). Innovation in radiotherapy: going from good to better. [Doctoral Thesis, Maastricht University]. Maastricht University. https://doi.org/10.26481/dis.20170622mj

Document status and date:

Published: 01/01/2017

DOI:

10.26481/dis.20170622mj

Document Version:

Publisher's PDF, also known as Version of record

\section{Please check the document version of this publication:}

- A submitted manuscript is the version of the article upon submission and before peer-review. There can be important differences between the submitted version and the official published version of record.

People interested in the research are advised to contact the author for the final version of the publication, or visit the DOI to the publisher's website.

- The final author version and the galley proof are versions of the publication after peer review.

- The final published version features the final layout of the paper including the volume, issue and page numbers.

Link to publication

\footnotetext{
General rights rights.

- You may freely distribute the URL identifying the publication in the public portal. please follow below link for the End User Agreement:

www.umlib.nl/taverne-license

Take down policy

If you believe that this document breaches copyright please contact us at:

repository@maastrichtuniversity.nl

providing details and we will investigate your claim.
}

Copyright and moral rights for the publications made accessible in the public portal are retained by the authors and/or other copyright owners and it is a condition of accessing publications that users recognise and abide by the legal requirements associated with these

- Users may download and print one copy of any publication from the public portal for the purpose of private study or research.

- You may not further distribute the material or use it for any profit-making activity or commercial gain

If the publication is distributed under the terms of Article $25 \mathrm{fa}$ of the Dutch Copyright Act, indicated by the "Taverne" license above, 


\section{INNOVATION IN RADIOTHERAPY GOING FROM GOOD TO BETTER}

in:

MARIA JACOBS 



\title{
INNOVATION IN RADIOTHERAPY
}

\author{
Going from good to better
}

Maria Josephina Gerarda Jacobs 


\section{ISBN}

978-94-6295-681-0

\section{Cover}

C.Rousseau, "Beweging”

\section{Print}

ProefschriftMaken || www.proefschriftmaken.nl

(C) Maria Jacobs, Maastricht 2017 


\section{PROEFSCHRIFT}

ter verkrijging van de graad van doctor aan de Universiteit Maastricht, op gezag van de Rector Magnificus, Prof. dr. Rianne Letschert, volgens het besluit van het College van Decanen, in het openbaar te verdedigen op donderdag 22 juni 2017 om 14.00 uur 


\section{Promotores}

Prof. Dr. Frits van Merode, Professor in logistics and operational management in healthcare, Executive Board, Maastricht University Medical Centre+, Maastricht, Netherlands

Prof. Dr. Philippe Lambin, Professor in functional imaging in radiation oncology, Department of Radiation Oncology, MAASTRO clinic \& GROW School for Oncology and Developmental Biology, Maastricht University Medical Centre+, Maastricht, Netherlands

\section{Co-promotor}

Prof. Dr. Liesbeth Boersma, Professor in radiotherapy for breast cancer, Director Patient Care of department of Radiation Oncology, MAASTRO clinic \& GROW School for Oncology and Developmental Biology, Maastricht University Medical Centre+, Maastricht, Netherlands

\section{Beoordelingscommissie}

Prof. Dr. Trudy van der Weijden, Professor in implementation of guidelines, CAPHRI Care and Public Health Research Institute (Full professor), University Maastricht, Maastricht, Netherlands (chair)

Prof. Dr. Marja van Dieijen-Visser, Professor in clinical chemistry, Chairman Executive Board, Maastricht University Medical Centre+, Maastricht, Netherlands

Prof. Dr. Marcel Verheij, Professor in translational radiotherapy, Head of department of Radiation Oncology, Antoni van Leeuwenhoek - The Netherlands Cancer Institute, Amsterdam, Netherlands

Prof. Dr. Philip Poortmans, Professor in radiotherapy, Head of department of Radiation Oncology, Institute Curie, Paris, France 


\section{Contents}

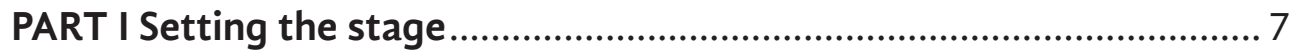

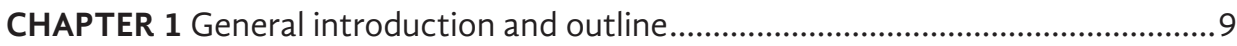

CHAPTER 2 Innovation in radiotherapy, how to measure it ....................................23

PART II Innovations reaching and not reaching the clinic

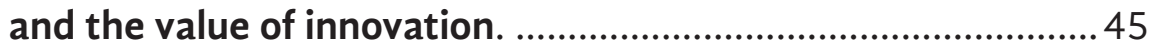

CHAPTER 3 The degree of innovation routinely

implemented in clinical routine.

CHAPTER 4 The efficiency of translational research in radiotherapy........................75

CHAPTER 5 The relationship between innovation and output ................................93

PART III Example implementation design

organizational innovation. ...................................................... 143

CHAPTER 6 Organizational innovation of a large radiotherapy department

set up similar to a prospective clinical trial.

PART IV Conclusions.

CHAPTER 7 General discussion and conclusions

Summary / Samenvatting

Dankwoord...... 207

Curriculum Vitae 



\section{PART 1}

\section{Setting the stage}





\section{CHAPTER 1}

General introduction and outline

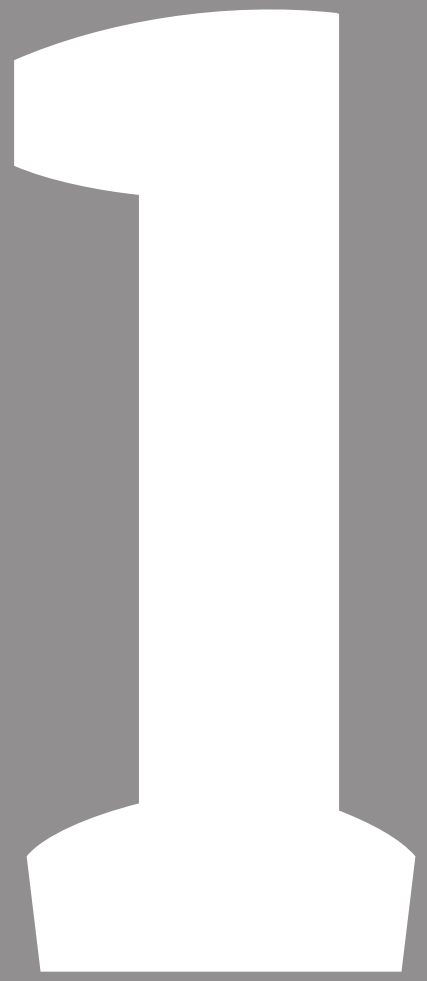


$\frac{1}{0}$
$\frac{1}{4}$
$\frac{2}{0}$
$\frac{1}{U}$
$\vdots$
$\vdots$ 


\section{INTRODUCTION TO SUBJECT OF STUDY}

Innovation in health care is undoubtedly necessary to ensure continuous progress in caring for patients at affordable costs. Medicine has made astonishing advances over the past years [1]. Also in radiotherapy, the remarkable progress in the past has been largely due to the ability to visualize, focus and deliver radiation to the tumour target volume more effectively as a result of the implementation of innovations [2]. These innovations have been guided by research, which can provide a rationale for choosing the best treatment for an individual patient. Health care is among the best endowed of all industries in the richness of its scientific base [3]. This is particularly the case in clinical science and, albeit to a much lesser extent, in healthcare management science. Nevertheless, there is a huge amount of scientific knowledge that remains unused and never reaches the clinic $[4,5]$. Figure 1 shows two possible leaks for research never reaching the clinic: the first one from preclinical research to clinical trials, the second one from clinical trials to clinical routine.

The adoption of innovations in healthcare in general is often complicated because of extensive and strict regulations by law; clinicians' tendency to protect their individual autonomy and reputation; fear for performance gaps which may harm patients; and a lack of knowledge derived from social studies by clinicians to evaluate organizational/ managerial innovations, with the result that in the eyes of medical practitioners these evaluations lack credibility [5].

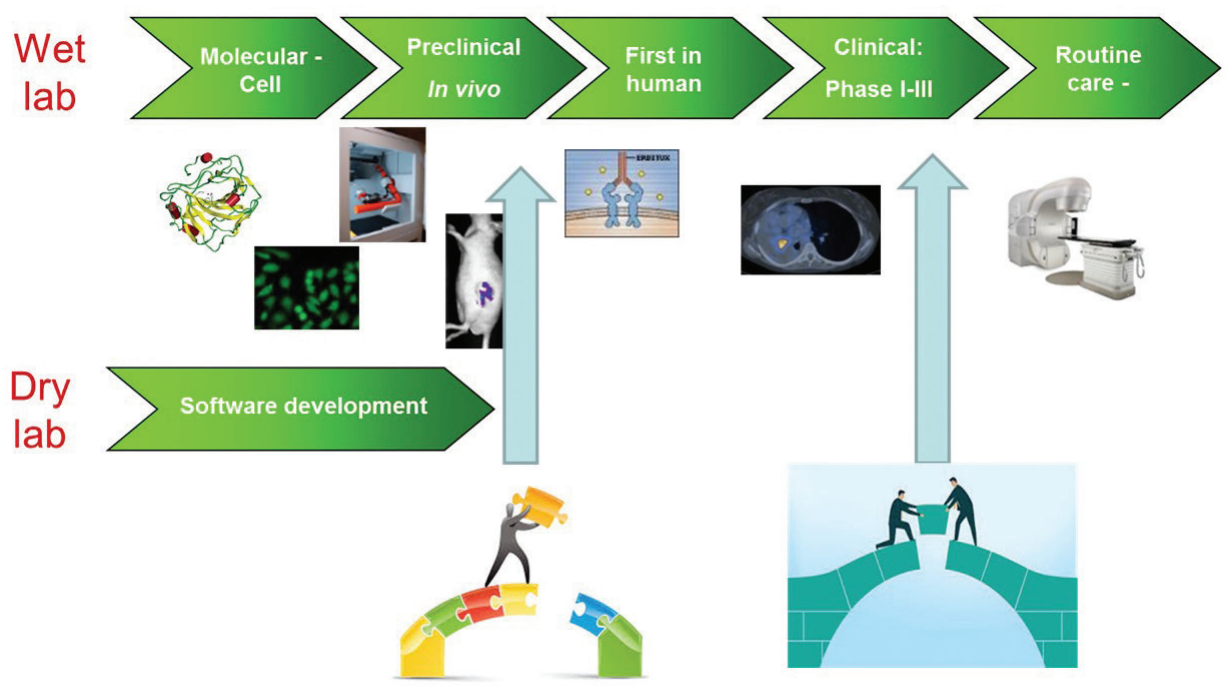

Figure 1: The two leaks for research never reaching the clinic in the research-innovation pipeline 
Beside the "research/implementation gap", meaning that some innovations never reach the clinic at all, diffusion of innovations from one clinic to other clinics can also be a challenge. Some innovations that are not yet well evaluated and have not proven their value might diffuse rapidly, while others with high potential show a slow uptake in practice. Both may lead to disappointments or even damaging effects for care outcomes and patients $[6,7]$.

Furthermore, innovation often also has an economic price. For example, technological innovation in healthcare is an important driver of cost growth $[8,9]$. New technologies can be more expensive and the number of patients treated with these new technologies are often expanded. Doctors and patients sometimes embrace new modes of treatment before their (potential) merits and weaknesses are fully understood. In radiotherapy, the continuous risk of hype regarding the introduction of new technologies has also been described [10]. Innovative radiotherapy technologies typically result in an improved dose distribution or a more accurate dose delivery. However, it is not always certain to what extent these dosimetric advantages will translate into better patient outcomes.

Technological advances frequently lead to higher costs, for example in case of particle radiotherapy, intensity-modulated radiotherapy and positron emission tomography for treatment planning [11]. The costs are to a large extent irreversible and thus cannot be recovered if the expected clinical benefit of the technology does not live up to its expectations [12]. The increase of health-care costs is problematic, because health-care is to a large extent publicly funded. Health care costs have started increasing again, after their growth ground to a halt in 2010 in the wake of the global financial and economic crisis. In the EU, the average annual growth rate in health-care costs per capita in real terms for the period 2005 to 2015 was 3.1\% (2005-2009) and 0.7\% (2009-2015). In 2015 , health-care costs accounted for $9.9 \%$ of GDP in the EU, $10.8 \%$ in the Netherlands and $16.9 \%$ in the US [13].

Not all researchers are convinced of the causality between medical innovation and health-care expenditures. In their opinion, the causality might in fact be reversed, with technological innovation being the result rather than the cause of increased health-care expenditures [14]. Society wants to improve health care and as a result, innovations are made possible. Furthermore, in the literature it is sometimes argued that ultimately, the medical advances have proven to be worth far more than their costs when taking into account both treatment costs and human benefits, measured in quality-adjusted life years (QALYs), for several physical conditions $[9,15]$. The QALY is a product of the quantity and the quality of life lived. It measures both life expectancy and generic healthrelated quality of life in a single value. The amount of money that society is willing to 
pay per gained QALY is referred to as the ceiling ratio. In the Netherlands, the informal ceiling ratio for a high burden of disease is $€ 80,000$ per QALY gained [12]. These QALYs are incorporated in a Markov model which makes economic evaluation regarding the long-term cost-benefit ratio of treatment innovations possible. Insurance companies in the Netherlands increasingly require cost-effectiveness studies to substantiate their decisions regarding reimbursement of new treatments. However, cost-effectiveness studies before innovations are implemented are not yet common practice.

Even if the last-mentioned group of researchers is right in claiming that innovation in health care has no causal relation with higher costs, this does not at all eliminate the obligation to prevent inappropriate use of innovations by failing to use available science and by inefficient and ineffective implementation and diffusion of innovations.

Apart from the possible negative effects for patients and the macro-economic costs, this is also important at the level of every single hospital. In order to realize sustainable hospital performance, there must be a balance between operations, research \& development and innovation. Developing and implementing the right innovation in a cost-effective way is the great challenge!

The aim of this thesis is to investigate how radiotherapy centres in the Netherlands are performing with regard to this challenge. Radiotherapy is a technology-driven medical discipline, where innovation as a continuous activity is an important driver of the strategy in most radiotherapy centres. The performance on research and innovation and the consequent implementation strategies are relevant to individual organisations and to society as a whole. However, few scientific publications address this theme. This thesis aims to contribute to the development of scientific knowledge on innovation implementation in radiotherapy centres, which will offer insight to the radiotherapy community on how to improve their performance in this regard.

The central research question of this thesis is therefore formulated as follows:

Is it possible in radiotherapy to find clues on how to innovate more effectively and more efficiently?

\section{RESEARCH QUESTIONS}

To derive an answer to the central research question, the following specific research questions were investigated:

1. What is defined as innovation in radiotherapy and how can it be measured? 
2. What is the degree of innovation routinely implemented at Dutch radiotherapy centres and what are the differences between centres? To the extent that differences exist, what causes them?

3. How efficient is translational research in radiation oncology; i.e. how big are the leaks in the research-innovation pipeline, what are the facilitators for, barriers to and actions needed for the successful implementation of research as innovations in clinical practice?

4. Is the reported output of healthcare/radiotherapy innovation studies supported by high-level evidence, and to what extent are innovations implemented at Dutch radiotherapy centres based on scientific evidence?

5. Is it possible for an organisational innovation process to simultaneously improve patient care processes and clinical research activities, and is it possible to structure this in a manner similar to a prospective clinical trial?

Ad 1. When investigating the challenge of developing and implementing the right innovation in a cost-effective way, the first requirement is a clear definition of what the concept of innovation means in radiotherapy. After all, the body of literature on innovation in general is very rich and encompasses a whole range of different aspects [16]. Some definitions are based on the process of innovation, others on the degree of novelty of the innovation (radical or incremental), on the competences of the organisation (innovation generating or innovation adopting), or on the content of the innovation itself (types of innovation). There are also discussions in the literature about the question whether inventions that result from research ought to be considered as innovations. There is a general definition of innovation which is largely accepted among researchers in the field: "The intentional introduction and application within a role, group or organization of ideas, processes, products or procedures new to the relevant unit of adoption, designed to significantly benefit the individual, group or wider society" $[5,17,18]$. Important is the phrase "intentional application". This means that basic research, referring to experimental or theoretical work undertaken primarily to acquire new knowledge without any particular application or use in clinical practice, is not seen as innovation but as an invention, as is the case, for example, with some research in the area of radiobiology and physics. This definition, however, gives insufficient depth to all different aspects of innovations described above.

This leads to our first research question:

"What is defined as innovation in radiotherapy and how can it be measured?"

Ad 2. Knowing the definition of innovation in radiotherapy, the next step is to investigate the degree of innovation routinely implemented in radiotherapy centres in the Netherlands. 
We investigated if radiotherapy centres quickly adopt innovations within their discipline and if there are differences between centres (especially academic and non-academic centres). The Dutch, European, and American professional societies for radiotherapy and oncology take a very active part in sharing knowledge and experience. However, the present focus is more on the scientific basis of the innovation process and much less on the practical implications. From the literature, it is known that even when innovations are implemented successfully in one location, they often disseminate slowly, if at all [3]. Studies of the dissemination of innovation focus on three basic clusters of influence that in descriptive studies correlate with the rate of spread of a change: a. perceptions of the innovation, b. characteristics of the people who adopt the innovation, or fail to do so, c. contextual factors, especially involving communication, incentives, leadership and management [3].

The second research question is thus formulated as:

"What is the degree of innovation routinely implemented at Dutch radiotherapy centres and what are the differences between centres? To the extent that differences exist, what causes them?"

Ad 3. The previous research questions have the intention of offering more insight into the innovation concept in radiotherapy, and of actually achieving more knowledge about the degree of innovation in radiotherapy centres. However, concrete and scientifically based information about the question whether scientific findings in radiotherapy remain unused, and to what extent, is still lacking. This is a matter of interest, because the pace of translation of scientific discoveries into clinical practice in radiotherapy is not well known, but is described as slow in health care in general [19-21]. This affects the challenge of implementing the right innovation in a cost-effective way as described in the introduction above. In Figure 1, we showed the two leaks in the research-innovation pipeline. From the literature, we know that decisions to implement innovations or improvements in health care are influenced by many contextual factors at micro (individual/group), meso (organizational/system) and macro (regulatory/policy) levels [22]. Research evidence is only one of the multiple factors [23]. Obviously, the implementation of evidence-based health innovation is a complex process. If a research/implementation gap also exists in radiotherapy, we need to know more about facilitators and barriers in radiotherapy centres and about what actions can be taken to improve implementation rates.

Therefore, the third research question is:

"How efficient is translational research in radiation oncology (how big are the leaks in the research-innovation pipeline, Figure 1) and what are facilitators, barriers and actions to be taken for successful implementation of research as innovations in clinical practice?" 
Ad 4. Innovation implementation does not always result in better performance. This can be the case because some innovations which are not well evaluated, or the value of which has not been proven, sometimes diffuse rapidly $[6,7]$.

This can lead to disappointments or even damaging effects for care outcomes and patients. Furthermore, this can be a waste of time and money. Therefore, more knowledge is required on the relation between innovation implementation and performance for innovations in radiotherapy centres; this holds both for clinical innovations and managerial innovations.

This leads to our fourth research question:

"Is the output of innovation studies in health care/radiotherapy reported with high-level evidence, and to what extent are implemented innovations in Dutch radiotherapy centres based on scientific evidence?"

Ad 5. Clinical innovations such as new treatments and new technology can often be examined before introduction with extensive phase I, II and III trials. If performed properly, this type of research can come with a high level of evidence. It is not easy to perform randomized controlled trials in management innovation practice. Instead, observational studies or other research designs with lower evidence levels are used. An evidence base is created by performing the research several times and regularly under different circumstances. Although in the past two decades a large number of studies have been conducted with the intention to provide research into management practice, a solid evidence base is still lacking. Most insights are still based on the personal experience of experts. This has much lower evidential value [24-26]. Clinicians are often, by virtue of their training, familiar with experimental research methods driven by the fields of basic and life sciences. For certain organizational innovations, clinicians are forced to venture outside the familiar life sciences methodologies. These often fail to produce the types of quantitative answers to research questions that clinicians want and expect. This causes credibility problems in the eyes of many medical practitioners [27].

An aim of this thesis is to explore if research designs more similar to clinical research are possible in managerial implementation studies, since it can be expected that this will help medical professionals to get confidence in carrying out managerial innovations in their daily practice. For that purpose, a frequently introduced organizational innovation was selected: an organizational development process of a radiotherapy department. With this process, the aim was to improve the integration of innovation and research in clinical routine. 
Therefore, the fifth research question of this thesis is:

"Is it possible for an organisational innovation process to simultaneously improve patient care processes and clinical research activities, and is it possible to structure this in a manner similar to a prospective clinical trial?"

\section{OUTLINE OF THE THESIS AND METHODS USED}

The outline of the thesis is shown in Figure 2

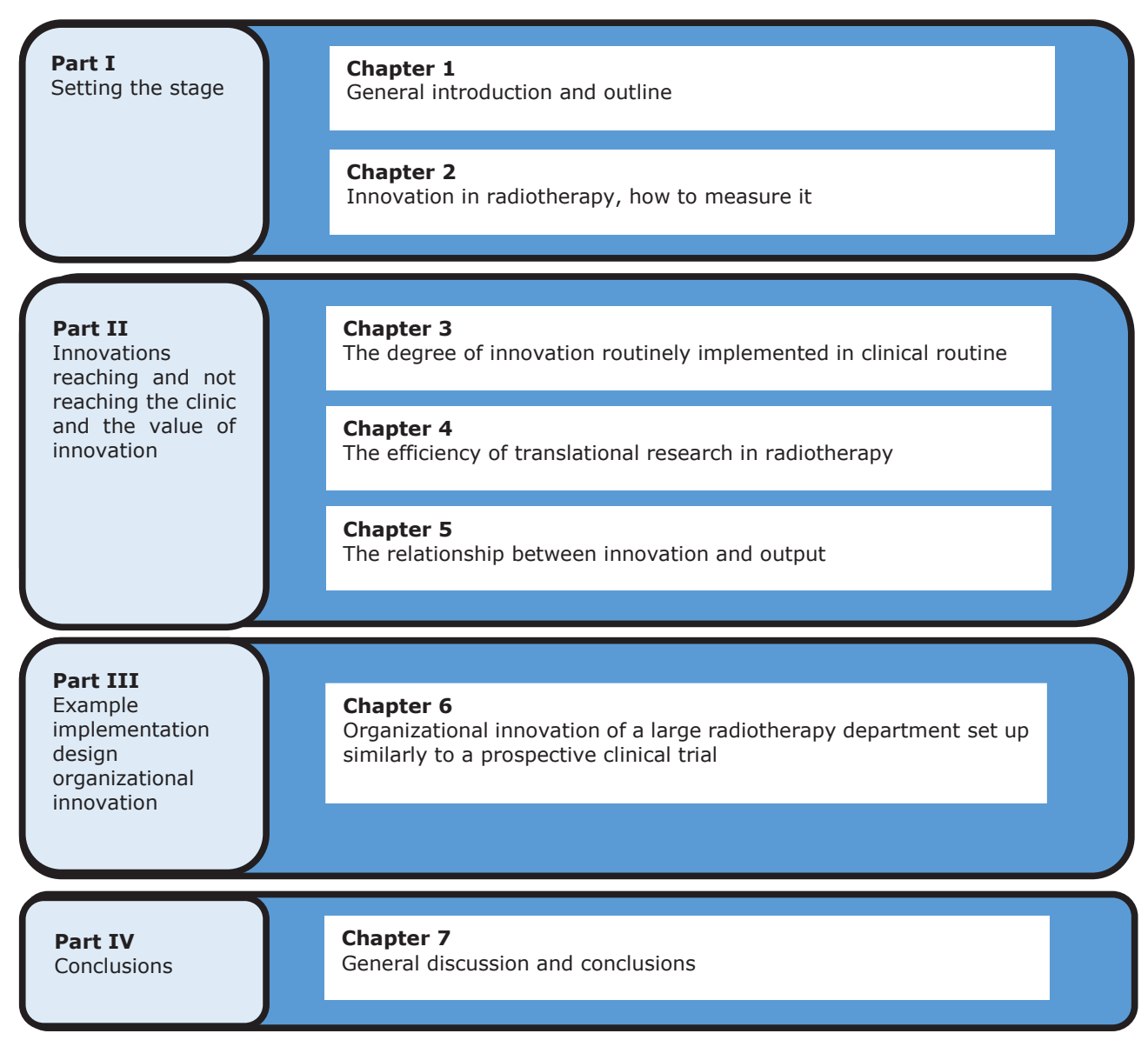

Figure 2: Outline of the thesis 
The thesis consists of four parts:

- Part I: setting the stage (Chapters 2 and 3)

Chapter 2 describes the concept of innovation and presents a selection of viewpoints that are relevant to understanding innovation in radiotherapy centres. Also, an instrument is provided for measuring innovation in radiotherapy centres (research question 1).

The Delphi method will be applied with four rounds to identify these indicators. For the Delphi panel, both experts in the field of radiotherapy (professors and chairs of radiotherapy departments) and experts in the field of innovation (professors with a chair at Dutch universities related to innovation sciences) will be consulted.

- Part II: Innovations reaching and not reaching the clinic and the value of innovation In Chapter 3 the degree of innovations in Dutch radiotherapy centres is measured with the instrument developed, which is described in Chapter 2. Differences between academic and non-academic centres will be investigated. Furthermore, it will be examined whether the innovation implementation performance of centres shows a broad range or if centres are performing equally (research question 2 ).

For the research design of this study, a descriptive multicentre cross-sectional design is used. With this design, an observational study will be conducted that analyses data collected from a population or a representative subset (in our case, all radiotherapy centres in the Netherlands will be asked to participate), over a specific time period (in our case three years, 2011-2013).

To get an idea of the degree of unused scientific (innovative) findings in radiotherapy practice, the efficiency of research implementation in radiotherapy will be studied in Chapter 4 (research question 3). This study will be conducted in a large academic radiotherapy institute in the Netherlands, both in clinical routine and in clinical trials approved by the internal review board as well (two leaks).

The design of this study is a quantitative single case-report. The number of implementations of scientific findings published in the period 2008-2011 (four years) in the period from 2008 until 2016 will be studied. Furthermore, facilitators and barriers for research implementation will be listed. Implementation rates and the frequency of facilitators and barriers will be calculated.

Because innovation implementation is not without problems when considering the introduction of poorly evaluated innovations or the slow uptake in practice of 
innovations with a high potential, the relation between innovation implementation and performance is investigated in Chapter 5 (research question 4).

The design of the study is a systematic literature review. Three searches are performed. The first one is a general search including innovations in hospital care. The second is a search specific to radiotherapy. The third one is performed per cancer care path and radiotherapy technique. Furthermore, the results of the review per cancer care path/ radiotherapy technique will be compared with the results of the implementation of new treatment innovations as studied in Chapter 3.

- Part III: Example implementation design organizational innovation

Chapter 6 examines the possibility of using a research design which is familiar to clinicians for organizational innovations in radiotherapy centres (research question 5). A restructuring process with the objective of simultaneously improving patient care processes and clinical research activities will be selected. The results of mimicking the rigorous methodology of a prospective clinical trial in an academic radiotherapy department will be reported.

The design of this study is a single case-report with quantitative data and qualitative data gathering.

- Part IV: General discussion and conclusions

In Chapter 7, a general discussion will be presented including the limitations of this research, the concluding remarks, recommendations for fostering innovations in a rational way and future perspectives. 


\section{REFERENCES}

1. Herzlinger RE. Why innovation in health care is so hard. Harvard business review. 2006;84(5):58.

2. Bortfeld T, Jeraj R. The physical basis and future of radiation therapy. The British journal of radiology. 2014.

3. Berwick DM. Disseminating innovations in health care. Jama. 2003;289(15):1969-75.

4. Corrigan JM. Crossing the quality chasm. Building a Better Delivery System. 2005.

5. Länsisalmi H, Kivimäki M, Aalto P, Ruoranen R. Innovation in healthcare: a systematic review of recent research. Nursing science quarterly. 2006;19(1):66-72.

6. Tymstra T. The imperative character of medical technology and the meaning of "anticipated decision regret". International journal of technology assessment in health care. 1989;5(02):207-13.

7. Dixon-Woods M, Amalberti R, Goodman S, Bergman B, Glasziou P. Problems and promises of innovation: why healthcare needs to rethink its love/hate relationship with the new. BMJ quality \& safety. 2011;20(Suppl 1):i47-i51.

8. Barbash GI, Glied SA. New technology and health care costs-the case of robot-assisted surgery. New England Journal of Medicine. 2010;363(8):701-4.

9. Bodenheimer T. High and rising health care costs. Part 2: technologic innovation. Annals of internal medicine. 2005;142(11):932-7.

10. Bortfeld T, Marks LB. Hype cycle in radiation oncology. International Journal of Radiation Oncology• Biology• Physics. 2013;86(5):819-21.

11. Peeters A, Grutters JP, Pijls-Johannesma M, Reimoser S, De Ruysscher D, Severens JL, et al. How costly is particle therapy? Cost analysis of external beam radiotherapy with carbon-ions, protons and photons. Radiotherapy and Oncology. 2010;95(1):45-53.

12. Ramaekers B. Acknowledging Patient Heterogeneity in Health Technology Assessment: Towards Personalized Decisions in Innovative Radiotherapy Treatments: Maastricht University; 2013.

13. OECD/EU. Health at a Glance: Europe 2016: OECD Publishing.

14. Djellal F, Gallouj F. Innovation in hospitals: a survey of the literature. The European Journal of Health Economics. 2007;8(3):181-93.

15. Cutler DM, McClellan M. Is technological change in medicine worth it? Health affairs. 2001;20(5):11-29.

16. van Poucke A. Towards radical innovation in knowledge-intensive service firms. 2005.

17. Anderson N, De Dreu CK, Nijstad BA. The routinization of innovation research: A constructively critical review of the state-of-the-science. Journal of organizational Behavior. 2004;25(2):147-73.

18. Omachonu VK, Einspruch NG. Innovation in healthcare delivery systems: a conceptual framework. The Innovation Journal: The Public Sector Innovation Journal. 2010;15(1):1-20. 
19. Sung NS, Crowley Jr WF, Genel M, Salber P, Sandy L, Sherwood LM, et al. Central challenges facing the national clinical research enterprise. Jama. 2003;289(10):1278-87.

20. Bero LA, Grilli R, Grimshaw JM, Harvey E, Oxman AD, Thomson MA. Closing the gap between research and practice: an overview of systematic reviews of interventions to promote the implementation of research findings. British Medical Journal. 1998;317(7156):465-9.

21. Lenfant C. Clinical research to clinical practice-lost in translation? New England Journal of Medicine. 2003;349(9):868-74.

22. Turner S, Morris S, Sheringham J, Hudson E, Fulop NJ. Study protocol: DEcisions in health Care to Introduce or Diffuse innovations using Evidence (DECIDE). Implementation Science. 2016;11(1):1.

23. Sanson-Fisher RW. Diffusion of innovation theory for clinical change. Medical journal of Australia. 2004;180(6):S55.

24. Management THC. In search of evidence 2009. Available from: http://www. changemanagementonline.com/in-search-of-evidence/.

25. ten Have S, ten Have W, Huijsmans A-B, Otto M. Reconsidering Change Management: Applying Evidence-Based Insights in Change Management Practice: Routledge; 2016.

26. Steven ten Have MOEB. In search of evidence. Steering clear of 'sirens' in consulting and management. TEN HAVE Change Management. 2015.

27. Mays N, Pope C. Qualitative research in health care: Wiley Online Library; 1996. 



\section{CHAPTER 2}

\section{Innovation in radiotherapy, how to measure it}

Maria Jacobs

Liesbeth Boersma

Andre Dekker

Mark Govers

Philippe Lambin

Frits van Merode

How to measure innovation in radiotherapy: an application of the Delphi method

Published in: Journal of Hospital Administration, 2015 April;4(4):14-23. DOI: $10.5430 /$ jha.v4n4p14

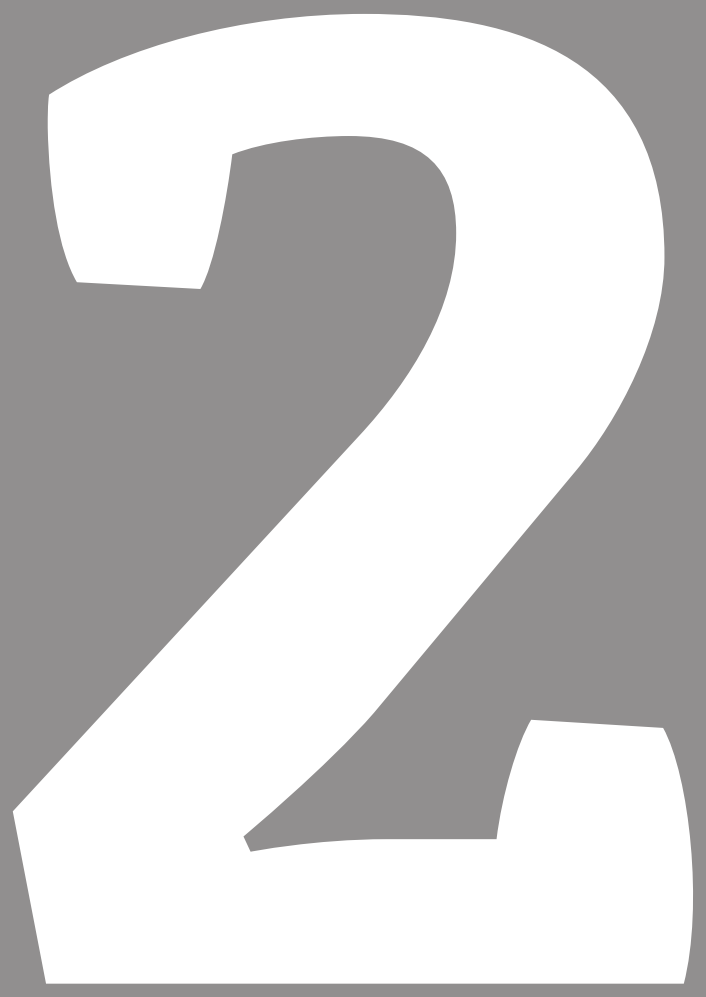




\section{ABSTRACT \\ Objective}

Innovation is an important driver for improving the quality of health care, yet a tension exists between innovation and providing cost-effective health care. To develop strategies that promote innovation, parameters are needed that are indicative of innovation. However, no recognised indicators of innovation in radiotherapy are currently available. The aim of this study is to fill that gap by providing a framework for measuring innovation. This should facilitate future multi-centric studies on strategies aimed at promoting innovation in radiotherapy.

\section{Methods}

We applied the Delphi method in four rounds. The chairpersons of all Dutch radiotherapy departments were asked to suggest indicators. The resulting inventory was assessed by a number of Dutch radiation oncologists, medical physicists and managers. After implementing a cut-off score on suitability and measurability, we asked Dutch professors on innovation to assess the remaining indicators. Finally, the chairpersons reached consensus.

\section{Results}

On the basis of the Delphi study, we derived 13 indicators in four categories, more specific product innovation, technology innovation, market innovation and organisational innovation, for measuring both incremental and radical innovations in radiotherapy; these indicators are also suitable for measuring the generation and adoption of innovations.

\section{Conclusions}

We were successful in reaching consensus amongst the experts on indicators that measure innovations in radiotherapy. The developed tool will be used to investigate the relation between innovation and possible factors inhibiting or stimulating successful innovation and between the level of innovation and its effects. 


\section{INTRODUCTION}

As in general healthcare, there is an increasing pressure in radiotherapy to deliver costeffective treatment [1]. This pressure threatens the continuous development and implementation of innovations, and thereby the quality of radiotherapy, since innovation has been shown to be an important driver of quality care [2-9]. Technological innovations in radiotherapy have, for instance, resulted in better treatment outcomes by fostering the ability of radiation oncologists to deliver radiation more precisely, increasing the dose to tumour targets and reducing the dose to normal tissues and critical structures $[10,11]$. This is in line with findings in general hospitals; Wu et al., for example, have shown that medical and administrative innovations have a positive effect on care outcomes [9]. The tension between cost containment and innovation can be felt at several levels.

First of all, the tension between innovation and cost containment arises in particular in situations where innovations and daily practice are integrated, as is the case in many radiotherapy departments, which are often affiliated to or embedded in a university medical centre [12-14]. Whereas efficiency requires standardisation and meta-routines for non-routine activities, small-step or incremental innovations call for experimentation (on existing practices) and experience-based approaches [15, 16]. To develop and implement innovations, treatment processes are in constant evaluation and experiments must be conducted to improve processes and treatments. Such an approach demands additional means and experimentation time, which could be regarded as a waste if the experiment turns out to be unsuccessful.

Second, the organisational conditions and organisations' management styles vary from efficiency-oriented to more experiment-oriented organisations. In an efficiency-oriented setting, monitoring, controlling and a coordinative management style are required [17]. In an experimental setting, a consultative, coaching management style is more suitable [18]. If an organisation strives to make not just incremental but also more radical and major innovations, the demands for organisational conditions and management style will change again, as new external knowledge has to be imported. An adhocratic, entrepreneurial and visionary management style is paramount when radical innovations are to be made, because this can encourage employees to move across organizational and technical boundaries $[15,17,19]$.

A third aspect that influences the degree of tension is the distinction between generating innovation by means of research and adopting innovations. Some experts suggested that innovation refers solely to the implementation of new or significantly improved treatment or technologies. Others state that innovation can also refer to research that generates new knowledge. This distinction is important because generating innovation 
requires different conditions than implementing innovations or improving efficiency [14]. Aiming for all these aspects simultaneously might cause tension in the organisation, because of conflicting requirements.

Since continuous innovation is essential for improving the quality of care, [2-9] the tension between cost containment and innovation as described above needs to be handled adequately. Organisations that are more successful in this respect may for example adapt their management style to the situation at hand [20].

To investigate which strategies are effective in stimulating different kinds of innovations, measurable and validated indicators are needed to measure innovation. These indicators could help organisations to develop and monitor their innovation ability and practices, by clarifying what they need to focus on in order to maximise their innovation success rate [21]. Because our research concerns the field of radiotherapy, we need to find indicators that are suitable for measuring innovation in radiotherapy centres.

In literature no closely defined or generally accepted approach has been found for measuring innovation in general $[8,21-23]$. For the service sector, to which health care including radiotherapy more or less belong, indicators have been developed and listed in the Community Innovation Survey (CIS) [24]. The development of the CIS was instigated by the European Commission, as a follow-up of the OECD initiative (Organisation for Economic Co-operation and Development) to develop a manual for a survey on innovation. The guidelines of the OECD manual only comprised manufacturing activities and technological and product innovation [25]. However, the CIS also has limitations in the sense that it is focussed on technological innovation and concentrates mainly on business services and not on health care $[26,27]$. Previous research has emphasised that a sector-specific measurement tool is needed "in this case radiotherapy-specific" because activities can vary greatly within the different service sectors [28]. Furthermore, measurement tools have to render a very exact measurement of what is most important in a certain innovation phase in a particular sector, and register specific characteristics such as knowledge-intensity [21, 29]. Finally, embedded knowledge must be measured as well; this is knowledge that is not codified but is "stored" in individuals' minds or organisational routines [21].

Several studies on innovation indicators have been conducted which show that, over time, innovation indicators have evolved, becoming progressively more complex and meaningful $[21,30,31]$. In fact, there are potentially hundreds of indicators imaginable. Which indicators are most suitable for measuring innovation in a specific situation or sector is still debatable, however, and needs to be clarified in each specific sector and situation such as in our case in radiotherapy $[32,33]$. 
The aim of this study is to identify indicators of innovation that are suitable for measuring innovation in radiotherapy. It is required that these indicators can be applied in a multicentric setting, can capture both incremental innovation and more radical innovations, and can distinguish between generating and implementing innovations.

\section{METHODS}

We applied the Delphi method to identify the indicators with four rounds (see Figure 1) $[34,35]$. This method makes it possible to consult both experts in the field of radiotherapy and experts in the field of innovation (professors with a chair related to the

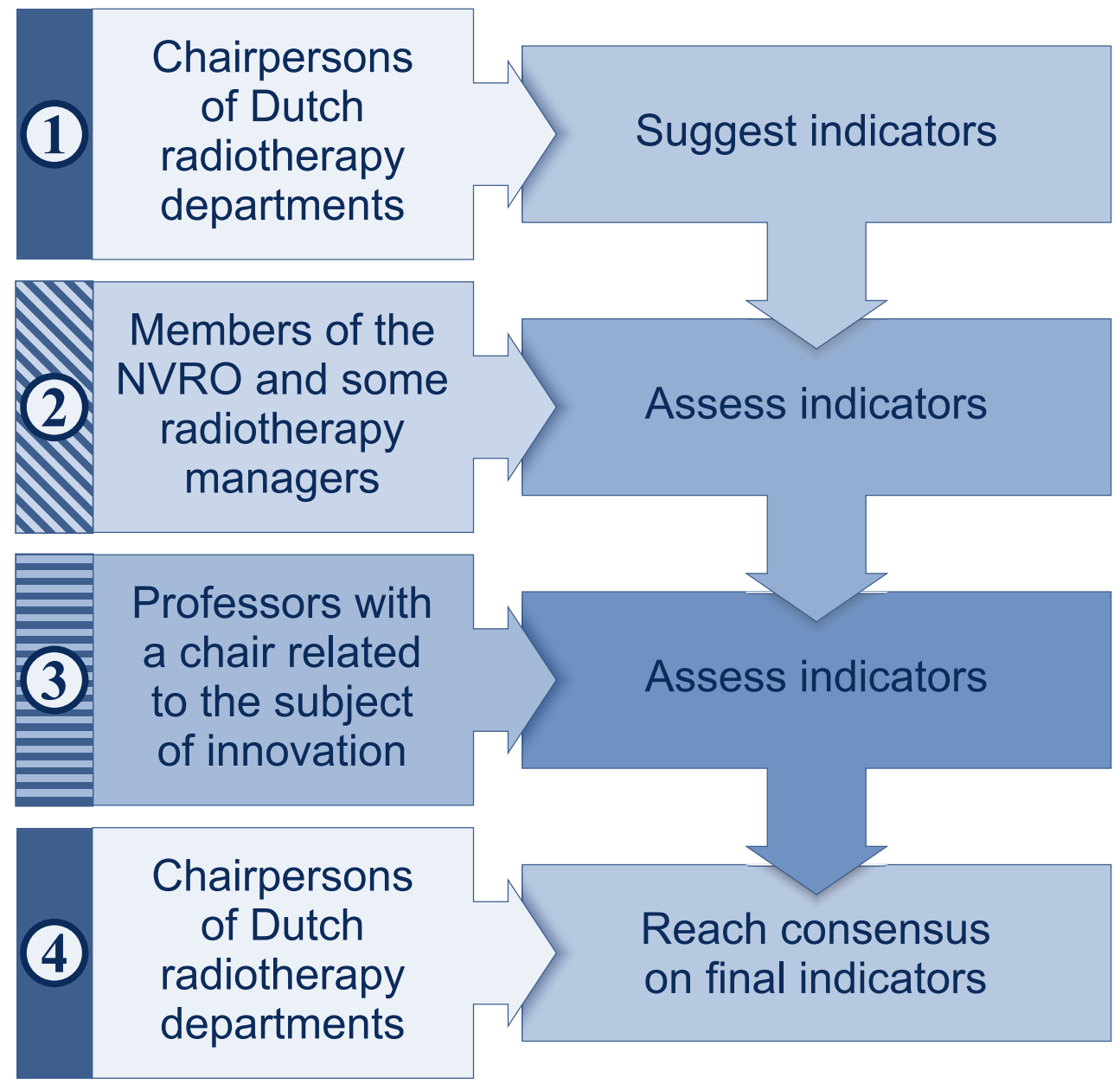

Figure 1. Overview of the Delphi rounds 
field of innovation). This method has been successfully followed in radiotherapy research as well as other research fields [36-42].

Since no patients were involved in our surveys, the law in the Netherlands does not require ethics clearance.

\section{Round 1}

\subsubsection{Methods and materials}

Based on literature, we distinguished four types of innovation [43]. For each type of innovation, we started by defining a few indicators in a brainstorm session in our clinic $(\mathrm{MJ} / \mathrm{LB} / \mathrm{AD} / \mathrm{PL})$. These indicators were put together in a questionnaire, sent out in Round 1 to the chairpersons of all 21 Dutch radiotherapy departments (experts in radiotherapy). The chairpersons were asked to agree or disagree with the indicators listed and to suggest additional indicators.

\subsubsection{Data analysis}

All suggested indicators were included in the next round without further assessment.

\section{Round 2}

\subsubsection{Methods and materials}

The indicators (96) suggested by participants in Round 1 were put in a questionnaire. The questionnaire was sent to a group of 330 people, mainly members of the NVRO (the Dutch Society for Radiation Oncology) and a small number of managers active in the radiotherapy domain (also experts in radiotherapy). These people were asked to rate each indicator on its suitability and measurability. A 5-point Likert scale was used for all answers; participants could also add comments of their own. To improve the response rate, two questionnaire reminders were sent out.

\subsubsection{Data analysis}

We ranked the indicators obtained in the second round on the basis of agreement of the scores assigned by the respondents. To do this, we calculated the mean scores and interquartile ranges (IQR) [44]. The IQR is the absolute value of the difference between the 75th and 25th percentiles, with smaller values indicating a higher degree of consensus.

Indicators were selected on the basis of a cut-off: a mean score of $\geq 3.00$ for suitability, $\geq 3.50$ for measurability and an IQR of 2 . This cut-off value was chosen in a way that the number of indicators was reduced to the most suitable and measurable ones; literature shows that it is important to keep the list of indicators as short and simple as possible [45]. Because suitability was also assessed by the innovation professors (which also 
reduced the number of indicators to the cut-off), we decided to set the cut-off for measurability at 0.5 higher than for suitability. We used a box-plot analysis to determine whether the experts differed in their opinions on the suitability and measurability of the indicators.

\section{Round 3}

\subsubsection{Methods and materials}

We sent a questionnaire to 26 innovation experts (all Dutch professors with a chair related to the field of innovation, as described on their universities' websites), asking them to approve or reject the indicators suggested by the radiotherapy experts, so as to obtain greater certainty that the indicators did indeed measure innovation.

\subsubsection{Data analysis}

We decided to accept an indicator if it was not rejected by the majority of the Round 3 innovation experts assessing the indicator. To promote consistency in terminology, we reformulated some of the indicators.

\section{Round 4}

\subsubsection{Methods and materials}

We sent a questionnaire to the Round 1 chairpersons of radiotherapy departments if they agreed with the indicators chosen in the previous rounds.

\subsubsection{Data analysis}

Research into Delphi studies shows that no clear criteria are available for the moment when consensus is reached [46]. We decided that consensus had been reached when $80 \%$ of the Round 1 respondents agreed that the selected indicators were good measures for the four types of innovation, because this is the percentage that is usually applied [36]. After consensus was reached, the Delphi study was closed.

\section{RESULTS}

\section{Response rate}

In Delphi Round 1, 15 of the 21 chairpersons from the radiotherapy departments we approached accepted the invitation to participate in our study; one person asked if they could skip Round 1. In the end, 14 chairpersons responded to the questionnaire on indicators.

The Round 2 questionnaire had a 20\% response rate, and was completed by 66 of the 330 invited NVRO members/ managers of radiotherapy departments. An additional 56 of the 330 invitees (17\%) stated their reason for not participating in the study. 
In Round 3, 18 of the 26 professors with a chair related to innovation who we approached gave an initial reply. Four of these professors added comments but made no assessment, while another four people stated that, due to circumstances, they had no time to participate. In total, 10 of the 26 professors we approached assessed the indicators.

In Round 4, 14 of the 15 chairpersons of Dutch departments of radiotherapy reached an agreement on the indicators suggested in the previous rounds.

\section{Indicators for innovation}

Round 1 resulted in a lot of possible indicators (96 indicators).

The analysis of the Round 2 assessments resulted in 17 remaining indicators. After comparing these indicators with the literature, we moved one indicator from "product innovation" to "technological innovation" [47]. The box-plot analysis showed that there were no significant differences between the appraisals by different professionals $(p>.05)$.

In Round 3, the professors we consulted varied in their opinion on the indicators suggested. In some cases, the professors suggested we reword an indicator. We reformulated some of the indicators to make them more consistent. We used the wording chosen in the CIS for a number of comparable indicators. Because only one indicator remained for organizational innovation, we also added some relevant indicators from the CIS to our list.

In Round 4, 14 of the 15 chairpersons responded to the list resulting from Round 3. The experts all approved of the indicators suggested, which renders a $93 \%$ consensus, far more than the required $80 \%$ usually applied in Delphi studies [36]. Figure 2 presents an overview of the radiation-oncology-related indicators of innovation that were finally agreed upon.

\section{DISCUSSION}

This paper describes the first attempt to develop a set of indicators that measure innovation in radiotherapy. Our Delphi study design seems to have been an effective tool for generating such indicators. Unlike the approach taken in most Delphi studies, we included experts from different disciplines, namely, the fields of radiotherapy and innovation [37]. The advantage of taking this approach was that we could combine the knowledge and insights from experts in radiotherapy with those from experts in the field of innovation. We considered it important to apply such an integrated approach, because as yet no clear picture of innovation exists in the literature, or in the fields of innovation and radiotherapy. 

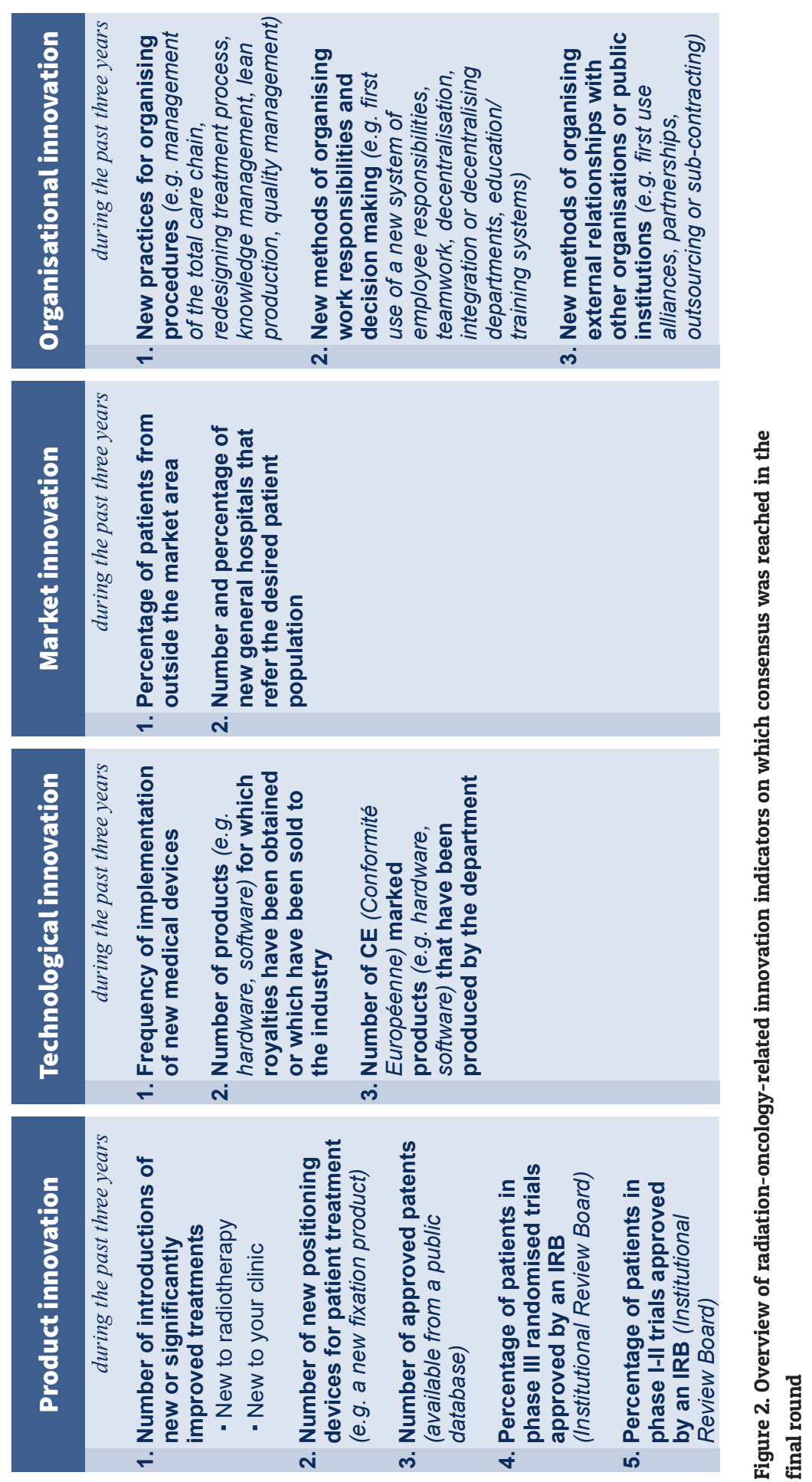
The indicators of innovation we developed could be applied in future studies aimed at analysing and quantifying the aspects of innovation that are either present or absent in radiotherapy departments. The indicators could subsequently be used to find the keys to improving innovation. The latter in particular would be extremely useful, as innovation is often thought to be related to the quality of care.

\section{Views on innovation in radiotherapy derived from the literature}

Innovation is a complex concept [48]. The literature on innovation is extensive, offering many different, but often vague definitions [15]. Indeed, only a few well-designed studies on health care can be said to exist [49]. A frequent problem is that often it is not clear from which viewpoint innovation is being approached. For example, the focus of study can be on the process of innovation, the degree of novelty of the end product, product content or organisational competence [15].

In our study, we decided to select the three viewpoints we assumed to be most relevant for the development of measurement indicators. The first viewpoint concerns the type of innovation. Describing innovation on the basis of the type of innovation was done as early as 1934, and has had widespread applications since then [43]. In this view, a distinction is made between innovation as concerning new products (e.g. in radiotherapy new treatments such as stereotactic body radiation therapy have been introduced), new technology or production methods (e.g. new planning methods, such as atlas based planning), new markets (e.g. a new hospital referring patients), new forms of organisation (e.g. a lean redesign), or new sources of supply of raw materials or half manufactured goods (in radiotherapy, an example could be that of using a mouldable rubber bolus instead of the outmoded wax bolus). The last type of innovation, introducing new sources of supply, does not occur frequently in radiotherapy, which is why we excluded this type from our study. All other types are included.

The second viewpoint concentrates on the innovation competence of the organisation and makes a distinction between generating innovation by means of research and the adoption of innovations by organisations or units [14]. Distinguishing between the generating and adopting innovations is essential, because the organisational conditions required for each activity can vary considerably [15]. As a consequence, organisations that both try to generate and adopt innovations could experience tension in daily practice. Further research needs to point out whether this is actually the case.

The third and final viewpoint centres on the degree of innovation, with a special focus on radical innovation (innovations which discontinue the existing practice of treatments, technology, markets or organisational behaviour, systems, structures and so on) in knowledge-intensive firms [15]. We believe that radiotherapy centres can be 
characterised as such. The MRlinac (completely new radiation equipment) is an example of such a radical innovation in radiotherapy.

As a last point to mention, the innovation process itself is not considered in this study, as our main interest lies in measuring the outcome of innovation.

\section{First viewpoint: types of innovation}

To categorise the indicators, we applied the first viewpoint. The professionals participating in the study were asked to submit indicators for each type of innovation. Below, we describe the types of innovation distinguished by converting them from Schumpeter and the third edition of the OECD manual to radiotherapy $[43,50]$. We also compare our indicators with previous findings from the literature.

- Product innovation can be described as the introduction of treatments that are new or which constitute a significant improvement in terms of their characteristics or intended use. Such innovations include improvements in technical specifications, components and materials, incorporated software, user-friendliness and other functional characteristics. Product innovations sometimes utilise new knowledge or technologies.

We found five indicators for this type of innovation. Similar indicators are found in the literature $[20,30,31]$.

Our list contains a patent indicator. In the literature, there is some discussion about the appropriateness of this indicator. A systematic relationship has been found between an organisation's innovation output and its actual patenting behaviour [51]. The correlation between these two factors is far from perfect, however. This might be due to research and development collaboration interfering with the correlation: contract research may result in patents being assigned to the one who pays for the research rather than the hospital which first registered the patent. Sometimes, too, it is said that services (to which the hospital sector belongs) tend to apply more frequently for copyright than for patents [26]. Despite these considerations, we decided to keep the indicator on the list; as the discussion above implies, having no patents as a clinic does not necessarily mean that no innovation takes place. On the contrary, if patents are assigned to a clinic, this could be characterised as a form of innovation (generating innovation).

- Technological innovation is the implementation of a new or significantly improved treatment process or delivery method that has no noticeable consequences for the end-product. Technological innovation includes significant changes in the techniques 
applied, the equipment used or the available software. In our study, we decided to classify a new method as a technological innovation only if it led to renewal of the production process or constituted a significant improvement, without immediate and noticeable consequences for the patient. We also proceeded from the view that the acquisition of entirely new equipment or devices should always be labelled as technological innovation, irrespective of the effects on the patient - except when a completely new treatment is introduced, for example, using protons.

Our indicators of technological innovation concur with the Schumpeterian definition, because they all refer to production methods. In the literature, input indicators such as Research \& Development expenditures are sometimes used to measure technological innovation. However, as stated, in recent years output indicators have been described as being more suitable $[32,52]$. Studies on technological innovation often focus on manufacturing, and examples of the output indicators used in these studies all refer to production methods, such as new production techniques, automation, and fundamentally new production systems [53]. In addition, output indicators of device innovation are often used, such as the number of products regulated by the FDA for medical devices (comparable to the European indicator of CE [Conformité Européene] marking) [54].

Lastly, there exists a body of literature on Literature-Based Innovation Output (LBIO) indicators that are generated by sampling the "new product announcement" section in technical and trade journals, a method which is also applied in public services [48, 52]. Converting this procedure to radiotherapy is not impossible, but it would be very complex and labour-intensive.

- Market innovation refers to new patients, and includes the opening up of a new hospital market in which the relevant clinic has not operated before. When it comes to market innovation indicators, our findings bear a close similarity to the results from previous research, such as the reports on "new customers gained through innovation" and "number of new customers of new products/services who go on to buy existing products/services" [55].

- Organisational innovation is the implementation of new or significant changes in clinic organizational structure or management methods aimed at improving the use of knowledge, the quality of treatments and services, or the efficiency of workflow. Such changes can include new practices of organisation procedures, new methods of organising work responsibilities and decision making, and new methods of organising external relationships with other organisations or public institutions. 
Research on defining and measuring organizational innovation is still lacking due to a lack of empirical data, clear definitions and suitable measurement constructs [56-58]. Organisational innovation is often rather broadly defined, and indicators vary greatly [57]. An additional complexity is caused by the different types of organisational innovation that can be discerned, the long lifecycle of organisational innovations, differences in the extent of use and implementation of such innovations, and also by the fact that certain labels (e.g. teamwork) are differently formulated across organisations. The professors in innovation rejected three of the four indicators of organisational innovation.

Strikingly, the radiotherapy experts, who have no theoretical background in innovation concepts, were able to formulate appropriate product, technology and market indicators, although they failed to formulate acceptable organisational indicators. The possible reason for this is that most radiotherapists focus on innovation within the content of radiotherapy, rather than on the processes that facilitate organisational innovation.

\section{Second viewpoint: innovation competence}

The second viewpoint we considered relevant for radiotherapy concentrates on how organisations or units generate and adopt innovations, which can be helpful for answering the question whether research can be seen as innovation [14]. Two of the professors in innovation stated explicitly that implementation is a "conditio sine qua non" to classify something as an innovation; however, other professors approved our two research indicators of trials and patents, which pertains to innovations that are not necessarily implemented in practice. The question arises whether new knowledge that results from research but is not yet implemented in clinical practice must be considered as innovative. To answer this question, we applied two insights from the literature. First of all, sometimes a distinction is made between invention and innovation, with invention being the first mention of an idea for a new product or process, whereas innovation applies to the first time that an idea is commercialized [47]. Although invention and innovation are sometimes hard to distinguish from each other, often there is a considerable time lag between the two stages [59]. Secondly, in the literature a distinction is made between generating and adopting an innovation [14]. Generating innovations is a creative process, which is characterised by variation, search, experimentation and discovery, and which produces new knowledge and information. Innovation adoption, on the contrary, is a problem-solving process, which is planned more tightly, and can be characterised by selection, refinement, choice and execution. In our opinion, actual implementation in the inventing organisation is not a "condition sine qua non" for innovation in radiotherapy centres. The development of a new product, service, market or technology is valuable in itself, even if the innovation is not implemented in the organisation which first generated it. Indeed, the generation 
of innovative ideas creates the possibility to adopt the innovation elsewhere, and thus improve health care delivery in general. For this reason, we decided that the research indicators that survived the cut-off could all justifiably be included.

When considering our list of indicators, some clear innovation-generating indicators can be seen, for example, the patent indicator (indicator 3 ) and the research indicators on patients in clinical trials (indicators 4 and 5 ). All other indicators will have to be evaluated during actual measurement, with the researcher classifying a particular innovation as being of either the generating or the adoptive kind. By following such a procedure, it will be possible to measure the level of different innovation activities that can potentially cause tension in the organisation and which may constitute a hurdle for applying an innovation.

\section{Third viewpoint: degree of innovation}

The third and final viewpoint concentrates on the degree of innovation, with a special focus on more radical types of innovation (as opposed to incremental innovation). Radical innovations are mostly, but not always, based on yet unused engineering and scientific principles, and often open up new markets and potential applications.

These innovations are non-linear, resulting in a discontinuation of the existing line regarding treatments, technology, markets, organizational behaviour, systems, structure and so on [15]. Incremental innovation refers to alterations to existing products, which lead to improvement in content or efficiency. The latter type of innovation is mostly linear and continuous in character.

The view on degree of innovation can help to clarify discussions about the true nature of innovation. Some people (including some respondents in our Delphi study) qualify small innovations as an improvement rather than a true innovation. In our opinion, however, improvement can be regarded as incremental innovation, although the impact and underlying conditions are different than in the case of radical innovation. Our indicators do not aim to quantify how radical an innovation is, yet when measuring innovation in practice, all innovations can be classified by categorisation in terms of our indicators: they can range from incremental or radical, depending on the basis of the definition used and the subject of measurement. For example, incremental product innovation is innovation in existing products (e.g. hypo-fractionation in radiotherapy, as an advancement on conventional fractionation), while radical innovation signifies the development of a completely new product (e.g. proton therapy).

Capturing incremental innovation is difficult, however, because generally speaking incremental innovation is a continuous process that forms part of the daily routine of 
employees [30]. It is therefore hard to measure all incremental innovation. Nonetheless, measurement can give an impression of the level of radical and incremental innovation which has been noted. This implies that, although we cannot get full information on the potential causes of tension, we can arrive at the best possible estimate. It is important to realise this, because the widely-held opinion is that the cumulative impact of incremental innovation might well be equivalent to - if not bigger than - the impact of radical innovation. To ignore this fact would result in a biased view [47].

\section{Final remarks}

We expect that by using these indicators of innovation in daily practice, a distinction can be made between innovation generating and innovation-adopting activities, and between radical or incremental innovation. This can be done by comparing the innovation activities by type of innovation with the definitions concerning radical or incremental innovation and innovation generation or innovation adoption. It is important to make this distinction, because certain forms of innovation can create tension in an organisation, particularly if innovation takes place in an environment that is dominated to some extent by efficiency goals or considerations for patient care. Such tensions can hinder successful innovation.

In addition, it should be noted that, remarkably enough, all our remaining indicators concern output measures. This implies there is no need for factors to determine the efficiency of input indicators, such as the number of research staff, because high input does not necessarily mean high output of innovation [32].

Finally, this study has focussed on innovation indicators without addressing the data collection methods to measure the level of innovation in radiotherapy centres. In the literature, a number of shortcomings are listed of data collection in organisations by means of questionnaires $[33,48]$. Such data are not completely objective, as the respondent decides what exactly constitutes an innovation. Also, indicators from surveys sometimes suffer from estimated-answer bias and low response rates. This means that, to use our indicators in future studies, questionnaires are probably not the most suitable method. Instead, an approved protocol is needed, with one or two investigators systematically interviewing a specified sample of the staff in the centres involved.

\section{Limitations and further studies}

There are several limitations to our study. First, although the Round 1 response rate was reasonably good "with 14 out of 21 respondents (67\%) submitting indicators for innovation" the Round 2 response rate was much lower (20\%). A low response rate is also seen in many studies requiring response by physicians; Willis et al. showed for instance 
that only $1 / 3$ of the health care providers reported response rates higher than $60 \%$ in the 2005-2009 period [60]. Response rates as low as $5 \%$ to $10 \%$ are also commonly reported in health care [61]. In our case, we think that the disappointing response rate in Round 2 can be explained by the fact that most of the potential respondents were radiotherapy professionals, who are not very active in the area of management. Since we used a third round, where we asked the professors with a chair in innovation to review the results gained so far, we feel that the response rate of Round 2 is unlikely to constitute a problem. Also, although this specific response rate was low, we still received feedback from a considerable group of professionals $(n=66)$. Furthermore, we only accepted indicators if consensus was reached in Round 4 between the department chairpersons: the review by the Round 2 NVRO members was just an aid for reaching consensus. For these reasons, we consider our results to be valid.

Second, in order to arrive at a workable set of indicators, we defined subjective cutoff scores for measurability and suitability. We feel comfortable with our decision, because our indicators are comparable to the indicators mentioned in the literature; nevertheless, our decision was not based on previous research, as the necessary data were not available.

Third, we performed this study in one country only (the Netherlands), which may affect the potential to generalize our results to different settings. Finally, to test the selected indicators, they need to be measured in practice. We recommend future research be done on testing the set, especially its measurability.

Having said all this, we do feel we have taken an essential first step towards developing indicators for measuring the degree and type of innovation in radiotherapy centres. It is clear that these indicators have to be validated further by measuring them in actual clinical practice. These validated indicators will then allow us to investigate the relation between innovation and its effects, and relate the degree of innovation in radiotherapy centres with organisational and work characteristics in further multi-centric studies.

\section{CONCLUSIONS}

We developed a tool for measuring the level of innovation in radiotherapy centres. This tool will be used to investigate in radiotherapy centres the relation between innovation and possible factors inhibiting or stimulating successful innovation and between the level of innovation and its effects. We expect that the resulting data will assist us in deciding how to organise our clinics to combine innovation with costefficient patient care. 


\section{REFERENCES}

1. Lievens $Y$, Van den Bogaert W, Rijnders A, et al. Palliative radiotherapy practice within Western European countries: impact of the radiotherapy financing system? Radiotherapy and oncology. 2000; 56(3): 289-95. http://dx.doi.org/10.1016/S0167-8140(00)00214-0

2. McKee M, Chow CK. Improving health outcomes: innovation, coverage, quality and adherence. Isr J Health Policy Res. 2012; 1(1): 43. PMid: 23098127. http://dx.doi.org/10.1186/20454015-1-43

3. Apekey TA, McSorley G, Tilling M, et al. Room for improvement? Leadership, innovation culture and uptake of quality improvement methods in general practice. Journal of evaluation in clinical practice. 2011; 17(2): 311-8. PMid: 20438607. http://dx.doi.org/10.1111/j.13652753.2010.01447.x

4. Agha L. The Effects of Health Information Technology on the Costs and Quality of Medical Care. Journal of health economics. 2014. PMid: 24463141. http://dx.doi.org/10.1016/j. jhealeco.2013.12.005

5. Blayney DW. Enhancing quality through innovation: American Society of Clinical Oncology presidential address 2010. Journal of Clinical Oncology. 2010; 28(28): 4283-8. PMid: 20697071. http://dx.doi.org/10.1200/JCO.2010.31.1696

6. Karanikolos M, Ellis L, Coleman MP, et al. Health systems performance and cancer outcomes. JNCI Monographs. 2013; 2013(46): 7-12. PMid: 23962507. http://dx.doi.org/10.1093/ jncimonographs/lgt003

7. O'Higgins N. Advancing cancer care: the quality spiral. Irish journal of medical science. 2014; 183(1): 7-13. PMid: 24166048. http://dx.doi.org/10.1007/s11845-013-1029-4

8. Walker K, Allen J, Andrews R. Optimizing quality, service, and cost through innovation. Nursing administration quarterly. 2011; 35(1): 68-71. PMid: 21157266. http://dx.doi.org/10.1097/ NAQ.0b013e3182032208

9. Wu I-L, Hsieh P-J. Understanding hospital innovation enabled customer-perceived quality of structure, process, and outcome care. Total Quality Management. 2011; 22(2): 227-41. http://dx.doi.org/10.1080/14783363.2010.532343

10. Heron DE, Godette KD, Wynn RA, et al. Radiation medicine innovations for the new millenium. Journal of the National Medical Association. 2003; 95(1): 55. PMid: 12656450.

11. Winkler C, Duma M, Popp W, et al. Protection of quality and innovation in radiation oncology. Strahlentherapie und Onkologie. 2014; 190(10): 950-6. PMid: 24658604. http://dx.doi. org/10.1007/s00066-014-0615-3

12. Martini A, Laugen BT, Gastaldi L, et al. Continuous innovation: Towards a Paradoxical, Ambidextrous combination of exploration and exploitation. International Journal of Technology Management. 2013; 61(1): 1-22. http://dx.doi.org/10.1504/IJTM.2013.050246

13. O'Reilly III CA, Tushman ML. Ambidexterity as a dynamic capability: Resolving the innovator's dilemma. Research in organizational behavior. 2008; 28: 185-206. http://dx.doi.org/10.1016/ j.r iob.2008.06.002 
14. Damanpour F, Daniel Wischnevsky J. Research on innovation in organizations: Distinguishing innovation-generating from innovationadopting organizations. Journal of Engineering and Technology Management. 2006; 23(4): 269-91. http://dx.doi.org/10.1016/j. jengtecman.2006.08.002

15. van Poucke A. Towards radical innovation in knowledge-intensive service firms: Erasmus School of Economics (ESE). 2005.

16. Adler PS, Goldoftas B, Levine DI. Flexibility versus efficiency? A case study of model changeovers in the Toyota production system. Organization science. 1999; 10(1): 43-68. http://dx.doi.org/10.1287/orsc.10.1.43

17. Cameron KS, Quinn RE. Diagnosing and changing organizational culture: Based on the competing values framework: John Wiley \& Sons; 2011.

18. Savolainen TI. Cycles of continuous improvement: realizing competitive advantages through quality. International Journal of Operations \& Production Management. 1999; 19(11): 120322. http://dx.doi.org/10.1108/01443579910291096

19. McDermott CM, O'Connor GC. Managing radical innovation: an overview of emergent strategy issues. Journal of product innovation management. 2002; 19(6): 424-38. http:// dx.doi.org/10.10 16/S0737-6782(02)00174-1

20. Rosing K, Frese M, Bausch A. Explaining the heterogeneity of the leadership-innovation relationship: Ambidextrous leadership. The Leadership Quarterly. 2011; 22(5): 956-74. http://dx.doi.org/10.1016/j.leaqua.2011.07.014

21. Gamal D, Salah ET, Elrayyes EN. How to measure organization Innovativeness? Technology Innovation and Entrepreneurship Center. 2011.

22. Hagedoorn J, Cloodt M. Measuring innovative performance: is there an advantage in using multiple indicators? Research policy. 2003; 32(8): 1365-79. http://dx.doi.org/10.1016/ S0048-7 333(02)00137-3

23. Adams R, Bessant J, Phelps R. Innovation management measurement: A review. International Journal of Management Reviews. 2006; 8(1): 21-47. http://dx.doi.org/10.1111/j.1468-237 0.2006.00119.x

24. Van Leeuwen $G$. Linking innovation to productivity growth using two waves of the community Innovation Survey. OECD Publishing; 2002. http://dx.doi.org/10.1787/620221544571

25. Djellal F, Gallouj F. Innovation in hospitals: a survey of the literature. The European Journal of Health Economics. 2007; 8(3): 181-93. PMid: 17186204. http://dx.doi.org/10.1007/s1019 8-006-0016-3

26. Szczygielski K. What are service sector innovations and how do we measure them? CASECenter for Social and Economic Research. 2011. PMid: 22000146.

27. Smith K. Measuring innovation: Oxford University Press; 2005.

28. Bloch C, Bugge MM. Public sector innovation-From theory to measurement. Structural Change and Economic Dynamics. 2013; 27: 133- 45. http://dx.doi.org/10.1016/j. strueco.2013.06.008 
29. Hipp C, Grupp H. Innovation in the service sector: The demand for service-specific innovation measurement concepts and typologies. Research policy. 2005; 34(4): 517-35. http://dx.doi. org/10.1016/j.respol.2005.03.002

30. Rose S, Shipp S, Lal B, et al. Frameworks for Measuring Innovation: Initial Approaches. Athena Alliance, Washington. 2009(s5).

31. Milbergs E, Vonortas N. Innovation metrics: measurement to insight. Center for Accelerating Innovation and George Washington University, National Innovation Initiative 21st Century Working Group. 2004; 22.

32. Kleinknecht A, Van Montfort K, Brouwer E. The non-trivial choice between innovation indicators. Economics of Innovation and new technology. 2002; 11(2): 109-21. http://dx.doi. org/10.1080/10438590210899

33. Makkonen T, van der Have RP. Benchmarking regional innovative performance: composite measures and direct innovation counts. Scientometrics. 2013; 94(1): 247-62. http://dx.doi. org/10.1007/s11192-012-0753-2

34. Dalkey NC, Brown BB, Cochran S. The Delphi method: An experimental study of group opinion: Rand Corporation Santa Monica, CA; 1969.

35. Beretta R. A critical review of the Delphi technique. Nurse Researcher. 1996; 3: 79-89.

36. Keeney S, Hasson F, McKenna H. Consulting the oracle: ten lessons from using the Delphi technique in nursing research. Journal of advanced nursing. 2006; 53(2): 205-12. PMid: 16422719. http://dx.doi.org/10.1111/j.1365-2648.2006.03716.x

37. Keeney S, Hasson F, McKenna HP. A critical review of the Delphi technique as a research methodology for nursing. International journal of nursing studies. 2001; 38(2): 195-200. http://dx.doi.org/10.1016/S0020-7489(00)00044-4

38. Hasson F, Keeney S, McKenna H. Research guidelines for the Delphi survey technique. Journal of advanced nursing. 2000; 32(4): 1008-15. http://dx.doi.org/10.1046/j.1365-2648.2000. t01-1-01567.x

39. Delbecq AL, Van de Ven AH, Gustafson DH. Group techniques for program planning: A guide to nominal group and Delphi processes: Scott, Foresman Glenview, IL; 1975. PMid: 126959.

40. Linstone HA, Turoff M. Delphi: a brief look backward and forward. Technological Forecasting and Social Change. 2011; 78(9): 1712-9. http://dx.doi.org/10.1016/j.techfore.2010.09.011

41. Valentini V, Aristei C, Glimelius B, et al. Multidisciplinary rectal cancer management: 2nd European rectal cancer consensus conference (EURECA-CC2). Radiotherapy and oncology. 2009; 92(2): 148-63. PMid: 19595467. http://dx.doi.org/10.1016/j.radonc.2009.06.027

42. Giuliani ME, Gillan C, Milne RA, et al. Determining an imaging literacy curriculum for radiation oncologists: an international Delphi study. International journal of radiation oncology, biology, physics. 2014; 88(4): 961-6. Epub 2014/03/13. PMid: 24606855. http://dx.doi. org/10.1016/j.ijrobp.2013.12.009

43. Schumpeter JA. The theory of economic development: An inquiry into profits, capital, credit, interest, and the business cycle: Transaction Publishers; 1934. 
44. Brown BB. Delphi process: A methodology used for the elicitation of opinions of experts. DTIC Document. 1968.

45. Kleinknecht A, Kleinknecht A, Bain D. Testing innovation indicators for postal surveys. New Concepts in Innovation Output Measurement Macmillan: London. 1993: 153-88.

46. Van Zolingen SJ, Klaassen CA. Selection processes in a Delphi study about key qualifications in Senior Secondary Vocational Education. Technological forecasting and social change. 2003; 70(4): 317-40. http://dx.doi.org/10.1016/S0040-1625(02)00202-0

47. Fagerberg J. Innovation: A guide to the literature. 2004. [48] Walker RM, Jeanes E, Rowlands R. Measuring Innovation-Applying the Literature-Based Innovation Output Indicator to Public Services. Public Administration. 2002; 80(1): 201-14. http://dx.doi.org/10.1111/14679299.00300

48. Walker RM, Jeanes E, Rowlands R. Measuring Innovation-Applying the Literature-Based Innovation Output Indicator to Public Services. Public Administration. 2002; 80(1): 201-14. http://dx.doi.org/10.1111/1467-9299.00300

49. Fleuren M, Wiefferink K, Paulussen T. Determinants of innovation within health care organizations Literature review and Delphi study. International journal for quality in health care. 2004; 16(2): 107-23. PMid: 15051705. http://dx.doi.org/10.1093/intqhc/mzh030

50. Oecd E. Oslo Manual. Proposed Guidelines for Collecting and Interpreting Innovation Data, 3rd Edition Paris. 2005. http://dx.doi.org/10.1787/9789264013100-en

51. Brouwer E, Kleinknecht A. Innovative output, and a firm's propensity to patent: An exploration of CIS micro data. Research Policy. 1999; 28(6): 615-24. http://dx.doi.org/10.1016/S00487333(99)00003-7

52. Coombs R, Narandren $P$, Richards A. A literature-based innovation output indicator. Research policy. 1996; 25(3): 403-13. http://dx.doi.org/10.1016/0048-7333(95)00842-X

53. Hollenstein H. A composite indicator of a firm's innovativeness. An empirical analysis based on survey data for Swiss manufacturing. Research Policy. 1996; 25(4): 633-45. http://dx.doi. org/10. 1016/0048-7333(95)00874-8

54. Littell CL. Innovation in medical technology: reading the indicators. Health Affairs. 1994; 13(3): 226-35. PMid: 7927153. http://dx.doi.org/10.1377/hlthaff.13.3.226

55. Davila T, Epstein MJ, Shelton RD. The Creative Enterprise [Three Volumes]. Greenwood Publishing Group; 2006.

56. Armbruster $\mathrm{H}$, Bikfalvi A, Kinkel S, et al. Organizational innovation: The challenge of measuring non-technical innovation in large-scale surveys. Technovation. 2008; 28(10): 644-57. http:// dx.doi.org/10.1016/j.technovation.2008.03.003

57. Sapprasert K, Clausen TH. Organizational innovation and its effects. Industrial and Corporate Change. 2012; 21(5): 1283-305. http://dx.doi.org/10.1093/icc/dts023

58. Lam A. Organizational Innovation In: J. Fagerberg DCM, \& R. R. Nelson, editor. The Oxford handbook of Innovation. Oxford University Press: USA; 2004. 115-47.

59. Rogers EM. Diffusion of innovations: Simon and Schuster; 2010. 
60. Willis GB, Smith T, Lee HJ. Do additional recontacts to increase response rate improve physician survey data quality? Medical care. 2013; 51(10): 945. PMid: 23969583. http:// dx.doi.org/10.1097/MLR.0b013e3182a5023d

61. Hikmet N, Chen SK. An investigation into low mail survey response rates of information technology users in health care organizations. International journal of medical informatics. 2003; 72(1): 29-34. PMid: 14644304. http://dx.doi.org/10.1016/j.ijmedinf.2003.09.002 



\section{PART II}

\section{Innovations reaching and not reaching the clinic and the value of innovation.}





\section{CHAPTER 3}

\section{The degree of innovation routinely implemented in clinical routine}

Maria Jacobs

Liesbeth Boersma

Andre Dekker

Geert Bosmans

Frits Van Merode

Frank Verhaegen

Dirk De Ruyscher

Rachelle Swart

Cindy Kengen

Philippe Lambin.

What is the degree of innovation routinely implemented in Dutch radiotherapy centres?

A multicenter cross-sectional study

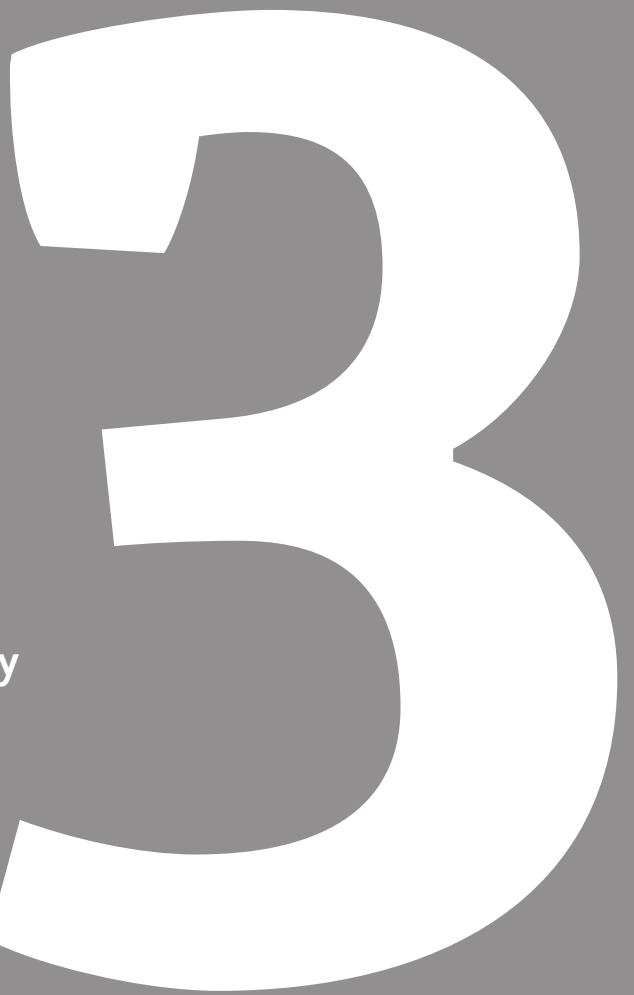

Published in: British Journal of Radiology, 2016; 89: 20160601. 


\section{ABSTRACT \\ Objective}

To study the implementation of innovation activities in Dutch radiotherapy (RT) centres in a broad sense (product, technological, market and organizational innovations).

\section{Methods}

A descriptive cross-sectional study was conducted in 15 Dutch RT centres. A list of innovations implemented from 2011 to 2013 was drawn up for each centre using semistructured interviews. These innovations were classified into innovation categories according to previously defined innovation indicators. Where applicable, each innovation was rated by each centre on the effort required to implement it and on its expected effects, to get an impression of how far reaching and radical the innovations were and to be able to compare the number of innovations between centres.

\section{Results}

The participating RT centres in the Netherlands implemented 12 innovations per year on average (range 5-25); this number was not significantly different for academic $(n=13)$ or non-academic centres $(n=10)$. Several centres were dealing with the same innovations at the same time. The average required effort and expected output did not differ significantly between product, technological and organizational innovation or between academic and non-academic centres.

\section{Conclusion}

The number of innovations observed per centre varied across a large range, with a large overlap in terms of the type of innovations that were implemented. Registering innovations using the innovation indicators applied in our study would make it possible to improve collaboration between centres, e.g. with common training modules, to avoid duplication of work.

\section{Advances in knowledge}

This study is the first of its kind investigating innovation implementation in RT in a broad sense. 


\section{INTRODUCTION}

Radiotherapy (RT) centres have the complex task of simultaneously improving patient outcomes (tumour control, survival and toxicity), safety, patient service (such as taking into account patients' preferences for the time to come for RT, shared decision making for treatment selection etc.) and efficiency. It is generally agreed that innovation implementation helps to tackle this many-faceted challenge. This is despite the fact that data from randomized trials are often lacking, for instance, due to the experienced ethical difficulties or acceptance for patients and physicians to investigate innovations in a clinical controlled randomized trial, e.g. if it is clear that the innovation leads to less radiation dose in the normal tissue. Consequently, the outcome of innovation strategies is often merely based on retrospective series. In this study, innovation is defined as "the intentional introduction and application within a role, group or organization of ideas, processes, products or procedures new to the relevant unit of adoption, designed to significantly benefit the individual, group or wider society" [1]. This definition is largely accepted among researchers in the field [2]. In the current study, we take into account four types of innovations: product innovation, technological innovation, market innovation and organizational innovation (Table 1) [3].

\section{Table 1. Definitions of the various innovation types used in our study}

\begin{tabular}{ll}
\hline Type of innovation & Definition \\
\hline Product (treatment) innovation & $\begin{array}{l}\text { The introduction of treatments that are new or which } \\
\text { constitute a significant improvement in terms of their } \\
\text { characteristics or intended use. } \\
\text { Technological innovation }\end{array}$ \\
$\begin{array}{l}\text { The introduction of new or significantly improved } \\
\text { technological processes or methods that have no noticeable } \\
\text { consequences for the patient. This also includes new } \\
\text { equipment or devices. } \\
\text { Market innovation }\end{array}$ & $\begin{array}{l}\text { The entry into a hospital area in which the clinic has not } \\
\text { operated before. } \\
\text { The introduction of new or significantly improved forms of } \\
\text { organizational structure, management methods and systems } \\
\text { aimed at improving the use of knowledge, the quality of } \\
\text { services or the efficiency of the workflow. }\end{array}$ \\
\hline
\end{tabular}

Innovative technology plays a vital role in improving the quality of care for patients receiving radiation therapy, provided that new clinical treatments enabled by the new technology are not only theoretically better but also lead to improved patient outcomes $[4,5]$. Technological advances allow radiation oncologists to deliver radiation more precisely, increasing the dose to tumour targets and reducing the dose to normal tissues and critical structures [5-7]. Successful examples include stereotactic RT of intracranial 
and extracranial primary tumours and metastases and the incorporation of molecular imaging in treatment planning $[4,8,9]$.

Organizational innovations, such as adopting the lean philosophy and introducing lean tools, can also help to decrease waiting times and increase safety and cost-effectiveness [10-12]. Both lower doses to normal tissues and shorter waiting times or fewer interruptions of the treatment are clearly desirable outcomes.

To improve their quality of care as well as cost-effectiveness, RT centres in the Netherlands are currently developing and implementing a range of the innovations mentioned above. The Dutch, European and American Societies for Radiotherapy and Oncology take a very active part in sharing knowledge and experience. However, as is the case with nearly all guidelines and recommendations, at present the focus is on the scientific basis of the innovation, much less on its practical implementation. The failure rates for implementing complex innovations in healthcare are high [13]. The failure rate for RT is unknown. Previously, we conducted a Delphi study to determine indicators for innovation for the four types of innovations described (Table 1) [3]. The general objective of our study is, first, to gather information on the annual number and type of innovation activities in a broad sense in Dutch RT centres, according to the previously determined innovation indicators. Furthermore, we aim to obtain more insight into how far-reaching and radical innovations are and to take into account the effort required to implement them and their expected output, e.g. their effect on outcome, illustrating a better treatment quality, or their effect on service, illustrating process optimizations. Subsequently, we want to explore the effect of two potential variables on the amount and types of innovations: academic vs non-academic centres, and the impact of innovative work behaviour (IWB). IWB refers to the behaviour of individuals aiming to achieve innovation as defined above [14]. We investigate this correlation because IWB is important in creating innovative solutions, but it is not known if this is also the case for innovation implementation.

The broader motivation for this study is the belief that gaining more information about innovation activities in RT in a broad sense could help accelerate the implementation of innovations and save costs by preventing different organizations from struggling with the same problems [15].

\section{METHODS AND MATERIALS}

\section{Design}

A descriptive cross-sectional study was conducted to list and categorize the innovations implemented in Dutch RT centres from 2011 to 2013. 


\section{Procedure}

We asked all Dutch RT centres to participate in our study. Centres were classified as academic (affiliated with a university) and non-academic. Semi-structured interviews were conducted by two researchers, followed by a request for additional information by email. The following issues were addressed:

Number and type of implemented innovations per centre from 2011 to 2013

To address this point, the centres (mostly the head of medical physics and/or head of department, and/or a manager) usually used their annual policy plans from 2011 to 2013.

If a centre did not have a detailed policy plan, we asked them to provide us with an inventory of all the innovations they implemented. In a final step, all participating centres received a list with all innovations mentioned by other centres with the request to check if their own list was complete.

The researchers subsequently classified the innovations on these lists according to the previously identified innovation indicators into three innovation categories (product, technology and organizational innovation; Figure 1) [3]. Since some indicators were quite broad, a further subclassification was conducted according to the treatment phase of the care path.

Since the annual policy plans did not provide information on the product innovation indicator "number of patients in trials" and on the market innovation indicators, we subsequently asked the centres for information on these issues by email regarding the period 2011-13. We excluded the patent, royalty and Conformité Européenne (CE)-marking indicators, as included in Figure 1, because our study investigates clinical practice. The excluded indicators refer respectively to granted rights to inventors or assignees, payments to licensors and to a manufacturers' declaration that the product complies with the essential requirements of the relevant European health, safety and environmental protection legislations [17].

\section{Effort required and impact on output for each innovation, and innovative working behaviour}

Since we expected a large variation across the innovations with respect to the required effort and expected output and also aimed to obtain more insight into how far-reaching and radical innovations are, we looked for a method to take into account these aspects when comparing, for instance, academic with non-academic centres. Therefore, we provided each centre with the complete overview of all product, technology and organizational innovations (Tables $2-4$ ) and asked them to rate each innovation on a scale of 1-5 ( 1 = no impact at all, 5 = very large impact) regarding the effort required from the organization and employees (effort) and also regarding the effect on output (outcomes, service, safety and efficiency) (output). 

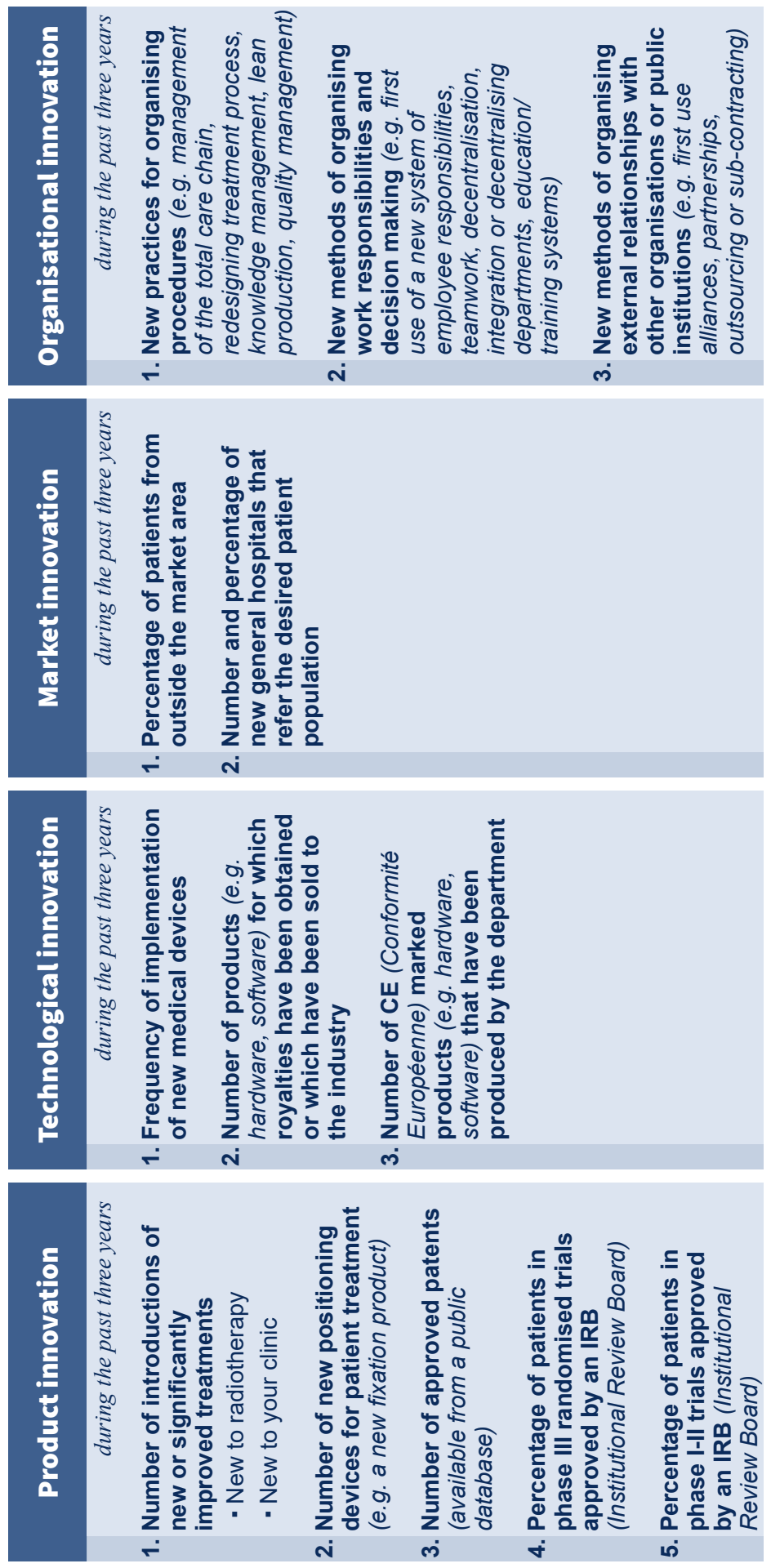

ปั

형

.

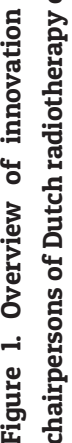


Subsequently, we calculated the number of innovations per centre, weighted for effort and output by multiplying the frequency of the innovation with the average "impact score". In addition, we used these average impact scores to investigate whether different types of innovations required more or less effort or had more or less output.

We asked the medical chairpersons to rate the innovative behaviour of their medical staff according to a nine-item questionnaire measuring innovative work behaviour (IWB) [18]. This scale has a Cronbach's $\alpha$ of 0.95 for the self-rated and 0.96 for the leaderrated scale and a strong correlation between both scales $(r=0.35)$ [14].

Finally in the spring of 2016, we asked all centres again if there were any important innovations (impact on effort from organization/employee or an impact on outcome 23) implemented in their clinic since 2014.

\section{Statistical analysis}

A Mann-Whitney $U$ test was used to analyse differences between academic and nonacademic centres. We assumed a significance level of 0.05 . A one-way analysis of variance was used to analyse differences between impact-scores of product, and technological and organizational innovations. Because of the small size of the sample $(n=15)$, a Spearman's rho test was used to analyse the correlation between perceived innovative behaviour of the medical staff and innovation.

\section{RESULTS}

\section{Response rate}

Of the 20 RT centres invited to participate in our study, 15 responded (75\%). One organization declined because they could not generate the necessary data and another one declined because they were in the middle of a large transition project. Three organizations declined without mentioning a reason. 
Table 2. All product innovations and frequencies in the period 2011-13

\begin{tabular}{|c|c|c|}
\hline Indicator & Product Innovations & Total \\
\hline \multirow[t]{30}{*}{$\begin{array}{l}\text { 1. Number of introductions of new or } \\
\text { significantly improved treatments }\end{array}$} & $\begin{array}{l}\text { Treatment preparation: imaging, positioning } \\
\text { and delineation }\end{array}$ & \\
\hline & CT - technique optimisation & 3 \\
\hline & Simulation - technique optimisation & 1 \\
\hline & Upgrade positioning devices & 8 \\
\hline & New imaging modalities for target delineation & 11 \\
\hline & Brachytherapy - MRI guided & 3 \\
\hline & $\begin{array}{l}\text { Introducing spacer between prostate and } \\
\text { rectum }\end{array}$ & 1 \\
\hline & Frameless Radiosurgery & 4 \\
\hline & Orthovolt therapy - changing technique & 1 \\
\hline & Subtotal & 32 \\
\hline & $\begin{array}{l}\text { Treatment delivery, including set-up and } \\
\text { adaptive RT }\end{array}$ & \\
\hline & Implementing 6 Degree of Freedom couch & 1 \\
\hline & SBRT/SRS - technique optimisation & 17 \\
\hline & IGRT - kV CBCT 2 & 19 \\
\hline & IGRT - software upgrade & 2 \\
\hline & Adaptive Radiotherapy & 4 \\
\hline & Subtotal & 43 \\
\hline & Extending techniques to other patientgroups & \\
\hline & VMAT - extending indications & 25 \\
\hline & $\begin{array}{l}\text { Brachytherapy - implementation for other } \\
\text { indications }\end{array}$ & 8 \\
\hline & Intra-operative RT (IORT) & 2 \\
\hline & IMRT & 37 \\
\hline & SBRT/SRS - extending indications & 15 \\
\hline & Subtotal & 87 \\
\hline & Adjust fractionation scheme's & \\
\hline & From normofx to hypofractionation & 3 \\
\hline & Subtotal & 3 \\
\hline & Improved follow-up & \\
\hline & Standardised medical protocols & 1 \\
\hline & Subtotal & 1 \\
\hline \multirow[t]{2}{*}{$\begin{array}{l}\text { 2. Number of new positioning devices } \\
\text { for patient treatment }\end{array}$} & $\begin{array}{l}\text { Treatment delivery, including set-up and } \\
\text { adaptive RT }\end{array}$ & \\
\hline & Patient positioning - technique optimisation & 2 \\
\hline
\end{tabular}




\begin{tabular}{llc}
\hline Indicator & Product Innovations & Total \\
\hline & Total & $\mathbf{1 6 8}$ \\
3. Number of approved patents & & $\begin{array}{c}\text { Not } \\
\text { applicable }\end{array}$ \\
$\begin{array}{l}\text { 4. Percentage of patients in phase I-II } \\
\text { trials approved by an IRB }\end{array}$ & Range & $0 \%-1 \%$ \\
$\begin{array}{l}\text { 5. Percentage of patients in phase III } \\
\text { randomised controlled trials approved } \\
\text { by an IRB }\end{array}$ & Range & $0 \%-6.6 \%$ \\
\hline
\end{tabular}

CBCT, cone beam CT; IGRT, image-guided radiation therapy; IMRT, intensity-modulated radiation therapy; IORT, Intraoperative radiation therapy; IRB, institutional review board; kV, kilovoltage; RT, radiotherapy; SBRT/ SRS, stereotactic body radiation therapy/stereotactic radiosurgery; VMAT, volumetric arc therapy.

Table 3. All technological innovations and frequencies in the period 2011-13

\begin{tabular}{|c|c|c|}
\hline Indicator & Technological Innovations & Total \\
\hline \multirow[t]{23}{*}{$\begin{array}{l}\text { 1. Frequency of implementation of } \\
\text { new medical devices }\end{array}$} & $\begin{array}{l}\text { Treatment preparation: imaging, positioning } \\
\text { and delineation }\end{array}$ & \\
\hline & Imaging - new hardware & 8 \\
\hline & Imaging - software upgrade & 2 \\
\hline & Imaging - protocol optimisation & 12 \\
\hline & Subtotal & 22 \\
\hline & Treatment technique and TPS optimisation & \\
\hline & TPS - new software & 6 \\
\hline & TPS - software upgrade & 7 \\
\hline & TPS - optimisation & 1 \\
\hline & TPS - protocol optimisation & 27 \\
\hline & Brachy - technique optimisation & 7 \\
\hline & $\begin{array}{l}\text { Photodynamic Therapy (PDT) - technique } \\
\text { optimisation }\end{array}$ & 1 \\
\hline & Subtotal & 49 \\
\hline & Treatment delivery, including patient set-up & \\
\hline & Linac - new equipment & 12 \\
\hline & Brachy - new hardware & 1 \\
\hline & Linac - new software / upgrade & 7 \\
\hline & Linac - protocol optimisation & 1 \\
\hline & Patient positioning & 4 \\
\hline & Upgrade positioning devices & 1 \\
\hline & Subtotal & 26 \\
\hline & IGRT & \\
\hline & IGRT - introduction $\mathrm{kV}$ imaging & 2 \\
\hline
\end{tabular}




\begin{tabular}{llc}
\hline Indicator & Technological Innovations & Total \\
\hline & IGRT - software upgrade & 2 \\
& DGRT - implementation & 8 \\
& IGRT - new modality & 2 \\
& IGRT - protocol optimisation & 12 \\
& IGRT - technique optimisation & 2 \\
& Subtotal & 28 \\
& QA and connectivity & \\
& QA - new hardware 3 & 1 \\
& Connectivity software & 18 \\
& OIS (Oncology Information System) - upgrade & $\mathbf{2 3}$ \\
& Subtotal & $\mathbf{1 4 8}$ \\
$\begin{array}{l}\text { 2. Number of products for which } \\
\text { royalties have been obtained or which } \\
\text { have been sold to the industry }\end{array}$ & Total & Not \\
$\begin{array}{l}\text { 3. Number of CE marked products } \\
\text { that have been produced by the }\end{array}$ & & applicable \\
department & & \\
\hline
\end{tabular}

CE, Conformité Européenne; DGRT, dose-guided radiotherapy; IGRT, image-guided radiation therapy; kV, kilovoltage; Linac, linear accelerator; OIS,' Oncology information system; PDT, Photodynamic therapy; QA, quality assurance; TPS, treatment planning system.

Table 4. All organizational innovations and frequencies in the period 2011-13

\begin{tabular}{llc}
\hline Indicator & Organizational Innovations & Total \\
\hline 1. New practices for organizing & IT projects & \\
procedures & Software for patient care & 19 \\
& Implementation of EHR (Electronic Health & \\
& Records): & \\
& $*$ completely & 4 \\
& $*$ just some specific parts & 6 \\
& Introduction of new Patient Service/ & \\
& Reachability projects & \\
& $*$ completely & 1 \\
& $*$ just some specific parts & 19 \\
& Software for telecommuting/communication & 12 \\
& Software for clinical data/imaging exchange & 8 \\
& Software for operational management & 14 \\
& Subtotal & $\mathbf{8 3}$
\end{tabular}




\begin{tabular}{|c|c|c|}
\hline Indicator & Organizational Innovations & Total \\
\hline & $\begin{array}{l}\text { Projects to improve patient flow / reduce } \\
\text { waiting time / LEAN projects }\end{array}$ & \\
\hline & Improve time referral - intake & 5 \\
\hline & Improve time intake - start RT & 34 \\
\hline & Improve efficiency work at the linear accelerator & 3 \\
\hline & Subtotal & 42 \\
\hline & $\begin{array}{l}\text { Safety and Quality Management / ERM / } \\
\text { Information Security Management }\end{array}$ & \\
\hline & Safety / Risk system & 10 \\
\hline & Quality systems & 8 \\
\hline & Subtotal & 18 \\
\hline \multirow{9}{*}{$\begin{array}{l}\text { 2. New methods of organizing work } \\
\text { responsibilities and decision making }\end{array}$} & Broad organizational innovations & \\
\hline & HRM + Culture projects & 10 \\
\hline & Reorganisation & 11 \\
\hline & Subtotal & 21 \\
\hline & Employee development & \\
\hline & Introduction of new jobs & 5 \\
\hline & $\begin{array}{l}\text { Staff - Redefining tasks and responsibilities of } \\
\text { staff members }\end{array}$ & 11 \\
\hline & Educational projects & 6 \\
\hline & Subtotal & 22 \\
\hline \multirow{5}{*}{$\begin{array}{l}\text { 3. New methods of organizing } \\
\text { external relationships with other } \\
\text { organizations or other institutions }\end{array}$} & Growth -external relations & \\
\hline & New alliances/external collaborations & 8 \\
\hline & New outpatient clinic/annexe for department & 15 \\
\hline & Subtotal & 23 \\
\hline & Total & 209 \\
\hline
\end{tabular}

ERM, enterprise risk management; HRM, human resource management; IT, information technology; LEAN, lean management; RT, radiotherapy.

\section{Number and type of implemented innovations}

Tables 2-4 list all product, technological and organizational innovations in the period 2011-13 reported by the centres, according to the innovation indicators and subdivided according to treatment phase of the care path, including the frequency with which it was mentioned. Several centres were implementing the same innovations. The majority of the innovations can be classified as organizational innovations $(n=209)$. Most of these 
organizational innovations can be classified as an IT project $(n=83)$. In addition, 168 product innovations and 148 technological innovations were reported.

Most product innovations relate to extending existing techniques to other patient groups $(n=87)$, whereas most technological innovations relate to treatment technique and treatment planning software optimization $(n=49)$. In the period 2011-13, most centres implemented intensity-modulated RT (IMRT) and volumetric arc therapy (VMAT) in clinical routine (Table 5 ). The other top five innovations were stereotactic body radiation therapy/ stereotactic radiosurgery technique optimization, treatment planning system (TPS) protocol optimization, oncology information system upgrade and software for patient care.

Table 5. Top five of each innovation category

\begin{tabular}{|c|c|c|c|c|c|}
\hline Type of innovation & Innovation & Frequency & $\begin{array}{l}\text { Number } \\
\text { of centres }\end{array}$ & $\begin{array}{l}\text { Score } \\
\text { effort }\end{array}$ & $\begin{array}{l}\text { Score } \\
\text { output }\end{array}$ \\
\hline \multirow[t]{5}{*}{ Product Innovation } & IMRT & 37 & 12 & 3 & 4 \\
\hline & VMAT - extending indications & 25 & 8 & 4 & 4 \\
\hline & IGRT - kV CBCT 2 & 19 & 8 & 3 & 4 \\
\hline & $\begin{array}{l}\text { SBRT/SRS - technique } \\
\text { optimisation }\end{array}$ & 17 & 11 & 4 & 4 \\
\hline & $\begin{array}{l}\text { SBRT/SRS - extending } \\
\text { indications }\end{array}$ & 15 & 9 & 4 & 4 \\
\hline \multirow[t]{5}{*}{$\begin{array}{l}\text { Technological } \\
\text { Innovation }\end{array}$} & TPS - protocol optimisation & 27 & 11 & 3 & 4 \\
\hline & $\begin{array}{l}\text { OIS (Oncology Information } \\
\text { System) - upgrade }\end{array}$ & 18 & 11 & 4 & 3 \\
\hline & Imaging - protocol optimisation & 12 & 4 & 3 & 3 \\
\hline & Linac - new equipment & 12 & 8 & 5 & 4 \\
\hline & IGRT - protocol optimisation & 12 & 8 & 3 & 3 \\
\hline \multirow[t]{5}{*}{$\begin{array}{l}\text { Organizational } \\
\text { innovation }\end{array}$} & Improve time intake - start RT & 34 & 10 & 4 & 4 \\
\hline & Software for patient care & 19 & 12 & 3 & 3 \\
\hline & $\begin{array}{l}\text { Introduction of new Patient } \\
\text { Service/Reachability projects * } \\
\text { just some specific parts }\end{array}$ & 19 & 10 & 3 & 3 \\
\hline & $\begin{array}{l}\text { New outpatient clinic/annexe } \\
\text { for department }\end{array}$ & 15 & 10 & 4 & 4 \\
\hline & $\begin{array}{l}\text { Software for operational } \\
\text { management }\end{array}$ & 14 & 9 & 3 & 3 \\
\hline
\end{tabular}

CBCT, cone beam CT; IGRT, image-guided radiation therapy; IMRT, intensity-modulated radiation therapy; kV, kilovoltage; Linac, linear accelerator; RT, radiotherapy; SBRT/SRS, stereotactic body radiation therapy/ stereotactic radiosurgery; TPS, treatment planning system; VMAT, volumetric arc therapy. 
The top five innovations cover $295 / 525$ innovations (56\%). A wide variation was seen in the number of centres that implemented each innovation; for example, 61 innovations were implemented by $1-3$ centres, and 103 innovations were implemented by $4-6$ centres (Figure 2 ). The majority of the innovations $(n=361$ ) was implemented by 7 or more centres.

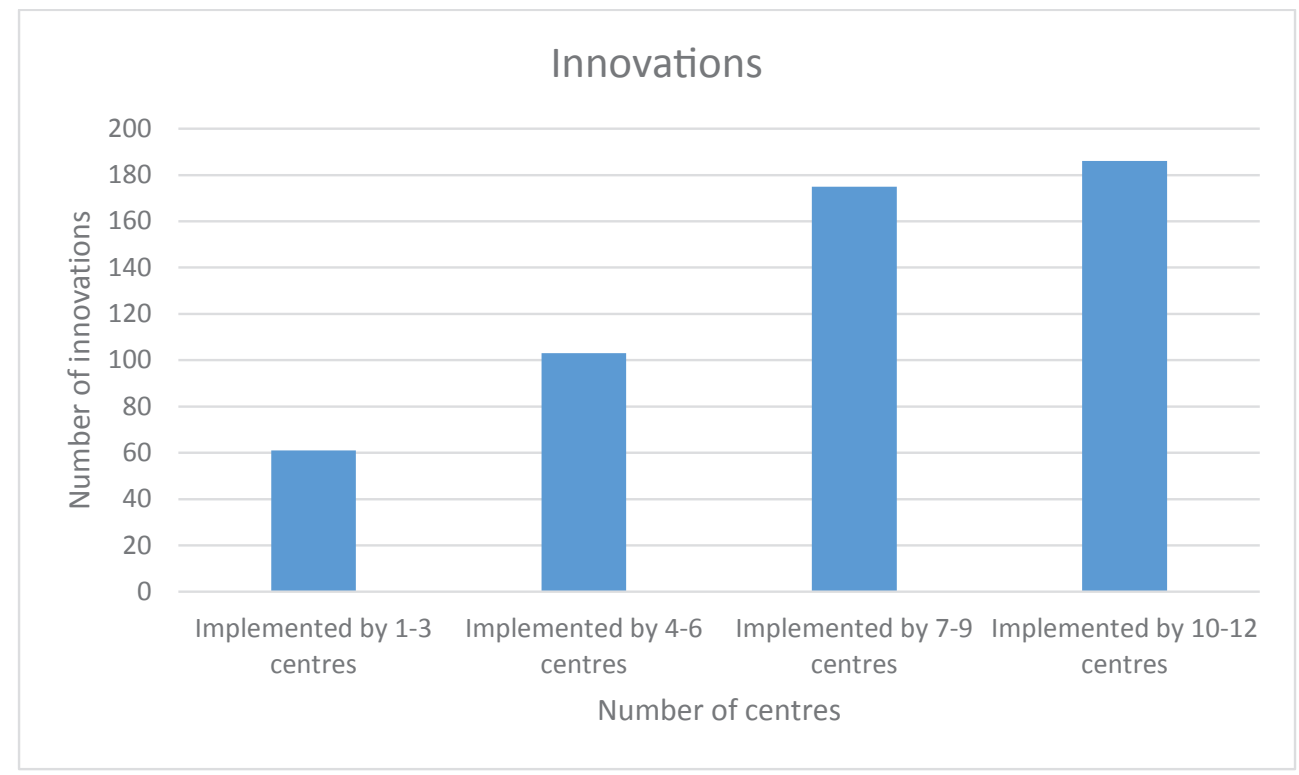

Figure 2: Number of innovations implemented by number of centres.

For the product innovation indicator "percentage of patients in trials", six participating centres could not generate data and one centre had no patients in trials. Nevertheless, for the centres that could, we obtained the percentage of patients in Phase I-II trials and in Phase III trials (Table 2 and Figure 3). During the time of the study, there were $10 \mathrm{RT}$ trials open for recruitment in the Netherlands according to the information on http://www.trialregister.nl and http://www.clinicaltrials.gov. These trials included innovations such as image- and dose-guided RT, multimodality and molecular imaging, and VMAT techniques.

The included innovations were mandatory for these trials. However, in only in three trials, the innovation as such was tested against the standard treatment. Three of the innovations in our study could be related to these trials. 


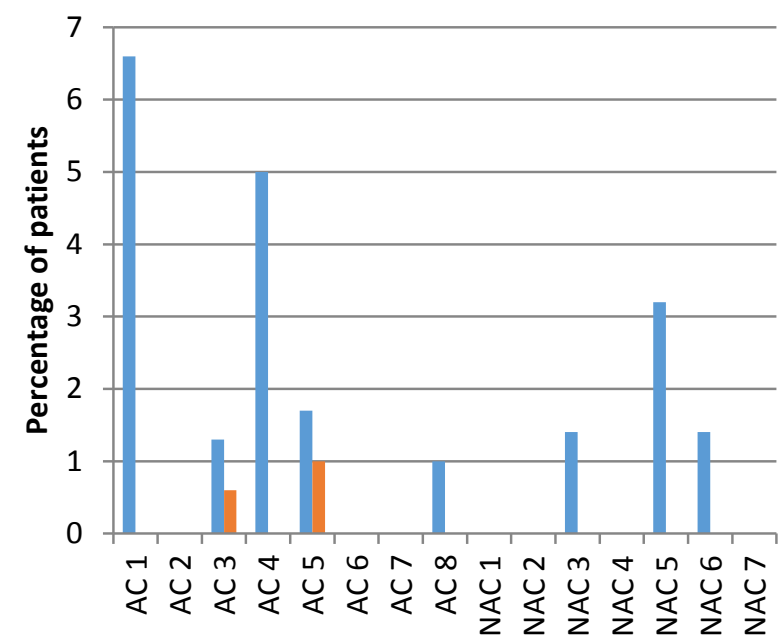

Percentage of patients in phase III trials

Percentage of patients in phase I-II trials

\section{Centre}

Figure 3: Percentage of patients in Phase III and Phase I-II trials on a scale from $0 \%$ to $7 \%$.

Concerning market innovation, we asked for their activities on two indicators: (1) percentage of patients from outside the market area referred by physicians from hospitals which do not regularly refer their patients to this centre and (2) number and percentage of new general hospitals that refer the desired patient population [3]. Concerning the first market innovation indicator, one participating centre considered their figures too confidential to hand over, whereas five centres did not register this information. The results from the remaining nine centres that did provide data on this indicator are listed in Figure 4.

Regarding the second market innovation indicator, we found that 10 out of 15 participating RT centres opened one or two new satellites/outpatient clinics. In total, 12 new satellites/ outpatient clinics (which are not counted as a separate centre in this study) were opened in the period 2011-13. Most of them treat patients who would also be referred to the original RT centre if there were no satellite/outpatient clinic. In two cases, the newly opened satellites/outpatient clinics treat patients who would not have been referred before the opening. 


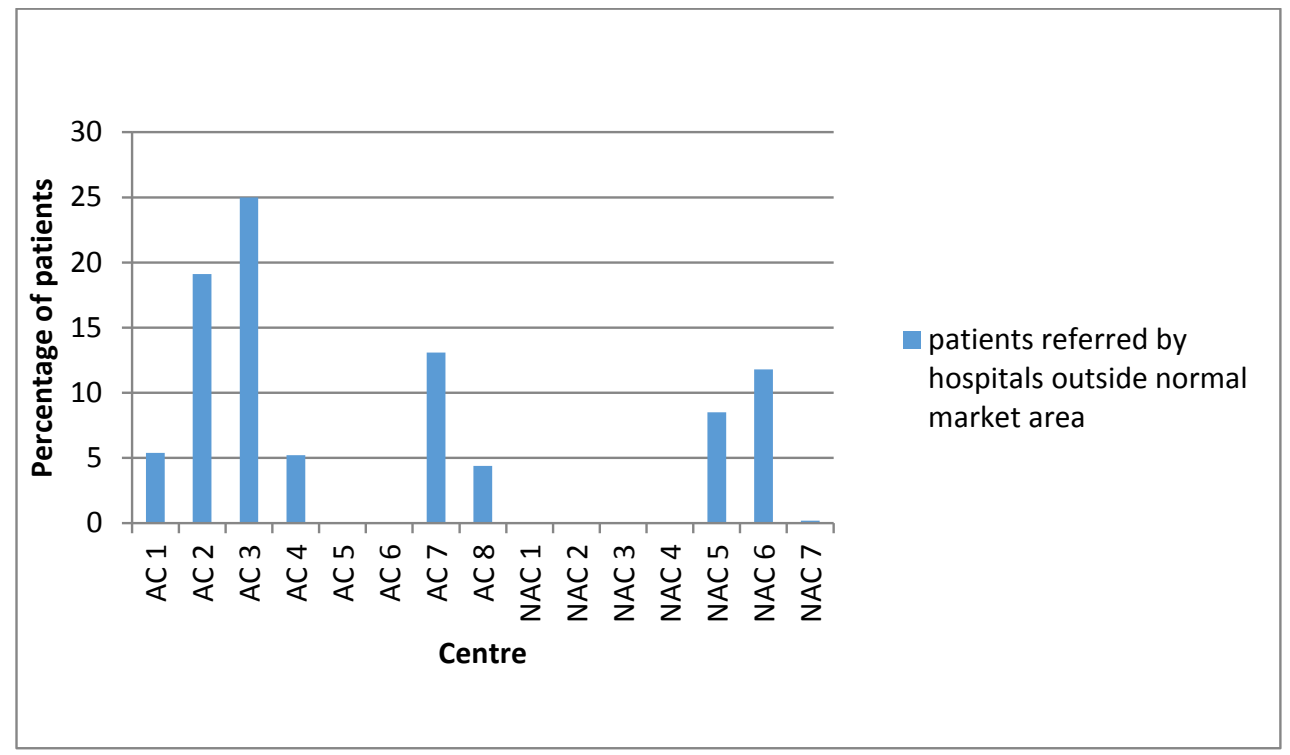

Figure 4: Percentage of patients referred by hospitals outside the normal market area on a scale from $0 \%$ to $30 \%$.

\section{Effort required and impact on output for each innovation, and innovative working behaviour}

Table 6 shows that product, technological and organizational innovations are scored almost equally regarding average effort required and impact on output. For the average effort score, there is no significant difference between the different kinds of innovations $(p=0.249)$. However, for the average output, there is a significant difference $(p=0.000)$. This difference can be found between product innovations and technological innovations $(p=0.000)$ and between product innovations and organizational innovations $(p=0.000)$. There is no significant difference between technological and organizational innovations $(p=0.327)$. Innovative work behaviour varied between 3.3 and 4.9 (Table 7).

Table 6. Average score impact effort organization/employee and average score impact output

\begin{tabular}{llllll}
\hline $\begin{array}{l}\text { Type of } \\
\text { innovation }\end{array}$ & $\begin{array}{l}\text { Number of } \\
\text { innovations }\end{array}$ & $\begin{array}{l}\text { Total effort } \\
\text { score }\end{array}$ & $\begin{array}{l}\text { Average effort } \\
\text { score (SD) }\end{array}$ & $\begin{array}{l}\text { Total output } \\
\text { score }\end{array}$ & $\begin{array}{l}\text { Average output } \\
\text { score (SD) }\end{array}$ \\
\hline $\begin{array}{l}\text { Product } \\
\text { innovation }\end{array}$ & 168 & 592 & $3.52(0.538)$ & 654 & $3.89(0.329)$ \\
$\begin{array}{l}\text { Technological } \\
\text { innovation }\end{array}$ & 148 & 526 & $3.55(0.712)$ & 498 & $3.39(0.502)$ \\
$\begin{array}{l}\text { Organizational } \\
\text { innovation }\end{array}$ & 209 & 747 & $3.62(0.524)$ & 722 & $3.45(0.499)$ \\
\hline
\end{tabular}

SD, standard deviation. 


\section{Short repeat survey}

In the inquiry in 2016, two completely new innovations were reported which entered into clinical routine after 2013: three dimensional printing of the bolus for electrons and the implementation of MR-guided RT with online adaptation. The introduction of protons and of MR-linear accelerator that was also mentioned was not counted, because it was not yet integrated into clinical routine.

Table 7. Weighted innovations (frequency x score) for the period 2011-2013, academic centres (AC) vs non-academic (NAC) centres

62
n
$\frac{1}{ \pm}$
$\frac{1}{0}$
$\frac{0}{0}$
$\frac{c}{\cup}$
$\vdots$

\begin{tabular}{|c|c|c|c|c|c|c|c|}
\hline \multirow[t]{2}{*}{ Clinic } & \multicolumn{3}{|c|}{ Effort } & \multicolumn{3}{|c|}{ Output } & \multirow{2}{*}{$\begin{array}{c}\text { Mean } \\
\text { Innovative } \\
\text { Work } \\
\text { behaviour }\end{array}$} \\
\hline & $\begin{array}{l}\text { Product } \\
\text { Innovations }\end{array}$ & $\begin{array}{l}\text { Technological } \\
\text { Innovations }\end{array}$ & $\begin{array}{l}\text { Organizational } \\
\text { Innovations }\end{array}$ & $\begin{array}{l}\text { Product } \\
\text { Innovations }\end{array}$ & $\begin{array}{l}\text { Technological } \\
\text { Innovations }\end{array}$ & $\begin{array}{l}\text { Organizational } \\
\text { Innovations }\end{array}$ & \\
\hline \multicolumn{8}{|l|}{ Academic: } \\
\hline AC 1 & 54 & 49 & 104 & 60 & 47 & 102 & 3.7 \\
\hline AC 2 & 46 & 45 & 51 & 47 & 45 & 46 & 4.9 \\
\hline AC 3 & 24 & 0 & 32 & 24 & 0 & 30 & 4.2 \\
\hline AC 4 & 11 & 4 & 51 & 12 & 3 & 49 & 4 \\
\hline AC 5 & 65 & 128 & 71 & 66 & 126 & 70 & 4 \\
\hline AC 6 & 56 & 14 & 11 & 63 & 15 & 10 & 3.4 \\
\hline AC 7 & 21 & 66 & 54 & 23 & 61 & 50 & 4.8 \\
\hline AC 8 & 59 & 20 & 76 & 63 & 15 & 80 & 3.7 \\
\hline Mean AC & 42 & 41 & 56 & 45 & 39 & 55 & 4.1 \\
\hline Range AC & $11-65$ & $0-128$ & $11-104$ & $12-66$ & $0-126$ & $10-102$ & $3.4-4.9$ \\
\hline \multicolumn{8}{|l|}{$\begin{array}{l}\text { Non } \\
\text { academic: }\end{array}$} \\
\hline NAC 1 & 55 & 35 & 28 & 66 & 34 & 28 & 3.3 \\
\hline NAC 2 & 31 & 25 & 57 & 40 & 22 & 52 & 4.2 \\
\hline NAC 3 & 24 & 23 & 11 & 28 & 23 & 10 & 4.4 \\
\hline NAC 4 & 33 & 29 & 50 & 35 & 24 & 47 & 3.6 \\
\hline NAC 5 & 36 & 29 & 56 & 39 & 25 & 54 & 3.6 \\
\hline NAC 6 & 38 & 42 & 57 & 44 & 38 & 56 & 4.4 \\
\hline NAC 7 & 39 & 17 & 38 & 44 & 20 & 38 & 4.2 \\
\hline Mean NAC & 37 & 29 & 42 & 42 & 27 & 41 & 4.0 \\
\hline Range NAC & $24-55$ & $17-42$ & $11-57$ & $28-66$ & $20-38$ & $10-56$ & $3.3-4.4$ \\
\hline $\begin{array}{l}\text { Total } \\
\text { Weighted } \\
\text { Innovations }\end{array}$ & 592 & 526 & 747 & 654 & 498 & 722 & \\
\hline P-value & 0.524 & 0.908 & 0.384 & 0.722 & 1.000 & 0.452 & 0.727 \\
\hline
\end{tabular}




\section{Academic vs non-academic centres, and influence of innovative work behaviour}

The number of innovations in academic centres was higher but not significantly different from non-academic centres $(p=0.325)$ (Table 8$)$. This also holds for every innovation type separately. On average, academic centres implemented 39 (range 1475) innovations in the period 2011-13, whereas non-academic centres implemented 30 (range 17-38). In academic centres, a larger range in number of innovations was observed than in non-academic centres. As is shown in Table 7, also when weighted for required effort and expected output, we did not find any significant difference between academic and non-academic centres for any of the types of innovation. We found that the innovation categories with the fewest implemented innovations and also those that were implemented in the fewest centres are more often implemented in academic centres. 22 out of these 29 innovations are implemented in academic centres.

No significant differences in IWB were seen between academic and non-academic centres (Table 7). In addition, no significant correlation was found between the number of innovations and innovative work behaviour $(p=0.972)$. This also holds for the weighted total of innovations and innovative work behaviour (effort $p=0.939$, output $p=0.992$ ).

Table 8. Innovations per centre and per innovation type from 2011 to 2013, academic centres (ACs) vs non-academic centres (NACs)

\begin{tabular}{|c|c|c|c|c|}
\hline \multirow[t]{2}{*}{ Clinic } & \multicolumn{3}{|c|}{ Innovations } & \multirow{2}{*}{$\begin{array}{c}\text { Total } \\
\text { innovations } \\
\text { per clinic }\end{array}$} \\
\hline & $\begin{array}{c}\text { Product } \\
\text { Innovations }\end{array}$ & $\begin{array}{l}\text { Technological } \\
\text { Innovations }\end{array}$ & $\begin{array}{l}\text { Organizational } \\
\text { Innovations }\end{array}$ & \\
\hline \multicolumn{5}{|l|}{ Academic: } \\
\hline AC 1 & 16 & 13 & 30 & 59 \\
\hline AC 2 & 12 & 14 & 14 & 40 \\
\hline AC 3 & 6 & 0 & 8 & 14 \\
\hline AC 4 & 3 & 1 & 14 & 18 \\
\hline AC 5 & 17 & 38 & 20 & 75 \\
\hline AC 6 & 16 & 4 & 3 & 23 \\
\hline AC 7 & 6 & 18 & 14 & 38 \\
\hline AC 8 & 17 & 5 & 23 & 45 \\
\hline Mean AC & 12 & 12 & 16 & 39 \\
\hline Range AC & $3-17$ & $0-38$ & $3-30$ & $14-75$ \\
\hline \multicolumn{5}{|c|}{ Non-academic: } \\
\hline NAC 1 & 17 & 10 & 8 & 35 \\
\hline NAC 2 & 10 & 7 & 16 & 33 \\
\hline
\end{tabular}




\begin{tabular}{lcccc}
\hline \multicolumn{1}{c}{ Clinic } & Innovations & & $\begin{array}{c}\text { Total } \\
\text { innovations } \\
\text { per clinic }\end{array}$ \\
NAC 3 & 7 & 7 & 3 & 17 \\
NAC 4 & 9 & 7 & 13 & 29 \\
NAC 5 & 10 & 8 & 16 & 34 \\
NAC 6 & 11 & 11 & 16 & 38 \\
NAC 7 & 11 & 5 & 11 & 27 \\
Mean NAC & 11 & 8 & 12 & 30 \\
Range NAC & $7-17$ & $5-11$ & $3-16$ & $17-38$ \\
Total & 168 & 148 & 209 & 525 \\
innovations & & & & \\
\hline
\end{tabular}

\section{DISCUSSION}

This study shows that RT centres in the Netherlands innovate a great deal: for the product, technological and organizational innovation categories, academic centres count 13 innovations a year and non-academic centres count 10 innovations a year. However, the range between centres is large: in 3 years, this range was 14-75 for academic centres and 17-38 for non-academic centres. There are no significant differences between academic and non-academic centres. Even when weighting for the effort required by organizations/employees or for perceived impact on output, no significant differences were found between academic and non-academic centres.

The product innovation indicators "patients in trials Phase I-II or III" were not registered in $6 / 15$ centres ( 3 academic). During the period of the study, 3 trials out of the 10 trials open for recruitment were randomizing or evaluating an innovation against standard RT. Three of the innovations in our study could be related to these trials.

Regarding market innovation, no registration on market performance outside the normal market area was available in 5/15 centres ( 2 academic). Starting new outpatient clinics/ departments was only aimed at entering new markets in 2/12 cases. Innovative work behaviour of the medical staff (physicians and physicists) was not correlated with the degree of innovation.

\section{Differences between centres: academic vs non-academic and the wide range}

The literature shows that the implementation of health innovations is affected by many factors, including leadership, slack time (the positive difference between the available resources of an organization/department of the employee and the combination of 
demands made on that resource) [19], shared vision, communication, team responsibility and innovation capacity (the organizational potential to innovate, which is determined by the skills and strengths in basic research and development and technology). Basic research and development refers to experimental or theoretical work undertaken primarily to acquire new knowledge without any particular application or use in view of RT, for example, some research in the area of radiobiology and physics $[14,16$, 20-26]. In a systematic review, 62 measures were identified in a multilevel framework predicting implementation outcomes [27]. These factors can differ between different centres, which is a possible explanation for the large range in innovation performance in our study. In addition, these factors are not by definition more common in academic centres, which we think partly explains why we did not find differences between academic and non-academic centres. Furthermore, academic centres are, based on their function, more focused on research than non-academic centres. Research can be seen as innovation generation. In the literature, this is described as an innovation competence and distinguished from innovation adoption [28]. Generating innovation is a creative process, which is characterized by variation, search, experimentation and discovery and which produces new knowledge and information. Innovation adoption, on the other hand, is a problem-solving process, which is planned more tightly and can be characterized by selection, refinement, choice and execution. An academic centre should have more innovation-generating capacity but not per definition more employees with innovation-adoption competences. The fact that the innovation categories with the fewest implemented innovations and those that were implemented in the fewest centres are more often implemented in academic centres is probably also related to innovationgenerating competences. More specifically, the five fewest implemented innovations in each innovation category (product, technological and organizational) count a total of 29 different innovations. 22 out of these 29 innovations are implemented in academic centres, probably as a continuation of research, such as the introduction of the spacer prostate-rectum and the introduction of the six-dimensional couch.

It is not clear whether the degree and nature of the types of innovation in Dutch RT centres is comparable with centres abroad. In research, new developments are described but not the extent to which these developments are introduced in clinical practice.

For example, in a worldwide literature review from 2010, new developments in arc-based RT techniques are described with attention given to VMAT, tomotherapy and the new approach to IMRT. [29] We showed that in the period 2011-13, most centres implemented IMRT and VMAT in clinical routine. The other top five innovations were stereotactic body radiation therapy/stereotactic radiosurgery technique optimization, TPS protocol optimization, oncology information system upgrade and software for patient care. 
More recently, expert clinicians and scientists in the field of RT discussed how innovative technology in radiation oncology is being developed and translated into clinical practice in the face of current and future challenges and opportunities [4]. The workshop focused on the challenges posed by new technologies, addressed the state of the science for several disease sites, discussed clinical trials for advanced technology and reviewed the future promise and potential pitfalls of emerging, innovative technologies. Themes to help guide innovative technology-based research for radiation oncology included: (a) innovative treatment-delivery technology, (b) advances in imaging for quantitative and validated treatment design, (c) oncology informatics and (d) evidence building. The description of the workshop results contains important information about the field of future innovation, but it cannot serve as a benchmark for implemented innovations in clinical routine.

As mentioned earlier, there were 10 trials open for recruitment in the period of our investigation, 3 of which were randomizing or evaluating innovations against standard RT. It could be helpful to perform a trial to implement an innovation. The implementation of complex techniques may vary per country. In the UK, advanced treatment techniques will continue to be introduced nationally via well-designed clinical trials [30-33]. However, in the Netherlands, we also allow model-based approaches, as we are currently using for the introduction of proton therapy. Sometimes, complemented cost-effectiveness studies are used [34-37].

\section{The degree of innovations in radiotherapy: radical or incremental innovations}

Radical innovations include those treatments, technologies, and markets and organizational changes that are completely new to the clinic. Such major innovations require skills, abilities and knowledge different from those required to master the old technologies. Incremental innovation, by contrast, introduces alterations to existing treatments, technologies, methods or systems that lead to improvements in content or efficiency [38]. The factors affecting the implementation of incremental innovations are different from those affecting radical innovations [3]. It is therefore important for organizations that have the ambition to improve their innovation implementation to consider how radical the intended innovations are.

As shown in Figure 5, on required effort by organization/employees and on expected output, the vast majority of innovations score a 3 (moderate impact, $46 \%$ and $42 \%$, respectively) or 4 (large impact, $50 \%$ and $58 \%$, respectively). Only $4.2 \%$ of all innovations are considered to have a very large impact on the effort required from organization and employees, for example, the introduction of a completely new electronic health records system, or a TPS or new linear accelerators. It is debatable whether these innovations with a score of 5 can be seen as radical. 
Some innovations in some academic centres such as the introduction of protons, MRIlinear accelerators, trials with RT and immunotherapy or decision support systems are in our opinion more in line with the characteristics of radical innovations as defined above but are not scored as such due to the fact that they are still in preparation. Clinical introduction of radical innovations requires a long period of preparation.

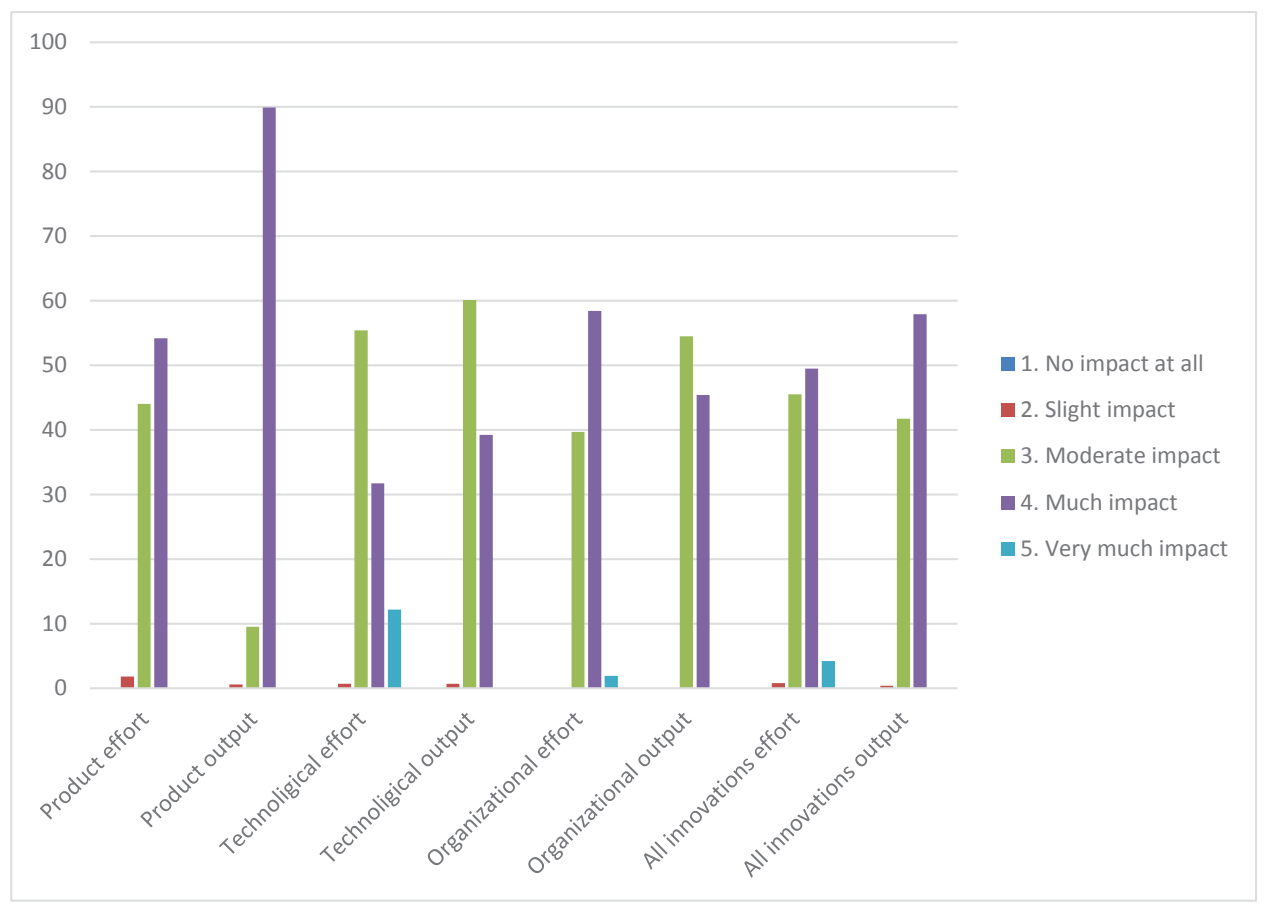

Figure 5: Percentage of innovations per score category and distinguished by impact on effort required by organization/employees and expected output of the innovation.

Nevertheless in our study, product innovations, with a high potential to improve treatment quality, scored a significantly higher impact on expected output than the other two categories of innovations and are especially beneficial from a patient's perspective.

\section{Product innovation indicators regarding patients in trials}

The lack of registration of patients in trials is surprising, especially for academic centres. In addition, 8 out of 10 of the registered percentages are $<5 \%$, which is relatively low than found in the literature $[39,40]$. Clinical trials play a dominant role in clinical oncology [41]. To improve the quality of innovation, we consider it valuable to systematically measure these indicators and to provide the centres with feedback on their results compared with the other centres. Therefore, it is important to set up an adequate registration system, 
since this may help to identify barriers and facilitators. Such a system may therefore help to develop strategies that will increase trial participation.

\section{Market innovations}

With regard to market innovation, too, a comprehensive registration system is lacking in several centres. Geographically, it seems that there are only a few possible avenues for market innovations.

Most of the time, new outpatient clinics/satellites treat patients from already connected market areas. Often, this reduces travel time for patients. It is generally known that new satellites are also established to protect the existing market area. With new RT indications, new markets can be entered (for example, RT combined with immunotherapy); the introduction of, for example, hypofractionation may also be able to attract new patients.

\section{Correlation innovative work behaviour and innovations}

We investigated the correlation of IWB with innovation implementation because IWB is important for innovation generation [14]. We found no correlation. Apparently, for innovation implementation, IWB alone is not a determining factor.

\section{Limitations}

One limitation of this study concerns the sample size. Data from only a limited number of 15 treatment centres ( 8 academic and 7 non-academic) were available for analysis. Because of the limited number of RT treatment centres in the Netherlands, it was not possible to markedly increase the sample size. This severely limits the power of the statistical tests to detect a statistically significant difference and a statistically significant correlation. Therefore, all relevant descriptive statistics are also presented to get an indication of the estimated size of an effect and the accompanying uncertainty of these estimates.

Another limitation is that we used a cross-sectional design; therefore, we measured the innovation performance of centres in a specific period but not the innovation performance in an absolute sense. For example, the three centres which implemented no IMRT innovations in the period of our study had already introduced IMRT before 2011.

Finally, our study does not offer insight into the question whether innovations are sufficiently evaluated and actually improve treatment quality before their introduction in clinical routine. For example, does VMAT with full Arc possibly increase toxicity compared with three-dimensional conformal radiation therapy [42]? Investigating this research question would be very meaningful. We are convinced, however, that a systematic collaboration between centres, e.g. through joint training, either face to face 
or with e-learning modules, or through the exchange of standard operating procedures could avoid duplication of work and increase the efficiency of innovation implementation at the national level.

\section{CONCLUSION}

RT centres in the Netherlands implement on average 12 innovations per year in their department (range: 5-25); this number is not significantly different for academic $(n=13)$ or non-academic centres $(n=10)$. This study has shown that several centres are dealing with the same innovations in a certain period.

The numbers confirm that RT centres quickly adopt innovations within their discipline and are very dynamic and innovative. However, there is a large range with regard to innovation implementation performance. There is room for improvement for centres with low numbers and centres can definitely help each other more to reduce this range. Further research is necessary to get more insight into the innovation performance degree in an absolute sense. We conclude it is important that all centres use an adequate, preferably uniform, registration system on innovation indicators and propose to select the system we used because it has been developed and approved by the sector itself. Furthermore, we suggest promoting systematic collaboration between centres not only for the scientific basis of innovations but also for innovation implementation, because this could avoid duplication of work. This can best be carried out by the national RT societies. Although the framework of our study can be used worldwide, communication across countries can be complicated because every country has its own context, systems, rules etc. National recommendations on the implementation of innovations can be helpful. On the other hand, European Society for Radiotherapy and Oncology/American Society for Radiation Oncology could also play a role in particular in training.

\section{ACKNOWLEDGMENTS}

The authors thank the participants from all the centres for their willingness to share their information on innovation with them. 


\section{REFERENCES}

1. Omachonu VK, Einspruch NG. Innovation in healthcare delivery systems: a conceptual framework. Innov J 2010; 15: 1-20.

2. Anderson N, De Dreu CK, Nijstad BA. The routinization of innovation research: a constructively critical review of the state-of-the-science. J Organiz Behav 2004; 25: 147-73. doi: http:// dx.doi.org/10.1002/job.236

3. Jacobs M, Boersma L, Dekker A, Govers M, Lambin P, van Merode F. How to measure innovation in radiotherapy: an application of the Delphi method. J Hosp Adm 2015; 4: 14. doi: http:// dx.doi.org/10.5430/jha.v4n4p14

4. Chetty IJ, Martel MK, Jaffray DA, Benedict SH, Hahn SM, Berbeco R, et al. Technology for innovation in radiation oncology. Int J Radiat Oncol Biol Phys 2015; 93: 485-92. doi: http:// dx.doi.org/10.1016/j.ijrobp.2015.07.007

5. Winkler C, Duma MN, Popp W, Sack H, Budach V, Molls M, et al. Protection of quality and innovation in radiation oncology: the prospective multicenter trial QUIRO of DEGRO: evaluation of time, attendance of medical staff, and resources during radiotherapy with tomotherapy. Strahlenther Onkol 2014; 190: 950-6. doi: http://dx.doi.org/10.1007/s00066-014-0615-3

6. Heron DE, Godette KD, Wynn RA, Arterbery VE, Streeter OA, Roach M 3rd, et al. Radiation medicine innovations for the new millenium. J Natl Med Assoc 2003; 95: 55-63.

7. Bortfeld T, Jeraj R. The physical basis and future of radiation therapy. Br J Radiol 2011; 84: 485-98. doi: http://dx.doi.org/10.1259/bjr/86221320

8. Van De Voorde L, Vanneste B, Houben R, Damen P, van den Bogaard J, Lammering G et al. Image-guided stereotactic ablative radiotherapy for the liver: a safe and effective treatment. Eur J Surg Oncol 2015; 41: 249-56. doi: http://dx.doi.org/10.1016/j.ejso.2014.10.053

9. De Ruysscher D, Belderbos J, Reymen B, van Elmpt W, van Baardwijk A, Wanders R, et al. State of the art radiation therapy for lung cancer 2012: a glimpse of the future. Clin Lung Cancer 2013; 14: 89-95. doi: http://dx.doi.org/10.1016/j.cllc.2012.06.006

10. Simons PA, Houben R, Vlayen A, Hellings J, Pijls-Johannesma M, Marneffe W, et al. Does lean management improve patient safety culture? An extensive evaluation of safety culture in a radiotherapy institute. Eur J Oncol Nurs 2015; 19: 29-37. doi: http://dx.doi.org/10.1016/j. ejon.2014.08.001

11. Chera BS, Jackson M, Mazur LM, Adams R, Chang S, Deschesne K, et al. Improving quality of patient care by improving daily practice in radiation oncology. Semin Radiat Oncol 2012: 22: 77-85. doi: http://dx.doi.org/10.1016/j.semradonc.2011.09.002

12. van Harten MC, Hoebers FJ, Kross KW, van Werkhoven ED, van den Brekel MW, van Dijk BA. Determinants of treatment waiting times for head and neck cancer in the Netherlands and their relation to survival. Oral Oncol 2015; 51: 272-8. doi: http://dx.doi.org/10.1016/j. oraloncology.2014.12.003

13. Jacobs SR, Weiner BJ, Reeve BB, Hofmann DA, Christian M, Weinberger M. Determining the predictors of innovation implementation in healthcare: a quantitative analysis of 
implementation effectiveness. BMC Health Serv Res 2015; 15: 6. doi: http://dx.doi. org/10.1186/s12913-014-0657-3

14. De Jong J, Den Hartog D. Measuring innovative work behavior. Creativ Innovat Manag 2010; 19: 23-36. doi: http://dx.doi.org/10.1111/j.1467-8691.2010.00547.x

15. Thoma-L"urken T, Bleijlevens MH, Lexis MA, Hamers JP, de Witte LP. An overview of potential labor-saving and quality-improving innovations in long-term care for older people. J Am Med Dir Assoc 2015; 16: 482-9. doi: http://dx.doi.org/10.1016/j. jamda.2014.12.017

16. Rosing $K$, Frese $M$, Bausch A. Explaining the heterogeneity of the leadership-innovation relationship: ambidextrous leadership. Leadership Quart 2011; 22: 956-74. doi: http://dx.doi. org/10.1016/j.leaqua.2011.07.014

17. European Commission. Guidelines on the qualifictaion and classification of stand alone software used in healthcare within the regulatory framework of medical devices; 2016 . Cited 9 September 2016. Available from: http://www.google.nl/url?sa5t\&rct5j\&q5\&esrc5s\&source5 web\&cd51\&ved50ahUKEwjgqlaF1I7PAhUFORoKHTamC6UQFggoMAA\&url5http\% 3A\%2F\%2Fec.europa.eu\%2FDocsRoom\%2Fdocuments\%2F10362\%

2Fattachments\%2F1\%2Ftranslations\%2Fen\%2Frenditions\%2 Fnative\&usg5AFQjCNEhbJftEVjWPWhvLGWe6NOm3yRVXA

18. Janssen $\mathrm{O}$. Job demands, perceptions of effort-reward fairness and innovative work behaviour. J Occup Organ Psychol 2000; 73:287-302. doi: http://dx.doi.org/10.1348/096317900167038

19. Youn KI, Wan TT. Effects of environmental threats on the quality of care in acute care hospitals. J Med Syst 2001; 25: 319-31. doi: http://dx.doi.org/10.1023/A:1010637324420

20. Zacher H, Rosing K. Ambidextrous leadership and team innovation. Leader Organ Dev J 2015; 36: 54-68.

21. Zinn J, Flood AB. Commentary: slack resources in health care organizations-fat to be trimmed or muscle to be exercised? Health Serv Res 2009; 44: 812-20. doi: http://dx.doi. org/10.1111/j.1475-6773.2009.00970.x

22. Pearce $C L$, Ensley MD. A reciprocal and longitudinal investigation of the innovation process: the central role of shared vision in product and process innovation teams (PPITs). J Organiz Behav 2004; 25: 259-78. doi: http://dx.doi.org/10.1002/job.235

23. Ghosh K. Developing organizational creativity and innovation: toward a model of selfleadership, employee creativity, creativity climate and workplace innovative orientation. Manage Res Rev 2015;38: 1126-48.

24. Jong JPJ. Individual innovation: the connection between leadership and employees' innovative work behavior. EIM; 2007.

25. Thakur R, Hsu SH, Fontenot G. Innovation in healthcare: issues and future trends. J Bus Res 2012; 65: 562-9. doi: http://dx.doi.org/10.1016/j.jbusres.2011.02.022

26. May C, Finch T, Mair F, Ballini L, Dowrick C, Eccles M, et al. Understanding the implementation of complex interventions in health care: the normalization process model. BMC Health Serv Res 2007; 7: 148. doi: http://dx.doi.org/10.1186/1472-6963-7-148 
27. Chaudoir SR, Dugan AG, Barr CH. Measuring factors affecting implementation of health innovations: a systematic review of structural, organizational, provider, patient, and innovation level measures. Implement Sci 2013; 8: 22. doi: http://dx.doi.org/10.1186/1748-5908-8-22

28. Damanpour F, Wischnevsky JD. Research on innovation in organizations: distinguishing innovation-generating from innovationadopting organizations. J Eng Technol Manage 2006; 23: 269-91. doi: http://dx.doi.org/10.1016/j.jengtecman.2006.08.002

29. Palma DA, Verbakel WF, Otto K, Senan S. New developments in arc radiation therapy: a review. Cancer Treat Rev 2010; 36: 393-9. doi: http://dx.doi.org/10.1016/j. ctrv.2010.01.004

30. Miles $\mathrm{E}$, Venables K. Radiotherapy quality assurance: facilitation of radiotherapy research and implementation of technology. Clin Oncol (R Coll Radiol) 2012; 24: 710-2. doi: http://dx.doi. org/10.1016/j.clon.2012.06.006

31. Nutting CM, Morden JP, Harrington KJ, Urbano TG, Bhide SA, Clark C, et al. Parotid-sparing intensity modulated versus conventional radiotherapy in head and neck cancer (PARSPORT): a phase 3 multicentre randomised controlled trial. Lancet Oncol 2011; 12: 127-36. doi: http://dx.doi.org/10.1016/S1470-2045(10)70290-4

32. Donovan E, Bleakley N, Denholm E, Evans P, Gothard L, Hanson J, et al; Breast Technology Group. Randomised trial of standard 2D radiotherapy (RT) versus intensity modulated radiotherapy (IMRT) in patients prescribed breast radiotherapy. Radiother Oncol 2007; 82: 254-64. doi: http://dx.doi.org/10.1016/j.radonc.2006.12.008

33. Bartlett FR, Colgan RM, Donovan EM, McNair HA, Carr K, Evans PM, et al. The UK HeartSpare Study (Stage IB): randomized comparison of a voluntary breath-hold technique and prone radiotherapy after breast conserving surgery. Radiother Oncol 2015; 114: 66-72. doi: http:// dx.doi.org/10.1016/j.radonc.2014.11.018

34. Langendijk JA, Lambin P, De Ruysscher D, Widder J, Bos M, Verheij M. Selection of patients for radiotherapy with protons aiming at reduction of side effects: the modelbased approach. Radiother Oncol 2013; 107: 267-73. doi: http://dx.doi.org/10.1016/j.radonc.2013.05.007

35. Bongers ML, Coup'e VM, De Ruysscher D, Oberije C, Lambin P, Uyl-de Groot CA. Individualized positron emission tomography-based isotoxic accelerated radiation therapy is cost-effective compared with conventional radiation therapy: a modelbased evaluation. Int J Radiat Oncol Biol Phys 2015; 91: 857-65. doi: http://dx.doi.org/10.1016/j.jjrobp.2014.12.012

36. Cheng Q, Roelofs E, Ramaekers BL, Eekers D, van Soest J, Lustberg T, et al. Development and evaluation of an online three-level proton vs photon decision support prototype for head and neck cancer-comparison of dose, toxicity and cost-effectiveness. Radiother Oncol 2016; 118: 281-5. doi: http://dx.doi.org/10.1016/j.radonc.2015.12.029

37. Vanneste BG, Pijls-Johannesma M, Van De Voorde L, van Lin EN, van de Beek K, van Loon J, et al. Spacers in radiotherapy treatment of prostate cancer: is reduction of toxicity cost-effective? Radiother Oncol 2015; 114: 276-81. doi: http://dx.doi.org/10.1016/j.radonc.2015.01.005

38. van Poucke A. Towards radical innovation in knowledge-intensive service firms; 2005.

39. Sinha G. United Kingdom becomes the cancer clinical trials recruitment capital of the world. J Natl Cancer Inst 2007; 99: 420-2. doi: http://dx.doi.org/10.1093/jnci/djk140 
40. Mathews C, Restivo A, Raker C, Weitzen S, Disilvestro P. Willingness of gynecologic cancer patients to participate in clinical trials. Gynecol Oncol 2009; 112: 161-5. doi: http://dx.doi. org/10.1016/j.ygyno.2008.09.003

41. Roberson NL. Clinical trial participation. Viewpoints from racial/ethnic groups. Cancer 1994; 74(Suppl. 9): 2687-91. doi: http://dx.doi.org/10.1002/10970142(19941101)74:91,2687::AIDCNCR2820741817.3.0.CO;2-B

42. Chan C, Lang S, Rowbottom C, Guckenberger M, Faivre-Finn C; IASLC Advanced Radiation Technology Committee. Intensity-modulated radiotherapy for lung cancer: current status and future developments. J Thorac Oncol 2014; 9: 1598-608. doi: http://dx.doi.org/10.1097/ JTO.0000000000000346 



\title{
CHAPTER 4
}

\section{The efficiency of translational research in radiotherapy}

\author{
Maria Jacobs \\ Liesbeth Boersma \\ Frits van Merode \\ Andre Dekker \\ Frank Verhaegen \\ Luc Linden \\ Philippe Lambin
}

How efficient is translational research in radiation oncology? The example of a large Dutch academic radiation oncology department

Published in: British Journal of Radiology, 2016; 89: 20160129.

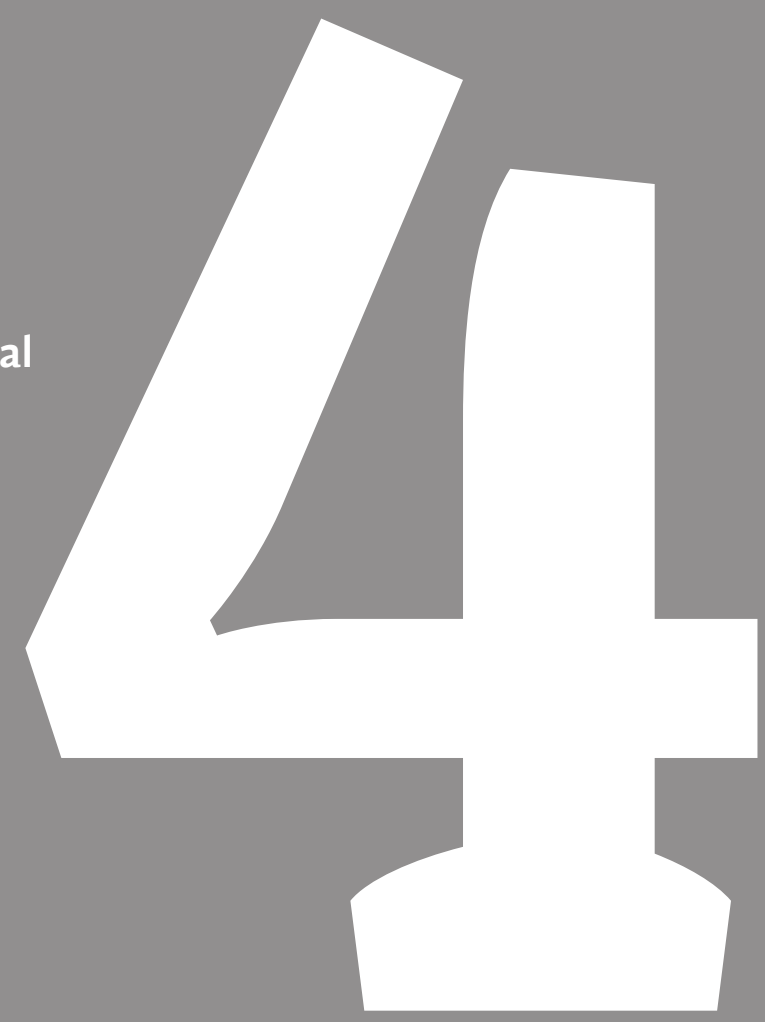




\section{ABSTRACT \\ Objective}

To study the efficiency of research implementation in a large radiotherapy institute, in either an internal review board-approved clinical trial or clinical routine.

\section{Methods}

Scientific publications of the institute were listed. We asked clinicians from tumour expert groups whether the study had been implemented yet in a clinical trial or in clinical practice and which facilitators or barriers were relevant. An independent investigator verified all results. We calculated the implementation rates and the frequency of mentioned facilitators and barriers.

\section{Results}

Resident researchers had published 234 studies over the past 4 years. Overall, 70/234 (30\%) technical or preclinical studies were tested or implemented in a clinical environment in either trials or routine. In total, 45/234 (19\%) studies were routinely implemented; in the 61 clinical studies, this percentage was higher: $38 \%(23 / 61)$. The main facilitator was the level of evidence and the main barriers were workload and high complexity.

\section{Conclusion}

We were able to calculate the implementation ratio of published research into clinical practice and set benchmark figures for other radiotherapy clinics. Level of evidence was an important facilitator, while workload and high complexity of the new procedures were important barriers for implementation. Recent articles suggest that academic entrepreneurship will facilitate this process further.

\section{Advances in knowledge}

This study is the first of its kind calculating implementation rates of published studies in the clinical environment and can contribute to the efficiency of translational research in radiotherapy. We propose to use this metric as a quality indicator to evaluate academic departments. 


\section{INTRODUCTION}

Innovation in radiotherapy has resulted in remarkable progress in the quality of care and outcomes owing to the growing ability to identify and target tumours with a high accuracy and precision $[1,2]$. In order to innovate continuously in the face of future challenges and opportunities, translating research findings into clinical practice is very important. The pace of the translation of scientific discoveries into clinical practice is not well known in radiotherapy and is described as slow in healthcare in general $[3,4]$. The literature frequently reports on the gap between the findings in published empirical literature and the actual use of this evidence in clinical practice [5-9]. However, calculated implementation rates of research findings into clinical practice are lacking. Figures about the gap are based, for example, on published research regarding the integration of evidence-based interventions within clinical practice relative to basic research, the number of patients receiving recommended care or the percentage of basic scientific findings licensed for clinical use $[6,7,10,11]$.

Because of the importance of the continuous translation of research into clinical radiotherapy practice, we want to investigate the real implementation rates. Our aim was to study the efficiency of research implementation, in either clinical routine or clinical trials in a large radiotherapy institution in the Netherlands over a period of 4 years and to provide other radiotherapy centres figures for benchmarking.

The institution that is the subject of our study has stated in its policy plan that it has an integrated strategy for research, technology transfer and patient care (i.e. the same focus in each area with strong alignments between these areas) and facilities such as a data centre for clinical trials and a software development team.

The main research questions are threefold:

1. What is the rate of clinical testing of published preclinical (laboratory) and technological findings?

2. What is the percentage of published findings routinely implemented in clinical practice?

3. What are the facilitators of and barriers to the implementation process in the clinical environment?

For the second research question, we also analysed the impact of national and international collaboration on implementation efficiency, since research collaboration has been reported to be related to research productivity and we want to know whether this is also the case for implementation [12]. Finally, we investigated whether the type of funding is related to 
implementation rates because research funding agencies are held accountable for the public money they spend $[13,14]$. Clinical use of research findings legitimizes research expenditures. Companies also provide funding with the aim to make research findings available in the near future. Our longterm ambition is to identify quality indicators of academic departments and key variables to improve the efficiency of innovation implementation.

\section{METHODS AND MATERIALS}

\section{Data collection}

The scientific publications of researchers at the institute, as included in its annual report, were listed for the period from 2008 to 2011 (4 years). Radiotherapy department figures are listed in Table 1.

Table 1. Radiotherapy department 2011 figures FTE, full time equivalent.

\begin{tabular}{lc}
\hline Characteristics of department & Number \\
\hline Number of treatments & 3802 \\
Number of patients treated & 3015 \\
Number of accelerators & 7 \\
Number of brachytherapy suites & 1 \\
Radiation oncologists in the clinic (FTE) & 14 \\
Physicists (FTE) & 8 \\
Radiation oncologists in training (FTE) & 8 \\
Physicists in training (FTE) & 2 \\
Technologists (FTE) & 56 \\
Researchers (FTE) & 20 \\
\hline
\end{tabular}

FTE, full time equivalent.

Each author was asked to place his or her study (or studies) into one of the following categories: clinical research study (retrospective, prospective cohort, clinical trial); preclinical research; technical research (physics, information communication technology/computer science, imaging); other categories (reviews, case reports, costbenefit analysis, in silico trial), as shown in Table 2.

Subsequently, we asked (in 2015) 15 clinicians (all of whom were either radiotherapy oncologists or physicists) from tumour expert groups at our institute to judge whether the published study had been implemented in the institute in (1) daily routine clinical practice before or after the study; (2) studies with patient material or patient data; and (3) an internal review board approved prospective clinical trial. This has been verified by an independent investigator who was not involved in the data analysis. 


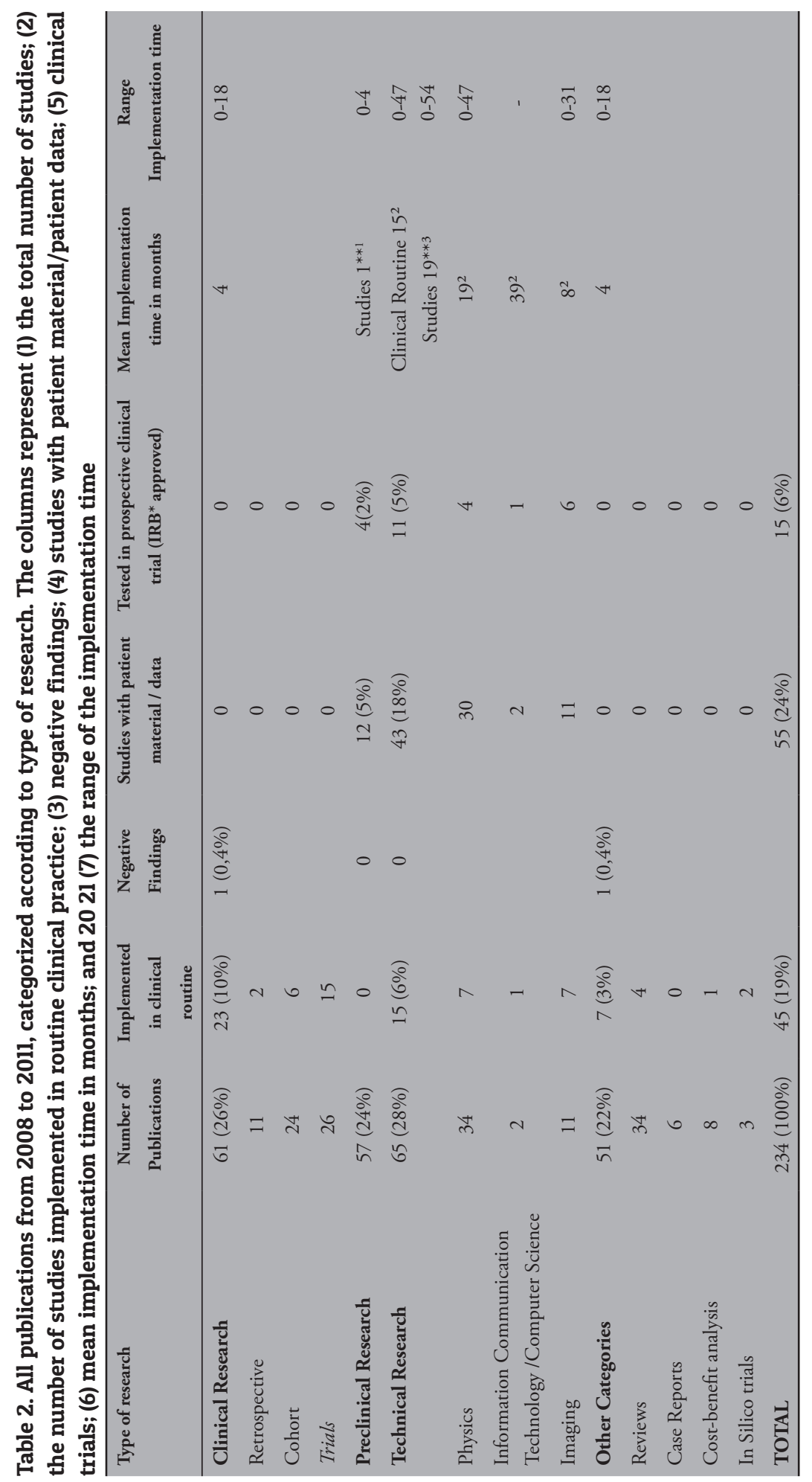

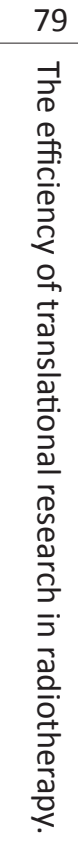


Studies which evaluated the outcome of a previously implemented innovation in the treatment process, but did not result in an adjustment of the treatment as a consequence of the evaluation, were not counted as implemented. Also, studies which added knowledge for the physicians/physicists (e.g. knowledge on certain risk factors for toxicity), but did not result in an adjustment of guidelines/local protocols, were not included in the implementation figures. Finally, we inquired about the time between publication and implementation and whether there were publications with negative findings.

On the basis of the literature, we listed the facilitators and barriers in the implementation process in clinical routine $[5,11,15-17]$. We listed the perceived level of evidence, relative advantage (the degree to which the implementation of the scientific finding is perceived as being better than the existing practice), compatibility (the degree to which the finding is perceived as consistent with the existing values, past experiences and needs of the clinicians), complexity (the degree to which a scientific finding is perceived as relatively difficult to understand and use), trial ability (the degree to which an innovation resulting from a scientific finding may be experimented with on a limited basis), observability (the degree to which the results of the implementation of scientific findings are visible to others), inter-organizational connections (implementing the scientific findings together with other organizations), workload and researchers-clinicians gap (no common vision and no alignment between researchers and clinicians). We then asked the clinicians from the tumour expert groups which facilitators or barriers regarding implementation in clinical routine were applicable for studies concerning findings that could potentially be implemented in clinical practice. We also asked whether other barriers or facilitators than the ones we had listed were present. We put the number of times the item was mentioned by the clinicians as a barrier or a facilitator on a numerical scale.

Finally, all studies were categorized according to single-centre, national multicentre or international multicentre research and according to national, international and corporate funding. In $45 \%$ of the studies, there was no funding source mentioned in the study, probably in most cases because the research was "internally" funded, i.e. the scientists conducted the research within their regular working schedule paid by the clinic or university.

\section{Data analysis}

We calculated the implementation rate by dividing the number of publications implemented in clinical trials and/or in daily routine clinical practice by the total number of publications. In addition, we scored the frequency of attributes which facilitate innovations if findings were implemented or barriers which block innovation. To study the impact of the national or international setting of the studies and the type of funding on the implementation rate, we used a $X^{2}$ test. In these tests, we calculated the expected implementation rates by combining the observed average implementation 
rate with the frequency distribution of the setting (single-centre vs multicentre national vs multicentre international) and the frequency distribution of the funding (national/ international/company/mixed). Subsequently, we calculated the sum of the squares of observed values minus the expected values divided by the expected values using SPSS ${ }$ (IBM Corp., New York, NY; formerly SPSS Inc., Chicago, IL).

\section{RESULTS}

\section{Categorization of publications}

Resident researchers published 234 articles in 4 years, of which 61 (26\%) articles were judged to be clinical studies, 57 (24\%) studies were preclinical, 65 (28\%) studies were technical and 51 (22\%) studies were other categories (Table 2).

\section{Implementation rate}

In total, 100/234 (43\%) studies were implemented in a clinical environment (Table 2):

- $45 / 234$ (19\%) studies were implemented in clinical routine; in the 61 clinical studies, this percentage was even higher: $38 \%$ (23/61).

- $55 / 234$ (24\%) technical or preclinical (laboratory) studies were tested in a clinical environment, mostly in the context of a research project. Of these technical or preclinical studies, 15 studies were tested in a prospective clinical trial (15/122=12\%).

\section{Facilitators and barriers}

The radiation oncologists/physicists (15) interviewed most often mentioned "perceived level of evidence" as a facilitator of the implementation of the published scientific findings in clinical routine. The barriers for not implementing the published research findings in clinical routine mentioned most often were workload and high complexity of the new procedure (Figure 1).

Facillitators

Percieved level of evidence high

Complexity low

Compatibility high

Observalibilty good

Interorganisational connections

\section{Barriers}

Workload / lack of resources

Complexity high

Gap researchers / clinicians

Perceived level of evidence low

Relative advantage / practical value low

Triability low

Compatibility low

Observability low

Other vendor
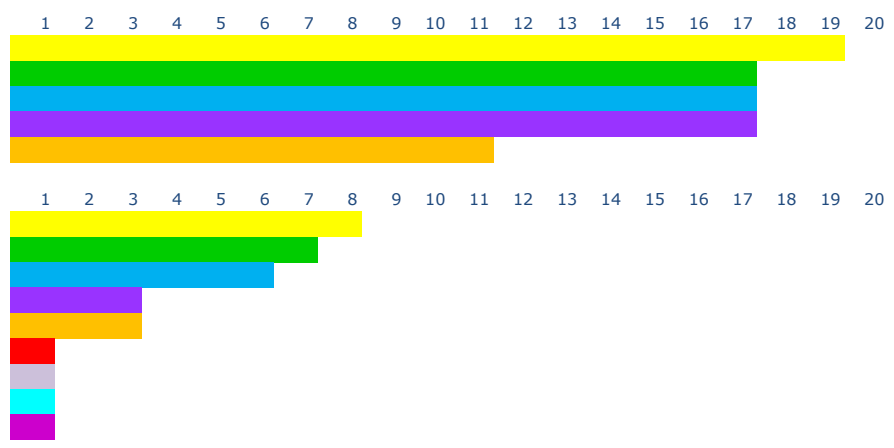

Figure 1: Overview of the mentioned facilitators of and barriers to publications which concern findings that could potentially be implemented in clinical practice. 


\section{Impact of collaboration and funding on implementation rate}

The implementation rate of international multicentre studies was significantly lower than the observed average implementation rate in our study (11\% vs $19 \%$ ), whereas single centre studies ( $28 \%$ vs $19 \%$ ) or national multicentre studies (30\% vs $19 \%$ ) had much higher implementation rates than the observed average implementation rate (Pearson $\mathrm{X}^{2} \mathrm{p}=0.003$ ) (Table 3 ).

Table 3. Cross-tabulation study setting and implementation counts

\begin{tabular}{lllll}
\hline Studysetting & (Expected)Count & Implemented & Notimplemented & Total \\
\hline Internationalmulticentre & Count & $14.0(11 \%)$ & $112.0(89 \%)$ & 126.0 \\
& Expectedcount & $24.2(19 \%)$ & $101.8(81 \%)$ & 126.0 \\
Nationalmulticentre & Count & $16.0(30 \%)$ & $38.0(70 \%)$ & 54.0 \\
& Expectedcount & $10.4(19 \%)$ & $43.6(81 \%)$ & 54.0 \\
Single-centrelocal & Count & $15.0(28 \%)$ & $39.0(72 \%)$ & 54.0 \\
& Expectedcount & $10.4(19 \%)$ & $43.6(81 \%)$ & 54.0 \\
Total & Count & $45.0(19 \%)$ & $189.0(81 \%)$ & 234.0 \\
& Expectedcount & $45.0(19 \%)$ & $189.0(81 \%)$ & 234.0 \\
\hline
\end{tabular}

In terms of type of funding, the observed implementation rate was higher than the average observed implementation rate in our study for studies with national funding ( $32 \%$ vs $14 \%$ ) and was lower than the average for studies with funding from mixed sources ( $0 \%$ vs $14 \%$ ). Implementation rates for international or company funding were not significantly different from the observed average implementation rate (Pearson $\chi 2 p=0.003$ ) (Table 4).

Table 4. Cross-tabulation funding and implementation counts

\begin{tabular}{llllr}
\hline Funding & (Expected) Count & Implemented & Not implemented & Total \\
\hline Company funding & Count & $4.0(19 \%)$ & $17.0(81 \%)$ & 21.0 \\
& Expected count & $3.0(14 \%)$ & $18.0(86 \%)$ & 21.0 \\
International funding & Count & $5.0(11 \%)$ & $39.0(89 \%)$ & 44.0 \\
& Expected count & $6.2(14 \%)$ & $37.8(86 \%)$ & 44.0 \\
Mixed funding & Count & $0.0(0 \%)$ & $35.0(100 \%)$ & 35.0 \\
& Expected count & $4.9(14 \%)$ & $30.1(86 \%)$ & 35.0 \\
National funding & Count & $9.0(32 \%)$ & $19.0(68 \%)$ & 28.0 \\
& Expected count & $3.9(14 \%)$ & $24.1(86 \%)$ & 28.0 \\
Total & Count & $18.0(14 \%)$ & $110.0(86 \%)$ & 128.0 \\
& Expected count & $18.0(14 \%)$ & $110.0(86 \%)$ & 128.0 \\
\hline
\end{tabular}




\section{DISCUSSION}

Dissemination and implementation of research findings in practice are necessary to improve the outcomes of radiotherapy treatment and also to achieve a return on investment for research expenses. Investigating a large radiotherapy department in 2015 , we found that $19 \%$ of studies published in 2008-2011 were implemented in routine clinical practice, another $6 \%$ studies in clinical trials and another $24 \%$ studies in studies with patient material/data. In addition, national studies or studies using national funding had higher implementation rates than international studies or studies funded by companies.

Negative findings were presented in only 2 out of 234 articles. This could be explained by the wellknown publication bias: studies with statistically significant results are more likely to be published than studies with non-significant results [18-21].

The implementation time in clinical practice was 4 months for clinical research and 15 months for technical research. It was possible in only 20 of the 55 cases to discover the date on which a study was continued as part of further studies in the clinical setting. The implementation times for preclinical studies and technical studies were 1 month $(n=4)$ and 19 months $(n=16)$, respectively.

The main facilitators of implementation were high level of evidence, low complexity and high compatibility and observability, whereas the main barriers were high complexity, high workload and a large gap between researchers and clinicians. As far as we know, we are the first to report implementation figures like these; so, we cannot compare our figures with the literature. To get a rough indication of implementation rates, other researchers tend to examine, for example, the types of articles appearing in the peer-reviewed literature or studies about the number of patients receiving recommended care $[6,7,10,11]$.

Despite this lack of comparable studies, much of the literature states that implementation rates are low, but that it is not completely clear why implementation rates are low, and that disseminating new evidence and treatments into clinical practice is a slow and poorly understood process [22]. It is common to refer to the "pipeline" from research to practice, where the "leakage" or loss of medical clinical research is described at each stage from completed research to the ultimate implementation [23].

In addition, in radiotherapy, the interval from the development of new technologies to their application as clinical tools can be long as well (e.g. $\geq 10$ years) [24]. Looking closer at the implementation rates in the department in our study, the following remarks can be made. 
Clinical research $(n=61)$ had the highest implementation rate, 38\% (23/61), and a short implementation time ( 4 months), which can be explained by the fact that this research is performed by clinician scientists, is well known by other members of the medical staff and has already been shown to be compatible with daily practice.

Among the preclinical studies ( $n=57), 21 \%(12 / 57)$ studies were tested in patients and $7 \%(4 / 57)$ studies resulted in a clinical trial. When investigating implementation rates of studies published in 2008-11, in 2015, high implementation rates cannot be found because the pipeline of this kind of preclinical research is usually longer than 4-7 years. Previous research even found that it takes an average of 17 years for only $14 \%$ of new scientific discoveries to enter day-to-day clinical practice. [7] Taking into account this long pipeline, the above-mentioned scores of $21 \%$ and $7 \%$ cannot be qualified as low.

Among the technical studies ( $n=65), 23 \%(15 / 65)$ studies were implemented in clinical routine, $66 \%(43 / 65)$ studies were tested in patients and $17 \%(11 / 65)$ studies resulted in a clinical trial. These high implementation rates of technical studies are probably owing to the fact that radiation therapy is situated at the interface between many disciplines and relies heavily on physics (including imaging). The department in our study is pioneering in the fields of dose-guided radiotherapy (DGRT) and image guided radiotherapy, resulting in commercialization of the developed software. The high percentage of technical research is in line with this focus on DGRT and image-guided radiotherapy.

Possibly, the integrated strategy for research, technology transfer and patient care and the availability of a data centre for clinical trials including a software development team also influenced the high implementation rates of technical studies. We cannot prove this statement scientifically because we did not compare clinics with and without this strategy, but we hypothesize that the collaboration between clinician scientists, medical staff and basic researchers in networks based on common interests was one of the main factors for the high implementation rates, as mentioned in the literature [25].

In conclusion, to the best of our knowledge, implementation rates in clinical practice have not been investigated before. Further research in clinical practice elsewhere is necessary to make statistical comparisons. Our results can serve as a benchmark for such a comparison.

\section{Collaboration and funding}

We found higher implementation rates for national studies and for studies with national funding than the averages observed in our study (Tables 3 and 4). This may be explained by the fact that many of these studies have been initiated by our own clinicians or researchers. We cannot rule out that results of international studies, conducted by other 
researchers, have been implemented in one of the collaborating institutes or elsewhere, since we only looked at implementation in our own clinic.

\section{Barriers, facilitators and possible interventions}

The literature has identified the following barriers to be effective in the dissemination of (researchbased) innovations: researchers not being oriented to practical problems, practitioners not having useful solutions to their practical problems, perceived level of evidence and organizational barriers such as workload, lack of resources, workplace culture, poor implementation planning and ineffective leadership $[5,15,16]$. Radiotherapy-specific barriers are mentioned as well, such as the aggressive marketing of industrial partners promoting products that are premature and/or not really innovative

for further development in a research contract [24]. Furthermore, it is known that the attributes of a potential innovation resulting from research affect the rate of adoption [15]. These attributes are the relative advantage, compatibility, complexity, trial ability and observability [15].

The most frequently observed barrier in our study was workload/lack of resources followed by high complexity and a gap between researchers and clinicians. Workload is a barrier that is generally known and most frequently identified, especially in healthcare [5]. Therefore, it is necessary to regard research implementation not as something that comes on top of normal workload. Time management is an important skill for the individual worker; nevertheless, support from administration and healthcare funders is required to manage workload for each staff member and provide opportunities to invest time in research implementation [5]. In order to close the gap between researchers and clinicians, the clinic in our study takes further actions to involve both clinicians and researchers from the start of a new project. Only one barrier which we had not listed was mentioned: switching to another vendor. Because the research was performed on and based on the equipment of the specific vendor, the results could not be implemented when new accelerators of another vendor were introduced in the clinic.

The facilitators of implementation most frequently mentioned were a high level of evidence, low complexity and high compatibility and observability. If clinicians perceive a high level of evidence, there is a high likelihood for successful adoption. Conversely, a low perceived level of evidence can be an obstacle.

In addition, there is often a relationship with reimbursement. Lack of reimbursement hinders implementation [26]. Insurance companies in the Netherlands increasingly require costeffectiveness studies to substantiate their decisions regarding reimbursement of new treatments, although not yet systematically. If such a study is required, implementation of scientific findings may be delayed at the centre finding the results. However, once 
cost effectiveness has been proven, it can be a facilitator of fast implementation of the findings at many other centres. In our study, reimbursement was not mentioned by clinicians. Low complexity is a facilitator, but can obviously be a barrier if it is high.

Unfortunately, reducing complexity is difficult. Compatibility and observability were mentioned 17 times as a facilitator and only once as a barrier. In the literature, it is stated that compatibility can be further enhanced through multiple iterative trials that refine the intervention to meet the needs of practice, with results that are readily observable [17]. From the literature, we know that observability cannot really be enhanced by "passive" dissemination methods. These are, for example, educational material and distributions of recommendations for clinical care including guidelines, audio-visual material, electronic publications or lectures. Consistently effective interventions related to observability, and thus efficiency of translation, are, for example, interactive workshops, educational outreach visits, reminders (manual or computerized) or multifaceted interventions $[8,9]$.

Finally, a new trend where academic institutions invest in intellectual property management, academic entrepreneurship and technology transfer is becoming apparent, which is suggested to facilitate the implementation process [27-29]. Academic entrepreneurship offers an incredible potential for the commercialization and implementation of research discoveries. The setting up of technology transfer offices, which offer professional support for contacts with companies, can enhance technology transfer and translation of scientific findings into practice [30,31]. In our study, the abovementioned technology transfer of DGRT is a good example.

Most frequently mentioned barriers, facilitators and possible interventions are summarized in Table 5.

Table 5. Most frequently mentioned barriers, facilitators and possible interventions

\begin{tabular}{ll}
\hline Barriers and facilitators & Interventions \\
\hline Workload & $\begin{array}{l}\text { Support from administration and healthcare funders to provide time } \\
\text { for research } \\
\text { Involvement of clinicians and researchers from the start of a new } \\
\text { project }\end{array}$ \\
Researchers-clinicians gap & No general interventions but adjusted to specific situation \\
Complexity & Multiple iterative trials \\
Compatibility & NOT ONLY: educational material, distributions of \\
Observability & recommendations for clinical care including guidelines, audio-visual \\
& material, electronic publications and lectures. \\
& BUT ALSO: interactive workshops, educational outreach visits, \\
& reminders (manual or computerized) and multifaceted interventions \\
\hline
\end{tabular}




\section{Strengths and limitations}

In our view, the key strength of this study is that we are the first to provide actual data of true clinical implementation of research results. However, the disadvantage of being the first is that we cannot compare our results with those in the existing literature.

The main limitation of this study is its single-centre character, which may affect the generalizability of the results.

In addition, we should take into account that implementation rates calculated in a limited period do not reflect clinical impact. A study can be complex and thus poses a barrier to clinical implementation; but, once implemented, it can have a high impact and vice versa: an implemented study can have a low impact.

A final limitation is that it is known from the literature that self-assessments of adherence to guidelines are overestimated [32]. Our study does not concern adherence to guidelines but implementation of own scientific findings. Still, it remains a self-assessment, with the proviso that we asked clinicians from tumour expert groups to answer our questions, who are not always the same people as the scientists who have published the studies. In addition, an independent investigator verified the results.

\section{CONCLUSION AND FURTHER STUDIES}

We were able to calculate the implementation rates of published research from a large academic radiotherapy department in their own clinical practice and set benchmark figures for other radiotherapy clinics. Level of evidence was an important facilitator, whereas high workload and complexity were important barriers. The literature suggests some specific interventions to overcome these hurdles. Taking actions to improve implementation rates is an important task for the management of the institute, because research implementation is a key for improving outcomes, service, safety and efficiency in radiotherapy further. The next step will be to investigate implementation rates at national and international level and in other centres. We propose that the rate of clinical implementation of published research findings, in clinical routine or in trials, should be a quality indicator for organizations whose activities are both research and patient care, such as a comprehensive cancer centre. 


\section{Acknowledgments}

We would like to thank Misjael Lebbink for editing the figures and Ruud Houben for the statistical analysis. We would also like to express our gratitude to all clinicians and scientists for participating in this study. 


\section{REFERENCES}

1. Heron DE, Godette KD, Wynn RA, Arterbery VE, Streeter OA, Roach M 3rd, et al. Radiation medicine innovations for the new millenium. J Natl Med Assoc 2003; 95: 55-63.

2. Winkler C, Duma MN, Popp W, Sack H, Budach V, Molls M, et al. Protection of quality and innovation in radiation oncology: the prospective multicenter trial QUIRO of DEGRO: evaluation of time, attendance of medical staff, and resources during radiotherapy with tomotherapy. Strahlenther Onkol 2014; 190: 950-6. doi: http://dx.doi.org/10.1007/s00066-014-0615-3

3. Sung NS, Crowley WF Jr, Genel M, Salber P, Sandy L, Sherwood LM, et al. Central challenges facing the national clinical research enterprise. JAMA 2003; 289: 1278-87. doi: http://dx.doi. org/10.1001/jama.289.10.1278

4. Lenfant C. Clinical research to clinical practice-lost in translation? N Engl J Med 2003; 349: 868-74. doi: http://dx.doi.org/10.1056/NEJMsa035507

5. Williams B, Perillo S, Brown T. What are the factors of organisational culture in health care settings that act as barriers to the implementation of evidence-based practice? A scoping review. Nurse Educ Today 2015; 35: e34-41. doi: http://dx.doi.org/10.1016/j. nedt.2014.11.012

6. Brownson RC, Colditz GA, Proctor EK. Dissemination and implementation research in health: translating science to practice. Oxford, UK: Oxford University Press; 2012.

7. Khoury MJ, Gwinn M, Yoon PW, Dowling N, Moore CA, Bradley L. The continuum of translation research in genomic medicine: how can we accelerate the appropriate integration of human genome discoveries into health care and disease prevention? Genet Med 2007; 9: 665-74. doi: http://dx.doi.org/10.1097/GIM.0b013e31815699d0

8. Oxman AD, Thomson MA, Davis DA, Haynes RB. No magic bullets: a systematic review of 102 trials of interventions to improve professional practice. CMAJ 1995; 153: 1423-31.

9. Bero LA, Grilli R, Grimshaw JM, Harvey E, Oxman AD, Thomson MA. Closing the gap between research and practice: an overview of systematic reviews of interventions to promote the implementation of research findings. The Cochrane Effective Practice and Organization of Care Review Group. BMJ 1998; 317: 465-8. doi: http://dx.doi.org/10.1136/bmj.317.7156.465

10. Brownson RC, Kreuter MW, Arrington BA, True WR. Translating scientific discoveries into public health action: how can schools of public health move us forward? Public Health Rep 2006; 121: 97-103.

11. Farquhar CM, Stryer D, Slutsky J. Translating research into practice: the future ahead. Int J Qual Health Care 2002; 14: 233-49. doi: http://dx.doi.org/10.1093/oxfordjournals.intqhc. a002615

12. Subramanyam K. Bibliometric studies of research collaboration: a review. J Inf Sci 1983; 6: 33-8. doi: http://dx.doi.org/10.1177/016555158300600105

13. Holmes BJ, Schellenberg M, Schell K, Scarrow G. How funding agencies can support research use in healthcare: an online province-wide survey to determine knowledge translation training needs. Implement Sci 2014; 9: 71. doi: http://dx.doi.org/10.1186/1748-5908-9-71 
14. Woolf SH. The meaning of translational research and why it matters. JAMA 2008; 299: 211-3. doi: http://dx.doi.org/10.1001/jama.2007.26

15. Rogers EM. Diffusion of innovations. New York, NY: Simon and Schuster; 2010.

16. Longenecker CO, Longenecker PD. Why hospital improvement efforts fail: a view from the front line. J Healthc Manag 2014; 59: 147-57.

17. Bergman DA, Beck A. Moving from research to large-scale change in child health care. Acad Pediatr 2011; 11: 360-8. doi: http://dx.doi.org/10.1016/j.acap.2011.06.004

18. Krzyzanowska MK, Pintilie M, Tannock IF. Factors associated with failure to publish large randomized trials presented at an oncology meeting. JAMA 2003; 290: 495-501. doi: http:// dx.doi.org/10.1001/jama.290.4.495

19. Easterbrook PJ, Berlin JA, Gopalan R, Matthews DR. Publication bias in clinical research. Lancet 1991; 337: 867-72. doi: http://dx.doi.org/10.1016/0140-6736(91)90201-Y

20. Dwan K, Altman DG, Arnaiz JA, Bloom J, Chan AW, Cronin E, et al. Systematic review of the empirical evidence of study publication bias and outcome reporting bias. PLoS One 2008; 3: e3081. doi: http://dx.doi.org/10.1371/journal.pone.0003081

21. Dickersin K. The existence of publication bias and risk factors for its occurrence. JAMA 1990; 263: 1385-9. doi: http://dx.doi.org/10.1001/jama.1990.03440100097014

22. Col NF. Challenges in translating research into practice. J Womens Health (Larchmt) 2005; 14: 87-95. doi: http://dx.doi.org/10.1089/jwh.2005.14.87

23. Green LW, Ottoson JM, Garcia C, Hiatt RA. Diffusion theory and knowledge dissemination, utilization, and integration in public health. Annu Rev Public Health 2009; 30: 151-74. doi: http://dx.doi.org/10.1146/nnurev.publhealth.031308.100049

24. Bortfeld T, Marks LB. Hype cycle in radiation oncology. Int J Radiat Oncol Biol Phys 2013; 86: 819-21. doi: http://dx.doi.org/10.1016/j.ijrobp.2013.03.027

25. Lander B, Atkinson-Grosjean J. Translational science and the hidden research system in universities and academic hospitals: a case study. Soc Sci Med 2011; 72: 537-44. doi: http:// dx.doi.org/10.1016/j.socscimed.2010.11.019

26. de Souza JA, de Lima Lopes G. Medicare reimbursement changes and the practice of oncology: understanding of the past is a key to the future. J Oncol Pract 2011; 7: 306-8. doi: http:// dx.doi.org/10.1200/JOP.2010.000043

27. McGoldrick RB, Hui K, Chang J. Bench to bedside: integrating advances in basic science into daily clinical practice. Hand Clin 2014; 30: 305-17, vi. doi: http://dx.doi.org/10.1016/j. hcl.2014.04.004

28. Sanberg PR, Gharib M, Harker PT, Kaler EW, Marchase RB, Sands TD, et al. Changing the academic culture: valuing patents and commercialization toward tenure and career advancement. Proc Natl Acad Sci U S A 2014; 111: 6542-7. doi: http://dx.doi.org/10.1073/ pnas.1404094111

29. Patino RM. Moving research to patient applications through commercialization: understanding and evaluating the role of intellectual property. J Am Assoc Lab Anim Sci 2010; 49: 147-54. 
30. ZonMW PA. Organization of Knowledge Use. Inventory of provisions for implementation of fundamental medical research in the Netherlands Groninggen. [In Dutch.] 2011. Available from: http://www.zonmw.nl/uploads/tx_vipublicaties/Rapport_Organisatie_van_ Kennisgebruik_def.pdf

31. Itri JN, Ballard DH, Kantartzis S, Sullivan JC, Weisman JA, Durand DJ, et al. Entrepreneurship in the academic radiology environment. Acad Radiol 2015; 22: 14-24. doi: http://dx.doi. org/10.1016/j. acra.2014.08.010

32. Mickan S, Burls A, Glasziou P. Patterns of 'leakage' in the utilisation of clinical guidelines: a systematic review. Postgrad Med J 2011; 87: 670-9. doi: http://dx.doi.org/10.1136/ pgmj.2010.116012 



\section{CHAPTER 5}

\section{The relationship between innovation and output}

Maria Jacobs

Liesbeth Boersma

Andre Dekker

Philippe Lambin

Dirk de Ruyscher

Rachelle Swart

Frank Verhaegen

Joost Stultiens

Bram Ramaekers

Frits van Merode

What is the impact of innovation on output in health care with a special focus on treatment innovations in radiotherapy? A literature review

Submitted in: British Journal of Radiology

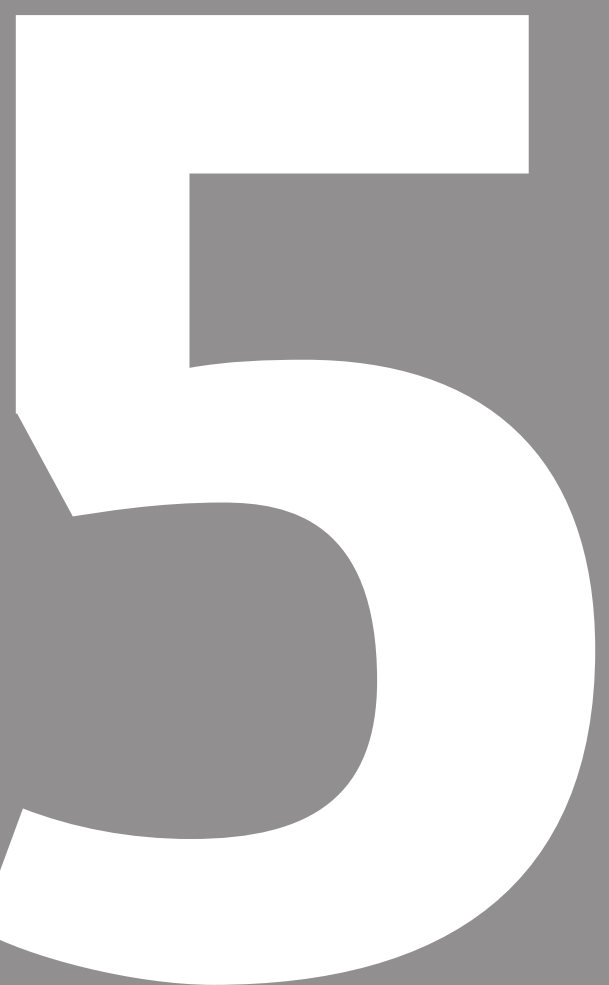




\section{ABSTRACT \\ Objective}

To analyse how often innovations in healthcare are evaluated regarding output, especially in radiotherapy. Output was defined as either survival, toxicity, safety, service, efficiency or cost-effectiveness.

\section{Methods}

A systematic literature review was conducted using a combination of three search strategies: 1 ) innovations in general healthcare; 2 ) radiotherapy-specific innovations, i.e. organisational innovations and general implementation of innovations; 3 ) innovations per tumour group/radiotherapy technique. Scientific levels were classified according to the system used in ESMO guidelines. Finally, we calculated the percentage of implemented innovations in Dutch radiotherapy centres for which we found evidence regarding output in the literature review.

\section{Results}

Only $94 / 1072$ unique articles matched the inclusion criteria. The scientific level of papers on organisational innovation was lower than clinical papers ( $23 \%$ vs. $47 \%$ level I; $54 \%$ vs. $15 \%$ level V). Significant results on patient outcome, service or safety were reported in $65 \%$ of papers, which rose to $76 \%$ if confined to radiotherapy reviews. A significant technological improvement was identified in $26 \%$ of papers, cost-effectiveness in $10 \%$ of papers and costs/efficiency in $36 \%$ of the papers. Dutch radiotherapy treatment innovations were adequately evaluated on outcome data before implementation in clinical routine in a minimum of $64-92 \%$ of cases.

\section{Conclusions}

Only few studies report on output when considering innovations in general, but radiotherapy reviews give a reasonably good insight into innovation output effects, with a higher level of evidence. In Dutch radiotherapy practice, clinical innovations are evaluated properly before implementation in daily routine. Only small improvements are possible. 


\section{INTRODUCTION}

Radiotherapy centres and other healthcare providers have the task of simultaneously improving patient outcomes, patient safety, patient service and cost-effectiveness [1]. In the past decades, the implementation of innovations, from new products, services and technologies to systematic changes, has helped make great progress in coping with this complex task. For example, in radiotherapy, technological innovations have improved the precision of radiation therapy, resulting in improved patient outcomes [2,3]. Despite medical advances, the literature on innovation also shows that some innovations that are not yet well evaluated and therefore have not been proven to be effective nevertheless diffuse rapidly. By contrast, other innovations with high potential sometimes show a slow uptake in practice $[4,5]$. In both cases, this may lead to disappointments or even damaging effects for care outcomes and patients. It is not clear whether this is also the case in radiotherapy. On the one hand, this medical discipline is increasingly evidence based, with many large randomised trials of high methodological quality [6]. On the other hand, however, in radiotherapy innovative technologies are also sometimes rapidly introduced into clinical practice without sufficient patient data, based on the presumption that dosimetric advantages will eventually lead to better treatment outcomes [7].

Thousands of studies on innovation in healthcare have looked into the effect of one single innovation intervention or a series of related interventions, on one or a few possible output dimensions. The limited scope of these studies makes it hard to draw scientific conclusions about the relationship between innovation and output in general and/or over time.

To prevent damaging effects caused by implementing innovations too rapidly or too slowly, and to improve cost effectiveness, it is necessary to get a better understanding of how innovation by care providers and especially radiotherapy centres affects performance. For example, the majority of the increase in healthcare spending is attributed to technological innovations [8]. In radiotherapy, too, innovative technologies often involve substantial investments in terms of equipment, quality assurance and additional training of staff, while it is often uncertain to what extent the innovations will translate into better patient outcomes [7]. The literature does not always provide a clear picture of how to evaluate innovations, for example because scientists argue that the generation of innovations is not suited to strict evaluation or that innovations are constantly evolving [9-14]. However, from a societal perspective, it is necessary to gain better insight into the expected benefits of a proposed innovative intervention in clinical practice versus the expected additional costs. 
It is therefore desirable to evaluate innovations not on just one dimension of output, but on the total performance. In the literature, this is defined as a combination of effectiveness and efficiency [15]. Here, effectiveness refers to external criteria used to evaluate the products and services; from a patient's perspective, we relate this in our study to patient outcomes and/or patient safety and/or service to the patient. Efficiency refers to how successful these products, services or treatments are in relation to their costs.

In healthcare, and thus also in radiotherapy, specific cost-effectiveness (economic analysis that compares relative cost and outcomes, commonly measured in quality adjusted life years -QALYs-) is also a dimension that should be included in the evaluation of performance, because in the Netherlands, for example, the Dutch Health Care Institute increasingly requires cost-effectiveness studies to substantiate their decision regarding reimbursement of new treatments [16].

The general aims of this study are:

A. to gain more insight into the extent to which studies on innovations evaluate output in general healthcare and, specifically, in radiotherapy.

B. to investigate if implemented innovations in Dutch radiotherapy centres are supported by adequate evidence in scientific literature.

Ad A: We carried out a review of the literature to answer the following three specific research questions, both with respect to general healthcare and more specifically for radiotherapy.

Does the results section of included studies report:

1. statistically significant results on one or more output dimensions (patient outcome, survival, toxicity, patient safety, patient service, efficiency and cost-effectiveness) related to innovation, and what is the scientific level of the study? (RQ1)

2. statistically significant technological or process improvements without patientrelated output or efficiency/cost-effectiveness output? (RQ2)

3. statistically significant results on multiple or all dimensions of output (outcome, service/ safety or efficiency/cost-effectiveness)? (RQ3)

Ad B: Subsequently, our fourth research question was:

4. Which percentage of innovations in treatment in Dutch radiotherapy centres are supported by adequate evidence in scientific literature before they are implemented in clinical routine? (RQ4) 


\section{METHODS}

We used three literature search strategies to find an answer to our first three research questions. The first two searches were on general innovations in general hospital care, and more specifically in radiotherapy; the last search focused on innovations related to tumour groups and radiotherapy techniques.

A five-year period was used for the general searches. For practical reasons (a five-year period resulted in 1923 articles) we used a shorter period (2015/2016) for the specific tumour/technique innovations.

\section{Search Strategy}

\section{General search strategy regarding innovations in general healthcare}

We searched the databases PubMed and Web of Science. We looked for relevant English language articles with an abstract from 2011 through 26 September 2016. We selected the following terms: hospital, innovation, continuous improvement, outcome, survival, toxicity, safety, efficiency, service, output, cost-effectiveness and patient satisfaction. An overview of the applied search terms is presented in Table 1.

\section{PubMed}

In PubMed we introduced the following limitation: written in English, and free full text available.

\section{Web of Science}

We used the same terms as with PubMed. We refined the search by language (English). Furthermore, the following Web of Science categories were included: health care sciences, computer science interdisciplinary applications, management, medical informatics, planning development, business, computer science information systems, economics, communication, business finance, operation research management science and oncology.

Table 1. Applied search terms for general search

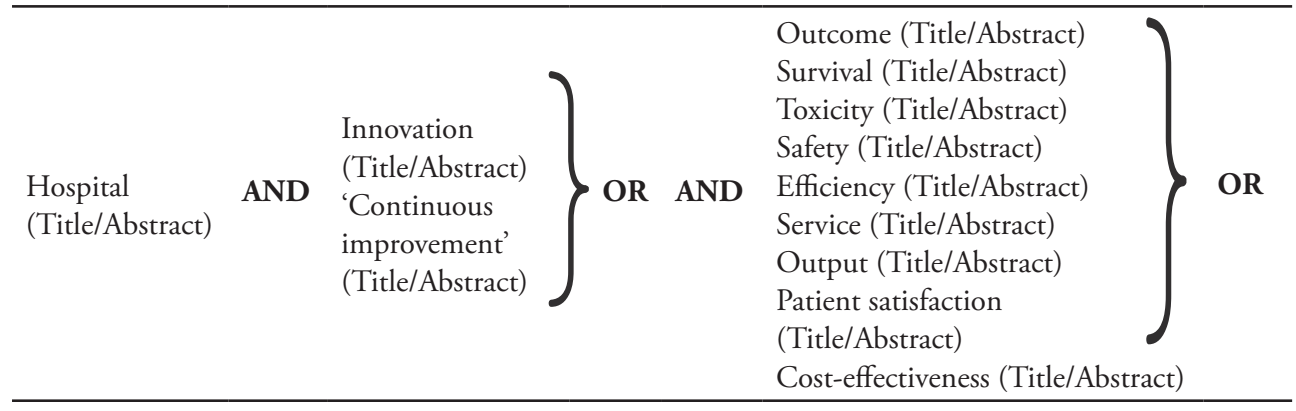




\section{Search strategy specifically for radiotherapy}

We also performed a search specific to radiotherapy, using the databases PubMed and Web of Science. We looked for relevant English-language articles with an abstract from 2011 through 2016. We looked for relevant articles and selected the following MESH terms: radiotherapy, radiation oncology, diffusion of innovation, organizational innovation. We also searched on radiotherapy, radiation oncology and innovation. A summary of the applied search terms is shown in Table 2.

Table 2. Applied search terms for the search specifically for radiotherapy

\begin{tabular}{|c|c|c|c|c|c|}
\hline \multicolumn{2}{|c|}{$\begin{array}{l}\text { Radiotherapy (Subheading) } \\
\text { Radiation oncology [MeSH] }\end{array}$} & \multicolumn{2}{|r|}{ AND } & $\begin{array}{l}\text { Diffusion of innovation }[\mathrm{MeSH}] \\
\text { Organizational innovation }[\mathrm{MeSH}]\end{array}$ & \multirow[t]{2}{*}{ OR } \\
\hline $\begin{array}{l}\text { Radiotherapy } \\
\text { (Title/Abstract) }\end{array}$ & \multirow{2}{*}{\multicolumn{2}{|c|}{ OR }} & AND & Innovation (Title/Abstract) & \\
\hline $\begin{array}{l}\text { Radiation oncology } \\
\text { (Title/Abstract) }\end{array}$ & & & & & \\
\hline
\end{tabular}

\section{3a. Search strategy per tumour group}

Finally, we also conducted a search in the database PubMed on reviews regarding tumour groups and radiotherapy techniques. We looked for relevant articles in the period 1-12015 through 17-08-2016 and selected the following terms when searching per cancer care path: radiotherapy, radiation oncology and breast cancer / head and neck cancer / neuro oncology / skin cancer / lung cancer / gastrointestinal oncology / gastrointestinal cancer / gynaecologic oncology / prostate cancer / sarcomas. The search strategy is presented in Table 3A.

Table 3A. Applied search terms for the search per tumour group

\begin{tabular}{l}
$\left.\begin{array}{l}\text { Radiotherapy (Title/Abstract) } \\
\begin{array}{l}\text { Radiation oncology } \\
\text { (Title/Abstract) }\end{array}\end{array}\right\}$ OR AND $\begin{array}{l}\text { Breast cancer/ head neck cancer/ neuro oncology / } \\
\text { skin cancer/lung cancer/gastrointestinal oncology } \\
\text { / gastrointestinal cancer/gynaecologic oncology / } \\
\text { prostate cancer/sarcomas (Title/Abstract) }\end{array}$ \\
\hline
\end{tabular}

* Each term was a separate search

\section{3b. Search strategy per radiotherapy technique}

We searched in the database PubMed for relevant articles from 1-1-2015 through 1708-2016 using the following terms (based on websites NVRO and NIH and brainstorm by authors): radiotherapy, radiation oncology and intensity modulated radiotherapy (IMRT) / image guided radiotherapy (IGRT) / 3D conformal radiotherapy (3DCRT) / dose guided radiotherapy (DGRT) / stereotactic body radiotherapy (SBRT) / volumetric modulated arc therapy (VMAT) / brachytherapy / stereotactic / protons / stereotactic ablative radiotherapy (SABR) / tomotherapy / particle therapy / intra 
operative radiotherapy (IORT) / respiratory gating / in vivo / adaptive radiotherapy / stereotactic radiosurgery. An overview of the applied search terms is presented in Table 3B.

\section{PubMed}

For search strategies $3 \mathrm{a}$ and $3 \mathrm{~b}$, we introduced the following limitations in Pubmed: review, free full text, must contain an abstract and be written in English.

Table 3B. Applied search terms for the search per radiotherapy technique.

\begin{tabular}{l}
$\left.\begin{array}{l}\text { Radiotherapy } \\
\text { (Title/Abstract) } \\
\text { Radiation oncology } \\
\text { (Title/Abstract) }\end{array}\right\}$ OR AND $\begin{array}{l}\text { IMRT / IGRT / 3DCRT / DGRT / SBRT / VMAT } \\
\text { / Brachytherapy / Stereotactic / Protons / SABR / } \\
\text { tomotherapy / particle therapy / IORT / respiratory gating } \\
\text { / in vivo / adaptive radiotherapy / stereotactic radiosurgery } \\
\text { (Title/Abstract)* }\end{array}$ \\
\hline
\end{tabular}

IMRT: intensity-modulated radiotherapy, IGRT: image-guided radiotherapy, 3DCRT: 3D conformal radiotherapy, DGRT: dose-guided radiotherapy, SBRT: stereotactic body radiotherapy, VMAT: volumetric modulated arc therapy, SABR: stereotactic ablative radiotherapy, IORT: intraoperative radiotherapy

* Each term was a separate search

\section{Study selection and data extraction}

We reviewed all articles resulting from searching the databases on the basis of their title and abstract. We considered any study in which innovation and output were discussed. We included these studies only if the output of the innovation was reported in the abstract. We decided to include all possible study designs for the first two searches. For the search on tumour group/radiotherapy techniques, only reviews were included.

Table 4 lists the inclusion and exclusion criteria for all the search strategies.

Two reviewers (MJ and RS) independently scanned titles and abstracts to select studies for consideration. Initial disagreements on study selection were resolved by reaching consensus. Publications were selected for further assessment of the full text if inclusion criteria were met or if it was impossible to determine this based on the abstract. We listed all results in Appendices 1, 2 and 3.

Table 4. Inclusion and exclusion criteria for all three searches)

\begin{tabular}{ll}
\hline INCLUSION criteria & EXCLUSION criteria \\
\hline Containing an abstract & $\begin{array}{l}\text { Only concerning innovation and no output } \\
\text { effects }\end{array}$ \\
Written in English & $\begin{array}{l}\text { Case report, letter to the editor, comment, or } \\
\text { opinion } \\
\text { Focus on healthcare organisations }\end{array}$ \\
Not concerning an innovation
\end{tabular}




\begin{tabular}{|c|c|}
\hline INCLUSION criteria & EXCLUSION criteria \\
\hline $\begin{array}{l}\text { Reports concerning effects of innovations on } \\
\text { performance }\end{array}$ & $\begin{array}{l}\text { Specifically for the general search: } \\
\text { - Not a hospital or hospital care } \\
\text { - Not in Europe or North-America }\end{array}$ \\
\hline Original scientific study & \\
\hline $\begin{array}{l}\text { Specifically for the general search: } \\
\text { - Concerning Europe or North-America } \\
\text { - Concerning hospitals (hospital care) } \\
\text { - Publication between 01-01-2011 and 26-09-2016 }\end{array}$ & \\
\hline $\begin{array}{l}\text { Specifically for the search per tumour group and } \\
\text { radiotherapy technique: } \\
\text { - Review } \\
\text { - Focus on radiotherapy or radiation oncology } \\
\text { - Publication between } 01-01-2015 \text { and 17-08-2016 }\end{array}$ & \\
\hline $\begin{array}{l}\text { Specifically for the radiotherapy search: } \\
\text { - Publication between } 2011 \text { and } 2016\end{array}$ & \\
\hline
\end{tabular}

The level of evidence was assessed by two reviewers (RS and JS). The assessment was based on the classification of level of evidence and grades of recommendation which is used by ESMO in their guidelines and is based on the Infectious Diseases Society of America - United States Public Health Service Grading System [17]. An overview of the different levels of evidence is provided in Table 5 [18].

Table 5. Level of evidence and grades of recommendation (adapted from the Infectious Diseases

\section{Society of America - United States Public Health Service Grading System*)}

\begin{tabular}{|c|c|}
\hline \multicolumn{2}{|c|}{ Level of evidence } \\
\hline $\mathbf{I}$ & $\begin{array}{l}\text { Evidence from at least one large randomised, controlled trial of good methodological } \\
\text { quality (low potential for bias) or meta-analysis of well-conducted randomised trials without } \\
\text { heterogeneity. }\end{array}$ \\
\hline II & $\begin{array}{l}\text { Small randomised trials or large randomised trials with a suspicion of bias (lower } \\
\text { methodological quality) or meta-analysis of such trials or of trials with demonstrated } \\
\text { heterogeneity. }\end{array}$ \\
\hline III & Prospective cohort studies \\
\hline IV & Retrospective cohort studies or case-control studies \\
\hline $\mathbf{V}$ & Studies without control group, case reports, expert opinions \\
\hline \multicolumn{2}{|c|}{ Grades of recommendation } \\
\hline A & Strong evidence for efficacy with a substantial clinical benefit, strongly recommended. \\
\hline B & $\begin{array}{l}\text { Strong or moderate evidence for efficacy but with a limited clinical benefit, generally } \\
\text { recommended. }\end{array}$ \\
\hline C & $\begin{array}{l}\text { Insufficient evidence for efficacy or benefit does not outweigh the risk or the disadvantages } \\
\text { (adverse events, costs, ...), optional. }\end{array}$ \\
\hline D & Moderate evidence against efficacy or for adverse outcome, generally not recommended. \\
\hline E & Strong evidence against efficacy or for adverse outcome, never recommended. \\
\hline
\end{tabular}

* Senkus E, Kyriakides S, Ohno S, Penault-Llorca F, Poortmans P, Rutgers E et al. Primary breast cancer: ESMO Clinical Practice Guidelines for diagnosis, treatment and follow-up. Annals of Oncology. 2015; 26(suppl 5):v8-v30. 


\section{Comparing review results with results from a study on degree of innovation in Dutch radiotherapy centres}

To answer RQ 4, we first selected the treatment (product) innovations from a previous study on innovation in Dutch radiotherapy centres in the years 2011-2013.We compared these innovations with the results which we found using search strategies $3 \mathrm{a}$ and $3 \mathrm{~b}$ of this study [19]. Subsequently, we counted the implementation frequency of these treatments in different centres, and calculated the percentage of significant innovations with proven patient-related output. We verified whether all innovations were evaluated before implementation in 2011-2013. We also counted implemented innovations which were significantly better technologically and should be implemented according to the ALARA (as low radiation as reasonable achievable) principle. We used a $95 \%$ confidence interval to determine the uncertainty of the calculated percentages as estimated for all innovations.

\section{RESULTS}

\section{Number of articles included}

Figure 1 shows the results of the three searches. The general search identified 396 unique articles. During the screening of the titles, 71 articles were excluded. After screening the abstracts and conclusions of these articles, 219 articles were excluded because they did not meet the inclusion criteria. We reviewed the remaining 106 articles in detail. This resulted in the exclusion of another 83 articles, leaving 23 papers for this study. In the search for radiotherapy-specific articles, 335 unique articles were identified. While screening the abstracts and conclusions, 266 articles were excluded because they did not meet the inclusion criteria. The remaining 69 articles were reviewed in detail. This resulted in the exclusion of 52 articles, leaving 17 articles for analysis.

In the search per tumour group, 202 unique articles were identified. After screening the titles and abstracts, 141 articles were excluded. The remaining 61 articles were reviewed in detail, resulting in the exclusion of another 37 articles. This left 24 articles to include in this review. The search per radiotherapy technique identified 181 articles; 42 articles were excluded because they were already included in the search per tumour group, leaving 139 unique articles. After screening these articles on title and abstracts, 65 articles were excluded because they did not meet the inclusion criteria. The remaining 74 articles were reviewed in detail. This ultimately led to the exclusion of 44 articles, leaving 30 papers for this review.

Taking all three literature searches combined, a total of 94 articles were included in this review out of 1072 unique articles (8.7\%). Figure 2 gives an overview of the included number of articles and those with significant evidence or without significant evidence and those with no significant output but a technological improvement with significant evidence (research questions 1 and 2 ). 
Potentially relevant articles identified and screened for retrieval

1. General search: $n=463$

- PubMed $n=121$

- Web of Science $n=342$

2. Specific search for radiotherapy: 390

- PubMed $n=165$

- Web of Science $n=225$

3a. Search per tumour group: $n=202$

- PubMed $n=202$

3b. Search per radiotherapy technique: $n=181$

- PubMed $n=181$

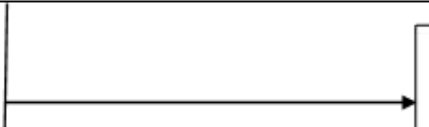

Duplicate articles excluded

1. General search: $n=67$

2. Specific search for radiotherapy: 55

3a. Search per tumour group: 0

Unique articles identified

3b. Search per radiotherapy technique: $n=42$

1. General search: $n=396$

2. Specific search for radiotherapy: $n=335$

3a. Search per tumour group: $n=202$

3b. Search per radiotherapy technique: $n=139$

Articles excluded on screening titles and abstracts

1. General search: $n=290$

2. Specific search for radiotherapy: $n=266$

3a. Search per tumour group: $n=141$

Potentially appropriate articles identified for further review

3b. Search per radiotherapy technique: $n=65$

1. General search: $n=106$

2. Specific search for radiotherapy: $n=69$

3a. Search per tumour group: $n=61$

3b. Search per radiotherapy technique: $n=74$

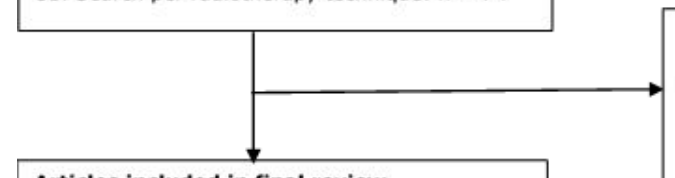

Articles included in final review

1. General search: $n=23$

2. Specific search for radiotherapy: $n=17$

3a. Search per tumour group: $n=24$

3b. Search per radiotherapy technique: $n=30$

\section{Articles excluded after full text review}

1. General search: $n=83$

2. Specific search for radiotherapy: $\mathbf{n}=52$

3a. Search per tumour group: $n=37$

3b. Search per radiotherapy technique: $n=$ 44

\section{Figure 1. Selection process per search}




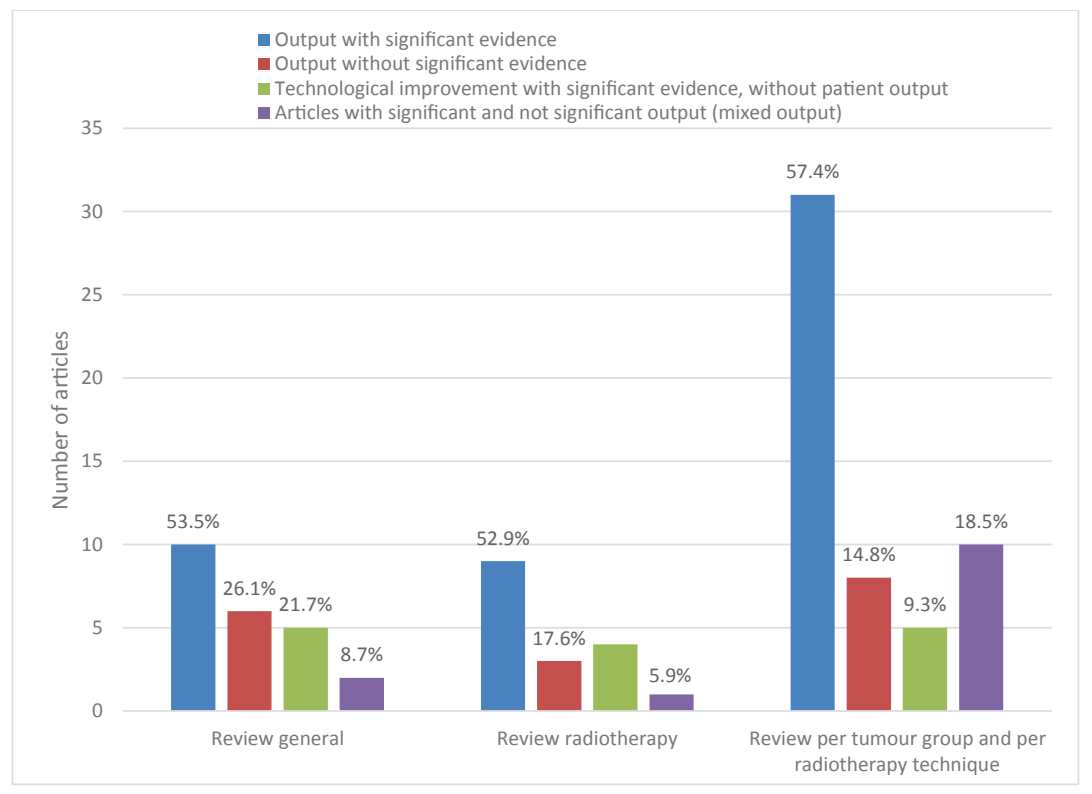

Figure 2. Overview of articles and the type of output

\section{Results for research questions 1 and 2 (see Figure 2)}

- General review regarding innovations in healthcare

The 23 studies in the general review included technological, treatment or organizational innovations. In Appendix 1, the output of the innovations and the scientific level of the studies are described. Ten out of 23 studies reported output with significant results, $6 / 23$ articles reported output without significant results and 6/23 articles were technological improvements with significant evidence, of which 5 have no reported patient outcomes. Furthermore, 2/23 articles reported mixed output (some significant results and some results not significant). In 2 of the 23 papers, cost-effectiveness of the innovation was mentioned. Costs/efficiency was mentioned in 17 papers. 12/23 papers were organizational innovation, while $11 / 23$ were clinical papers. The level of evidence of the organizational papers was $3 x$ level I evidence, $2 x$ level IV and $7 x$ level V. For the clinical papers this was $4 x$ level I, $1 x$ level III, $5 x$ level IV and $1 x$ level V.

- Review specific to radiotherapy

From the 17 studies specific to radiotherapy, 16 described product or technological innovations. From these 16 studies, 9 reported significant output (outcome, service, safety, efficiency or cost-effectiveness). There were 3 studies which mentioned output but where the results were described as 'promising', 'may potentially reduce treatment planning time and effort', 'potential to improve local control and toxicity', 'potential to improve outcomes of patients'. Six studies reported a technological 
improvement with significant results, of which four articles report no significant patient output.

One article reported both significant and not significant output. There were 2 studies that mentioned the cost-effectiveness of the innovation. Costs/efficiency was mentioned in 7 papers. There was 1 paper on organizational innovation. An overview of the studies is provided in Appendix 2. The level of evidence of the clinical papers was $9 x$ level I, $1 x$ level III, 1x level IV, $5 x$ level V. For the organizational paper this was level III.

- Review per tumour group and per radiotherapy technique

From the 54 papers in this search, 40 articles reported patient-related output with significant results (of which, 31 articles report only significant output, the other nine report mixed output), while 8 reported only output without significant results. Furthermore, twelve studies report a technological improvement with significant results; five of these reported no significant patient outcomes. The review included 10 studies that reported mixed output. Only 5 papers contained information on costeffectiveness. Costs/efficiency was mentioned in 10 papers.

Appendix 3 offers an overview of all innovations. The level of evidence of these papers was $25 x$ level I, $1 x$ level II, 9x level III, 2x level III/IV, 11x level IV and 6x level V.

Summarized, the scientific level of papers on organizational innovation was lower than clinical papers (23\% vs. $47 \%$ level I; $54 \%$ vs. $15 \%$ level V).

Table 6 summarizes the results of our study in relation to effectiveness (patient outcome, patient service and patient safety), efficiency and cost-effectiveness. Statistically significant outcome results were reported in $59 \%$. For safety results this was $1 \%$ and for service $5 \%$. (total $65 \%$ which rose to $76 \%$ for radiotherapy reviews). A significant technological improvement was identified in $26 \%$ of papers, cost-effectiveness in $10 \%$ of papers and costs/efficiency in $36 \%$ of the papers.

Table 6. Results in relation to effectiveness/efficiency/cost-effectiveness.

\begin{tabular}{llllllll}
\hline Review & $\begin{array}{l}\text { Number } \\
\text { articles }\end{array}$ & $\begin{array}{l}\text { Outcome } \\
\text { Sig./not sig. }\end{array}$ & $\begin{array}{l}\text { Safety } \\
\text { Sig./not sig. }\end{array}$ & $\begin{array}{l}\text { Service } \\
\text { Sig./not sig. }\end{array}$ & $\begin{array}{l}\text { Costs/ } \\
\text { Efficiency }\end{array}$ & $\begin{array}{l}\text { Technological } \\
\text { improvement }\end{array}$ & $\begin{array}{l}\text { Cost- } \\
\text { effectiveness }\end{array}$ \\
\hline $\begin{array}{l}\text { General } \\
\text { Radiotherapy }\end{array}$ & 23 & $8 / 1$ & $1 / 3$ & $3 / 2$ & 17 & 6 & 2 \\
$\begin{array}{l}\text { Tumour } \\
\text { group/ }\end{array}$ & 54 & $40 / 18^{*}$ & $0 / 1$ & $1 / 0$ & 10 & 6 & 2 \\
technique & & & $0 / 0$ & & & & 5 \\
\hline
\end{tabular}

\footnotetext{
* There are only 54 articles included in this review, however some articles report both significant and not significant outcomes.
} 


\section{Results for research question 3}

Regarding our third research question (to what extent are significant results reported on all output dimensions), we found the following (see Table 7):

- In the general review, 7/12 articles (58\%) with significant output combine effectiveness and efficiency, two studies report only on effectiveness and three article only on efficiency.

- The most common dimension of effectiveness is patient outcome. Service and safety are underrepresented.

- In the radiotherapy review, only $2 / 10$ articles (20\%) with significant output combine effectiveness and efficiency, six studies report only on effectiveness and two articles only on efficiency. The most common dimension of effectiveness is patient outcome. There are no articles in this review reporting on patient service and patient safety.

- In the review specific to radiotherapy per tumour group and per technique, only $4 / 40$ articles (10\%) with significant output report on a combination of effectiveness and efficiency; 36/40 articles only report on effectiveness; no articles report only on efficiency. The articles reporting on effectiveness do so only on one dimension, namely patient outcome. There was only one article that mentions efficiency, patient outcome and patient service.

- Cost-effectiveness was reported on in 2 articles with significant output in the general review. This number is similar for the radiotherapy review. The review per tumour group / radiotherapy technique counted 3 articles.

Table 7. To what extent are significant results reported on all output dimensions

\begin{tabular}{lllll}
\hline Review & $\begin{array}{l}\text { Significant output on } \\
\text { effectiveness and } \\
\text { costs/efficiency }\end{array}$ & $\begin{array}{l}\text { Significant } \\
\text { output only on } \\
\text { effectiveness }\end{array}$ & $\begin{array}{l}\text { Costs/ } \\
\text { efficiency }\end{array}$ & $\begin{array}{l}\text { Cost- } \\
\text { effectiveness }\end{array}$ \\
\hline General review & 7 & 2 & 3 & 2 \\
$\begin{array}{l}\text { Review radiotherapy } \\
\text { Review per tumour }\end{array}$ & 2 & 6 & 2 & 2 \\
$\begin{array}{l}\text { group / radiotherapy } \\
\text { technique }\end{array}$ & 4 & 36 & 0 & 3 \\
\hline
\end{tabular}

\section{Results on research question 4}

After comparing the results of this review per tumour group / radiotherapy technique with the study on implemented product or treatment innovations in Dutch radiotherapy centres in 2011-2013, we found 32 times an innovation that was also included in the reviews per tumour group/technique (see table 8). In 17/32 cases (59\%), these innovations were reported in this review with significant patient results. Furthermore, one product innovation, Deep Inspiration Breath Hold (DIBH), was implemented in eight centres. In accordance with the ALARA principle this innovation should be implemented 
despite the fact that patient outcome data are not available, especially because research showed that the actually delivered dose to the target volume is similar in case of DIBH compared to free breathing [20]. This means that in 25/32 cases innovations were adequately evaluated with regard to patient-related output before implementation.

Using a $95 \%$ confidence interval, it can be concluded that a minimum of $64-92 \%$ of all innovations, 168 times implemented in Dutch radiotherapy centres, were adequately evaluated on proven patient output before implementation in Dutch centres.

Table 8. Number of innovations implemented in Dutch radiotherapy departments in 2011-2013, according to innovations with or without report on outcome, as found in the current review

\begin{tabular}{llll}
\hline Innovations & $\begin{array}{l}\text { Innovations with } \\
\text { report on output } \\
\text { with significant } \\
\text { evidence }\end{array}$ & $\begin{array}{l}\text { Technological } \\
\text { improvements with } \\
\text { significant evidence, } \\
\text { no significant patient } \\
\text { outcomes reported }\end{array}$ & Level of evidence \\
\hline $\begin{array}{l}\text { Deep inspirational } \\
\text { breath hold (DIBH) }\end{array}$ & 8 & I/V \\
$\begin{array}{l}\text { VMAT prostate } \\
\text { SBRT pancreas }\end{array}$ & 2 & & I \\
$\begin{array}{l}\text { SBRT lung } \\
\text { Brachytherapy prostate }\end{array}$ & 2 & 1 & III \\
Brachytherapy skin & 1 & & I/III/IV/V \\
Hypofractionation breast & 3 & I \\
$\begin{array}{l}\text { Hypofractionation } \\
\text { prostate }\end{array}$ & 1 & & V \\
IMRT lung & & I \\
IMRT gynaecology & & 4 & I \\
SBRT intra- and extra \\
cranial
\end{tabular}

IMRT: intensity-modulated radiotherapy, SBRT: stereotactic body radiotherapy, VMAT: volumetric modulated arc therapy, IORT: intraoperative radiotherapy 


\section{DISCUSSION}

It is necessary to implement innovations in healthcare and radiotherapy to improve effectiveness (patient outcomes, patient safety and patient service), costs/efficiency or cost-effectiveness. However, the literature shows that innovations are not always properly evaluated before implementation.

Our literature review aimed to gain insight into the extent to which innovations are evaluated on output in scientific studies. Considering innovations in healthcare in general, we found that not many studies report statistically significant outputs. Radiotherapy reviews, on the other hand, offer good insight into output effects of innovations, with a higher level of evidence.

Furthermore, we found that studies on output effects of innovation often do not report on all relevant dimensions of output such as effectiveness (patient outcome, service and safety), costs/efficiency or cost-effectiveness. Furthermore, we found that between $64 \%$ and $92 \%$ of treatment innovations that were implemented in Dutch radiotherapy centres from 2011-2013 were adequately evaluated regarding patient output before implementation.

\section{Innovation studies and reported output}

These figures show that the general search term 'innovation' results in a low number of papers describing output effects as a result of innovation. From the few papers in our search covering a five-year period (not concerning tumour group and radiotherapy technique reviews) that met the inclusion criteria (respectively 23 and 17 out of $731=$ $5 \%$ ), the effect on output was significant in only $20 / 40$ papers (50\%). For the papers on tumour group / radiotherapy techniques this percentage is higher ( 24 and 30 out of 341 $=16 \%$ ), for a 1.5 -year period. Out of these 54 papers, 41 (76\%) report significant output.

The low number of papers using the term 'innovation' that met the inclusion criteria suggests that most papers on innovation do not study output effects in general, or do not use the term 'innovation' even if they do, in fact, deal with innovations. This is not what we expected. Already over ten years ago, Porter et al. introduced a famous model for value-based healthcare, in which they challenged healthcare organisations to increase value for patients by incorporating the outcomes of interventions that matter to patients in their organisation strategy, in relation to the costs of achieving those outcomes. They also stressed the importance of measuring, reporting and comparing those outcomes $[21,22]$. Healthcare is among the best-endowed of all industries in the richness of its scientific base [23]. However, with regard to the relation between innovation and output, this seems to apply much more to medical papers than to papers on innovation 
in general. There are likely many innovations that are not described with the term 'innovation', and were therefore missed in our review. For example, the introduction of an Electronic Health Record (EHR) is definitely an organizational innovation, but we did not find it with our search strategy. As a try-out, we did a search on the number of papers on EHR and output as defined above, and found a large number of hits, but these often had such a limited scope, that it was not possible for us to draw firm conclusions about the relationship between an EHR and output. The same probably holds true for numerous other innovations, which causes the fragmented picture described in the introduction. In medical disciplines, we expect that the problem that innovations are not described as 'innovation' can be solved by systematically investigating reviews. In management studies this is much more difficult, and if at all possible, also time-consuming because the field is very broad and a system to include all applicable reviews is lacking.

\section{Level of evidence}

Papers on organizational innovation had a lower level of evidence than radiotherapy-specific medical papers. New treatments and (sometimes) new technology in healthcare can be tested with extensive phase I, II and III trials, which have a higher level of evidence than the kind of research which is usually conducted in management practice. In management practice, it is usually not feasible to conduct randomised controlled clinical trials, so observational studies or research designs with less evidential value are mostly used.

An evidence base is often created by conducting the research several times under different circumstances [24,25]. Although in the past two decades a large number of studies have been conducted with the intention to provide a solid evidence base for management practice, most insights in management are still based on the personal experience of experts. Furthermore, in management practice researchers and practitioners mostly operate in different worlds, with the consequence that research results are regularly not fully understood and supported by the practitioners, and therefore not implemented in practice $[24,26]$.

\section{Output dimensions}

In our study, we investigated the output of innovations not only on one dimension of output but on the total performance. We think this is important to get a complete view. For example, an innovation with a very small advantage for patients at very high cost must be considered carefully before taking the decision to introduce or reject it in clinical routine. As defined in the introduction of this study, with respect to total performance we distinguished the following dimensions: effectiveness (patient outcome, patient service and patient safety), efficiency and cost-effectiveness. A combination of effectiveness and/or efficiency and/or costs/cost-effectiveness in articles with statistically significant results was reported in $7 / 23$ general papers $(30 \%)$, in $2 / 17$ radiotherapy papers 
(12\%) and in $4 / 40$ papers on tumour group / radiotherapy technique (10\%). We think the last two figures can be explained by the fact that the papers per tumour group / radiotherapy technique and radiotherapy-specific innovations are almost all written by professionals in the field of radiotherapy, who are logically most interested in patient outcomes because of the nature of their profession. Managers and policymakers in the field of healthcare and radiotherapy have to fill the gap regarding the other dimensions of output performance. Of course, professionals also have a clear responsibility to ensure efficiency and cost-effectiveness, but managers and policymakers have a greater responsibility to initiate research on these dimensions.

\section{Evaluation of output before implementation of innovations}

In our introduction, we motivated our interest in this research by mentioning the consequences of implementing poorly evaluated innovations or not implementing already proven innovations (the so-called 'research implementation gap'). In previous research in which we investigated the degree of innovations implemented in Dutch radiotherapy centres, we found that radiotherapy centres quickly adopt innovations within their discipline and are very dynamic and innovative. In the period from 2011-2013, radiotherapy centres implemented 525 innovations (168 of which were treatment innovations) [19].

When comparing the implemented treatment innovations with this literature review study, we found no reported significant effect on patient outcome (survival/toxicity) for breath-hold technique in breast cancer, SBRT for pancreatic cancer, intensity-modulated radiotherapy (IMRT) for lung cancer and IMRT for gynaecological cancers. The breathhold technique was found to be a significant technological improvement, however. It reduces the radiation dose to the heart significantly, and following the ALARA principle (as low as reasonably achievable), this innovation should be implemented. Since the reproducibility of this technique has been shown to be as high as radiotherapy during free breathing, the risk that tumour cells are missed is considered to be absent [20]. Although IMRT for lung cancer and SBRT for pancreatic cancer are also better from a technological point of view, it is desirable to have data on patient outcomes before implementation, because otherwise the effects on tumour control and normal tissue injury are not completely clear. Furthermore, IMRT for gynaecological cancers was implemented in 2012 while, according to a review, this therapy was proven to improve patient outcomes only a year later, in 2013. As reported, 64-92\% of implemented innovations in Dutch centres were properly evaluated regarding patient outcomes before implementation. It is debatable whether this is a good score. For example, medical oncology will probably never introduce a new drug in routine practice without one or several randomised trials. They will have a near $100 \%$ score. However, this can partly be explained by the fact that in oncology new drugs are given to patients in addition to the existing practice, while in radiotherapy most new technologies improve the precision of dose delivery. In this 
case, the ALARA principle can justify implementation if research shows that no tumour cells will be missed. Furthermore, in other medical disciplines we also see innovations (for example the DaVinci robot) being introduced before they are properly evaluated, while they have no decision-supporting information like in silico studies in radiotherapy. Nevertheless, we conclude that small improvements are still possible to improve evaluation before implementation (research question 4), as is also demonstrated by the current ordering of MR-linacs before the clinical outcome is precisely known.

It is possible that the implementations of IMRT for lung cancer and SBRT for pancreatic cancer took place in a multicentric study and that the two- or five-year outcome results are not yet known. However, in the Netherlands we found no such studies (also not for IMRT for gynaecological cancers) in that period on http://www.trialregister.nl and http://clinicaltrials.gov. We think it is important that innovations which have not been proven yet but are promising are implemented as much as possible in a study setting, unless the ALARA principle is applicable and the innovation is cost-effective. This is possible via well-designed clinical trials, but sometimes this is not considered possible due to practical and ethical limitations, since clinical trials are only possible if the treatment options being compared look like acceptable trade-offs between risks and benefits [27]. Methods from health technology assessment and health economics are useful complements to standard methods from evidence-based medicine [6]. Another option to evaluate effectiveness is to use a model-based approach, as is currently used for the introduction of proton therapy (preferably in existing centres) in the Netherlands [19].

\section{Limitations}

The main limitation of this review is that we found it impossible to develop a search strategy that guaranteed finding all reports of innovation in the literature. This means that organizational innovations are probably underrepresented. However, we think these organizational studies will likely have a limited scope and not address organizational innovations in a broader sense.

Another limitation is the fact that the table used to rank scientific level as used by ESMO was developed for use in medical science. This means, for example, that it does not say anything about cost-effectiveness for which we should record utilities (EuroQoL), and it does not distinguish between expert opinion papers and studies with measurements at baseline and one or two years after intervention. 


\section{CONCLUSION}

Only few studies report on output when considering innovations in general, but radiotherapy reviews give a reasonably good insight into the output effects of innovation, with a higher level of evidence. In Dutch radiotherapy practice, clinical innovations are properly evaluated before implementation in daily routine. There is room only for small improvements.

We recommend that managers in radiotherapy initiate research on organizational innovation with a more rigorous methodology to provide more high-level evidence on the output of organizational innovation. Organizational innovations should be further tested and evaluated, and not directly implemented.

In clinical radiotherapy, we recommend improving studies by evaluating innovations more systematically on all dimensions of output, including costs or cost-effectiveness. Furthermore, we recommend introducing medical innovations in clinical routine only after a thorough evaluation (through well-designed trials or model-based approaches) prior to implementation. 


\section{REFERENCES}

1. Janssen M, Moors EH. Caring for healthcare entrepreneurs-Towards successful entrepreneurial strategies for sustainable innovations in Dutch healthcare. Technological Forecasting and Social Change. 2013;80(7):1360-74.

2. Heron DE, Godette KD, Wynn RA, Arterbery VE, Streeter OA, Roach 3rd M, et al. Radiation medicine innovations for the new millenium. Journal of the National Medical Association. 2003;95(1):55.

3. Winkler C, Duma M, Popp W, Sack H, Budach V, Molls $M$, et al. Protection of quality and innovation in radiation oncology. Strahlentherapie und Onkologie. 2014;190(10):950-6.

4. Tymstra T. The imperative character of medical technology and the meaning of "anticipated decision regret". International journal of technology assessment in health care. 1989;5(02):207-13.

5. Dixon-Woods M, Amalberti R, Goodman S, Bergman B, Glasziou P. Problems and promises of innovation: why healthcare needs to rethink its love/hate relationship with the new. BMJ quality \& safety. 2011;20(Suppl 1):i47-i51.

6. Bentzen SM. High-tech in radiation oncology: should there be a ceiling? International Journal of Radiation Oncology* Biology* Physics. 2004;58(2):320-30.

7. Ramaekers B. Acknowledging Patient Heterogeneity in Health Technology Assessment: Towards Personalized Decisions in Innovative Radiotherapy Treatments: Maastricht University; 2013.

8. Dybczak K, Przywara B. The role of technology in health care expenditure in the EU. Directorate General Economic and Financial Affairs (DG ECFIN), European Commission, 2010.

9. Littman B, Di Mario L, Plebani M, Marincola F. What's next in translational medicine? Clinical science. 2007;112:217-27.

10. Damanpour F, Wischnevsky JD. Research on innovation in organizations: Distinguishing innovation-generating from innovation-adopting organizations. Journal of engineering and technology management. 2006;23(4):269-91.

11. O'Reilly CA, Tushman ML. Ambidexterity as a dynamic capability: Resolving the innovator's dilemma. Research in organizational behavior. 2008;28:185-206.

12. Martini A, Laugen BT, Gastaldi L, Corso M. Continuous innovation: towards a paradoxical, ambidextrous combination of exploration and exploitation. International Journal of Technology Management. 2013;61(1):1-22.

13. Tantchou JC. Blurring boundaries: Structural constraints, space, tools, and agency in an operating theater. Science, Technology \& Human Values. 2013:0162243913506617.

14. Janssen M. Situated Novelty: a study on healthcare innovation and its governance. 2016.

15. Hovmand PS, Gillespie DF. Implementation of evidence-based practice and organizational performance. The journal of behavioral health services \& research. 2010;37(1):79-94. 
16. Jacobs M, Boersma L, Merode FV, Dekker A, Verhaegen F, Linden L, et al. How efficient is translational research in radiation oncology? The example of a large Dutch academic radiation oncology department. The British Journal of Radiology. 2016;89(1064):20160129.

17. Senkus E, Kyriakides S, Ohno S, Penault-Llorca F, Poortmans P, Rutgers E, et al. Primary breast cancer: ESMO Clinical Practice Guidelines for diagnosis, treatment and follow-up. Annals of Oncology. 2015;26(suppl 5):v8-v30.

18. Burns PB, Rohrich RJ, Chung KC. The levels of evidence and their role in evidence-based medicine. Plastic and reconstructive surgery. 2011;128(1):305.

19. Jacobs M, Boersma L, Dekker A, Bosmans G, van Merode F, Verhaegen F, et al. What is the degree of innovation routinely implemented in Dutch radiotherapy centres? A multicentre cross-sectional study. The British Journal of Radiology. 2016;89(1067):20160601.

20. Brouwers PJ, Lustberg T, Borger JH, van Baardwijk AA, Jager JJ, Murrer LH, et al. Set-up verification and 2-dimensional electronic portal imaging device dosimetry during breath hold compared with free breathing in breast cancer radiation therapy. Practical radiation oncology. 2015;5(3):e135-e41.

21. Porter ME, Teisberg EO. Redefining health care: creating value-based competition on results: Harvard Business Press; 2006.

22. Porter ME. What is value in health care? New England Journal of Medicine. 2010;363(26):2477-81.

23. Berwick DM. Disseminating innovations in health care. Jama. 2003;289(15):1969-75.

24. Barends E. In search of evidence: empirical findings and professional perspectives on evidencebased management. 2015.

25. Walshe K, Rundall TG. Evidence-based management: from theory to practice in health care. The Milbank Quarterly. 2001;79(3):429-57.

26. Walshe K, Rundall TG. Evidence-based management: from theory to practice in health care. Milbank Quarterly. 2001;79(3):429-57.

27. Bentzen SM. Randomized controlled trials in health technology assessment: overkill or overdue? Radiotherapy and Oncology. 2008;86(2):142-7. 


\begin{tabular}{|c|c|c|c|c|c|c|c|c|c|}
\hline \multicolumn{2}{|l|}{ 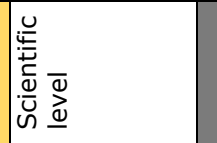 } & \multirow[b]{2}{*}{ 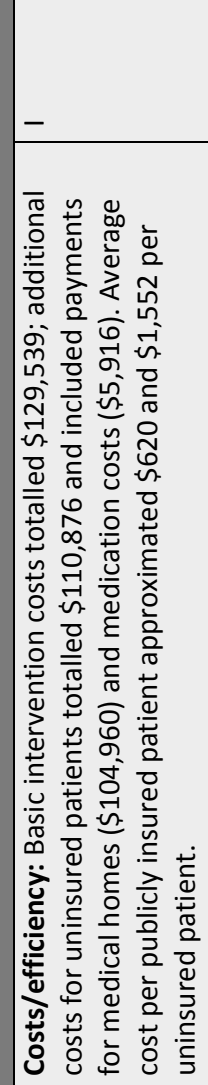 } & - & $>$ & \multicolumn{3}{|l|}{$>$} & \multirow{2}{*}{\multicolumn{2}{|c|}{ 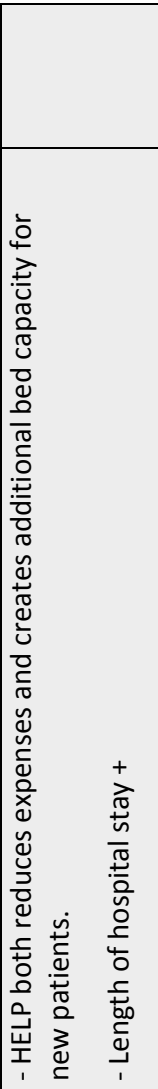 }} \\
\hline & 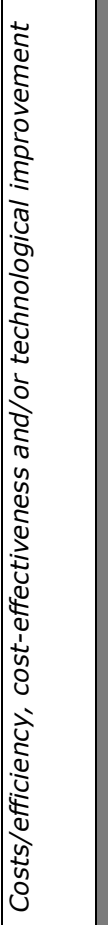 & & 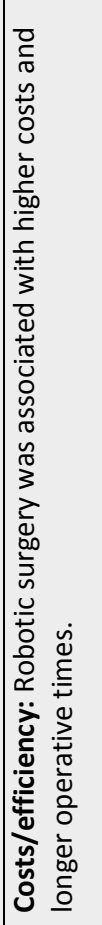 & 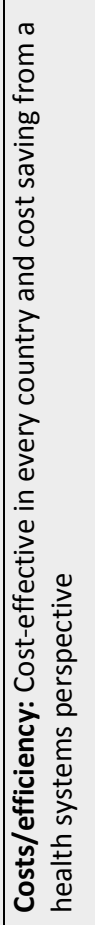 & 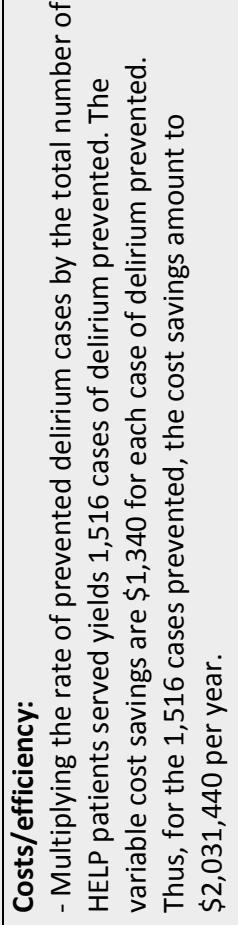 & 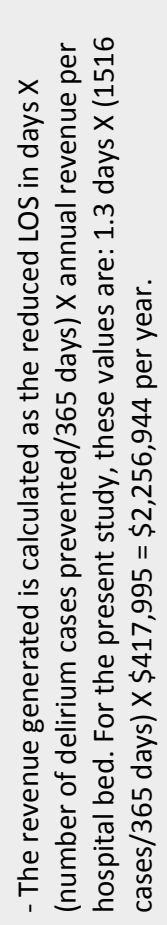 & 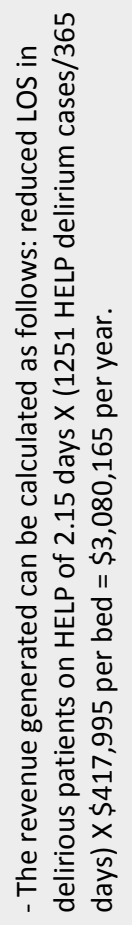 & & \\
\hline 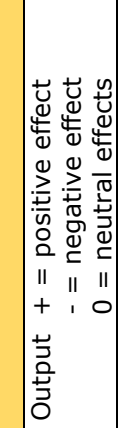 & 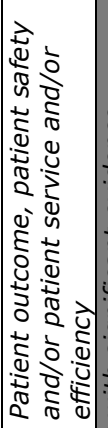 & 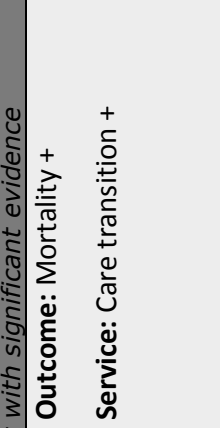 & 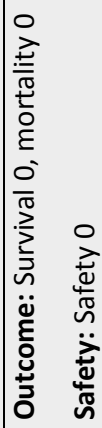 & & 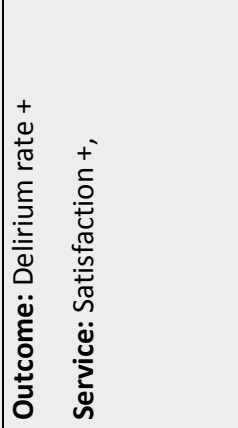 & & & & \\
\hline 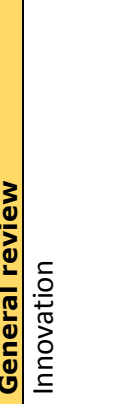 & & 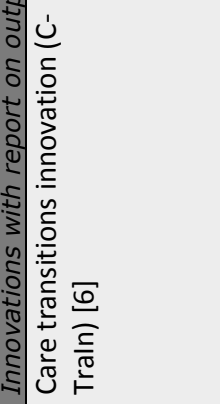 & 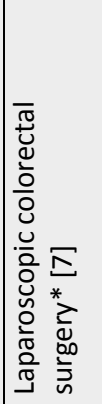 & 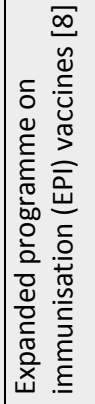 & 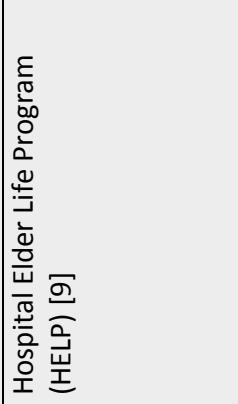 & & & & \\
\hline
\end{tabular}

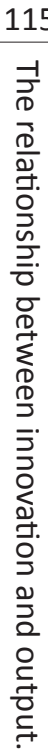




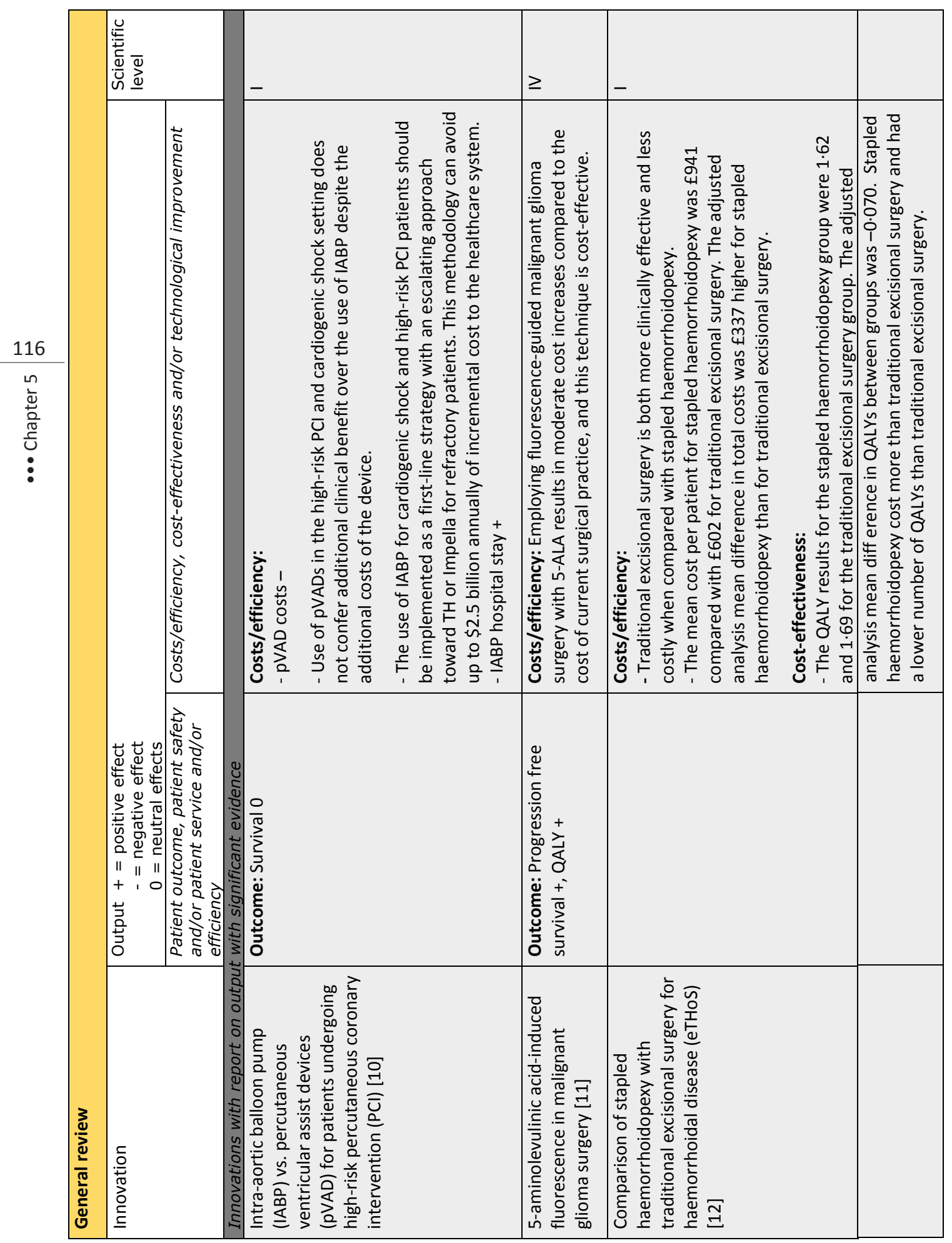




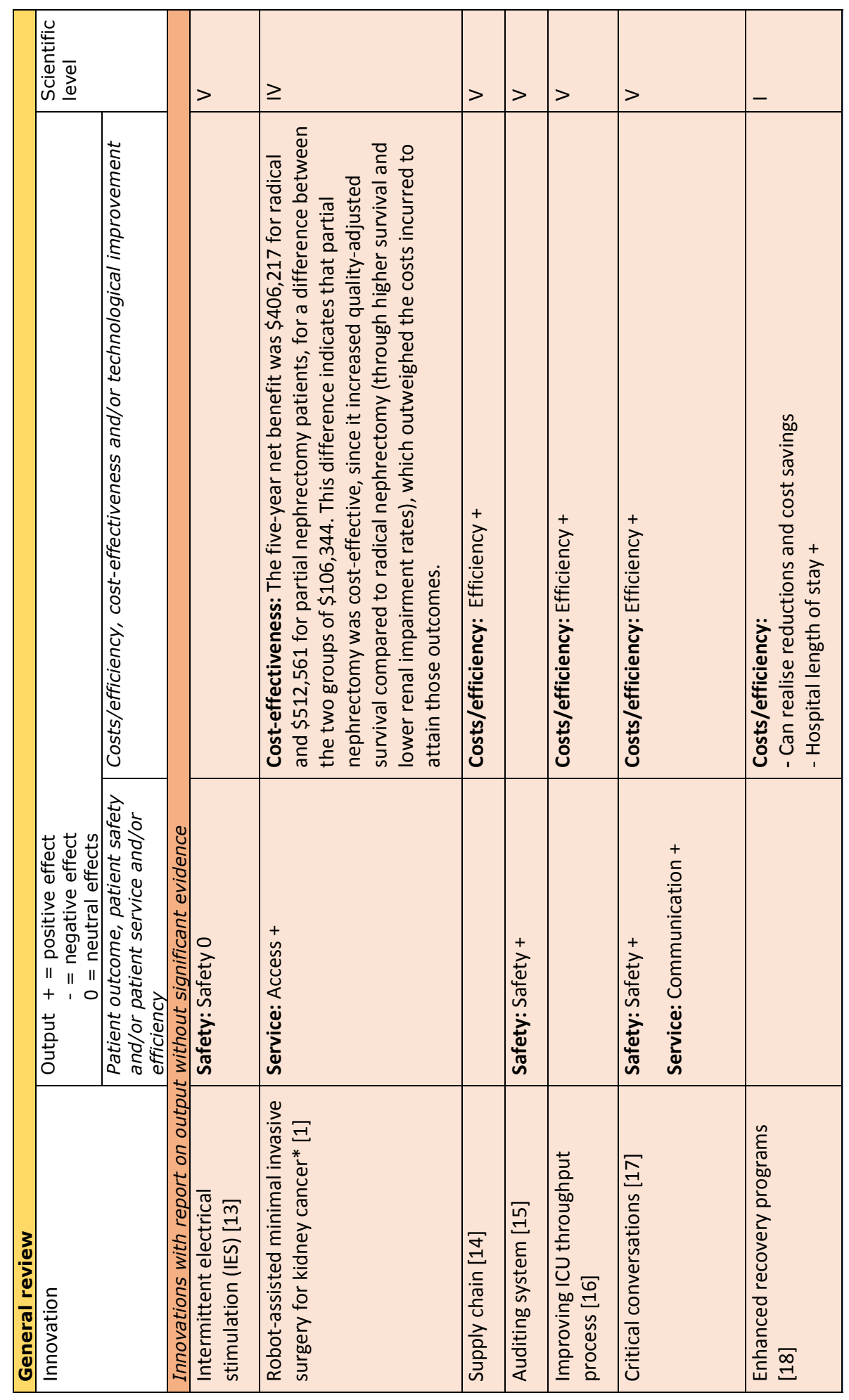

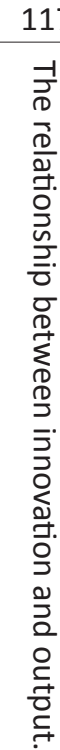




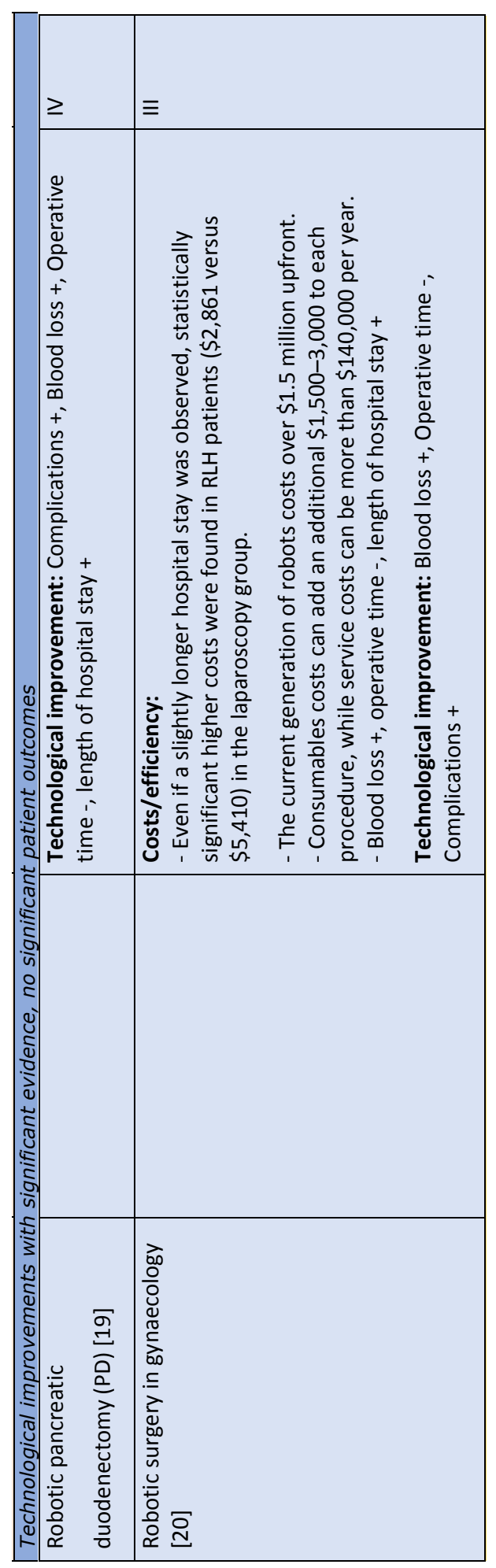




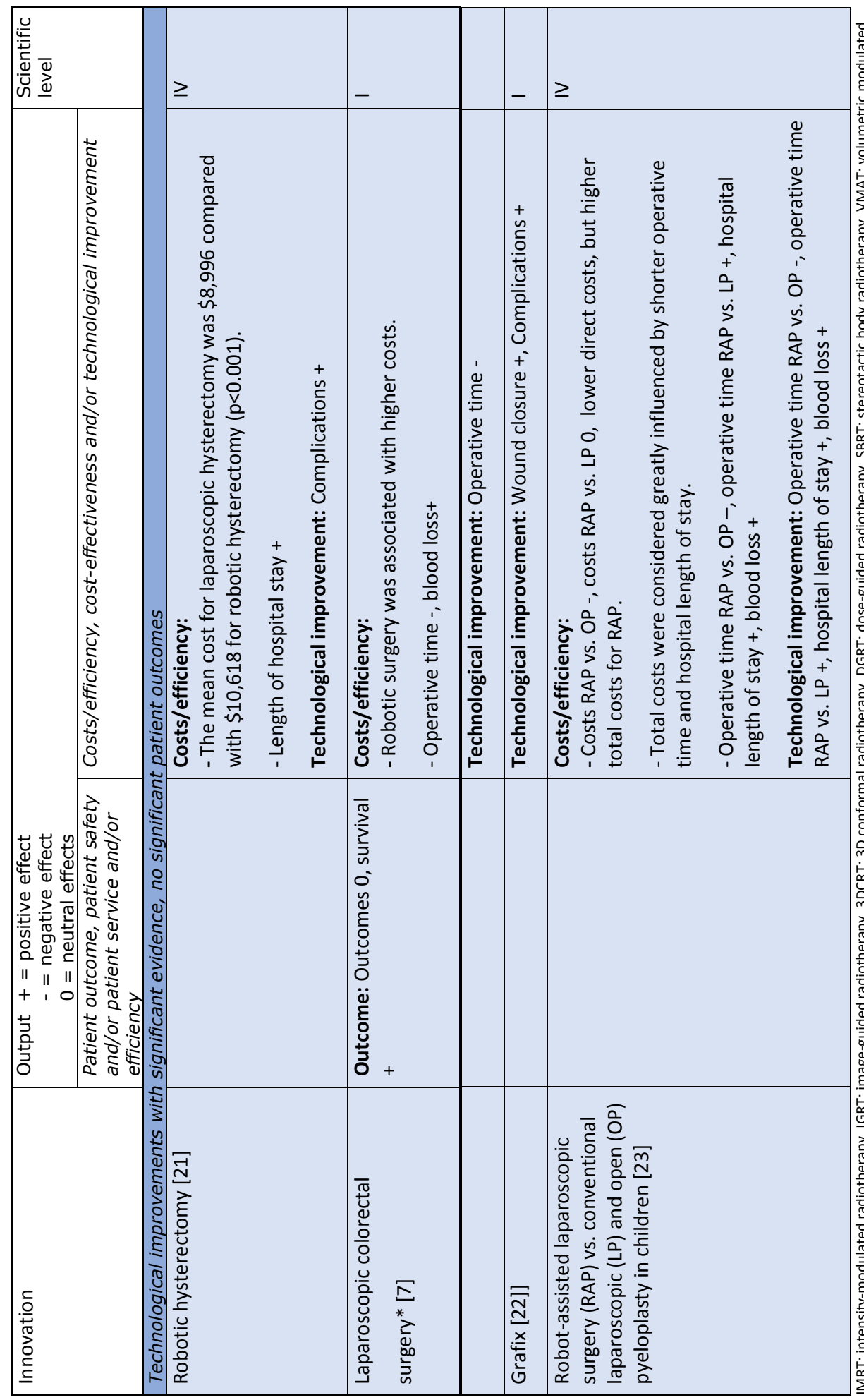

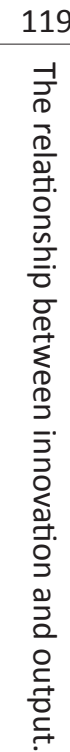




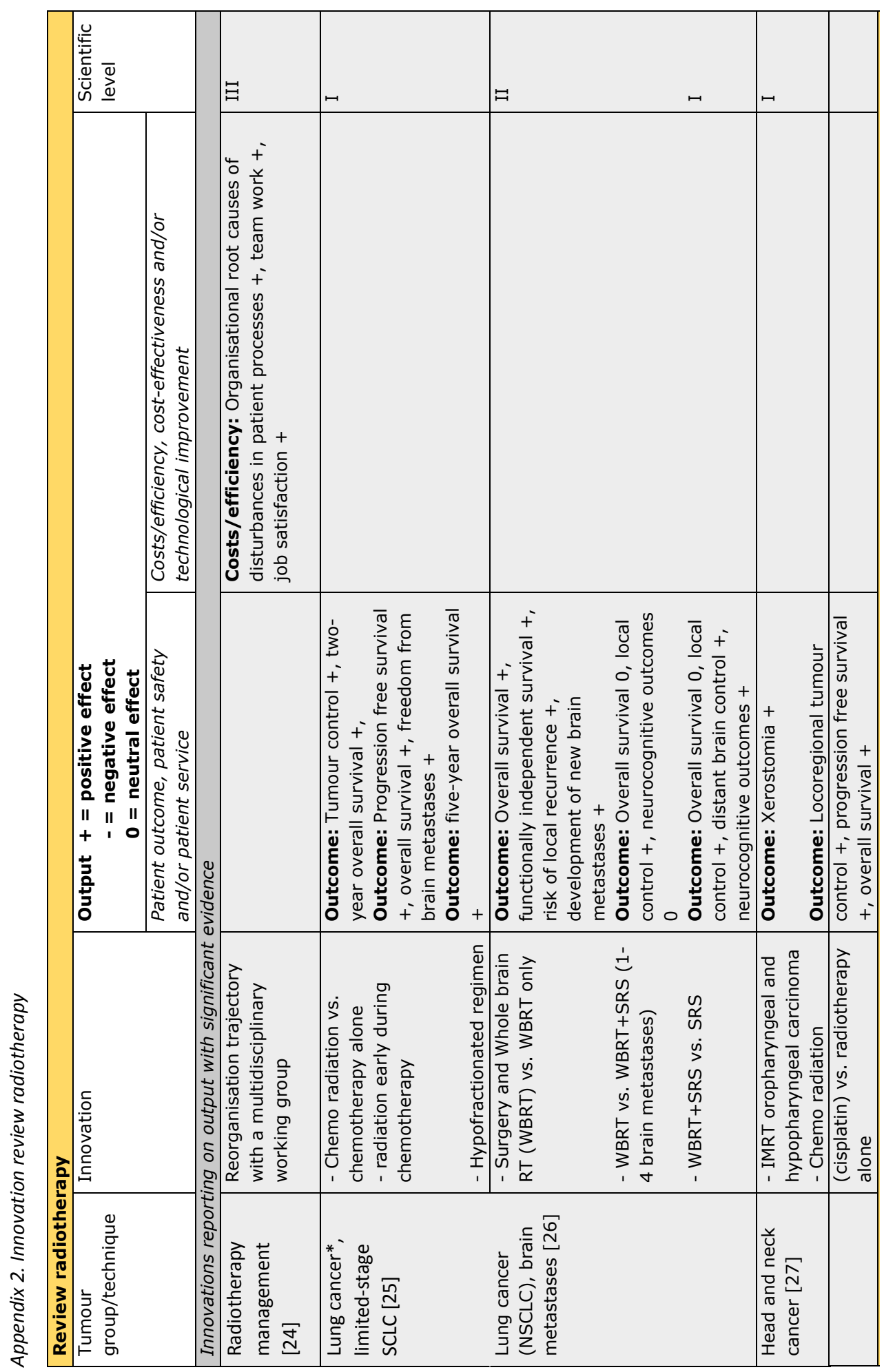




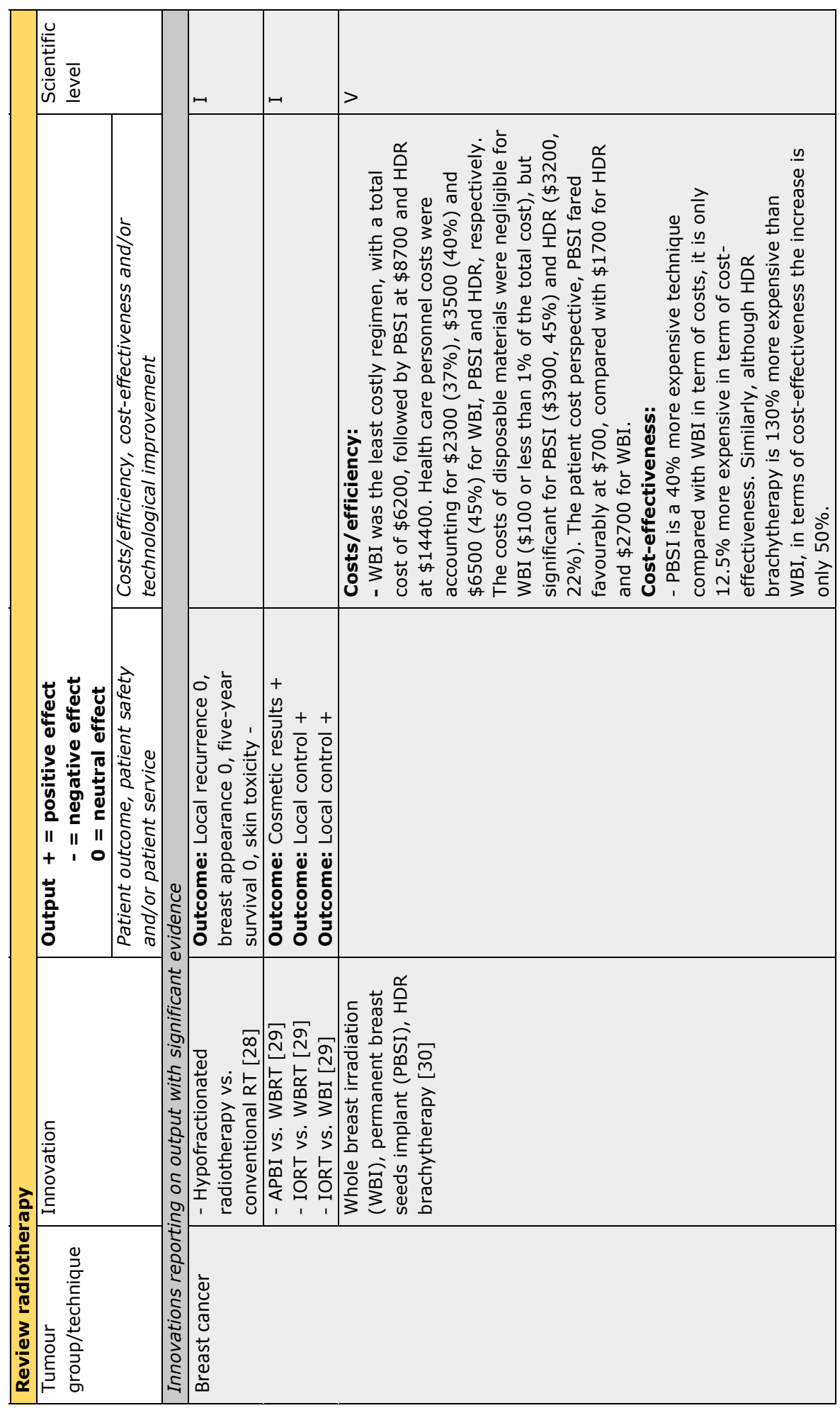

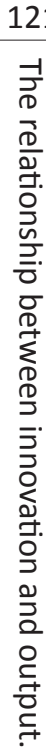




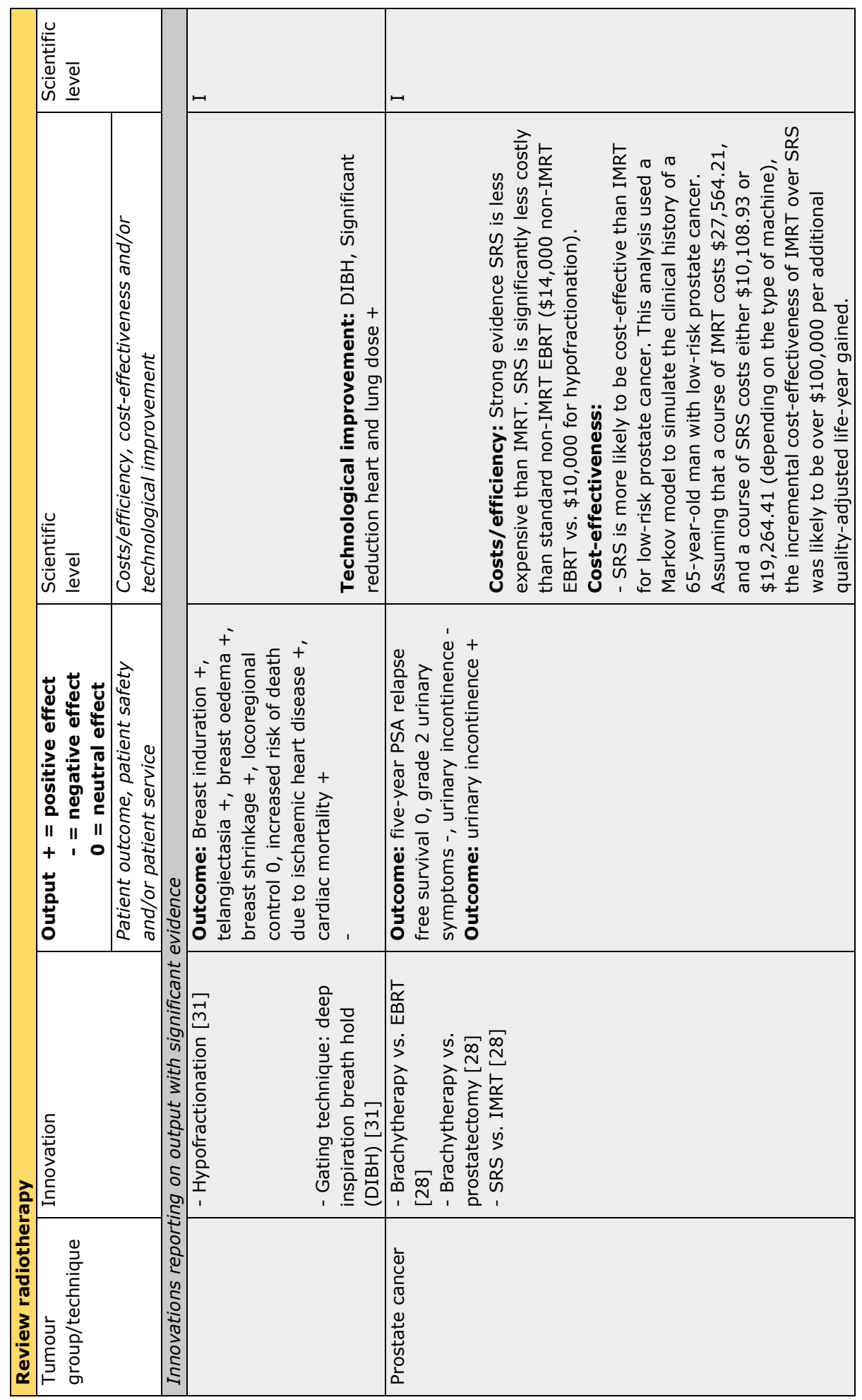




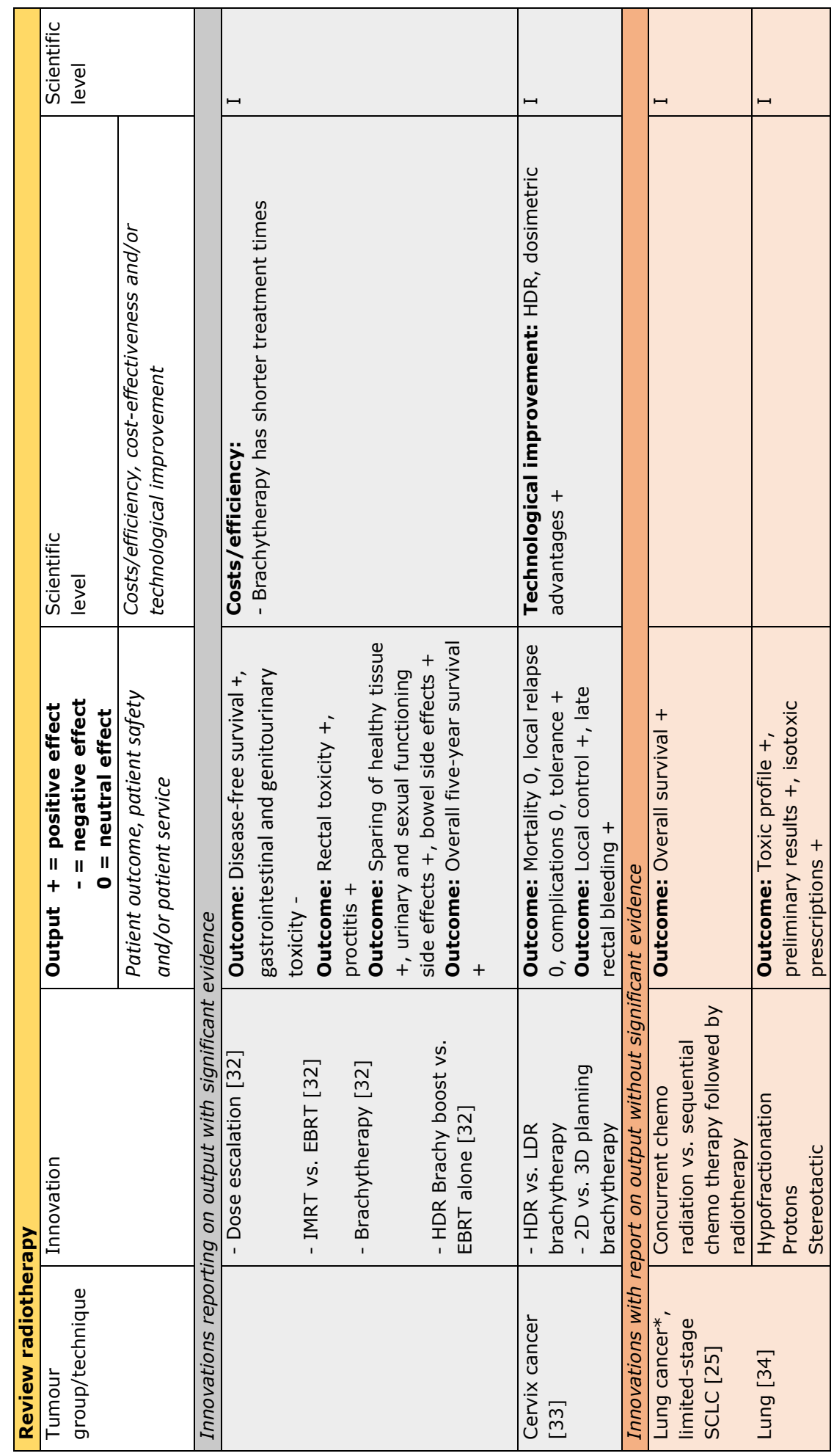

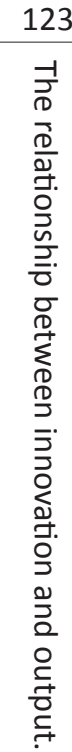




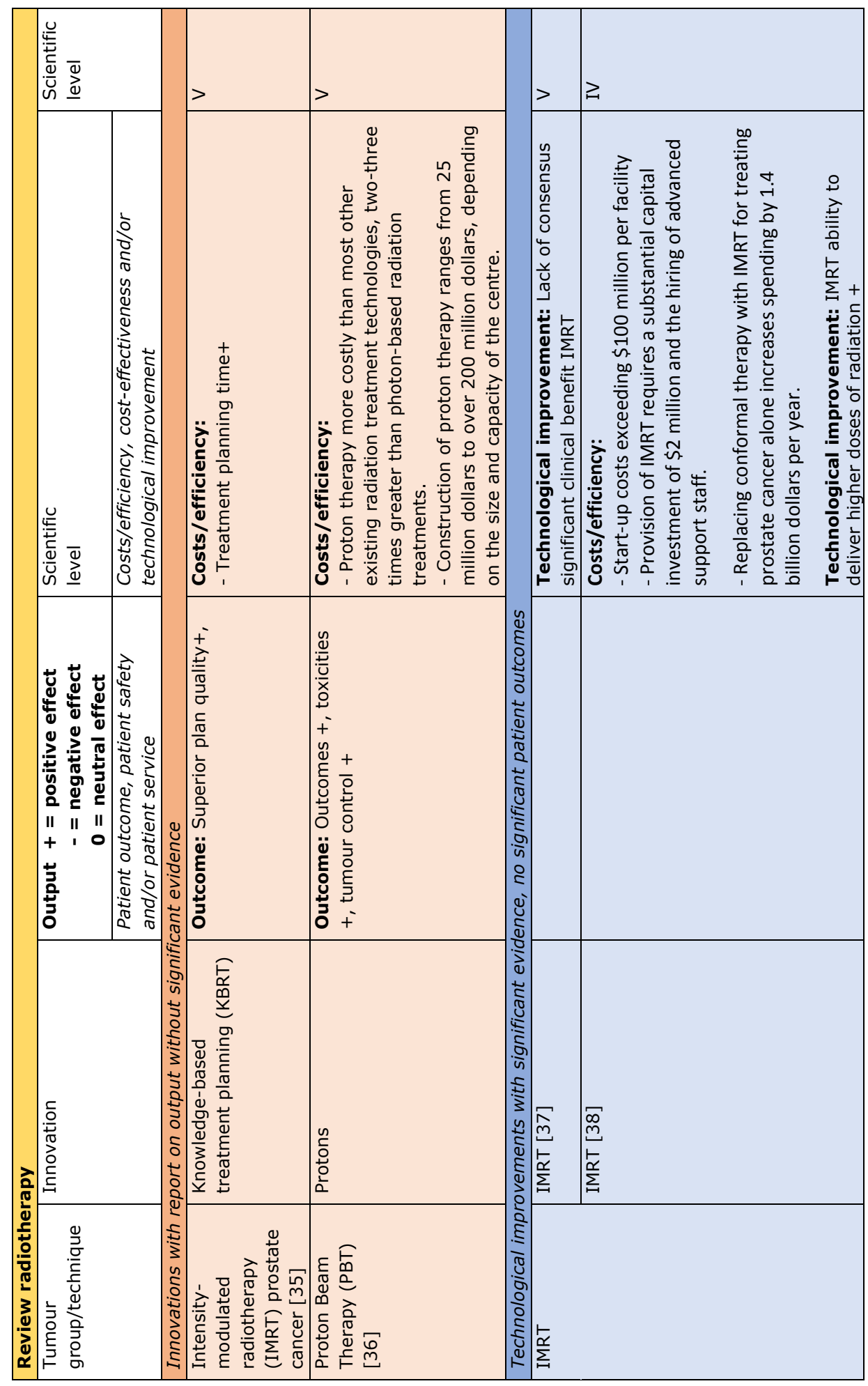




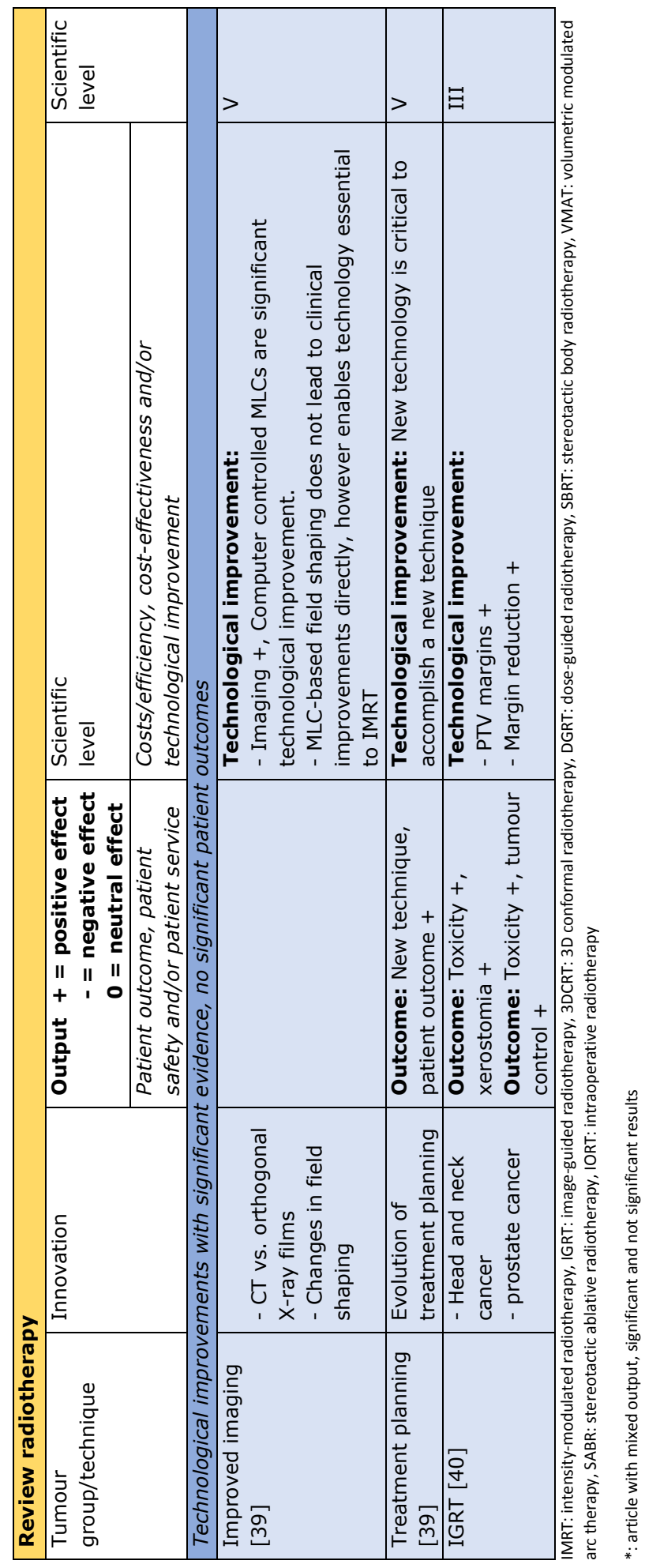

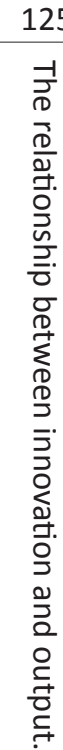




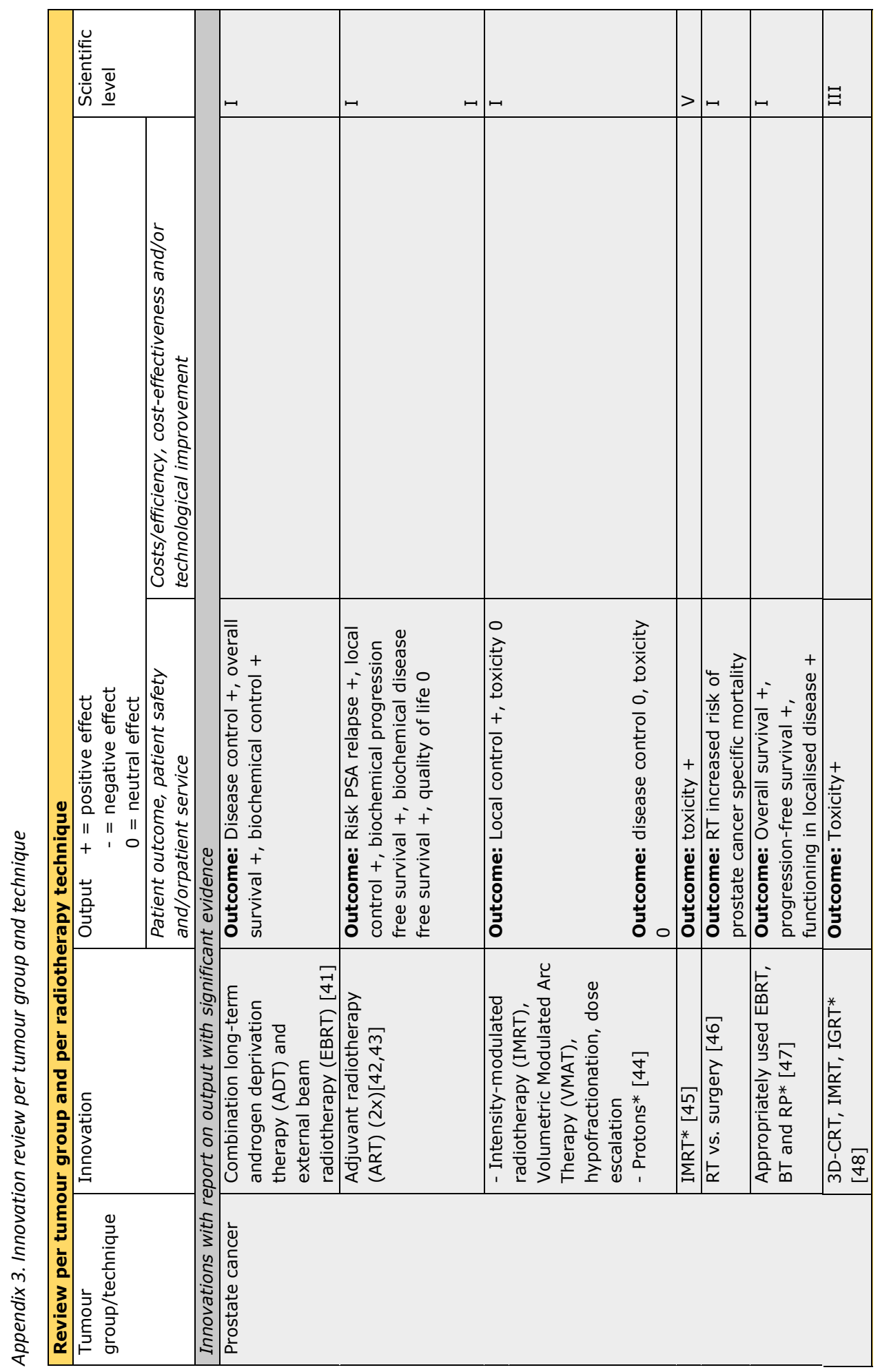




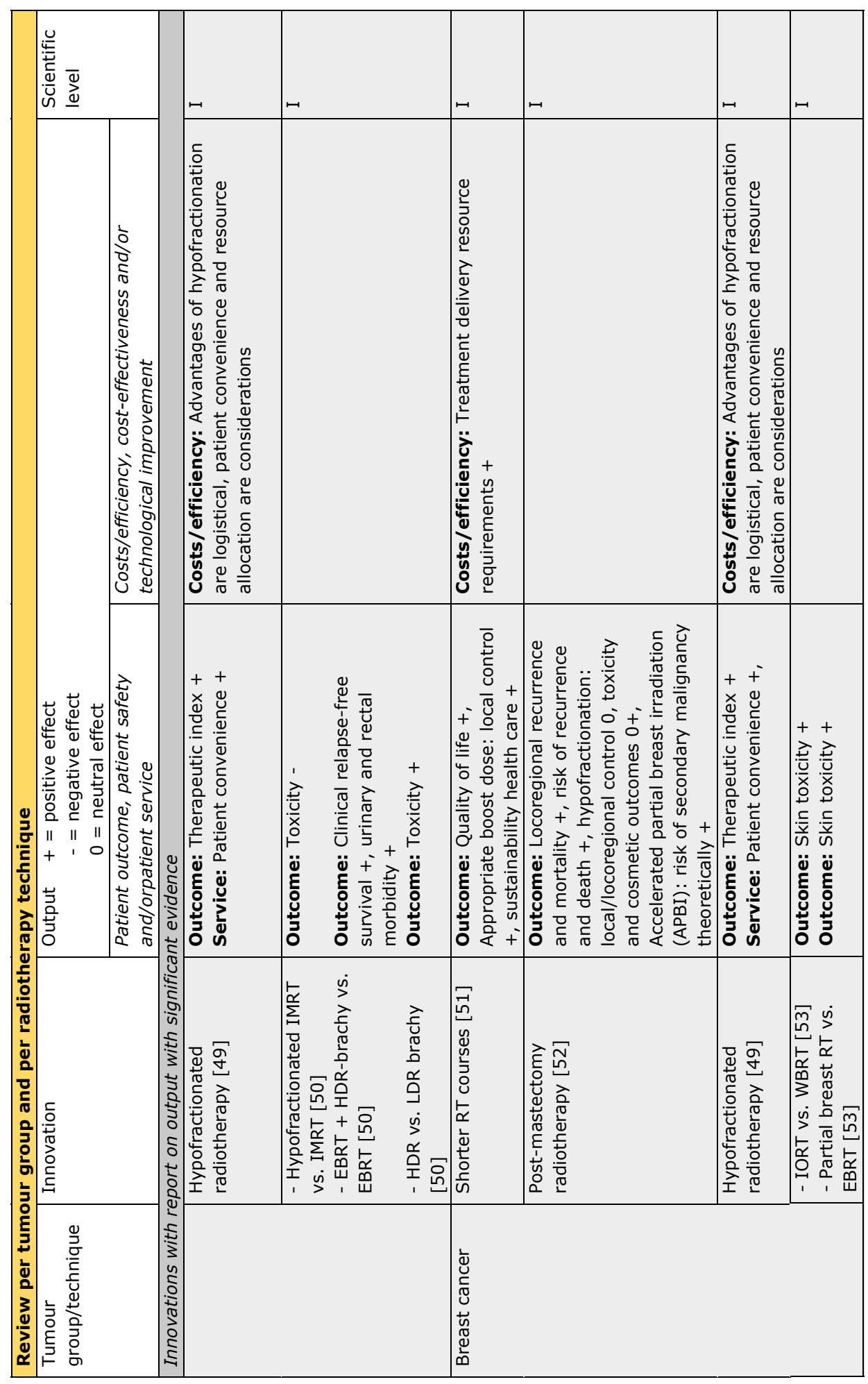

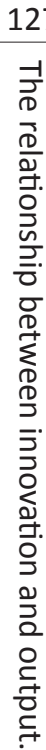




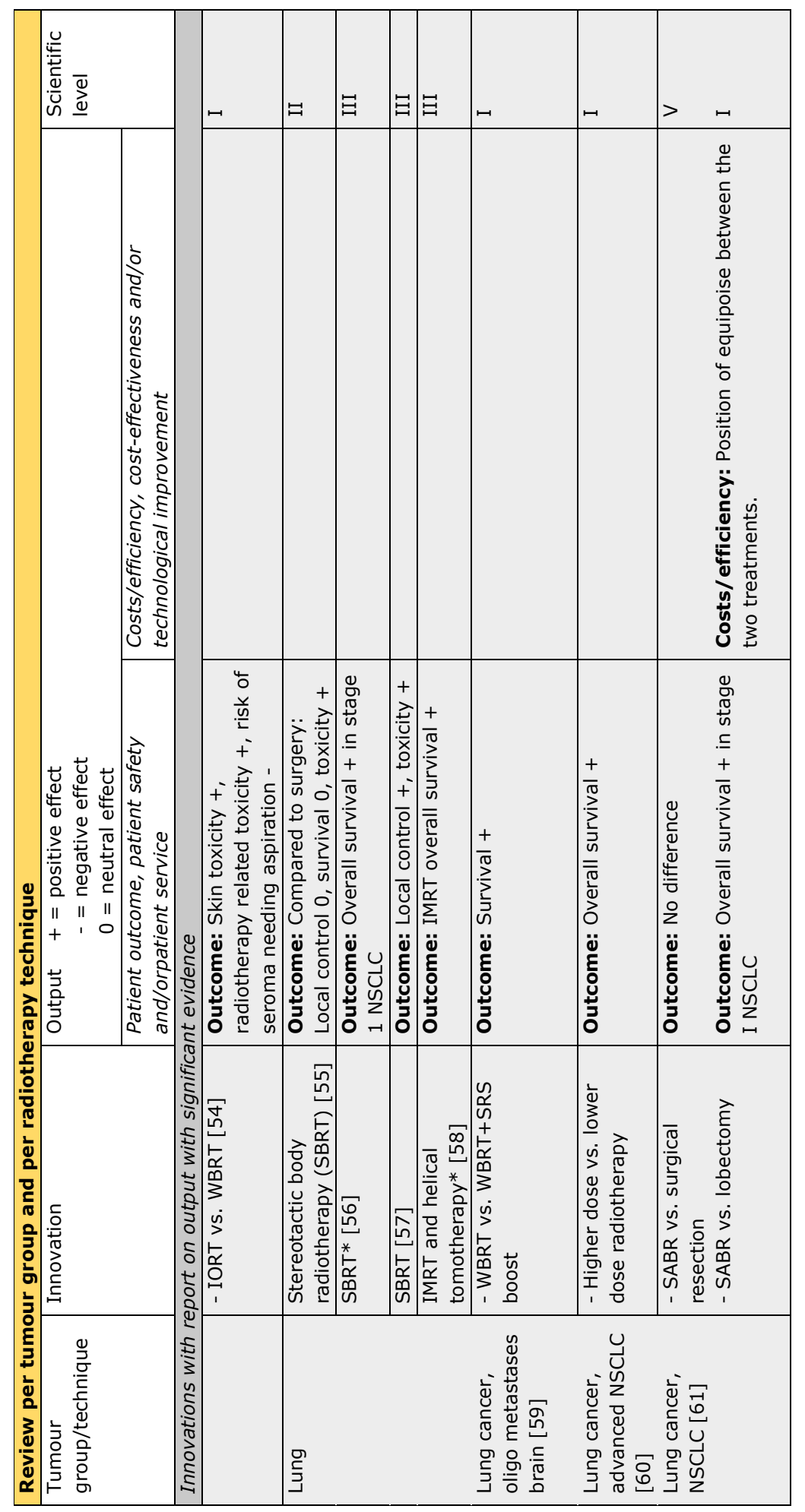




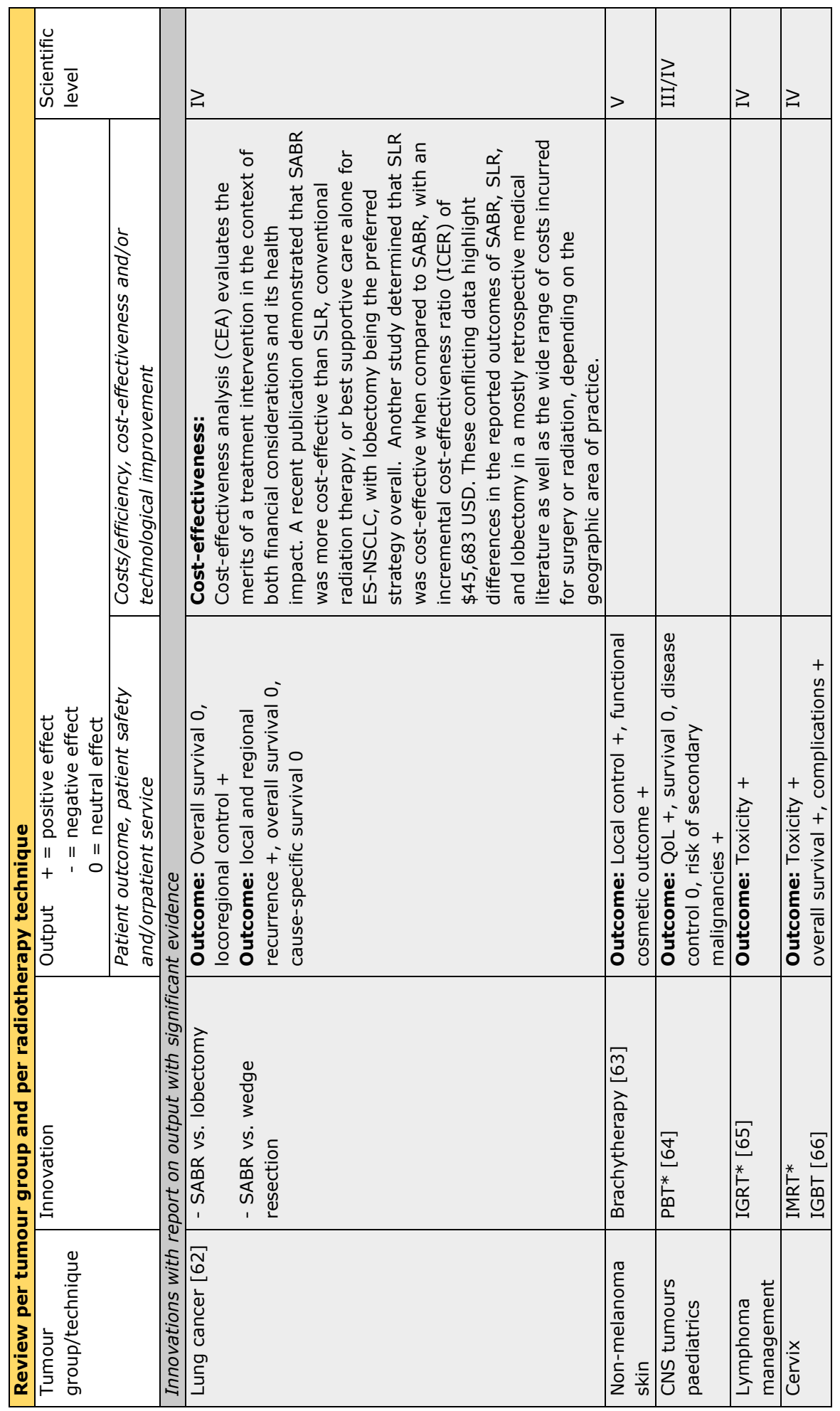




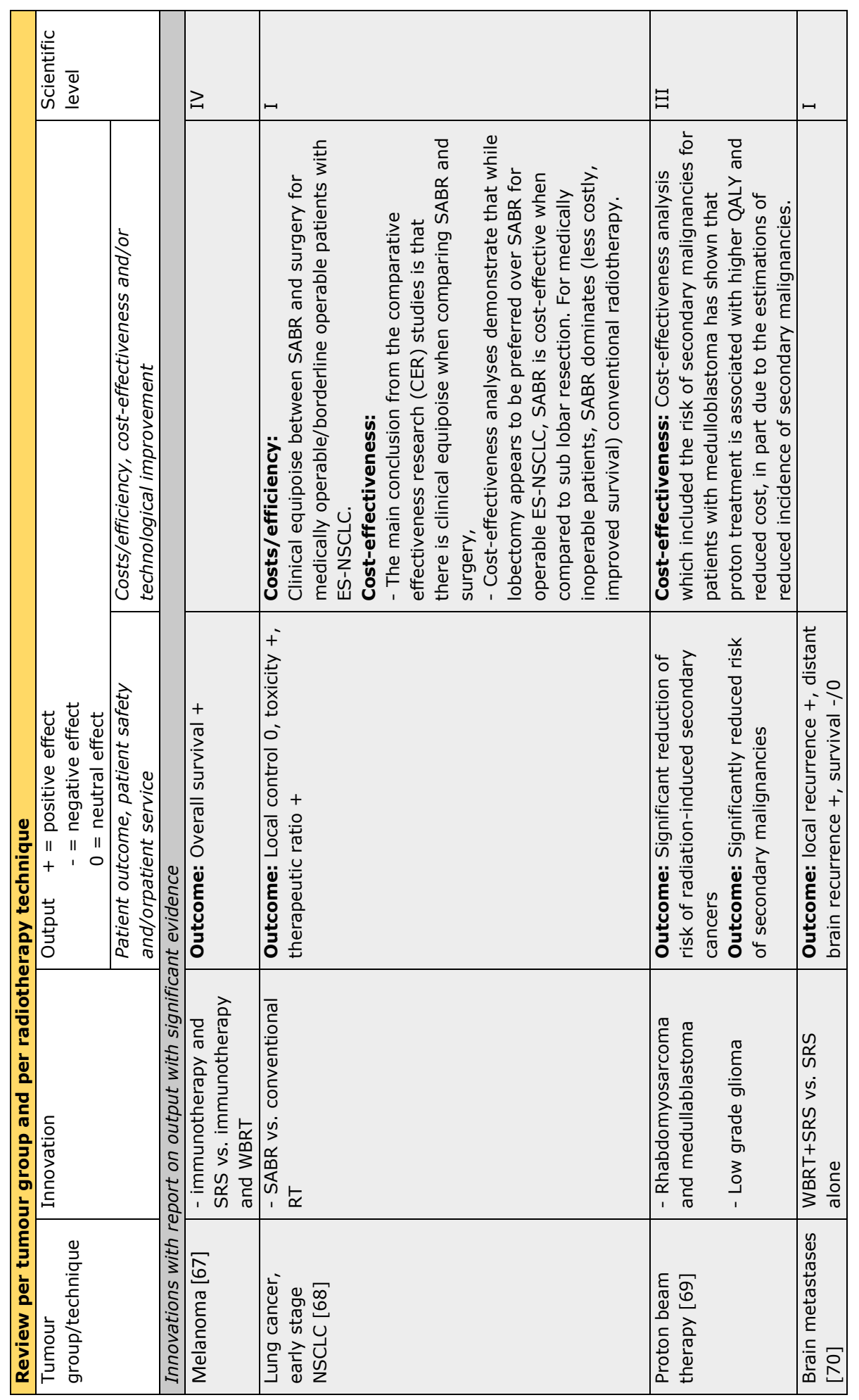




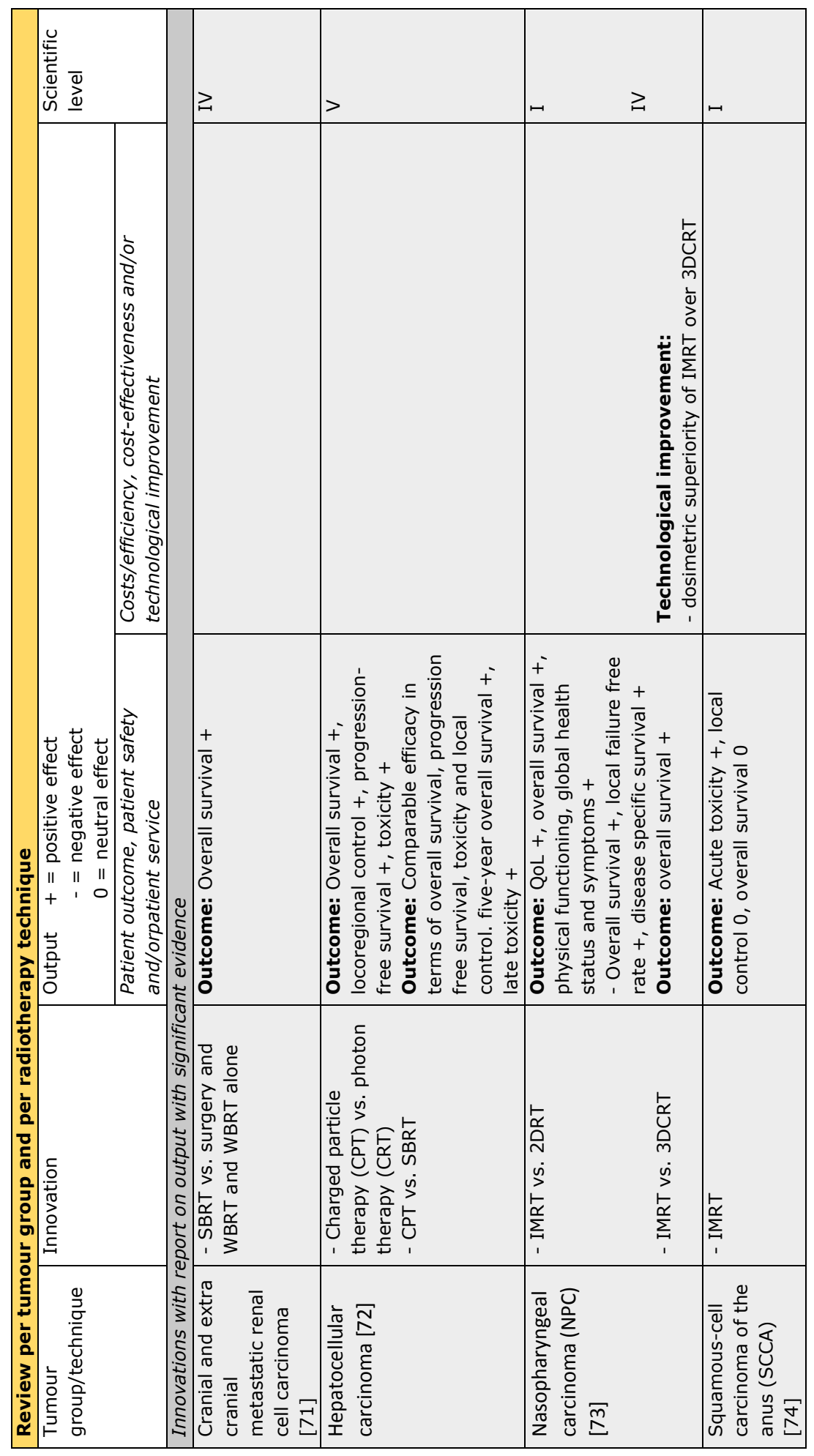

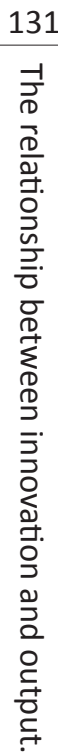




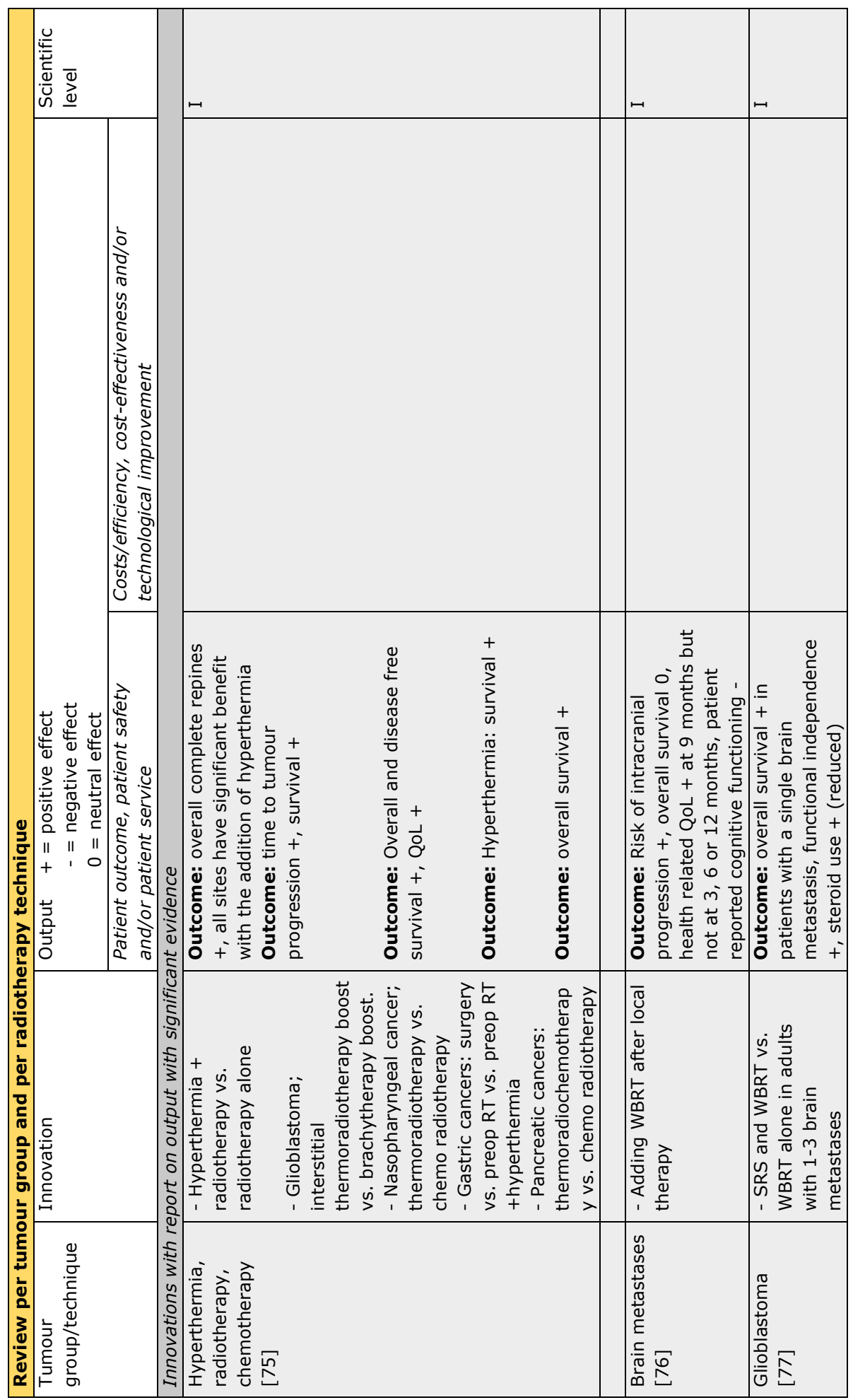




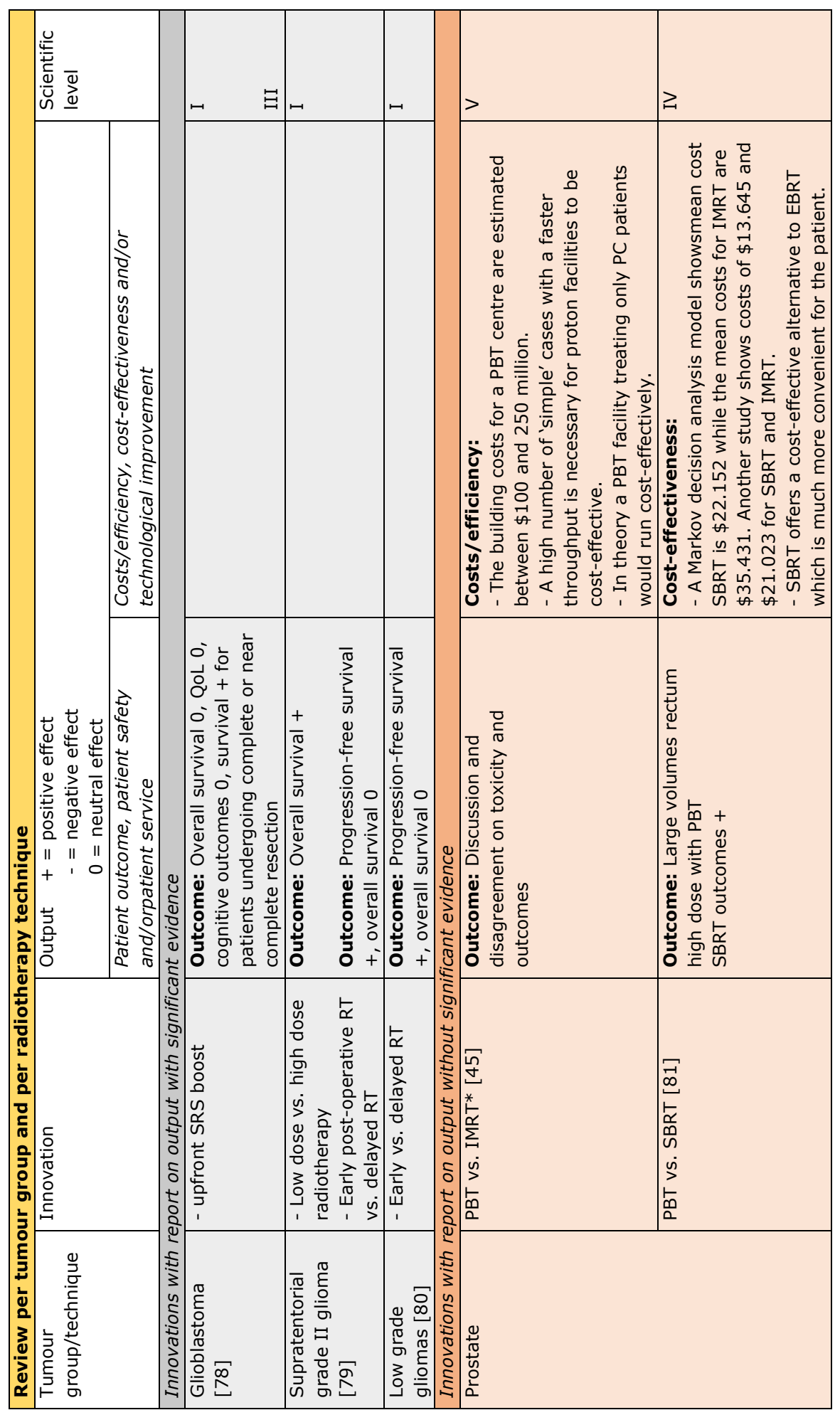




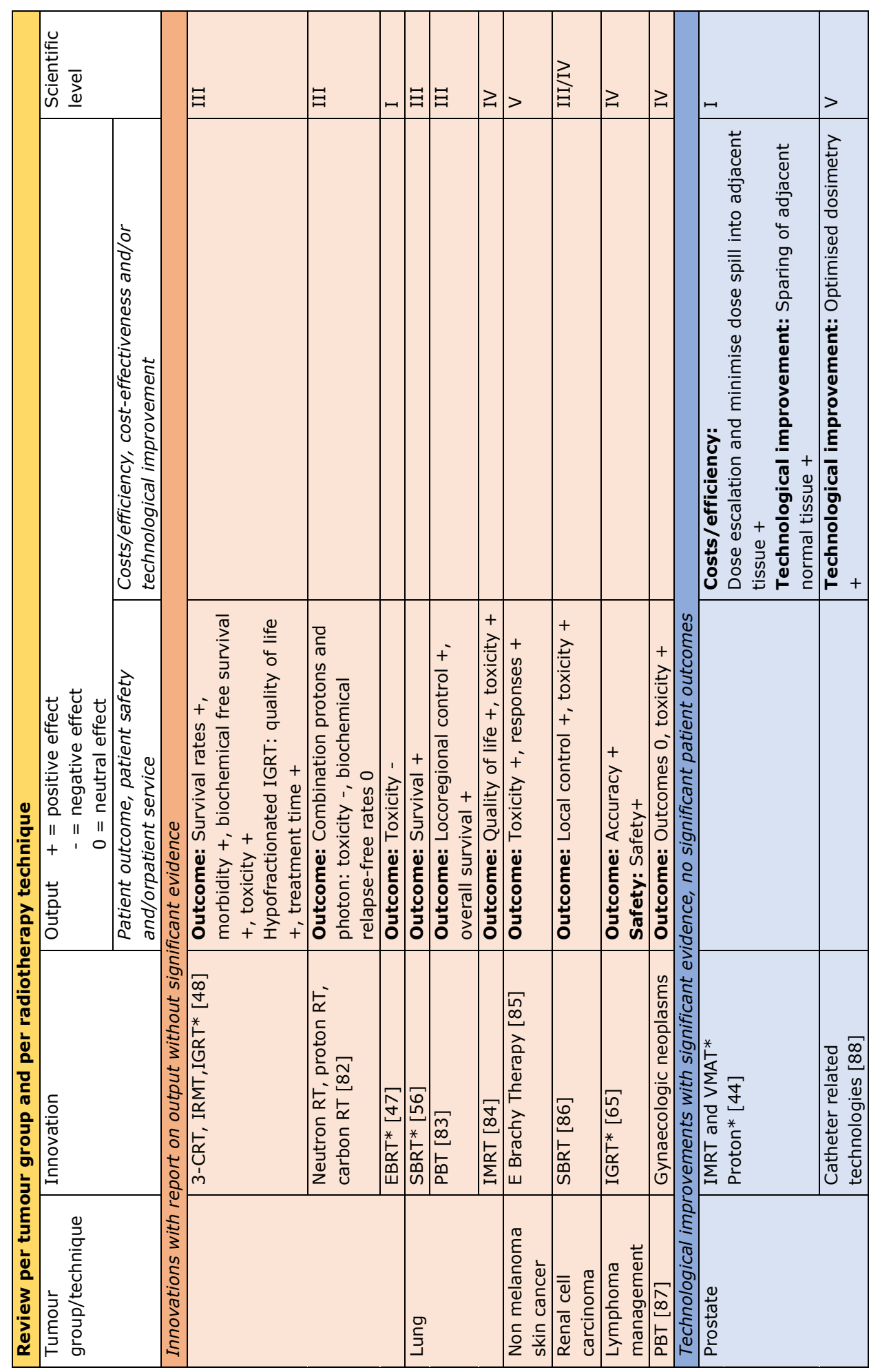




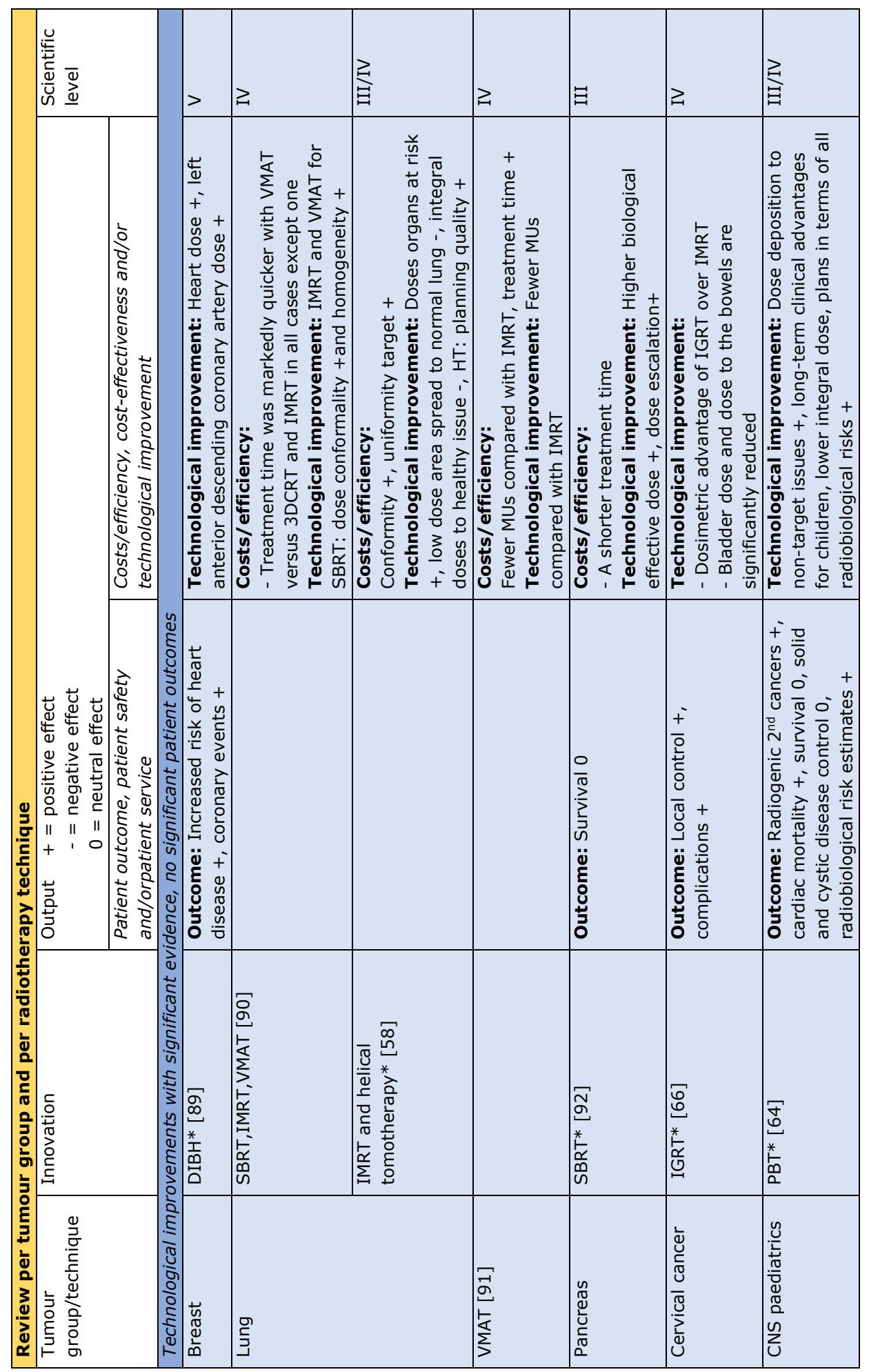

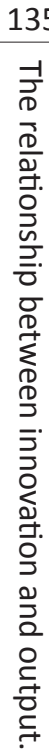




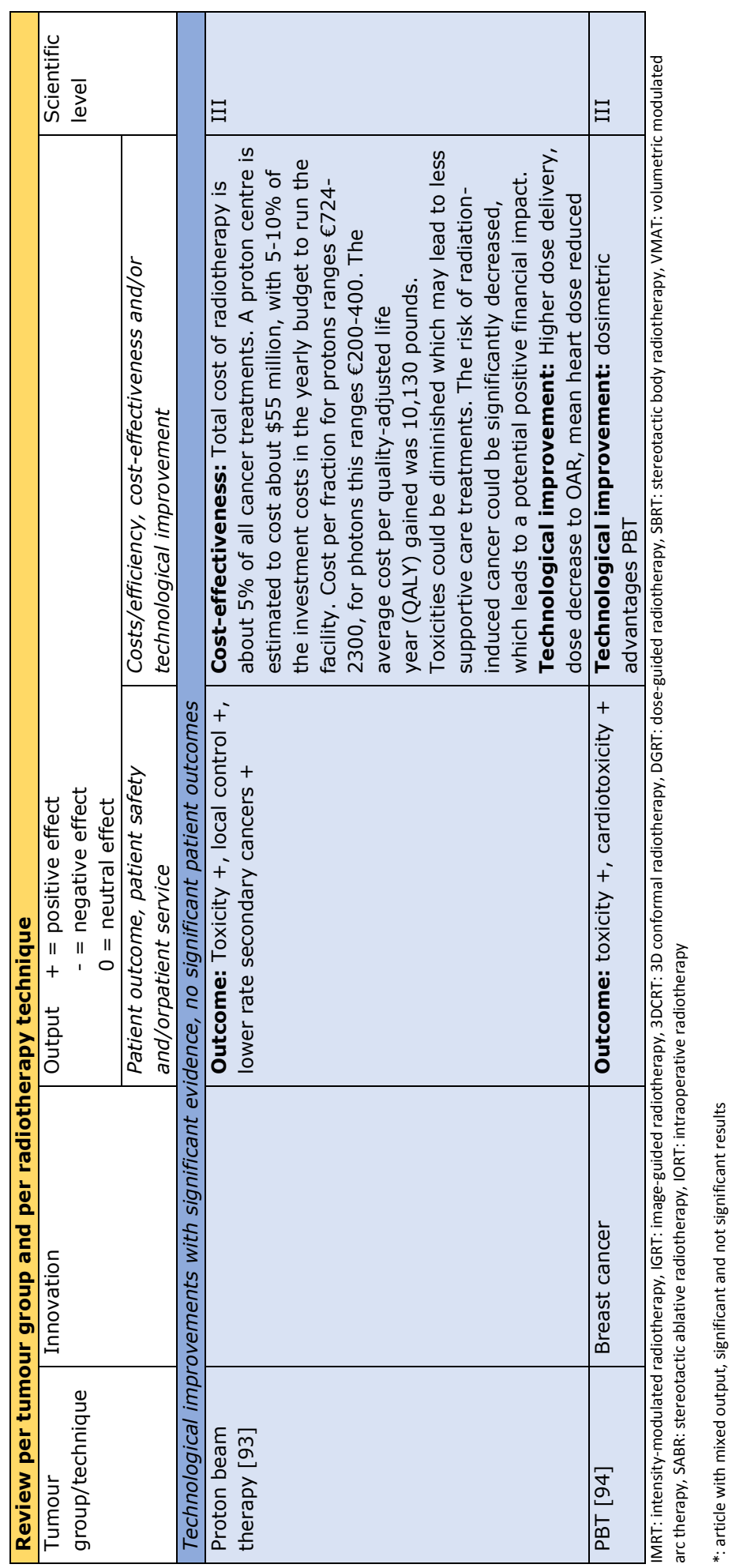




\section{REFERENCES APPENDIX}

1. Chandra A, Snider JT, Wu Y, Jena A, Goldman DP. Robot-assisted surgery for kidney cancer increased access to a procedure that can reduce mortality and renal failure. Health Affairs. 2015;34(2):220-8.

2. Calderon AS, Blackmore CC, Williams BL, Chawla KP, Nelson-Peterson DL, Ingraham MD, et al. Transforming ward rounds through rounding-in-flow. Journal of graduate medical education. 2014;6(4):750-5.

3. Cook D, Thompson JE, Habermann EB, Visscher SL, Dearani JA, Roger VL, et al. From 'solution shop'model to 'focused factory'in hospital surgery: increasing care value and predictability. Health Affairs. 2014;33(5):746-55.

4. Dobrzykowski DD, Callaway SK, Vonderembse MA. Examining pathways from innovation orientation to patient satisfaction: A relational view of healthcare delivery. Decision Sciences. 2015;46(5):863-99.

5. Paton F, Chambers D, Wilson P, Eastwood A, Craig D, Fox D, et al. Effectiveness and implementation of enhanced recovery after surgery programmes: a rapid evidence synthesis. BMJ open. 2014;4(7):e005015.

6. Englander H, Michaels L, Chan B, Kansagara D. The care transitions innovation (C-Traln) for socioeconomically disadvantaged adults: results of a cluster randomized controlled trial. Journal of general internal medicine. 2014;29(11):1460-7.

7. Pascual M, Salvans S, Pera M. Laparoscopic colorectal surgery: current status and implementation of the latest technological innovations. World journal of gastroenterology. 2016;22(2):704.

8. Jit M, Hutubessy R. Methodological Challenges to Economic Evaluations of Vaccines: Is a Common Approach Still Possible? Applied health economics and health policy. 2016;14(3):24552.

9. Rubin FH, Neal K, Fenlon K, Hassan S, Inouye SK. Sustainability and scalability of the hospital elder life program at a community hospital. Journal of the American Geriatrics Society. 2011;59(2):359-65.

10. Shah AP, Retzer EM, Nathan S, Paul JD, Friant J, Dill KE, et al. Clinical and economic effectiveness of percutaneous ventricular assist devices for high-risk patients undergoing percutaneous coronary intervention. The Journal of invasive cardiology. 2015;27(3):148-54.

11. Slof J, Valle RD, Galván J. Cost-effectiveness of 5-aminolevulinic acid-induced fluorescence in malignant glioma surgery. Neurología (English Edition). 2015;30(3):163-8.

12. Watson AJ, Hudson J, Wood J, Kilonzo M, Brown SR, McDonald A, et al. Comparison of stapled haemorrhoidopexy with traditional excisional surgery for haemorrhoidal disease (eTHoS): a pragmatic, multicentre, randomised controlled trial. The Lancet. 2016;388(10058):2375-85.

13. Ahmetović A, Mushahwar VK, Sommer R, Schnepf D, Kawasaki L, Warwaruk-Rogers R, et al. Safety and feasibility of intermittent electrical stimulation for the prevention of deep tissue injury. Advances in wound care. 2015;4(3):192-201. 
14. Lega F, Marsilio M, Villa S. An evaluation framework for measuring supply chain performance in the public healthcare sector: evidence from the Italian NHS. Production Planning \& Control. 2013;24(10-11):931-47.

15. Hanskamp-Sebregts M, Zegers M, Boeijen W, Westert GP, van Gurp PJ, Wollersheim H. Effects of auditing patient safety in hospital care: design of a mixed-method evaluation. BMC health services research. 2013;13(1):1.

16. Reddy AJ, Pappas R, Suri S, Whinney C, Yerian L, Guzman JA. Impact of throughput optimization on intensive care unit occupancy. American Journal of Medical Quality. 2014:1062860614531614.

17. Sehgal NL, Fox M, Sharpe BA, Vidyarthi AR, Blegen M, Wachter RM. Critical conversations: a call for a nonprocedural "time out". Journal of hospital medicine. 2011;6(4):225-30.

18. Paton F, Chambers D, Wilson P, Eastwood A, Craig D, Fox D, et al. Initiatives to reduce length of stay in acute hospital settings: a rapid synthesis of evidence relating to enhanced recovery programmes. 2014.

19. Baker EH, Ross SW, Seshadri R, Swan RZ, lannitti DA, Vrochides D, et al. Robotic pancreaticoduodenectomy for pancreatic adenocarcinoma: role in 2014 and beyond. Journal of gastrointestinal oncology. 2015;6(4):396.

20. de Joliniere JB, Librino A, Dubuisson J-B, Khomsi F, Ali NB, Fadhlaoui A, et al. Robotic surgery in gynecology. Frontiers in surgery. 2016;3.

21. Wright JD, Burke WM, Wilde ET, Lewin SN, Charles AS, Kim JH, et al. Comparative effectiveness of robotic versus laparoscopic hysterectomy for endometrial cancer. Journal of Clinical Oncology. 2012:JCO. 2011.36. 7508.

22. Gibbons GW. Grafix ${ }^{\circledR}$, a Cryopreserved Placental Membrane, for the Treatment of Chronic/ Stalled Wounds. Advances in wound care. 2015;4(9):534-44.

23. Cundy TP, Harling L, Hughes-Hallett A, Mayer EK, Najmaldin AS, Athanasiou T, et al. Metaanalysis of robot-assisted vs conventional laparoscopic and open pyeloplasty in children. BJU international. 2014;114(4):582-94.

24. Jacobs M, Boersma L, Dekker A, Hermanns E, Houben R, Govers M, et al. Organizational development trajectory of a large academic radiotherapy department set up similarly to a prospective clinical trial: the MAASTRO experience. The British journal of radiology. 2015;88(1049):20140559.

25. Amini A, Byers LA, Welsh JW, Komaki RU. Progress in the management of limited-stage small cell lung cancer. Cancer. 2014;120(6):790-8.

26. Dawe DE, Greenspoon JN, Ellis PM. Brain Metastases in Non-Small-Cell Lung Cancer. Clinical lung cancer. 2014;15(4):249-57.

27. Cmelak AJ. Current issues in combined modality therapy in locally advanced head and neck cancer. Critical reviews in oncology/hematology. 2012;84(2):261-73.

28. Aneja S, James BY, editors. Comparative effectiveness research in radiation oncology: stereotactic radiosurgery, hypofractionation, and brachytherapy. Seminars in radiation oncology; 2014: Elsevier. 
29. Kunkler IH, Ward C, Langdon SP. Technical innovation in adjuvant radiotherapy: Evolution and evaluation of new treatments for today and tomorrow. The Breast. 2015;24:S114-S9.

30. McGuffin M, Merino T, Keller B, Pignol J-P. Who Should Bear the Cost of Convenience? A Cost-effectiveness Analysis Comparing External Beam and Brachytherapy Radiotherapy Techniques for Early Stage Breast Cancer. Clinical Oncology. 2016.

31. Montero A, Sanz X, Hernanz R, Cabrera D, Arenas M, Bayo E, et al. Accelerated hypofractionated breast radiotherapy: FAQs (Frequently Asked Questions) and facts. The Breast. 2014;23(4):299-309.

32. Challapalli A, Jones E, Harvey C, Hellawell G, Mangar S. High dose rate prostate brachytherapy: an overview of the rationale, experience and emerging applications in the treatment of prostate cancer. The British journal of radiology. 2014.

33. Miglierini P, Malhaire J-P, Goasduff G, Miranda O, Pradier O. Cervix cancer brachytherapy: high dose rate. Cancer/Radiothérapie. 2014;18(5):452-7.

34. Giaj-Levra N, Ricchetti F, Alongi F. What is changing in radiotherapy for the treatment of locally advanced nonsmall cell lung cancer patients? A review. Cancer investigation. 2016;34(2):80-93.

35. Good D, Lo J, Lee WR, Wu QJ, Yin F-F, Das SK. A knowledge-based approach to improving and homogenizing intensity modulated radiation therapy planning quality among treatment centers: an example application to prostate cancer planning. International Journal of Radiation Oncology* Biology* Physics. 2013;87(1):176-81.

36. Swisher-McClure S, Hahn SM, Bekelman J. Proton beam therapy: the next disruptive innovation in healthcare? Postgraduate medical journal. 2015;91(1075):241-3.

37. Shumway DA, Griffith KA, Pierce LJ, Feng M, Moran JM, Stenmark MH, et al. Wide variation in the diffusion of a new technology: Practice-based trends in intensity-modulated radiation therapy (IMRT) use in the state of Michigan, with implications for IMRT use nationally. Journal of Oncology Practice. 2015;11(3):e373-e9.

38. Jacobs BL, Zhang Y, Skolarus TA, Hollenbeck BK. Growth of high-cost intensitymodulated radiotherapy for prostate cancer raises concerns about overuse. Health Affairs. 2012;31(4):750-9.

39. Fraass BA, Moran JM, editors. Quality, technology and outcomes: evolution and evaluation of new treatments and/or new technology. Seminars in radiation oncology; 2012: Elsevier.

40. Jaffray DA. Image-guided radiotherapy: from current concept to future perspectives. Nature Reviews Clinical Oncology. 2012;9(12):688-99.

41. Juloori A, Shah C, Stephans K, Vassil A, Tendulkar R. Evolving Paradigm of Radiotherapy for High-Risk Prostate Cancer: Current Consensus and Continuing Controversies. Prostate Cancer. 2016;2016.

42. Herrera FG, Berthold DR. Radiation therapy after radical prostatectomy: Implications for clinicians. Frontiers in oncology. 2016;6.

43. Raziee H, Berlin A. Gaps between evidence and Practice in Postoperative Radiotherapy for Prostate Cancer: Focus on Toxicities and the effects on Health-Related Quality of Life. Frontiers in oncology. 2016;6. 
44. Dulaney CR, Osula DO, Yang ES, Rais-Bahrami S. Prostate Radiotherapy in the Era of Advanced Imaging and Precision Medicine. Prostate cancer. 2016;2016.

45. Schiller KC, Habl G, Combs SE. Protons, Photons, and the Prostate-is There emerging evidence in the Ongoing Discussion on Particle Therapy for the Treatment of Prostate Cancer? Frontiers in oncology. 2016;6.

46. Wallis CJ, Saskin R, Choo R, Herschorn S, Kodama RT, Satkunasivam R, et al. Surgery versus radiotherapy for clinically-localized prostate cancer: a systematic review and meta-analysis. European urology. 2016;70(1):21-30.

47. Wolff RF, Ryder S, Bossi A, Briganti A, Crook J, Henry A, et al. A systematic review of randomised controlled trials of radiotherapy for localised prostate cancer. European Journal of Cancer. 2015;51(16):2345-67.

48. Nguyen NP, Davis R, Bose SR, Dutta S, Vinh-Hung V, Chi A, et al. Potential applications of image-guided radiotherapy for radiation dose escalation in patients with early stage high-risk prostate cancer. Frontiers in oncology. 2014;5:18-.

49. Ray K, Sibson N, Kiltie A. Treatment of breast and prostate cancer by hypofractionated radiotherapy: potential risks and benefits. Clinical Oncology. 2015;27(7):420-6.

50. Yamazaki H, Nakamura S, Suzuki G, Yoshida K, Yoshioka Y, Koizumi M, et al. Hypofractionated Radiotherapy for Localized Prostate Cancer: A Challenging Accelerated Hypofractionated Radiotherapy. Anticancer Research. 2015;35(10):5167-77.

51. Koulis TA, Phan T, Olivotto IA. Hypofractionated whole breast radiotherapy: current perspectives. Breast Cancer: Targets and Therapy. 2015;7:363.

52. Brown LC, Mutter RW, Halyard MY. Benefits, risks, and safety of external beam radiation therapy for breast cancer. International journal of women's health. 2015;7:449.

53. Hanna G, Kirby A. Intraoperative radiotherapy in early stage breast cancer: potential indications and evidence to date. The British journal of radiology. 2015;88(1049):20140686.

54. Zhang L, Zhou Z, Mei X, Yang Z, Ma J, Chen X, et al. Intraoperative radiotherapy versus wholebreast external beam radiotherapy in early-stage breast cancer: A systematic review and meta-analysis. Medicine. 2015;94(27).

55. Abreu CECV, Ferreira PPR, Moraes FYd, Neves Jr WFP, Gadia R, Carvalho HdA. Stereotactic body radiotherapy in lung cancer: an update. Jornal Brasileiro de Pneumologia. 2015;41(4):376-87.

56. Ricardi U, Badellino S, Filippi AR. Stereotactic radiotherapy for early stage non-small cell lung cancer. Radiation oncology journal. 2015;33(2):57-65.

57. Kang KH, Okoye CC, Patel RB, Siva S, Biswas T, Ellis RJ, et al. Complications from stereotactic body radiotherapy for lung cancer. Cancers. 2015;7(2):981-1004.

58. Zhu Z, Fu X. The radiation techniques of tomotherapy \& intensity-modulated radiation therapy applied to lung cancer. Translational lung cancer research. 2015;4(3):265.

59. Bergsma DP, Salama JK, Singh DP, Chmura SJ, Milano MT. The evolving role of radiotherapy in treatment of oligometastatic NSCLC. Expert review of anticancer therapy. 2015;15(12):1459-71. 
60. Hanna G, Landau D. Stereotactic body radiotherapy for oligometastatic disease. Clinical Oncology. 2015;27(5):290-7.

61. Palma DA, Louie AV, Rodrigues GB. New strategies in stereotactic radiotherapy for oligometastases. Clinical Cancer Research. 2015;21(23):5198-204.

62. Chen H, Louie AV. SABR vs. Limited Resection for Non-small Cell Lung Cancer: Are We Closer to an Answer? Current treatment options in oncology. 2016;17(6):1-14.

63. Rezarta Frakulli M, Andrea Galuppi M, Silvia Cammelli M, Gabriella Macchia M, Simona Cima M. Brachytherapy in non melanoma skin cancer of eyelid: a systematic review. Journal of contemporary brachytherapy. 2015;7(6):497-502.

64. Armoogum KS, Thorp N. Dosimetric comparison and potential for improved clinical outcomes of paediatric CNS patients treated with protons or IMRT. Cancers. 2015;7(2):706-22.

65. Eng T, Ha CS. Image-guided radiation therapy in lymphoma management. Radiation oncology journal. 2015;33(3):161-71.

66. Dutta S, Nguyen NP, Vock J, Kerr C, Godinez J, Bose S, et al. Image-guided radiotherapy andbrachytherapy for cervical cancer. Frontiers in oncology. 2015;5.

67. Bernstein MB, Krishnan S, Hodge JW, Chang JY. Immunotherapy and stereotactic ablative radiotherapy (ISABR): a curative approach? Nature Reviews Clinical Oncology. 2016.

68. Louie AV, Palma DA, Dahele M, Rodrigues GB, Senan S. Management of early-stage non-small cell lung cancer using stereotactic ablative radiotherapy: controversies, insights, and changing horizons. Radiotherapy and Oncology. 2015;114(2):138-47.

69. Eaton BR, MacDonald SM, Yock TI, Tarbell NJ. Secondary malignancy risk following proton radiation therapy. Frontiers in oncology. 2015;5.

70. Arvold ND, Lee EQ, Mehta MP, Margolin K, Alexander BM, Lin NU, et al. Updates in the management of brain metastases. Neuro-oncology. 2016;18(8):1043-65.

71. Kothari G, Foroudi F, Gill S, Corcoran NM, Siva S. Outcomes of stereotactic radiotherapy for cranial and extracranial metastatic renal cell carcinoma: A systematic review. Acta Oncologica. 2015;54(2):148-57.

72. Qi W-X, Fu S, Zhang Q, Guo X-M. Charged particle therapy versus photon therapy for patients with hepatocellular carcinoma: a systematic review and meta-analysis. Radiotherapy and Oncology. 2015;114(3):289-95.

73. Qu S, Liang Z-G, Zhu X-D. Advances and challenges in intensity-modulated radiotherapy for nasopharyngeal carcinoma. Asian Pac J Cancer Prev. 2015;16:1687-92.

74. Glynne-Jones R, Tan D, Hughes R, Hoskin P. Squamous-cell carcinoma of the anus: progress in radiotherapy treatment. Nature Reviews Clinical Oncology. 2016.

75. Datta N, Ordóñez SG, Gaipl U, Paulides M, Crezee H, Gellermann J, et al. Local hyperthermia combined with radiotherapy and-/or chemotherapy: Recent advances and promises for the future. Cancer treatment reviews. 2015;41(9):742-53.

76. Pinkham MB, Sanghera P, Wall G, Dawson B, Whitfield GA. Neurocognitive effects following cranial irradiation for brain metastases. Clinical Oncology. 2015;27(11):630-9. 
77. Pinkham MB, Whitfield GA, Brada M. New developments in intracranial stereotactic radiotherapy for metastases. Clinical Oncology. 2015;27(5):316-23.

78. Redmond KJ, Mehta M. Stereotactic Radiosurgery for Glioblastoma. Cureus. 2015;7(12).

79. Ryken TC, Parney I, Buatti J, Kalkanis SN, Olson JJ. The role of radiotherapy in the management of patients with diffuse low grade glioma. Journal of neuro-oncology. 2015;125(3):551-83.

80. Sarmiento JM, Venteicher AS, Patil CG. Early versus delayed postoperative radiotherapy for treatment of low-grade gliomas. The Cochrane Library. 2015.

81. Meier R. Dose-escalated robotic SBRT for Stage I-II prostate cancer. Frontiers in oncology. 2015;5.

82. Shioyama Y, Tsuji H, Suefuji H, Sinoto M, Matsunobu A, Toyama S, et al. Particle radiotherapy for prostate cancer. International Journal of Urology. 2015;22(1):33-9.

83. Berman AT, James SS, Rengan R. Proton beam therapy for non-small cell lung cancer: current clinical evidence and future directions. Cancers. 2015;7(3):1178-90.

84. Chang JY, editor Intensity-modulated radiotherapy, not 3 dimensional conformal, is the preferred technique for treating locally advanced lung cancer. Seminars in radiation oncology; 2015: Elsevier.

85. Kasper ME, Chaudhary AA. Novel treatment options for nonmelanoma skin cancer: focus on electronic brachytherapy. Medical Devices (Auckland, NZ). 2015;8:493.

86. Swaminath A, Chu W. Stereotactic body radiotherapy for the treatment of medically inoperable primary renal cell carcinoma: Current evidence and future directions. Canadian Urological Association Journal. 2015;9(7-8):275.

87. Verma V, Simone CB, Wahl AO, Beriwal S, Mehta MP. Proton radiotherapy for gynecologic neoplasms. Acta Oncologica. 2016;55(11):1257-65.

88. Zhou J, Zamdborg L, Sebastian E. Review of advanced catheter technologies in radiation oncology brachytherapy procedures. Cancer management and research. 2015;7:199.

89. Smyth LM, Knight KA, Aarons YK, Wasiak J. The cardiac dose-sparing benefits of deep inspiration breath-hold in left breast irradiation: a systematic review. Journal of medical radiation sciences. 2015;62(1):66-73.

90. Sapkaroski D, Osborne C, Knight KA. A review of stereotactic body radiotherapy-is volumetric modulated arc therapy the answer? Journal of medical radiation sciences. 2015;62(2):142-51.

91. Infusino E. Clinical utility of RapidArc ${ }^{\mathrm{TM}}$ radiotherapy technology. Cancer management and research. 2015;7:345.

92. Wei Q, Yu W, Rosati LM, Herman JM. Advances of stereotactic body radiotherapy in pancreatic cancer. Chinese Journal of Cancer Research. 2015;27(4):349.

93. Doyen J, Falk AT, Floquet V, Hérault J, Hannoun-Lévi J-M. Proton beams in cancer treatments: Clinical outcomes and dosimetric comparisons with photon therapy. Cancer treatment reviews. 2016;43:104-12.

94. Verma V, Shah C, Mehta MP. Clinical outcomes and toxicity of proton radiotherapy for breast cancer. Clinical breast cancer. 2016;16(3):145-54. 


\section{PART III}

\section{Example implementation design organizational innovation.}





\section{CHAPTER 6}

\section{Organizational innovation of a large radiotherapy department set up similar to a prospective clinical trial.}

$\underline{\text { M. Jacobs }}$

L. Boersma

A. Dekker

E. Hermanns

R. Houben

M. Govers

F. Van Merode

P. Lambin

Organizational development trajectory of a large academic radiotherapy department set up similarly to a prospective clinical trial: the MAASTRO experience

Published in: British Journal of Radiology, 2015;88:20140559.

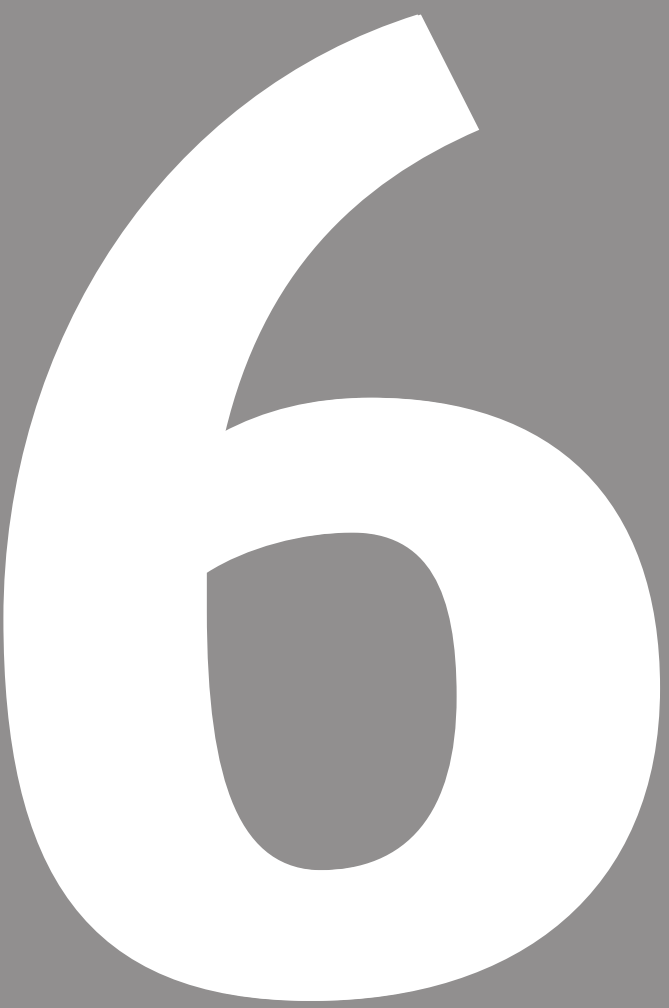




\section{ABSTRACT \\ Objective}

To simultaneously improve patient care processes and clinical research activities

by starting a hypothesis driven reorganization trajectory mimicking the rigorous methodology of a prospective clinical trial.

\section{Methods}

The design of this reorganization trajectory was based on the model of a prospective trial. It consisted of (1) listing problems and analysing their potential causes, (2) defining interventions, (3) defining end points and (4) measuring the effect of the interventions (i.e. at baseline and after 1 and 2 years). The primary end point for patient care was the number of organizational root causes of incidents/near incidents; for clinical research, it was the number of patients in trials. There were several secondary end points. We analysed the data using two sample $z$-tests, $\chi^{2}$ test, a Mann-Whitney $U$ test and the oneway analysis of variance with Bonferroni correction.

\section{Results}

The number of organizational root causes was reduced by $27 \%(p<0.001)$. There was no effect on the percentage of patients included in trials.

\section{Conclusion}

The reorganizational trajectory was successful for the primary end point of patient care and had no effect on clinical research. Some confounding events hampered our ability to draw strong conclusions. Nevertheless, the transparency of this approach can give medical professionals more confidence in moving forward with other organizational changes in the same way.

\section{Advances in knowledge}

This article is novel because managerial interventions were set up similarly to a prospective clinical trial. This study is the first of its kind in radiotherapy, and this approach can contribute to discussions about the effectiveness of managerial interventions. 


\section{INTRODUCTION}

Medical professionals are naturally sceptical about management theories that are usually supported by a much weaker level of evidence than are evidence-based medicine Levels I-II. Research on organizational design and before and after study designs frequently lacks quantitative measures and has limited scientific evidence [1]. Approaching management problems similarly to prospective clinical trials could narrow the potential gap between physicians and managers in solving managerial issues and consequently enhance managerial outcome performance.

The central management challenge of the radiotherapy institute MAASTRO Clinic reported in this study is the combination of lean patient care processes, growth, innovation and clinical research activities (which are, by definition, highly variable). This is not a unique challenge; instead, it is a manifestation of organizational ambidexterity. Ambidexterity refers to an organization's ability to simultaneously engage in sufficient exploitation (i.e. efficiently manage current operations) to ensure its current viability and, simultaneously, to devote enough energy to exploration (e.g. of new technologies, treatments, markets, organizational resources) to ensure its future viability [2].

More specifically, exploitation is not only about efficiency but also about productivity, control, certainty and variance reduction. Exploration concerns research, discovery, autonomy, innovation and embracing variation [2]. Exploitation and exploration have often been seen as a trade-off [2-4]. March [5] stated in his pioneering article that the two are fundamentally incompatible. Organizations pursuing both strategies simultaneously will become stuck in the middle. Since the publication of this paper, more and more papers have been published about ambidextrous organizations strategies. These studies suggest that under certain well-specified circumstances, related to leadership and organizational design, it may be possible for organizations to simultaneously excel in both exploration (e.g. research) and exploitation (e.g. innovation implementation and daily operation) [6]. However, no quantitative research has yet verified this statement. This study aims to test our hypothesis that a reorganization trajectory that deals with the above-mentioned management challenge and is set up similarly to a prospective clinical trial will improve both patient care processes and the output of clinical research activities.

\section{METHODS AND MATERIALS \\ Design}

We started the reorganization trajectory with a multidisciplinary working group that consisted of radiation oncologists, medical physicists, radiation technologists, administrators and representatives of the employee council, supervised by a consultant 
(professor in organizational design). It was based on a protocol defining an a prioritestable hypothesis with specific, measurable, attainable, realistic, time-bound indicators. The approach of this reorganization trajectory was based on the model of a prospective trial. The multidisciplinary working group applied the following steps: (1) listing problems and analysing their potential causes, (2) defining interventions and (3) defining end points to measure the effect of the interventions, both at baseline and at 1 and 2 years after the start of the trajectory.

The interventions (changes in the organization) were approved by the management board, the medical and physics staff, the employee council, the patient council and the board of supervisors.

We did not change anything in the functional tasks of the radiation technologists; in our department, all radiation technologists are versatile, meaning that they perform scans (positron emission tomography and $\mathrm{CT}$ ) and make treatment plans, and work at the linear accelerator (linac). To limit the number of skills required for their roles, radiation technologists are specialized in two to four disease entities.

\section{Measures}

The multidisciplinary working group devised several end points to measure the effect of the reorganization trajectory at baseline, and at 1 and 2 years after the start of the trajectory (see the Results section). These end points were related to either patient care or clinical research and were measured in the following ways.

The main patient care end point was the number of organizational root causes of incidents/near incidents. We used the existing incident reporting system to quantify root causes. In this system, all incidents are measured and classified according to their root cause [7-10] (for the potential types of root causes in this system, see Supplementary material). A near incident is an unforeseen event in the process that did not reach the patient. If this disturbance actually reaches the patient, it is called an incident.

The secondary patient care end points were measured in different ways. Successfully accomplished and approved policy projects were measured as a percentage of all approved projects in the policy plan. Job satisfaction was measured using an internationally validated questionnaire, the Index of Work Satisfaction [11, 12]. Labour productivity was measured as reimbursement per full-time equivalent (FTE). In the Netherlands, the reimbursement per treatment depends on the labour intensity of the treatment and reflects the weighted number of treatments. Teamwork was measured across and within units according to the Hospital Survey on Patient Safety Culture 
conducted by the Agency for Healthcare Research and Quality $[13,14]$. Variations in patient waiting times between work units were measured using our logistics database: waiting time was defined as the time between registration and the first fraction of radiotherapy.

We also decided to measure some other patient care parameters because these could be unintentionally influenced by the reorganization. Patient satisfaction was measured by our own green/yellow/red card system in which patients give us a compliment or a moderate or strong complaint. Furthermore, waiting time was measured using our logistics database and compared with the standards of the Dutch Society for Radiation and Oncology ( $80 \%$ of patients must start their treatment within 21 days after referral and $100 \%$ within 28 days).

The main clinical research end point was the number of patients in trials. This was measured by the ratio between the total number of patients seen in a year and the proportion of those patients in trials (not including patients in biobank studies).

Finally, we performed a qualitative evaluation at 1 and 2 years after the start of the trajectory. In each functional group, a meeting was organized to ask professionals how they felt about the reorganization trajectory.

\section{Statistical analysis}

In 2010, 3961 treatments were carried out in 3019 patients. In the Netherlands, radiation treatment of every single target volume is counted as one treatment, so a new patient can have more treatments. In the process of delivering these treatments, we identified 2184 organizational root causes of incidents/near incidents (i.e. this is $55 \%$ when we normalize this figure to the number of treatments; see the Discussion section for further consideration). Assuming that these figures would be representative for the baseline values for the primary end point of patient care, we hypothesized that a $20 \%$ reduction should be obtained (i.e. from $55 \%$ to $44 \%$ ). Assuming at least 4000 treatments are delivered per year and given a level of 0.05 , the power of the analysis to detect a difference of $20 \%$ is $>0.99$. For the primary end point of clinical research, we assumed a baseline value of $5 \%$ of patients included in clinical trials (excluding patients participating in the biobank) over a total of 3000 patients, which allowed us to detect an increase of $34 \%$ (i.e. to $6.7 \%$ ) with a power of 0.80 and an $\alpha$ of 0.05 .

We used various methods to measure different variables. We used $X^{2}$ tests to analyse the number of organizational root causes of incidents/near incidents, the number of patients in trials, teamwork within units, teamwork across units, the number of completed projects and patient satisfaction. We used an analysis of variance to analyse 
technologists' average job satisfaction and used a post hoc Bonferroni correction to measure changes in average job satisfaction over the years. A Mann-Whitney $U$ test was used to analyse differences in waiting times between units and a z-test for proportions for the changes in the percentages of patients reaching the waiting standards. In all cases, we assumed a significance level of 0.05 .

\section{RESULTS}

\section{Listing problems and root causes}

The following problems related to patient care were listed by the multidisciplinary working group that consisted of radiation oncologists, medical physicists, radiation technologists, administrators and representatives of the employee council (Figure 1, first row):

- too many organizational root causes of incidents/near incidents in our patient processes, resulting in disturbances requiring improvisation and rework

- many incomplete care innovation projects $(<50 \%)$

- job satisfaction of radiation technologists was too low (4 on a scale of $0-7$ )

- differences in work pressure from one working unit to other units

- problems related to the combination of patient care and research, mainly resulting in too few patients being included in trials (5.1\%).

The group discussed root causes and, to a large extent based on literature, assumed that there were five root causes of our problems (Figure 1, second row):

- co-ordination problems and process breakdown problems caused by our functional organizational structure being based on professional disciplines instead of on patient processes [15-18].

- distance between front-line employees and management $[2,6,18]$.

- disturbances of research on daily practice, and too little focus on the importance of research in the clinic $[3,19,20]$.

- lack of adjustment of management styles to activity, more specifically to daily operations, research and innovation adoption [20-23].

- an unequal workload between the three existing work units [each unit treated only a specific type of tumour site: Unit 1 (genitourological/gastroenterology tumours); Unit 2 (thoracic/ lymphoma/breast tumours); Unit 3 (head and neck/neurology/ children/sarcomas/breast tumours)]. 


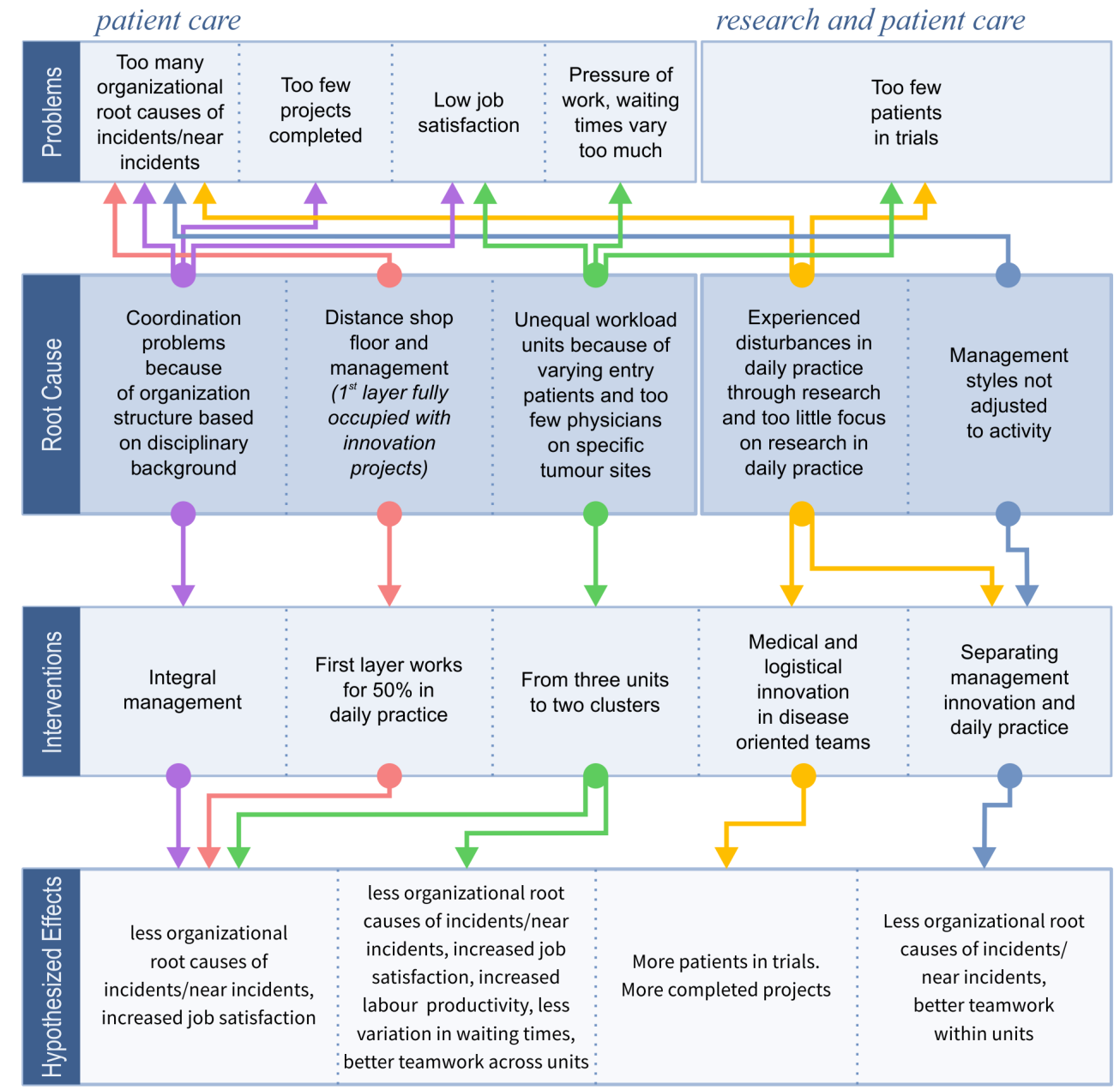

Figure 1. Overview of problems, root causes, interventions and hypothesized effects.

\section{Determining interventions and end points}

Under the consultant's supervision, the group devised several interventions (Figure 1, third row):

$>$ Moving from three independent work units to two clusters:

- patients with an oncological at disease above the diaphragm were treated in one cluster and patients with disease below the diaphragm were treated in the other cluster. Two patient groups (patients with palliative care and patients with breast cancer) were treated in both clusters to level the workload between them. This is possible because in the Netherlands, palliative care is not a specialization for radiation oncologists; since palliative patients comprise approximately $50 \%$ of all patients, all radiation oncologists frequently apply palliative radiotherapy. For 
breast cancer, dedicated radiation oncologists and technicians are present in both clusters.

$>$ Changes to management teams:

- Introduction of a multidisciplinary co-ordination team (i.e. including a radiation oncologist, radiation technologist and logistic administrative person) for each cluster; in the previous setting, each functional group had its own leader. The span of control (number of employees supervised) changed, as shown in Figure 2 ; in the old situation, each unit had a co-ordinator for radiation oncologists (supervising 7 radiation oncologists) and 1 for radiation technologists (supervising 20 technicians). For the administrative/supporting employees, 1 manager was assisted by a co-ordinating doctor's assistant $4 \mathrm{~h}$ a week and together they supervised 31 people. In the new situation, the span of control increased by $50 \%$ for the co-ordinators of the physicians and technologists and decreased by $50 \%$ for the supervisors of the administrative/ supporting staff.

- The co-ordinators were required to work in daily patient care for at least $50 \%$ of their working hours. Before the reorganization, this was already the case for the co-ordinators of the radiation oncologists but not for the co-ordinators of the technologists. They did not work in daily practice at all. For the administrative/ supporting staff, two co-ordinators were appointed, both of which were asked to work $50 \%$ in daily practice.

- Introduction of an integral management quartet supervising the co-ordination teams: one pair for daily patient care (i.e. a radiation oncologist and a logistics manager) and one pair for innovation (i.e. a medical physicist and a manager of innovation).

$>$ Apart from the 2 clusters, where daily operational practice was carried out, we introduced 11 multidisciplinary disease-oriented teams (e.g. the lung team, the head and neck team), each consisting of 13-23 employees. The major task for these teams was to maintain and improve treatment protocols, develop innovation and develop a yearly policy plan for a specific disease site. In this step of the reorganization trajectory, it was not considered feasible to give these teams daily operational responsibilities, since many professionals were members of more than one team. Therefore, our organizational design did not completely change from functional to process based (for the organization chart of daily operation, see Figure 2).

Finally, the group devised several end points (Figure 1, fourth row) to measure the effect of the reorganization trajectory. 


\section{Board of Directors}
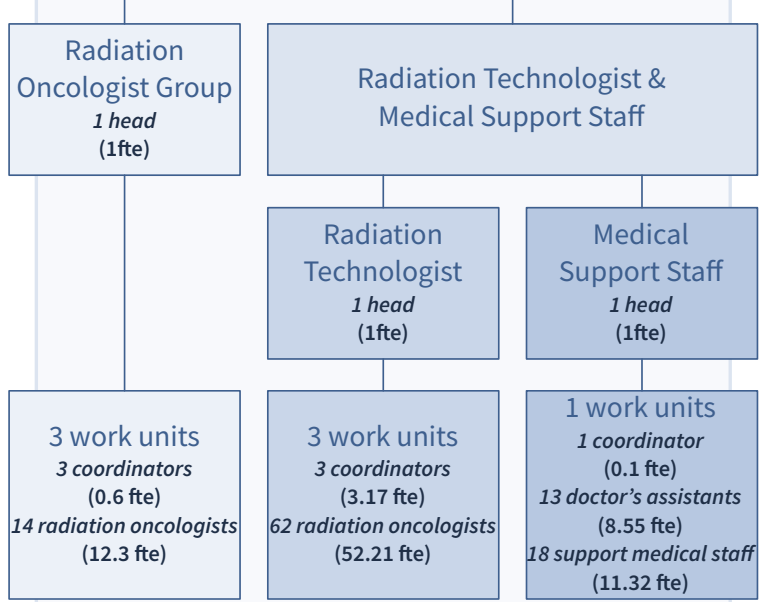

\section{Organization of Patient Treatment until 2010}

\section{Board of Directors}

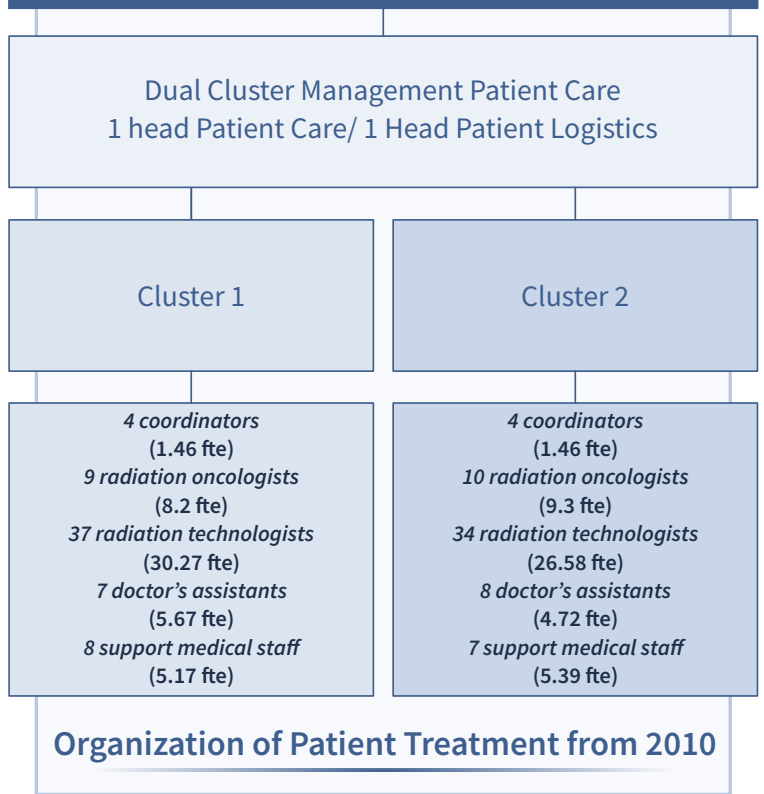

Figure 2. Transition of the organizational structure. FTE, full-time equivalent. 


\section{Results of the measures}

The primary end point for patient care, organizational root causes of disturbances in patient processes, improved by $27 \%$ in 2 years $(p=0.016)$ from a $55 \%$ occurrence in all treatments to $40 \%$ of all treatments. This was a $4 \%$ improvement over the target obtained in the sample size calculation. Two secondary end points, job satisfaction $(p=0.004)$ and teamwork across units $(p=0.001)$, improved as well.

Satisfaction of technologists improved from 5.7 to 6.4 , converted to a scale of $0-10$ $(p=0.001)$. The following components improved significantly: task requirements (from 5.3 to $6.2 ; p=0.032$ ), autonomy (from 5.4 to $6.0 ; p=0.035$ ), impact administration (from 3.8 to $4.7 ; \mathrm{P}=0.001$ ) and pay (from 4.3 to $5.7 ; \mathrm{p}=0.007$ ). Also, the difference in waiting time between clusters improved from 4.3 to 2.2 days $(p=0.022)$ (Table 1$)$.

Not all of the end points changed for the better. Reimbursement per FTE appeared to deteriorate. However, when we corrected this end point for FTEs devoted to training on new accelerators and new software (see the Discussion section), we found a slight increase in labour productivity.

One of the two parameters that we measured to study the possible unintentional influences of our reorganization changed. Patient waiting time worsened for both the 21-day standard and the 28-day standard $(p=0.001)$. Patient satisfaction showed no change.

The number of completed projects and teamwork within units were also unchanged. The primary end point for research, the number of patients in trials, also did not change significantly.

The qualitative evaluation demonstrated that the groups that were performing well or were strongly connected beforehand were less satisfied with the changes than the other groups.

\section{DISCUSSION}

This study shows that (a) a reorganization trajectory set up similarly to a prospective clinical trial is possible and (b) 2 years after the start of a hypothesis-driven reorganization trajectory, the main end point for clinical patient care (i.e. organizational root causes of incidents/near incidents) improved by $27 \%(p=0.016)$. The main end point for clinical research (i.e. the number of patients in trials) did not change significantly. Since several other changes occurred in the department during these 2 years, it is difficult to draw 
firm conclusions about the causal relationship between the reorganization trajectory and end points. For instance, two major processes that are likely to have influenced our end points are (1) in 2012, we set up a satellite department that required an increased speed (e.g. of digitalization) and (2) in 2011 and 2012, we replaced our six linacs and the treatment planning system. Nevertheless, we can conclude that despite these major confounding events, most of the end points, including one main end point, improved and only one end point worsened.

Primary end point: reduction of organizational root causes of incidents/near incidents

The number of organizational root causes of incidents/near incidents before the intervention seems quite high and could give the impression that this allows an obvious improvement with minimal effort. This needs to be clarified. Many incidents/near incidents is not, by definition, a representation of a poorly functioning organization. On the contrary, it often reflects the willingness of the clinic to report incidents/near incidents [24, 25]. In another study, we concluded that our clinic has a long history with safety improvement, which explains the high levels of willingness to report incidents/near incidents [26] (for the number of reports per radiotherapy centre in the Netherlands, see Figure 3).

Furthermore, the number of real incidents in this clinic was low (e.g. in $2012,98 \%$ of all incidents did not reach patients at all).We related the number of incidents/near incidents to the number of treatments as a normalization factor; this does not mean that $55 \%$ of the treatments had problems.

Before the reorganization trajectory, our institute had a functional organizational structure with different departments for radiation oncologists, technologists, physicists and supporting staff. Literature [15-18] has shown that this organizational structure results in a very complex system of flows and queues with many transfer points from one department to another that result in a long, slow and often inaccurate course. Defects in the transfer points result in an exponential increase of the effects and costs in the chain. In such a functionally organized structure, the organization is divided on the basis of the disciplinary background of the staff. Every discipline tries to optimize its own function instead of the whole patient process. As a result, processes frequently break down, resulting in coordination that becomes not only very important [17] but also complex $[16,17,27]$.

Based on these premises in the literature, we assumed that a less functional organizational design would result in fewer incidents/ near incidents with organizational root causes. In preceding years, several lean projects to improve compliance and quality in radiotherapy treatment were accomplished, but they all exclusively focussed on patient processes and 
not on organizational design. After an intervention on organizational design, further improvements were expected.

The reduction of organizational root causes of incidents/near incidents did occur, and we decided to investigate the causes. Some employees reported that the replacement of all the linacs and software meant that there were fewer technical-related organizational problems and concluded that the organizational intervention might not have caused the reduction of incidents/ near incidents with organizational root causes. We therefore looked specifically at incidents/near incidents, excluding linac issues. Here, we also found fewer reported events in proportion to the total number of treatments $(p=0.001)$ and interventions (Table 1).

Another explanation could be a decreased willingness to report incidents/near incidents. However, a further safety study at the MAASTRO clinic (Maastricht, Netherlands) found, based on a triangulation of methodologies (two surveys were distributed three times, workshops were performed twice, data from an incident reporting system was monitored and results were explored using structured interviews with professionals) that the decreased number of reported incidents/near incidents was not explained by decreased safety awareness or a decreased willingness to report, but by improved treatment processes [26].

Table 1. End points

\begin{tabular}{|c|c|c|c|c|c|c|c|}
\hline & $\begin{array}{l}\text { T0 } \\
\text { Baseline }\end{array}$ & $\begin{array}{l}\text { T1 } \\
\text { Year } 1\end{array}$ & $\begin{array}{l}\text { T2 } \\
\text { Year } 2\end{array}$ & $\begin{array}{l}\text { T0-T1 } \\
\text { p-value }\end{array}$ & $\begin{array}{l}\text { T0-T2 } \\
\text { p-value }\end{array}$ & $\begin{array}{l}\text { T1-T2 } \\
\text { p-value }\end{array}$ & $\begin{array}{l}\text { Chi-square } \\
\text { test }\end{array}$ \\
\hline \multicolumn{8}{|l|}{ Primary endpoints } \\
\hline $\begin{array}{l}\text { Number of reported } \\
\text { organisational root causes } \\
\text { of (near) incidents / } \\
\text { Total number of } \\
\text { treatments }\end{array}$ & $\begin{array}{l}2184 / 3961 \\
(55.1 \%)\end{array}$ & $\begin{array}{l}1803 / 3802 \\
(47.4 \%)\end{array}$ & $\begin{array}{l}1588 / 3939 \\
(40.3 \%)\end{array}$ & & & & $<0.001$ \\
\hline $\begin{array}{l}\text { Number of organisational } \\
\text { root causes of (near) } \\
\text { incidents without linac } \\
\text { reports/ } \\
\text { Total number of } \\
\text { treatments }\end{array}$ & $\begin{array}{l}1399 / 3961 \\
(35.3 \%)\end{array}$ & $\begin{array}{l}1110 / 3802 \\
(29.2 \%)\end{array}$ & $\begin{array}{l}1062 / 3939 \\
(27.0 \%)\end{array}$ & & & & $<0.001$ \\
\hline Number of patients in trial & $\begin{array}{l}153 / 3019 \\
(5.06 \%)\end{array}$ & $\begin{array}{l}158 / 3015 \\
(5.24 \%)\end{array}$ & $\begin{array}{l}175 / 3124 \\
(5.60 \%)\end{array}$ & & & & 0.634 \\
\hline
\end{tabular}




\begin{tabular}{|c|c|c|c|c|c|c|c|}
\hline & $\begin{array}{l}\text { T0 } \\
\text { Baseline }\end{array}$ & $\begin{array}{l}\text { T1 } \\
\text { Year } 1\end{array}$ & $\begin{array}{l}\text { T2 } \\
\text { Year } 2\end{array}$ & $\begin{array}{l}\text { T0-T1 } \\
\text { p-value }\end{array}$ & $\begin{array}{l}\text { T0-T2 } \\
\text { p-value }\end{array}$ & $\begin{array}{l}\text { T1-T2 } \\
\text { p-value }\end{array}$ & $\begin{array}{l}\text { Chi-square } \\
\text { test }\end{array}$ \\
\hline \multicolumn{8}{|l|}{ Secondary endpoints } \\
\hline \multicolumn{8}{|l|}{ Waiting time } \\
\hline $\begin{array}{l}\% \text { patients treated within } \\
21 \text { days }\end{array}$ & 81.8 & 79.3 & 62.6 & & $<0.001$ & $<0.001$ & \\
\hline $\begin{array}{l}\% \text { patients treated within } \\
28 \text { days }\end{array}$ & 93.7 & 92.9 & 84.3 & & $<0.001$ & $<0.001$ & \\
\hline $\begin{array}{l}\text { Median differences in } \\
\text { waiting time between units }\end{array}$ & 4.26 & 1.75 & 2.23 & $\leq 0.001$ & 0.022 & & \\
\hline $\begin{array}{l}\text { Teamwork across units } \\
\text { (percentage of scores } \\
\text { reported as positive) }\end{array}$ & 34 & & 51 & & & & $<0.001$ \\
\hline $\begin{array}{l}\text { Number of completed } \\
\text { projects (implementation } \\
\text { yes/no) }\end{array}$ & $\begin{array}{l}18 / 19 \\
(48.6 \%)\end{array}$ & $\begin{array}{l}23 / 20 \\
(53.5 \%)\end{array}$ & $\begin{array}{l}26 / 11 \\
(70.3 \%)\end{array}$ & & & & 0.140 \\
\hline $\begin{array}{l}\text { Average job satisfaction } \\
\text { technologists on a scale of } \\
0-7( \pm S D)\end{array}$ & $\begin{array}{l}4.04 \\
( \pm 0.63)\end{array}$ & $\begin{array}{l}4.16 \\
( \pm 0.56)\end{array}$ & $\begin{array}{l}4.42 \\
( \pm 0.59)\end{array}$ & & $<0.001$ & 0.004 & \\
\hline Number of technologists & 47 & 43 & 50 & & & & \\
\hline $\begin{array}{l}\text { Treatment reimbursement } \\
\text { in }(\mathrm{kEuro} / \mathrm{fte})\end{array}$ & 188 & 180 & 184 & & & & \\
\hline $\begin{array}{l}\text { After correcting for } \\
\text { training new equipment } \\
\text { and software } \\
\text { Patient satisfaction }\end{array}$ & & & 188.5 & & & & \\
\hline Number of complaints & $75 / 3019$ & $96 / 3015$ & $101 / 3124$ & & & & 0.006 \\
\hline Number of compliments & $135 / 3019$ & $107 / 3015$ & $165 / 3124$ & & & & \\
\hline No response & $2809 / 3019$ & $2812 / 3015$ & $2858 / 3124$ & & & & \\
\hline \multicolumn{8}{|l|}{ Excluding satellite (2012) } \\
\hline Number of complaints & & & $83 / 2782$ & & & & 0.204 \\
\hline Number of compliments & & & $113 / 2782$ & & & & \\
\hline No response & & & $2586 / 2782$ & & & & \\
\hline $\begin{array}{l}\text { Teamwork within units } \\
\text { (percentage of scores } \\
\text { reported as positive) }\end{array}$ & 70 & & 71 & & & & 0.930 \\
\hline
\end{tabular}




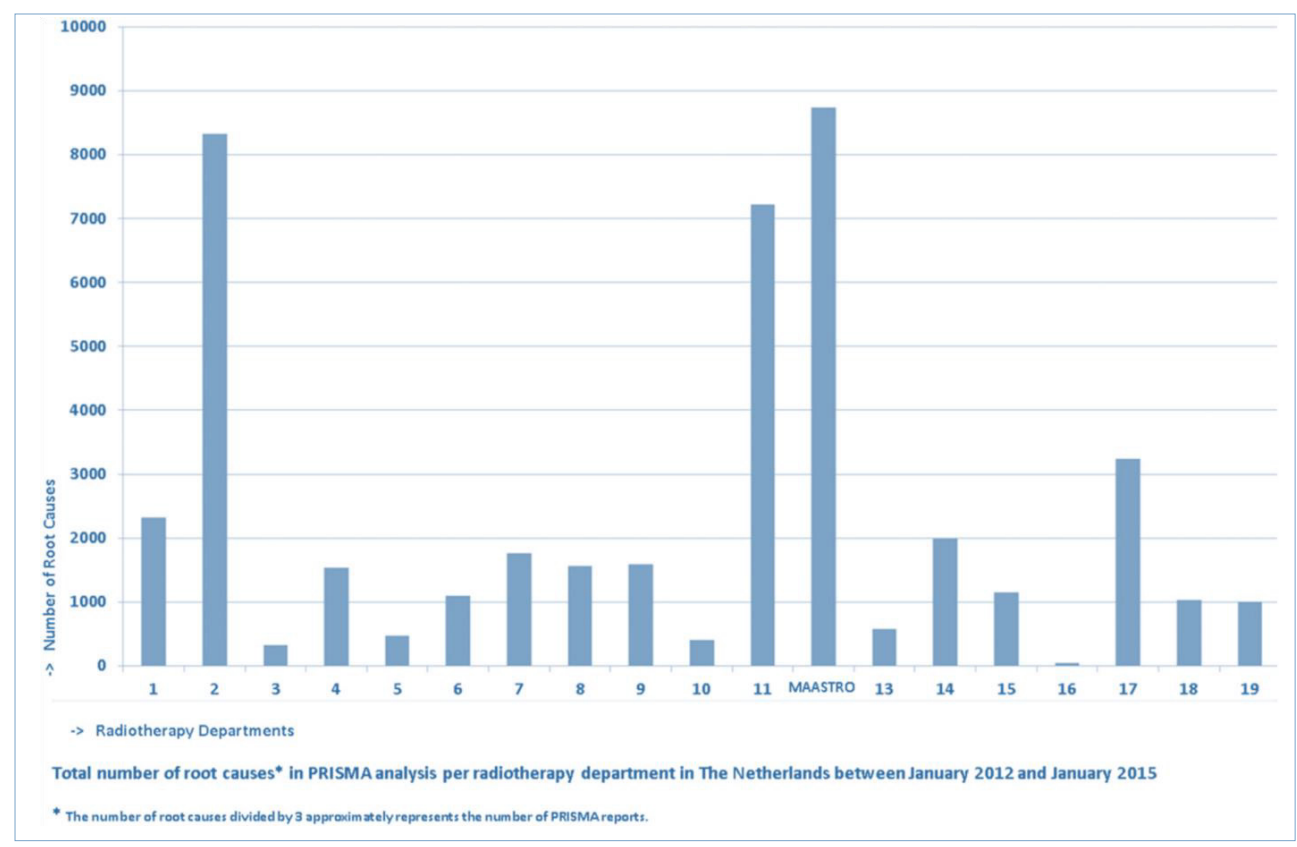

Figure 3. Number of safety system reports in the Netherlands. The horizontal axis shows the different types of incidents/near incidents; the vertical axis shows the number of reports.

\section{Primary end point: increase of patients in trials}

At the start of our reorganizational trajectory, we included $5 \%$ of our patients in clinical trials. This is much lower than participation rates reported in the UK [28], but 5\% is considered to be a reasonable score in a radiotherapy department in continental Europe or the USA $[28,29]$. The number of patients in trials did not increase after the start of our reorganizational trajectory.

Increasing participation rates for clinical therapeutic trials is a complex matter; participation rates depend on (a) key structural barriers (e.g. lack of physician's recommendation to participate or limited availability of active protocols), (b) personalrelated barriers (e.g. lack of knowledge, fear of receiving the placebo) and (c) emotional barriers on the part of patients [30]. The trial design can be another barrier [31]. We did not completely fulfill the conditions necessary to accomplish an ambidextrous strategy as described in literature. A lot more work beyond just organizational design is required to build on this study [5, 32-34]. Therefore, it is not surprising that changes to only the organizational design had negligible effects with respect to this end point. 


\section{Management interventions}

Our organization is carrying out research, as is clear from the number of publications and the Crown indicator (a well-known bibliometric indicator of research performance calculated from the number of citations compared with the expectation value for the scientific field: a value $>1.2$ indicates a high scientific impact; Figures 4 and 5 ).

From the literature, we know that research as an innovation generating process is facilitated in different organizational conditions (e.g. culture, the degree of control) as innovation implementation [19] and daily operations [3, 4, 35]. The different processes also have consequences for the leadership task [20-23]. Research is closely linked to exploration and, sometimes also, requires thinking outside the box and going beyond routines or common assumptions and experimentation. Innovation implementation and daily operations are closely linked to exploitation. They also need the above-mentioned research-related activities to some extent but are characterized more by efficiency, goal

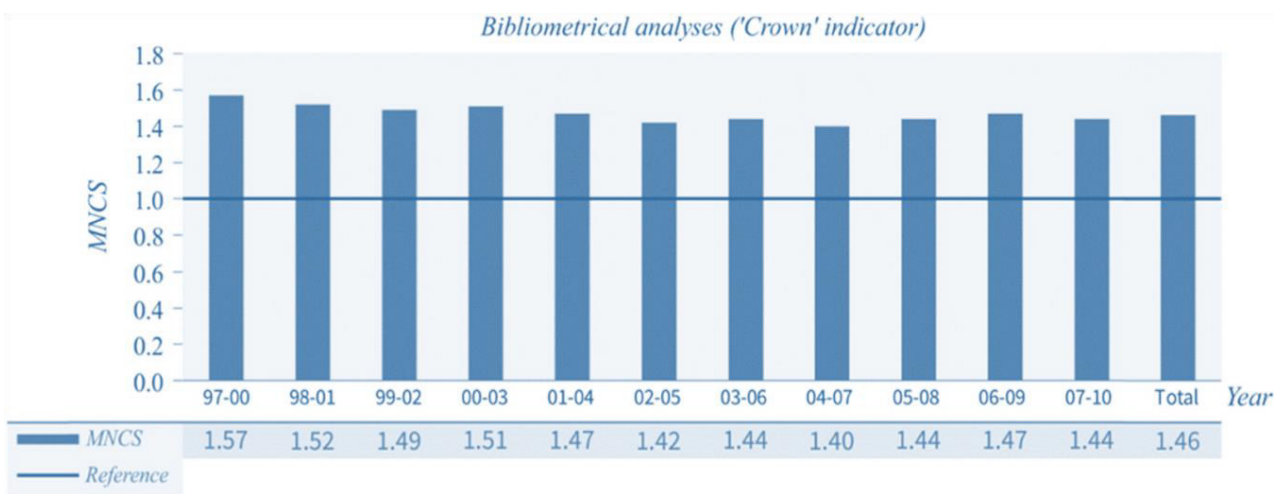

Figure 4. "Crown" indicator. MNCS, mean normalized citation score.

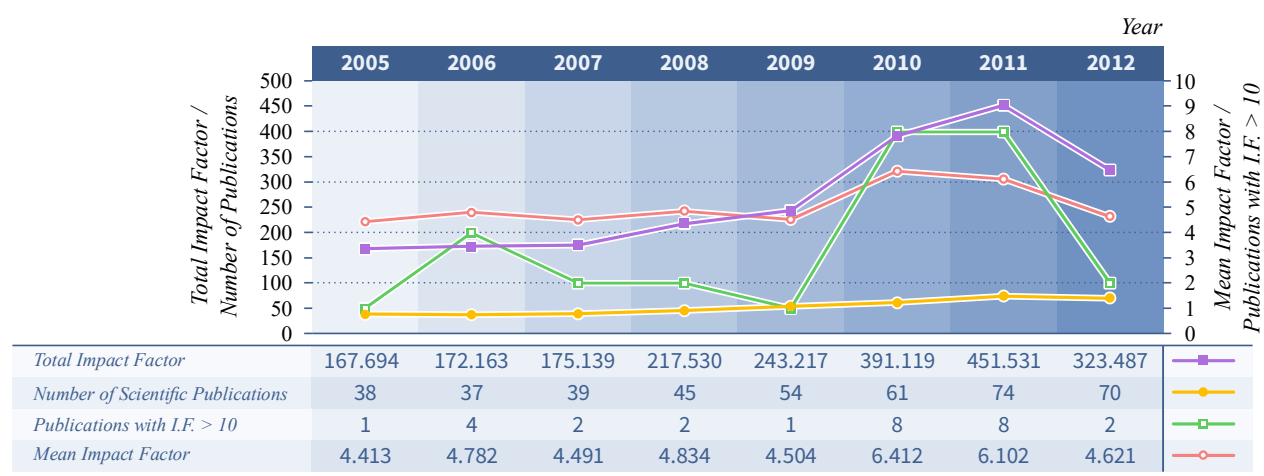

Figure 5. Publication and impact factors. I.F., impact factor. 
orientation and routine execution. These activities are not completely unnecessary for research but undoubtedly play second fiddle [33]. When exploration is needed, leaders need to behave in a way that encourages doing things differently and experimenting, making room for independent thinking, and acting and supporting attempts to challenge established approaches. Exploitation requires leaders to take corrective actions, set specific guidelines, establish routines, and monitor goal achievement and plans. Doing all these activities requires leaders to balance exploration and exploitation, to integrate them when needed and to flexibly switch between them as the situation requires [33].

Based on the findings above, we assumed that some of the listed problems were caused by the fact that MAASTRO supervisors usually used just one style (some mainly explorative, others mainly exploitative) regardless of whether they were involved in research, daily operations or innovation implementation. On this basis, we hypothesized that the organizational changes to management, especially distinguishing between innovation and daily operation, would also contribute to fewer incidents/near incidents with organizational root causes and the improvement of some other end points.

This was also expected from the other changes in the management structure. Less hierarchical levels and integral management were expected to benefit work outcome, and this was indeed the case as we looked to root causes of organizational incidents/ near incidents categorized as management decisions. This is described in our report system as errors in patient processes as a result of managerial decisions. These decisions are often taken by management when employees experience conflicting demands and need management to tell them what to do or when time pressure requires management to prioritize activities. Organizational root causes of incidents/near incidents referring to organizational management decisions decreased by $42 \%(p=0.002)$. We think this is another indicator for the success of our intervention.

Although we discussed whether it was good or bad to increase the span of control, and the literature often states that a "feasible span of control" is needed [36], our increased span of control did not hamper the decrease of incidents/near incidents. Nevertheless, there may be room for further improvement on this issue in the next step of our reorganizational trajectory.

We also expected that job satisfaction would increase because employees would experience more attention and less distance. This was only the case for technologists, who had the lowest levels of satisfaction before the intervention. Increasing job satisfaction more radically obviously requires more interventions, as we will describe in the section from three units to two work units. 


\section{Introduction of disease-oriented teams}

Implementing multidisciplinary teams dedicated to a specific patient group had the intended purpose of mobilizing mental power to innovate on the treatment itself and on logistics. We hypothesized that this intervention would improve both primary end points. We also expected to see beneficial effects on completed projects and teamwork within units.

The reduction of organizational root causes of incidents/near incidents occurred, which can only partly be ascribed to better multidisciplinary teamwork. This relationship, however, is in line with prior findings about the strength of lateral relationships (not only following the hierarchical way).

These lateral relationships make it possible to increase the capacity to process information, which is needed to fulfil all patient treatment tasks for all employees involved in a certain treatment $[27,37,38]$.

We did not see an increase in the percentage of completed projects, which can be ascribed to a lack of supervision. We discovered in the qualitative evaluation that for a team to function well, it was more important for the chair to have leadership skills than to be a radiation oncologist. In the management team, we are now creating conditions to improve selfmanagement of the teams with a balance between central control and local autonomy [18].

Teamwork within units did not improve either. The qualitative evaluation showed that people saw the teams in daily operation as their unit and not the disease-oriented team, which in fact is only a meeting setting where people reflect together on improvements in daily operations.

\section{From three to two work units}

The decision to move from three to two work units aimed to improve productivity because dividing the workload became easier. There was less variation in waiting times between units, which is an indicator that work pressure is more equal in the new situation $(p \leq 0.022)$. This is unlikely to have been affected by the new satellite or the new machinery. As a result, we also expected to see improvements on job satisfaction and teamwork across units. Labour productivity did not increase as measured by the treatment reimbursement/FTE, but we think this end point was heavily affected by the introduction of the new machinery. For example, the technologists were required to attend 1500 4-h training shifts on top of normal production. Correcting for this number of FTEs, we found an increase in labour productivity to $€ 188.5$ thousand per FTE, which is $€ 500$ per FTE above the 2010 level. 
The change from three to two working units implied that the radiation technologists had to broaden their skills, since a greater variety of tumours was treated in the new cluster than in the old work units. In the qualitative evaluation, discussions began about whether specialization [39] or generalization was the best course. The Dutch Society for Radiation and Oncology has made a clear statement that it is necessary for radiation oncologists to specialize in two to four diseases, whereas we were heading in the opposite direction for the technologists. The radiation oncologists were especially worried that this would lead to poorer quality, since they assumed a relationship between quality and volume [40], although no research has been carried out on this relationship in radiotherapy [41].

Another disadvantage of the large clusters was that the work became more anonymous. An individual did not always know who was working in the same patient process in the preceding or following steps. In the qualitative evaluation, this was most often mentioned by teams who were close and/or performing well before the reorganization. Despite the fact that teamwork within units did not worsen in the quantitative evaluation, this is a point of particular interest.

The construction of teams with specific characteristics is essential for employee involvement [18], which is an important determinant of job quality and job satisfaction [42]. These characteristics are complete area of responsibility with as little division of labour as possible, sufficient regulatory authority, insight and information, and accountability with efficient feedback mechanisms [18]. The reorganization did not result in teamwork with the above characteristics, especially because the task design was not based on a complete series of interrelated activities.

Therefore, it is not surprising that job satisfaction only slightly improved for radiation technologists and not at all for other employees.

On the basis of the above insights, we recently decided to take the next step in our journey from a functionally based organizational design towards a process-based one. We will establish more process-based teams in daily operation with more specialization as well as the above-described team characteristics.

End points that could unintentionally be influenced by the reorganization

\section{Waiting time}

In the Netherlands, a standard set by the Dutch Society for Radiation and Oncology states that $80 \%$ of all patients must have their first treatment within 21 days after referral and $100 \%$ within 28 days. The standard is not differentiated by disease. In 2010 , we achieved 
the 21-day standard with a value of $81.8 \%$. From 2010 to 2011, no significant change took place (the percentage was $79.3 \%$ in 2011). In 2012, the year in which MAASTRO opened the satellite and replaced five linacs, the percentage significantly reduced to $62.6 \%$ ( $p=0.001$ ). In 2010, we failed to meet the 28 -day standard (only $93.7 \%$ of patients had their first treatment within 28 days). In 2011, this percentage dropped to $92.2 \%$, which is not a significant change. In 2012, the percentage significantly reduced to $84.3 \%(p=0.001)$. Because there was less linac capacity available during the replacement and there was also less staff available (employees received $6000 \mathrm{~h}$ of training and also had to settle in to the new satellite), there is probably a relationship between the increased waiting time and the confounding events. We found no connection with the reorganization.

\section{Patient satisfaction}

We observed no influence of the reorganization. Patient satisfaction, excluding the satellite, did not change significantly (including the satellite, there was a perceptible improvement).

\section{The ambidextrous challenge of our study}

The ambidextrous challenge to simultaneously improve lean efficient patient care processes, growth and innovative (per definition, highly variable) clinical research activities with our reorganization trajectory was not completely successful within the 2 years after the reorganization.

Also, in the literature, it is stated that organizational design and structure alone are not enough to reach sustainable change and performance improvement in complex situations $[4,18]$. It may have been possible to improve both end points simultaneously if we had paid more managerial attention to the barriers for clinical trial participation and had also more closely followed the actions suggested in literature on ambidexterity. However, we think, in that case, the changing of the organization would have been more far reaching. We believe that combined with the two other major interfering processes (replacement of the linacs and the start of the satellite), this would have been a to-drastic change with accompanying risks. In future research, we will study the effect of additional actions in order to improve both end points.

We think that other radiotherapy centres (academic and otherwise) that want to improve patient care processes and research participation must decide if they want to do it simultaneously or successively. Our study showed that doing it simultaneously requires a plan that goes beyond organizational design.

\section{The set-up of the reorganization}

To the best of our knowledge, reorganizations set up similarly to a prospective clinical trial are scarce in general and have not been previously attempted in radiotherapy. Although 
there are limitations, this design gives employees more transparency about problems, root causes interventions and effects. This approach is also well accepted by medical professionals, as it became clear from the qualitative evaluation sessions. The set-up fits our company strategy to make data driven decisions. This approach is standard in the field of research [43], but this is the first attempt to do the same in the field of management. Future important managerial interventions will be taken in a similar way, according to the flowchart in Figure 6. The approach in this flowchart is "transplantable" to all other radiotherapy centres or even clinical departments, regardless of whether they are academic, peripheral or categorical.

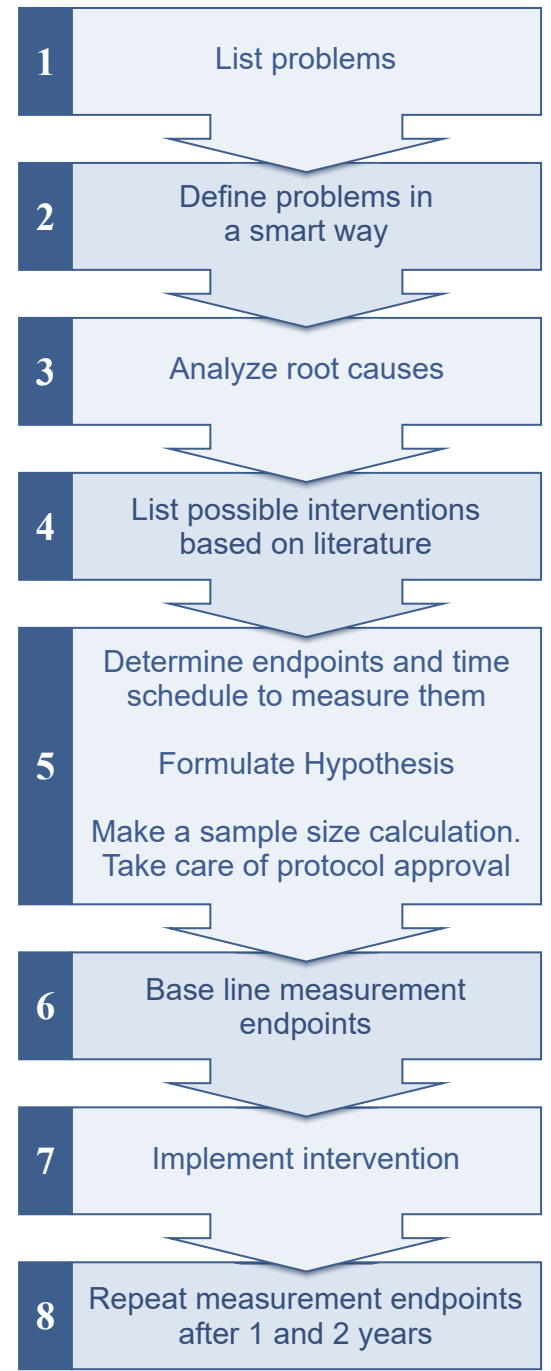

Figure 6. The set-up of managerial interventions. 


\section{Limitations}

First, as described, we identified two major confounding events that occurred over 1 year. These events certainly affected the formulated end points.

Second, we cannot be completely sure that the end points were purely determined by our organizational design interventions. The study's setting did not allow for a control group. So, for example, it is not unthinkable that job satisfaction increased because employees felt more comfortable with their new supervisors.

Third, we know from the literature [16] that organizational development requires an integrated approach to structure, culture, systems, strategy and leadership. This study was confined to only structure. In 2012, we started this integrated approach, paying much more attention to culture. Further research is necessary to study the interaction between all these parameters and end points.

Finally, the findings reported here are confined to one radiotherapy centre, which may affect the generalization of the results.

\section{CONCLUSIONS}

We initiated a hypothesis-driven reorganization trajectory of our department based on the model of prospective clinical trial. If we make a strict "intent to treat" analysis based on the main end points, this study is positive for patient care and neutral for research. The interfering events make it more difficult to establish a causal relationship between the intervention and the end points. We concluded that starting up a reorganization trajectory in a department based on the model of prospective clinical trials is a transparent approach, which is important for giving medical professionals confidence in carrying out changes in their daily practice. A systematic data driven approach as performed in this study gives the best possible insights into the relationship between managerial interventions, expectable results and confounding events. Although the relevance of the reorganization process itself depends on the context and the country, the approach that mimics the methodology of a prospective clinical trial is transplantable to all clinical departments.

We decided to move forwards with other organizational changes based on the same model. In future research, we will take further steps in our organizational development trajectory in order to change from a function-based to a more process-based organization, and to successfully use an ambidextrous strategy for daily practice, research and innovation implementation. 


\section{ACKNOWLEDGMENTS}

We would like to thank Simone Pittie for the secretarial work, Denis Eyssen for the reports on the safety system and Misjaël Lebbink for editing the figures. 


\section{REFERENCES}

1. Vos L, Chalmers SE, D"uckers ML, Groenewegen PP, Wagner C, van Merode GG. Towards an organisation-wide processoriented organisation of care: a literature review. Implement Sci 2011; 6: 8. doi: 10.1186/1748-5908-6-8

2. Ebben JJ, Johnson AC. Efficiency, flexibility, or both? Evidence linking strategy to performance in small firms. Strateg Manag J 2005; 26: 1249-59.

3. Gupta AK, Smith KG, Shalley CE. The interplay between exploration and exploitation. Acad Manag J 2006; 49: 693-706.

4. O'Reilly CA III, Tushman ML. Ambidexterity as a dynamic capability: resolving the innovator's dilemma. Res Organ Behav 2008; 28: 185-206.

5. March JG. Exploration and exploitation in organizational learning. Organ Sci 1991; 2: 71-87.

6. Benner MJ, Tushman ML. Exploitation, exploration, and process management: the productivity dilemma revisited. Acad Manag Rev 2003; 28: 238-56.

7. Battles JB, Kaplan HS, Van der Schaaf TW, Shea CE. The attributes of medical eventreporting systems: experience with a prototype medical event-reporting system for transfusion medicine. Arch Pathol Lab Med 1998; 122: 231-8.

8. van der Schaaf TW, Lucas DA, Hale AR, eds. Near miss reporting as a safety tool. Oxford, UK: Butterworth-Heinemann; 1991. pp. 1-5.

9. van Vuuren W, Shea CE, van der Schaaf TW. The development of an incident analysis tool for the medical field. Eindhoven, Netherlands: Eindhoven University of Technology; 1997.

10. Kaplan HS, Battles JB, Schaaf TW, Shea CE, Mercer SQ. Identification and classification of the causes of events in transfusion medicine. Transfusion 1998; 38: 1071-81.

11. Stamps PL, Piedmont EB, Slavitt DB, Haase AM. Measurement of work satisfaction among health professionals. Med Care 1978; 16: 337-52.

12. Stamps PL, Piedmonte EB. Nurses and work satisfaction: an index for measurement. Ann Arbor, Ml: Health Administration Press; 1986.

13. Smits M, Christiaans-Dingelhoff I, Wagner C, Wal Gv, Groenewegen PP. The psychometric properties of the "Hospital Survey on Patient Safety Culture" in Dutch hospitals. BMC Health Serv Res 2008; 8: 230. doi: 10.1186/1472-6963-8-230

14. Sorra JS, Dyer N. Multilevel psychometric properties of the AHRQ hospital survey on patient safety culture. BMC Health Serv Res 2010; 10: 199. doi: 10.1186/1472-6963-10-199

15. van Merode F, Molema H, Goldschmidt H. GUM and six sigma approaches positioned as deterministic tools in quality target engineering. Accred Qual Assur 2004; 10: 32-6.

16. Probst G, Raisch S, Tushman ML. Ambidextrous leadership: emerging challenges for business and HR leaders. Organ Dyn 2011; 40: 326-34.

17. De Sitter LU. Synergetic production [in Dutch]. Van Gorcum: Assen, Netherlands; 1998.

18. Van Amelsvoort P. The design of work and organisation. ST-Groep: Vlijmen, Netherlands; 2000. 
19. Damanpour F, Daniel Wischnevsky J. Research on innovation in organizations: distinguishing innovation-generating from innovation-adopting organizations. J Eng Technol Manag 2006; 23: 269-91.

20. Fagerberg J. Innovation: a guide to the literature. In: Fagerberg J, Mowery D, Nelson R, eds. The Oxford handbook of innovation. Oxford, UK: Oxford University Press; 2004. pp. 1-26.

21. Rogers EM. Diffusion of innovations. Simon and Schuster; 2010.

22. Duncan RB. The ambidextrous organization: designing dual structures for innovation. In: KilmannRH, Pondy LR, Slevin D, eds. The management organization, vol. 1. New York, NY: North-Holland; 1976. pp. 167-88.

23. Agha L. The effects of health information technology on the costs and quality of medical care. J Health Econ 2014; 34: 19-30. doi: 10.1016/j.jhealeco.2013.12.005

24. Leape LL. Reporting of adverse events. N Engl J Med 2002; 347: 1633-8.

25. Simons PA, Houben R, Benders J, Pijls- Johannesma M, Vandijck D, Marneffe W, et al. Does compliance to patient safety tasks improve and sustain when radiotherapy treatment processes are standardized? Eur J Oncol Nurs 2014; 18: 459-65. doi: 10.1016/j.ejon.2014.05.003

26. Simons PA, Houben R, Vlayen A, Hellings J, Pijls-Johannesma M, Marneffe W, et al. Does lean management improve patient safety culture? An extensive evaluation of safety culture in a radiotherapy institute. Eur J Oncol Nurs 2014; 19: 29-37. doi: 10.1016/j.ejon.2014.08.001

27. Mintzberg H. Structure in fives: designing effective organizations. Prentice-Hall, Inc.: Upper Saddle River, NJ; 1983.

28. Sinha G. United Kingdom becomes the cancer clinical trials recruitment capital of the world. J Natl Cancer Inst 2007; 99: 420-2.

29. Mathews C, Restivo A, Raker C, Weitzen S, Disilvestro P. Willingness of gynecologic cancer patients to participate in clinical trials. Gynecol Oncol 2009; 112: 161-5. doi: 10.1016/j. ygyno.2008.09.003

30. Quinn GP, Koskan A, Wells KJ, Gonzalez LE, Meade CD, Pozo CL, et al. Cancer patients' fears related to clinical trial participation: a qualitative study. J Cancer Educ 2012; 27: 257-62. doi: 10.1007/s13187-012-0310-y

31. Jenkins V, Farewell V, Farewell D, Darmanin J, Wagstaff J, Langridge C, et al. Drivers and barriers to patient participation in RCTs. Br J Cancer 2013; 108: 1402-7. doi: 10.1038/bjc.2013.113

32. Adler PS, Goldoftas B, Levine DI. Flexibility versus efficiency? A case study of model changeovers in the Toyota production system. Organ Sci 1999; 10: 43-68.

33. Rosing K, Frese M, Bausch A. Explaining the heterogeneity of the leadership-innovation relationship: ambidextrous leadership. Leadersh Q 2011; 22: 956-74.

34. Durisin B, Todorova G. A study of the performativity of the "ambidextrous organizations" theory: neither lost in nor lost before translation. J Prod InnovManag 2012; 29: 53-75.

35. Schrey“ogg G, Sydow J. Crossroads-organizing for fluidity? Dilemmas of new organizational forms. Organ Sci 2010; 21: 1251-62.

36. Lega $F$, DePietro C. Converging patterns in hospital organization: beyond the professional bureaucracy. Health Policy 2005; 74: 261-81. 
37. McKee M, Chow CK. Improving health outcomes: innovation, coverage, quality and adherence. Isr J Health Policy Res 2012; 1: 43. doi: 10.1186/2045-4015-1-43

38. Apekey TA, McSorley G, Tilling M, Siriwardena AN. Room for improvement? Leadership, innovation culture and uptake of quality improvement methods in general practice. J Eval Clin Pract 2011; 17: 311-18. doi: 10.1111/j.1365-2753.2010.01447.x

39. Hecker A. Specialization, implicit coordination and organizational performance: trading off common and idiosyncratic knowledge. Rev Manag Sci 2011; 5: 19-47.

40. Hodgson DC, Zhang W, Zaslavsky AM, Fuchs CS, Wright WE, Ayanian JZ. Relation of hospital volume to colostomy rates and survival for patients with rectal cancer. I Natl Cancer Inst 2003; 95: 708-16.

41. Rozema T, Bolt RJ, D ET. Evidence based standards for radiotherapy in the Netherlands. Dutch Society for Radiotherapy and Oncology 2014. Available from: http://www.nvro.nl/ publicaties/rapporten

42. Karasek RA. Job demands, job decision latitude, and mental strain: implications for job redesign. Adm Sci Q 1979; 24: 285-308.

43. Lambin P, Roelofs E, Reymen B, Velazquez ER, Buijsen J, Zegers CM, et al. "Rapid learning health care in oncology"-an approach towards decision support systems enabling customised radiotherapy. Radiother Oncol 2013; 109: 159-64. doi: 10.1016/j.radonc.2013.07.007 


\section{Supplement 1: Potential root causes: medical version (MERS TM, 2001; van Vuuren et al, 1997)}

\begin{tabular}{|c|c|c|c|}
\hline & Code & Category & Definition \\
\hline \multirow[t]{4}{*}{ Technical } & T-EX & External & $\begin{array}{l}\text { Technical failures beyond the control and } \\
\text { responsibility of the investigating organisation }\end{array}$ \\
\hline & TD & Design & $\begin{array}{l}\text { Failures due to poor design of equipment, } \\
\text { software, labels or forms }\end{array}$ \\
\hline & TC & Construction & $\begin{array}{l}\text { Correct design which was not constructed } \\
\text { properly or was set up in inaccessible areas }\end{array}$ \\
\hline & TM & Materials & $\begin{array}{l}\text { Material defects not classified under TD or } \\
\text { TC }\end{array}$ \\
\hline \multirow[t]{5}{*}{ Organisational } & O-EX & External & $\begin{array}{l}\text { Failures at an organisational level beyond the } \\
\text { control and responsibility of the investigating } \\
\text { organisation, such as in another department } \\
\text { or area (address by collaborative systems) }\end{array}$ \\
\hline & OK & Transfer of knowledge & $\begin{array}{l}\text { Failures resulting from inadequate measures } \\
\text { taken to ensure that situational or domain- } \\
\text { specific knowledge or information is } \\
\text { transferred to all new or inexperienced staff }\end{array}$ \\
\hline & OP & Protocols & $\begin{array}{l}\text { Failures relating to the quality and availability } \\
\text { of the protocols within the department (too } \\
\text { complicated, inaccurate, unrealistic, absent or } \\
\text { poorly presented) }\end{array}$ \\
\hline & OM & Management priorities & $\begin{array}{l}\text { Internal management decisions in which } \\
\text { safety is relegated to an inferior position when } \\
\text { faced with conflicting demands or objectives. } \\
\text { This is a conflict between production needs } \\
\text { and safety. An example of this category is } \\
\text { decisions that are made about staffing levels. }\end{array}$ \\
\hline & OC & Culture & $\begin{array}{l}\text { Failures resulting from collective approach } \\
\text { and its attendant modes of behaviour to risks } \\
\text { in the investigating organisation }\end{array}$ \\
\hline
\end{tabular}




\begin{tabular}{|c|c|c|c|c|}
\hline & & Code & Category & Definition \\
\hline \multirow{7}{*}{\multicolumn{2}{|c|}{$\begin{array}{l}\text { Knowledge- } \\
\text { based } \\
\text { behaviour }\end{array}$}} & H-EX & External & $\begin{array}{l}\text { Human failures originating beyond the } \\
\text { control and responsibility of the investigating } \\
\text { organisation. This could apply to individuals } \\
\text { in another department. }\end{array}$ \\
\hline & & HKK & Knowledge-based behaviour & $\begin{array}{l}\text { The inability of an individual to apply their } \\
\text { existing knowledge to a novel situation. } \\
\text { Example: a trained blood bank technologist } \\
\text { who is unable to solve a complex antibody } \\
\text { identification problem. }\end{array}$ \\
\hline & & HRQ & Qualifications & $\begin{array}{l}\text { The incorrect fit between an individual's } \\
\text { training or education and a particular task. } \\
\text { Example: expecting a technician to solve } \\
\text { the same type of difficult problem as a } \\
\text { technologist. }\end{array}$ \\
\hline & & HRC & Coordination & $\begin{array}{l}\text { A lack of task coordination within a health } \\
\text { care team in an organisation. Example: an } \\
\text { essential task not being performed because } \\
\text { everyone thought that someone else had } \\
\text { completed the task. }\end{array}$ \\
\hline & & HRV & Verification & $\begin{array}{l}\text { The correct and complete assessment of a } \\
\text { situation including related conditions of } \\
\text { the patient and materials to be used before } \\
\text { starting the intervention. Example: failure to } \\
\text { correctly identify a patient by checking the } \\
\text { wristband. }\end{array}$ \\
\hline & & HRI & Intervention & $\begin{array}{l}\text { Failures that result from faulty task planning } \\
\text { and execution. Example: washing red cells } \\
\text { using the same protocol as for platelets. }\end{array}$ \\
\hline & & HRM & Monitoring & $\begin{array}{l}\text { Monitoring a process or patient status. } \\
\text { Example: a trained technologist operating an } \\
\text { automated instrument and not realising that a } \\
\text { pipette that dispenses reagents is clogged. }\end{array}$ \\
\hline & $\begin{array}{l}\text { Skill-based } \\
\text { behaviour }\end{array}$ & HSS & Slips & $\begin{array}{l}\text { Failures in performance of highly developed } \\
\text { skills. Example: a technologist adding drops } \\
\text { of reagents to a row of test tubes and then } \\
\text { missing the tube or a computer entry error. }\end{array}$ \\
\hline & & HST & Tripping & $\begin{array}{l}\text { Failures in whole body movements. These } \\
\text { errors are often referred to as "slipping, } \\
\text { tripping or falling". Examples: a blood bag } \\
\text { slipping out of one's hands and breaking or } \\
\text { tripping over a loose tile on the floor. }\end{array}$ \\
\hline \multirow{2}{*}{\multicolumn{2}{|c|}{ Other factors }} & PRF & Patient-related factor & $\begin{array}{l}\text { Failures related to patient characteristics or } \\
\text { conditions, which are beyond the control of } \\
\text { staff and influence treatment }\end{array}$ \\
\hline & & $\mathrm{X}$ & Unclassifiable & $\begin{array}{l}\text { Failures that cannot be classified in any other } \\
\text { category }\end{array}$ \\
\hline
\end{tabular}





\section{PART IV}

\section{Conclusions}





\section{CHAPTER 7}

\section{General discussion and conclusions}

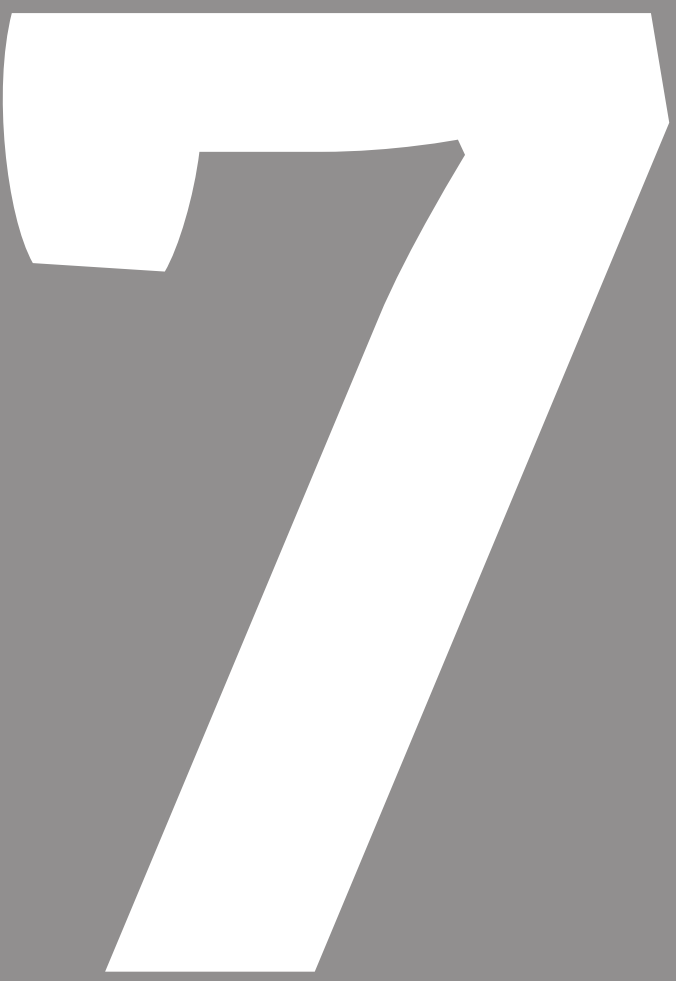



This thesis aims to contribute to scientific knowledge on innovation implementation in radiotherapy centres with as ultimate aim to find clues on how to improve and facilitate innovation implementation. Because radiotherapy is a technology driven medical discipline, innovation is considered an important prerequisite to improve care. After all, technological innovation has greatly improved medical treatment in the past years with excellent results for patients regarding survival and toxicity [1]. In view of these results, innovation is incorporated in the strategy of many radiotherapy centres. Despite the improved outcomes of radiotherapy treatment due to innovation, the substantial investment costs of new radiotherapy technology in terms of equipment, quality assurance and training are often also noted as being associated with the main causes for increasing health care costs [2]. However, within cancer care, radiotherapy is a very cost-effective discipline: in the Netherlands almost $50 \%$ of all cancer patients receive radiotherapy treatment, while this discipline only uses $5-6 \%$ of the national oncology budget [3]. From a societal perspective, however, it remains important for radiotherapy centres to develop and execute an efficient and effective innovation strategy. The discussion in the Netherlands about, for example, the introduction of proton therapy illustrates this.

Other types of innovation, such as organisational innovations, are frequently implemented, which also occurs in radiotherapy centres. Because organisational innovations can affect the clinical environment, it is important to evaluate innovations thoroughly before implementation.

The innovation strategies of radiotherapy centres should prevent inappropriate use of innovations, such as suboptimal innovation implementation and innovation diffusion, or failing to use available scientific findings. From literature, we know that this is a frequently mentioned problem in health care [4-7]. There are few studies in the field of radiotherapy regarding this theme, however.

The central research question of this thesis was therefore: "Is it possible in radiotherapy to find clues on how to innovate more effectively and more efficiently?" The following specific research questions were formulated to answer this central research question:

1. What is defined as innovation in radiotherapy and how can it be measured?

2. What is the degree of innovation routinely implemented at Dutch radiotherapy centres and what are the differences between centres? To the extent that differences exist, what causes them?

3. How efficient is translational research in radiation oncology; i.e. how big are the leaks in the research-innovation pipeline, what are the facilitators for, barriers to and actions needed for the successful implementation of research as innovations in clinical practice? 
4. Is the reported output of healthcare/radiotherapy innovation studies supported by high-level evidence, and to what extent are innovations implemented at Dutch radiotherapy centres based on scientific evidence?

5. Is it possible for an organisational innovation process to simultaneously improve patient care processes and clinical research activities, and is it possible to structure this in a manner similar to a prospective clinical trial?

\section{MAIN FINDINGS}

\section{Part one: setting the stage (research question 1)}

In order to gain a clear picture of what is meant by innovation in radiotherapy and how to measure it, an instrument was developed via a Delphi study with experts in the field of radiotherapy and with experts in the field of innovation science.

The instrument describes four types of innovation (product, technology, market and organisational) and is suitable to distinguish both the degree (radical or incremental) of innovation and type of innovation competences (generating or implementing innovation).

\section{Part two: innovations introduced to clinical practice or not and the value of innovation (research questions 2, 3 and 4)}

Subsequent investigation concerned how many innovations were implemented in clinical routine practice in Dutch radiotherapy centres from 2011-2013 and which differences exist between centres. The study showed that although radiotherapy centres innovate a lot (12 innovations per year on average), there are large differences between centres. Another finding was that there were no statistically significant differences between academic and non-academic centres, even weighted for the "size" of the innovation that is the perceived effort required by the centres or the perceived impact on output. Several centres were implementing the same innovations simultaneously. Almost all implemented innovations were incremental innovations. There were several radical innovations being prepared for introduction in clinical practice, especially in academic centres. The product innovation indicator 'patient in trials' was not registered in 6 out of 15 centres ( 3 academic), one centre had no patients in trials and 6 of 8 centres included fewer than $5 \%$ of their patients in trials. Five out of 15 centres had no registration on market performance outside the regular market area. In 10 out of 12 opened satellites, patients were treated who would also be referred to the original centre if there were no satellites. There appeared to be no relation between innovative work behaviour of physicians and physicists at a centre and the number of implemented innovations in that centre. In the discussion section of chapter 3 it was speculated on possible causes of the findings, for example the magnitude of factors influencing innovation implementation and the difference between innovation generating competences and innovation adoption competences. 
Investigating the implementation ratio of published research into innovations in clinical practice, it was found that $30 \%$ of technical or preclinical studies conducted by resident researchers were tested or implemented in their own clinic in a clinical environment, in either trials or routine treatment. In total, $19 \%$ of the included studies were implemented as an innovation in clinical practice. For clinical studies this percentage was higher (38\%). Facilitators and barriers and possible interventions were inventoried. The most frequently mentioned barriers were workload, the divide between researchers and clinicians, the complexity of the intervention and observability of the scientific findings. The most frequently mentioned facilitator was the perceived level of evidence.

Finally the relationship between innovation in health care in general and radiotherapy in particular and the resulting output was studied based upon a systematic literature review to form an idea of the number of well-evaluated innovations. Output dimensions were defined as either survival, toxicity, safety, service, efficiency or cost-effectiveness.

Statistically significant results on patient outcome, service, or safety were reported in $65 \%$ of all included papers. Per tumour group and radiotherapy technique this percentage was $76 \%$. A statistically significant improvement in technology was identified in $26 \%$ of the papers. Cost-effectiveness was addressed in $10 \%$ and costs/ efficiency in $36 \%$ of the papers.

From the innovations implemented in Dutch radiotherapy centres in 2011-2013, in 32 out of 168 cases this concerned an innovation which was also included in this literature review.

In 25 out of 32 cases the innovation appeared to be well evaluated in literature. Using a $95 \%$ confidence interval this means that between $64 \%$ and $92 \%$ of the implemented innovations in Dutch radiotherapy centres are well evaluated before implementation. For organisational innovations, it was not possible to gain insight into the relationship between output and implementation either because these innovations are not described as innovation in literature, or the studies have a limited scope, and/or a relatively low scientific level.

\section{Part 3: example of a scientific evaluative implementation design of an organisational innovation with quantitative measurements (research question 5)}

The rigorous design of a prospective clinical trial, with a hypothesis, sample size calculation, baseline measurements of endpoints and repeated measurements was mimicked. The aim was threefold: 1 . to evaluate the effects of organisational innovations; 2. to provide research an organisational design with more scientific evidence using quantitative measures; 3 . to reduce scepticism among physicians about managerial theories regarding organisational innovation. The study showed that this design is 
possible and provides more transparency about problems, roots, causes, interventions and effects. In the qualitative evaluation, the approach appeared to be well-accepted by medical professionals.

\section{DISCUSSION}

Implementation of innovations can help radiotherapy centres in their task of providing patients the best possible treatment, which of course should occur against acceptable costs. In this study, it became clear that there are major differences between Dutch radiotherapy centres regarding the number of implemented innovations.

\section{Complexity of innovation implementation}

According to literature, implementation of innovations is complex $[8,9]$. This is illustrated by a review of theories of innovation adoption which identified 20 theoretical frameworks with multiple major constructs associated with theories of innovation adoption [10]. In order to reduce complexity of innovation implementation, literature shows that collaboration between centres can help, since this makes it possible for centres to join forces and learn from each other, and prevents them from struggling individually with identical problems [11]. In case of collaboration, centres must ensure that reaching consensus causes no delay. In radiotherapy, scientific collaborations between centres, both at national and international level, have already been common practice for many years. The radiotherapy societies are very active in organising scientific congresses, training, and education. However, very little attention is paid in this scientific collaboration to innovation implementation and even less to organisational innovations, although these innovations frequently affect the clinical environment and cost time and/ or money. Nevertheless, several radiotherapy centres already collaborate on innovation implementation. Organised collaboration on innovation implementation on a broader level requires at least two important conditions being met. In the first place, centres should have a common vision on what is meant by innovation; not only in literature but also in the radiotherapy centres opinions differ on what can be labelled innovation [12]. Radiotherapy societies can create clarity in the field, for example by operationalising the concept of innovation for radiotherapy and by setting indicators to measure the amount of innovation.

This thesis provides a proposal for a framework of innovation indicators; a framework which is accepted by the key staff and chairpersons of Dutch radiotherapy centres and has been assessed by experts at Dutch universities in the field of innovation. A limitation is the fact that these innovation experts did not share an unambiguous opinion in their assessment of innovation indicators. This is, however, in line with the different opinions 
existing in the scientific literature on innovation. Radiotherapy societies of course can modify the framework if they think this is necessary, since it is important that all associated members support the concept and use it in their registration. Without clear definitions and indicators, benchmarking and collaboration is not easy to achieve.

In the second place, at several centres in our study innovation activities were poorly registered. Sometimes there were policy plans but they were not SMART (specific, measurable, attainable, realistic, timely) formulated ones. In addition, sometimes which plans had been realised and which had not had not been registered. One centre even was even unable to participate because there were no data at all. Registering data is not only an unavoidable prerequisite for performing research but also for data driven decisions with respect to all aspects of an organisation. Centres without transparent registration are not well able to verify their quality.

\section{Variation in innovation implementation}

We explained the differences in levels of innovation implementation between centres by the fact that previous studies outside the field of radiotherapy showed that there are dozens of factors and competences influencing the success rate of innovation implementation, but also that these factors can differ between centres [13-17]. For example a good score on the competence "innovative work behaviour of physicians/ physicists" is not enough to successfully innovate as this study shows. The magnitude of factors influencing successful innovation implementation suggests that it is impossible to identify one "good" way to innovate, just like there is no one right way to organise [18]. Similar to the contingency approach in organisational science, the success of innovation implementation depends on "contingencies", meaning that environmental factors determine the best way. Physicians/physicists and management must therefore join forces in creating a set of conditions which stimulate innovation implementation in their centre. In this study, there were several factors identified for this set in one clinic but these are definitely not complete and require further research and validation in other centres. Furthermore, each centre should probably adapt this set to their own situation and validate it.

Nevertheless, there are some general principles regarding different contingencies suitable for different kinds of innovation. For example, most innovations in radiotherapy centres are incremental innovations. For this type of innovation organisational conditions are required which enhance continuous reflection on improvement of processes accompanied by process audits. In addition, a coaching consultative flexible management style is required $[18,19]$. Employees must be trained to handle an exploitative learning style which is defined as the refinement and extension of existing competences [20]. In teams integrated autonomy must be organised [21]. 
For radical innovations, however, very different conditions and management approaches are necessary. This type of innovation - such as the introduction of MRlinac, protons or decision support systems - requires organisational conditions which facilitate acquiring new (external) knowledge and processing this by reflection and conceptualisation [20]. Here an adhocratic, entrepreneurial and visionary leadership is needed which is characterised more by facilitating than by steering [20].

The difference with the coaching, consultative style is the clarity regarding goals which must be achieved. A strong vision of the leader is the only guidance for the employees (instead of detailed work descriptions, standard operating procedures etc.), leaving these employees a lot of latitude. With regard to radical innovations, often a select group of employees is involved who act as gatekeepers; individual autonomy is also important. An explorative learning style (instead of an exploitative style) is needed which is defined as experimentation with new required competences [20]. Because of the differences between these two degrees of innovation, radiotherapy centres must not approach all innovations in the same way and with the same people. Organisational contingencies can either encourage or discourage innovations [21]. Therefore, radiotherapy centres need to distinguish between incremental and radical innovations regarding organisational conditions and management style. This is also true for innovation generation and innovation adoption. The organisational conditions for innovation generation are largely similar to the conditions needed for radical innovation. For innovation implementation, the conditions are similar to those of incremental innovation. A limitation for this conclusion is the circumstance that these conditions have mostly been investigated in manufacturing settings; consequently, further research is necessary to confirm whether these findings are also valid in the hospital environment [22].

Furthermore, it is important for radiotherapy centres to realise that focusing on radical innovations (e.g. the introduction of proton therapy) includes the risk of losing operative control in daily operations because this receives less attention. In clinical settings this potential conflict is dominant because of the demanding, uncertain and time-critical daily clinical processes. Hospitals therefore need to control the extent to which they want to be innovative [23]. This is even more necessary because radical innovations remain unpredictable in their technical and commercial outcomes [24].

Another interesting finding was the fact that academic and non-academic centres did not significantly differ in innovation implementation performance. We explained this fact by the magnitude of factors influencing this performance (also a possible explanation of the large range of differences between centres regarding implementation performance). In addition, we think the difference between the availability of innovation generating and innovation adopting competences plays a crucial role. Academic centres almost by 
definition have more innovation generating competences because research is an important task; however, they do not by definition have more innovation adopting competences. In this study, both competences were measured in the physician/physicist staff of Dutch centres via a questionnaire measuring innovative work behaviour. No differences were found, however, between academic and non-academic centres. Innovating generating competences in academic centres are possibly only more significantly present in the research staff of the hospital and not in the patient care staff.

\section{The research implementation gap}

This difference between the availability of innovation generating and innovation adopting competences can be an important factor influencing the "research implementation gap" which is described in chapter 4. If clinicians are not conducting research as well as providing patient care, a strong collaboration is necessary between researchers and clinicians. If this collaboration is not organised, there is a significant threat they will have different goals, strategies and priorities, which impedes implementation of scientific findings. This view is supported by literature.

Professional groups produce strong social and cognitive boundaries which can block externally oriented sources of change and learning [25]. Collaboration can enhance social interaction, trust and motivation to overcome different goals and priorities. Because key persons in research are often working on more radical innovation, special attention is necessary for the connection with the clinical staff, who are expected to implement those innovations and operate in their daily work in a more incremental innovation environment. Researchers and clinicians are each used to different organisational conditions and management approaches and probably value their own conditions and approaches most [26]. Therefore, innovations must be analysed not only in terms of their benefits for patients, but also in terms of their implications for the specific groups of employees who need to collaborate in their implementation [27].

\section{Facilitators and barriers}

For effective and efficient innovation implementation, management needs to acknowledge facilitators and barriers [28]. In chapter 4, these facilitators and barriers were described for one Dutch radiotherapy clinic. The many factors influencing the rate of innovation implementation as mentioned in chapter 3 are probably closely linked to these identified barriers and facilitators. We already concluded that physicians/physicists and management must join forces in creating a set of clinic-specific conditions which stimulate innovation implementation. The inventory in our study can be used for that purpose. Yet solely doing this is not enough. From literature, we know that there are also external forces affecting the success of innovation implementation [6]. External forces helping or hindering innovation implementation are, for example, industry players, 
funding, public policy, technology, patients (advocacy groups) and accountability rules $[6,14]$. It is important for radiotherapy centres to identify and to analyse relevant external forces and to incorporate necessary strategic actions in the innovation strategy. After all, analytical oriented hospitals that formalise their strategic search and decision processes apparently are able to have larger innovation portfolios. This is accompanied by more efficient innovation processes and therefore a higher capacity to innovate [23].

\section{Organisational innovations}

Investigating the innovation implementation in radiotherapy centres in chapter 3 , it was found that most innovations in radiotherapy centres concern organisational innovations. A likely explanation could be that product and technological innovations, such as the introduction of new treatments, are usually accompanied by organisational innovations that secure productivity, reliability and quality of hospital processes [29]. In addition, innovations are implemented in the field of HR, Finance, IT, Facilities and so on. In the literature review on innovation output in chapter 5 , it was concluded that implemented organisational innovations frequently have no (high level) proven scientific basis. This is in line with previous studies regarding evidence-based management in health care $[30,31]$. Outside health care, the evidence-based management concept has begun to spread to such areas as criminal justice and education [30]. Management of health care organisations, who often refuse to spend time and money on innovations in clinical practice which are not evidence based, have apparently been slow to apply this idea to their own managerial practice [30].

However, organisational innovations can affect the clinical environment. Therefore, in chapter 6 the possibilities were investigated of performing research on organisational innovation, with a rigorous design including the definition of endpoints related to patient care and measurements at baseline and after 1 and 2 years. The conclusion was that this method contributed to the transparency of the effectiveness of organisational innovation implementation. Radiotherapy centres in the Netherlands have a leading position in Europe and even the world regarding the amount and quality of research on product and technology innovation. More research on organisational innovation, especially when patient care is affected by the innovation, would better suit this leading research position. Especially academic centres should set an example in this regard.

Finally, market innovation is in its infancy in Dutch radiotherapy centres. Apparently, this is not seen as an important area to develop. Without further investigation it is difficult to explain this phenomenon. Is it because many centres have a de facto monopoly? Is competition in cancer care not considered to be desirable? These questions cannot be answered by this study. 


\section{Methodological considerations}

Overall, the studies presented in this thesis have some limitations. Two studies were performed in a single-centre setting: the research implementation study (chapter 4) and the organisational innovation study (chapter 6). This can affect the generalisability of the results. Nevertheless, the studies are an important starting point for more studies in a multi-centre environment. After all, there is scarcely any research in this area, which makes matters such as benchmarking impossible.

For organisational studies it is very difficult to eliminate cofounding factors. However, the organisational innovation study of this thesis showed that a study setting mimicking a prospective clinical design is valuable. Knowing this, expansion to multi-centre studies, could be a logical next step.

Furthermore, the study on innovation implementation (chapter 3 ) had a small sample size (15 of 21 Dutch centres) which could not be increased because we wanted to compare Dutch centres in a more or less similar situation regarding the health care system.

\section{Future prospects}

The studies performed in a single-centre setting should be continued in other centres at a national or international level, not only to learn from comparing results but also to investigate if our approach is reproducible in other centres. In addition, it would be valuable to compare the Dutch innovation implementation performance with quantitative markers of high performing centres in other countries, so that centres can learn from each other. For example, investigating a few centres abroad with an outstanding reputation and comparing the implementation policy and results to learn more about success factors could be of great value to centres with lower implementation rates. However, the many confounding factors would be a methodological challenge for an international comparison, such as health care systems varying from single payer to competitive markets and as a consequence potentially having very different stimuli for innovations.

Above all, it is necessary to perform further studies on organisational innovation with a more rigorous design, as is done in the study in chapter 6 . After all, organisational innovations are the most frequently implemented innovations in Dutch radiotherapy centres, whereas the research on these innovations is very scarce, and is often performed with a limited scope prior to the innovation implementation. Organisational innovations mostly affect the clinical environment, and with regard to changes with impact, it is not acceptable to implement these without prior scientific investigation. Especially academic centres should initiate this kind of research because they have the infrastructure to perform research. Collaboration between radiotherapy centres with medical faculties as well as with business administration faculties of universities could also possibly stimulate this. 


\section{RECOMMENDATIONS}

Although radiotherapy centres in the Netherlands are very innovative, they could be even more effective and efficient if they improve with regard to the following aspects:

\section{A. Implementation of innovations}

To improve implementation of innovations, we can make several recommendations:

A1. Improve collaboration between centres at a national level.

A2. Improve the relationship between research and innovation implementation.

A3. Improve scientific analysis of organisational innovations.

A4. Recognise that although research and innovation implementation should be integrated, they simultaneously require a different management style and different organisational conditions.

Ad A1. It is desirable to reduce the extensive differences in innovation implementation between centres. Radiotherapy centres already help each other on occasion with the implementation of innovations by exchanging information. We speculate that collaboration, which is supported by national radiotherapy societies, can enhance successful implementation. From literature we know that supported collaboration can help to accelerate the implementation of effective innovations which improve patient outcomes, service and safety, or save costs by preventing different organisations from struggling with identical problems [11]. This collaboration can consist of joint training or the exchange of standard operating procedures, which avoids duplication of work and increase the efficiency of innovation implementation.

To allow benchmarking of innovation performance, it is necessary to establish a national and international registration system regarding innovation indicators. This can be done in the same way as, for example, the benchmarking of production and resource data of radiotherapy departments in the Netherlands. Our innovation indicators have been conceived by the radiotherapy professionals themselves and assessed by professors in the field of innovation and could be a good starting point.

In such a national collaboration between centres, national recommendations on the implementations of innovations could also be more systematically formulated, as has already been done for proton therapy by the Dutch radiotherapy society. Here the modelbased approach provides guidelines for the selection of patients for proton therapy for all centres.

Ad A2. In addition, it is important to build a strong relationship between research and innovation implementation, since research is required to obtain evidence on the output 
of a proposed innovation. Evidence can consist of showing that the innovation improves patient outcome, or by showing in silico trials that the advantages of the innovation outweigh the disadvantages, or by showing an improved cost-effectiveness. Increasing the evidence will yield higher implementation rates. Innovations which do not meet these conditions should only be implemented in a study setting. In clinical radiotherapy studies, improvements are possible by more systematically evaluating innovations on all output dimensions (patient outcome, efficiency and/or cost-effectiveness) in studies.

Ad A3. Regarding organisational innovations, managers in radiotherapy, especially in academic centres, should initiate research with a more rigorous design to provide more high-level evidence on organisational innovation output and also strive to publish this research. Preferably, this ought to be done in a manner which is recognisable for clinical professionals and researchers in the radiotherapy field. Organisational innovations should also be further tested and evaluated and not directly implemented, especially when they can affect the clinic.

Ad A4. Considering organisational and managerial requirements for implementations, it is important to know that in this study it was concluded that most innovations in radiotherapy centres are incremental innovations. Management should therefore focus on requirements which facilitate incremental innovation. Radical innovations require other conditions, which can be fulfilled in the specific context of the radical innovation, which is usually a long-term project/research line, such as proton therapy, MRI-linac, the introduction of decision support systems or immunotherapy. In addition, it is important to recognise that generating innovation (including research) and implementing innovation is, on the one hand, improved by integrated involvement of both clinicians and researchers from the start of new (research) projects, but, on the other hand, should also be differentiated regarding management style and other organisational conditions.

\section{B. Non-implementation of innovations}

The leaks in the research-innovation-clinical routine pipeline must be stopped since cancer patients with a life-threatening disease should not be deprived of findings which could potentially help them. As described in the introduction there are two main leaks, the first one between preclinical research and the clinical trials, and the second one between the clinical trials and clinical routine practice. To reduce these leaks, we have the following recommendations.

B1. Increase the percentage of patients included in trials; all centres have a complete registration system for patients in trials.

B2. Measure the percentage of research translated into local clinical practice; preferably this indicator should be added to the set of quality indicators. 
B3. Management and health care funders should eliminate barriers and introduce facilitators to improve translation of research into clinical practice.

Ad B1. For both leaks it is important to have an active strategy regarding patients in trials because trials are still one of the main gateways to clinical routine. A first priority is a complete registration system for patients in trials, which is necessary in all centres. This is not yet the case. In addition, the percentage of patients in trials has to be increased. In our study 8 out of the 10 registered percentages of the 15 participating centres were below $5 \%$. It is important to benchmark information on trial participation on a regular basis. The national radiotherapy societies could facilitate and strongly encourage centres to in increase trial participation.

Ad B2. Furthermore, the percentage of studies translated into local clinical practice or into trials is an important metric. If possible, trials must be properly evaluated in a preclinical phase. Adding the rate of clinical implementation of published research findings in clinical routine or in trials to the set of quality indicators of integrated research-patient care organisations, such as comprehensive cancer centres, could support innovation implementation.

Ad B3. Attention is also required for interventions which eliminate barriers and fortify facilitators for translating research into clinical practice. Examples are support from administration and health care funders to provide time for studies which evaluate innovations, interactive workshops, educational outreach visits and multifaceted interventions.

\section{CONCLUSION}

The overarching research question of this thesis was formulated as follows:

"Is it possible in radiotherapy to find clues on how to innovate more effectively and more efficiently?"

This study shows that radiotherapy centres in the Netherlands are very innovative. However, effectiveness and efficiency can be increased since there are large differences between centres. The research implementation in clinical practice can be further improved. Furthermore, not all innovations are evaluated on patient output and scarcely on all output dimensions before implementation. Finally, studies on organisational innovations frequently have a limited scope and a lower level of evidence. This makes evaluation of innovation before implementation more difficult. 
Registering and benchmarking innovation implementation data can provide information for interventions which enhance successful innovation implementation. Furthermore, recommendations at a national level possibly can help effective and efficient innovation implementation. Finally, management should set the right stage for important innovations regarding management style, organisational contingencies and innovation strategy. 


\section{REFERENCES}

1. Bortfeld T, Jeraj R. The physical basis and future of radiation therapy. The British journal of radiology. 2014.

2. Okunade AA, Murthy VN. Technology as a "major driver"of health care costs: a cointegration analysis of the Newhouse conjecture. Journal of health economics. 2002;21(1):147-59.

3. van Loon J, Grutters J, Macbeth F. Evaluation of novel radiotherapy technologies: what evidence is needed to assess their clinical and cost effectiveness, and how should we get it? The lancet oncology. 2012;13(4):e169-e77.

4. Haines A, Kuruvilla S, Borchert M. Bridging the implementation gap between knowledge and action for health. Bulletin of the World Health Organization. 2004;82(10):724-31.

5. Dixon-Woods M, Amalberti R, Goodman S, Bergman B, Glasziou P. Problems and promises of innovation: why healthcare needs to rethink its love/hate relationship with the new. BMJ quality \& safety. 2011;20(Suppl 1):i47-i51.

6. Herzlinger RE. Why innovation in health care is so hard. Harvard business review. 2006;84(5):58.

7. Rogers EM. Diffusion of innovations: Simon and Schuster; 2010.

8. Omachonu VK, Einspruch NG. Innovation in healthcare delivery systems: a conceptual framework. The Innovation Journal: The Public Sector Innovation Journal. 2010;15(1):1-20.

9. Urquhart R, Sargeant J, Grunfeld E. Exploring the usefulness of two conceptual frameworks for understanding how organizational factors influence innovation implementation in cancer care. Journal of Continuing Education in the Health Professions. 2013;33(1):48-58.

10. Wisdom JP, Chor KHB, Hoagwood KE, Horwitz SM. Innovation adoption: a review of theories and constructs. Administration and Policy in Mental Health and Mental Health Services Research. 2014;41(4):480-502.

11. Thoma-Lürken T, Bleijlevens MH, Lexis MA, Hamers JP, de Witte LP. An Overview of Potential Labor-Saving and Quality-Improving Innovations in Long-Term Care for Older People. Journal of the American Medical Directors Association. 2015.

12. Page T. Notions of innovation in healthcare services and products. International Journal of Innovation and Sustainable Development. 2014;8(3):217-31.

13. Chaudoir SR, Dugan AG, Barr CH. Measuring factors affecting implementation of health innovations: a systematic review of structural, organizational, provider, patient, and innovation level measures. Implement Sci. 2013;8(1):22.

14. Länsisalmi H, Kivimäki $M$, Aalto $P$, Ruoranen R. Innovation in healthcare: a systematic review of recent research. Nursing science quarterly. 2006;19(1):66-72.

15. Greenhalgh T, Robert G, Macfarlane F, Bate P, Kyriakidou O. Diffusion of innovations in service organizations: systematic review and recommendations. Milbank Quarterly. 2004;82(4):581-629.

16. Fleuren $M$, Wiefferink $K$, Paulussen T. Determinants of innovation within health care organizations. International journal for quality in health care. 2004;16(2):107-23. 
17. Crossan MM, Apaydin M. A multi-dimensional framework of organizational innovation: A systematic review of the literature. Journal of management studies. 2010;47(6):1154-91.

18. Savolainen TI. Cycles of continuous improvement: realizing competitive advantages through quality. International Journal of Operations \& Production Management. 1999;19(11):1203-22.

19. Tang H. An inventory of organizational innovativeness. Technovation. 1998;19(1):41-51.

20. van Poucke A. Towards radical innovation in knowledge-intensive service firms. 2005.

21. Un CA. An empirical multi-level analysis for achieving balance between incremental and radical innovations. Journal of Engineering and Technology Management. 2010;27(1):1-19.

22. van Poucke A. Towards radical innovation in knowledge-intensive service firms: Erasmus School of Economics (ESE); 2005.

23. Schultz C, Zippel-Schultz B, Salomo S. Hospital innovation portfolios: Key determinants of size and innovativeness. Health care management review. 2012;37(2):132-43.

24. Pavitt K. The process of innovation: SPRU; 2003.

25. Ferlie E, Fitzgerald L, Wood M, Hawkins $C$. The nonspread of innovations: the mediating role of professionals. Academy of management journal. 2005;48(1):117-34.

26. Damanpour F, Wischnevsky JD. Research on innovation in organizations: Distinguishing innovation-generating from innovation-adopting organizations. Journal of engineering and technology management. 2006;23(4):269-91.

27. Denis J-L, Hébert Y, Langley A, Lozeau D, Trottier L-H. Explaining diffusion patterns for complex health care innovations. Health care management review. 2002;27(3):60-73.

28. Berwick DM. Disseminating innovations in health care. Jama. 2003;289(15):1969-75.

29. Damanpour F, Walker RM, Avellaneda CN. Combinative effects of innovation types and organizational performance: A longitudinal study of service organizations. Journal of management studies. 2009;46(4):650-75.

30. Walshe K, Rundall TG. Evidence-based management: from theory to practice in health care. The Milbank Quarterly. 2001;79(3):429-57.

31. Rousseau DM. Is there such a thing as "evidence-based management"? Academy of management review. 2006;31(2):256-69. 




\section{Summary}

This thesis consists of four parts.

\section{Part one: Setting the stage.}

Radiotherapy centres have a key task to continuously improve their treatment outcomes in an environment that is safe for patients. At the same time, they need to offer patients more services, such as shared decision-making, while also reducing costs. For radiotherapy centres to perform this multifaceted task well, innovation is vital. This includes technological innovations such as the remarkable advances in tumour visualisation and targeted delivery of radiation doses to tumour tissue, which have resulted in improved treatment outcomes, and organisational innovations such as certain lean initiatives that have achieved cost reductions and quality improvements. For this reason, many radiotherapy centres place a major emphasis in their strategy, either implicitly or explicitly, on innovation. However, to achieve sustainable performance, they must strike a balance between being a going concern, engaging in research and development, and pursuing innovation. This is an extremely complicated task, and the development and implementation of the right innovations in a cost-effective way is therefore a great challenge.

Chapter 1 provides some background on several aspects of this challenge, resulting in our central research question:

'Is it possible to find clues on how to innovate more effectively and more efficiently in radiotherapy?'

To answer this question, the following specific research questions were investigated:

1. What is defined as innovation in radiotherapy and how can it be measured?

2. What is the degree of innovation routinely implemented at Dutch radiotherapy centres and what are the differences between centres? To the extent that differences exist, what causes them?

3. How efficient is translational research in radiation oncology; i.e. how big are the leaks in the research-innovation pipeline, what are the facilitators for, barriers to and actions needed for the successful implementation of research as innovations in clinical practice?

4. Is the reported output of healthcare/radiotherapy innovation studies supported by high-level evidence, and to what extent are innovations implemented at Dutch radiotherapy centres based on scientific evidence?

5. Is it possible for an organisational innovation process to simultaneously improve patient care processes and clinical research activities, and is it possible to structure this in a manner similar to a prospective clinical trial? 
Chapter two investigates what the concept of innovation means in the field and provides a framework for measuring innovation (research question 1 ). The literature on innovation is extensive and offers many different definitions, yet these definitions often are vague as it is not clear from which viewpoint the concept is being approached. Possible viewpoints are 1) innovation type (i.e. product, technology, market, organisational), 2) innovation degree (i.e. radical or incremental), 3) innovation competence (i.e. generating or adopting) and 4) innovation process.

In order to answer the first research question (What is defined as innovation in radiotherapy and how can it be measured?) a measurement instrument was developed that covers the relevant aspects of innovation in radiotherapy and can provide insight into innovation performance.

This instrument was developed on the basis of a Delphi study conducted with experts in the fields of radiotherapy and innovation science. An explicit definition of each of the four types of innovation was formulated to ensure clarity. The resulting instrument describes types of innovations and is suitable for determining both the degree of innovation and the innovation competence for each type. In total, it consists of 13 indicators on four types of innovations.

In summary, this section serves to frame the concept of innovation in radiotherapy and describes the development of an instrument to measure it.

\section{Part two: What determines whether innovations make it into clinical practice?}

In part two we looked for clues as to why some innovations make it into clinic practice and other do not. Among other things, we tried to gain more insight into the relationship between innovation and output as this provides an indication of the value of the innovation and whether it is desirable to implement it (research questions 2, 3 and 4).

Chapter three applies the measurement instrument discussed in chapter 2 to investigate how many innovations were implemented in clinical routine at Dutch radiotherapy centres from 2011 to 2013, and what differences exist between centres (research question 2). The results show that radiotherapy centres in the Netherlands innovate a great deal: in the product, technology and organisational innovation categories, the country's seven academic medical centres averaged 13 innovations a year (17-38 over three years ) and the eight non-academic medical centres averaged 10 (14-75 over three years). This difference is not statistically significant. The majority of innovations appeared to be incremental innovations requiring mainly innovation-adopting competences. This may explain the lack of divergence between academic and nonacademic centres. Whereas academic centres probably have innovation-generating 
competences by virtue of their research focus, the same does not necessarily apply to innovation-adopting competences. The results suggest that there is room for improvement, especially at centres with a low number of innovations. Also interesting to note is that several centres had implemented the same innovations independently of each other. No correlation was found between the innovative work behaviour of a centre's medical staff (physicians and physicists) and the number of implemented innovations. In the discussion section of chapter 3 we speculate on possible causes of the differences between centres, such as the many factors that influence the implementation of innovations and the difference between radiotherapy centres' innovation-generating and innovation-adopting competences.

Summarized the number of innovations observed per centre varied across a large range with a large overlap in terms of the type of innovations that were implemented. Most innovations were incremental innovations.

Chapter four focuses on the extent to which scientific findings from research performed at a large Dutch radiotherapy centre were actually implemented in their own routine clinical practice (research question 3 ). This type of research has never yet been published, and figures relating to the frequently reported research/implementation gap are usually based for example on published research on the integration of evidence-based interventions in practice relative to basic research, the number of patients receiving newly recommended care, or the percentage of basic scientific findings licensed for clinical use. We found that as of 2015, out of the 234 studies published by the centre in 2008-2011, $19 \%$ had been implemented in clinical practice, another $6 \%$ in clinical trials and another $24 \%$ in studies with patient material/data. Negative findings were found in only two papers, probably as a result of publication bias. National studies and studies with national funding had a higher implementation rate than international studies and industry-funded studies. The time to implementation in clinical practice was four months for clinical research and 15 months for technological research. In only 20/55 papers was it possible to establish the interval between a study's finding and its continuation as part of further trials in the clinical setting. The implementation time for preclinical studies in further studies was 1 month $(n=4)$ and in technical studies 19 months $(n=16)$. Level of evidence was an important facilitator, whereas high workload and complexity of the innovation were important barriers.

In summary, this section shows the efficiency of translational research at a Dutch radiotherapy centre, with the number of studies not implemented measured at the junctures described in the literature as the two major leaks: at translation from preclinical to first human trials and from clinical trials to clinical routine. The main facilitators for and barriers to translation to clinical routine are identified and possible interventions to overcome these barriers as described in literature are presented. 
Chapter five presents a systematic literature review focusing on the relationship between innovation in healthcare/radiotherapy and the resulting output in order to gain an idea of the number of thoroughly evaluated innovations in radiotherapy (research question 4). Output was defined as either survival, toxicity, safety, service, efficiency or costeffectiveness. From a total of 1072 unique articles, 94 could be included. Significant results in respect of patient outcome, service or safety were reported in $65 \%$ of papers, or $76 \%$ if confined to radiotherapy reviews. A significant technological improvement was identified in $26 \%$ of the papers. Cost-effectiveness was addressed in $10 \%$ of the papers and costs/efficiency in $36 \%$ of the papers. There were only $13 / 94$ (14\%) organisational papers, with $3 / 13$ (23\%) having scientific level I and $7 / 13$ (54\%) having level V. Of the 81 clinical papers, $38(47 \%)$ had scientific level I and 12 (15\%) level V. No papers reported on all output dimensions.

It was concluded that radiotherapy reviews on tumour groups and technologies give a reasonably good insight with a good level of evidence into the innovation's effect on output. However, it is difficult to draw general conclusions about the impact of organisational innovations because they are not being approached as innovation and/ or are limited in scope.

Comparing the results of this review by tumour group or radiotherapy technology to the product innovations implemented at Dutch radiotherapy centres in 20112013 , it was found that at least $64-92 \%$ (95\% confidence interval) of innovations implemented at Dutch centres were thoroughly evaluated on data regarding patient outcome before implementation.

In summary, our review found that the output of innovation is not always reported in the scientific literature before implementing the innovation in clinical practice. However, in the case of Dutch radiotherapy centres, the majority of innovations is thoroughly evaluated before implementation. Where organisational innovations are concerned, it was not possible to gain a good insight into the relationship between evaluated output and implementations.

\section{Part three: Evaluation of organisational innovation using a prospective research design}

Part three investigates whether it is possible to evaluate an organisational innovation using a prospective research design that is more rigorous and familiar to clinicians (research question 5).

Specifically, in chapter six we describe the replication of the design of a prospective clinical trial, with a hypothesis, sample size calculation, baseline measurement of 
endpoints and repeated measurement of endpoints after one and two years. The aim is threefold: 1) to evaluate the effects of an organisational innovation, 2) to provide research on organisational design with more scientific evidence based on quantitative measures and 3) to reduce scepticism among physicians about managerial theories on organisational innovation.

This study shows that it is possible to structure a reorganisation process in a manner similar to a prospective clinical design. This gives employees more transparency about problems, root causes, interventions and effects. Based on our qualitative evaluation, it is clear that this approach is widely accepted among medical professionals (research question 5).

\section{Part four: General discussion, conclusions and recommendations}

Chapter seven presents the general discussion of this thesis. It concludes that Dutch radiotherapy centres are very innovative but that there is still room for improvement as centres diverge widely in the number of innovations they implement. In addition, innovation and research implementation can be improved, since not all treatment and technological innovations are being evaluated on the relevant output dimensions before implementation. Finally, studies on organisational innovations often have a limited scope and a lower level of evidence. This makes evaluation of innovations before implementation more difficult. We present recommendations for fostering innovations in a rational way such as registering and benchmarking performance on innovation indicators and further improving collaboration between centres when implementing innovations. Last but not least, it is important that management sets the stage for important innovations in management style, organisational contingencies and innovation strategy. 


\section{Samenvatting}

Deze thesis bestaat uit vier delen.

\section{Deel 1: bepalen van het speelveld.}

Radiotherapiecentra hebben de maatschappelijke taak om er voor zorg te dragen dat tegelijkertijd de behandeluitkomsten continue worden verbeterd in een voor de patiënt veilige omgeving, dat er meer service wordt geboden aan de patiënt, zoals bv shared decision making op het vlak van de behandelkeuze, en dat daarnaast de kosten worden verlaagd. Innovatie kan centra helpen deze meervoudige opgave goed invulling te geven. Zo is bijvoorbeeld de aanzienlijke vooruitgang op het vlak van het visualiseren, focusseren en het afgeven van de radiotherapie dosis op de tumor (hetgeen tot de verbeterde patiëntuitkomsten heeft geleid), mogelijk gemaakt door technologische innovatie. Een ander voorbeeld is de kostenreductie en kwaliteitsverhoging die is gerealiseerd door implementatie van organisatorische innovaties, zoals lean initiatieven. Veel radiotherapiecentra besteden in hun strategie dan ook vaak, impliciet of expliciet, veel aandacht aan innovatie.

Om verzekerd te zijn van blijvend goede zorg moet er een balans zijn tussen de dagelijkse operatie, research \& development en innovatie. Dit is een complexe taak. Het ontwikkelen en implementeren van de juiste innovatie op een kosteneffectieve wijze is een grote uitdaging. In hoofdstuk 1 is achtergrondinformatie opgenomen over diverse aspecten van deze uitdaging hetgeen resulteerde in de centrale onderzoeksvraag:

"Is het mogelijk binnen de radiotherapie aanknopingspunten te vinden om effectiever en efficiënter te innoveren?"

Om deze vraag te beantwoorden zijn de volgende specifieke onderzoeksvraagstellingen onderzocht.

1. Wat moet worden verstaan onder innovatie in radiotherapie en hoe kan dit worden gemeten?

2. In welke mate zijn innovaties geïmplementeerd in de klinische routine in Nederlandse radiotherapie centra en wat zijn verschillen tussen centra. Indien er verschillen zijn wat veroorzaakt deze verschillen?

3. Hoe efficiënt is de translatie van wetenschappelijke vindingen in radiotherapie (hoe veel lekt weg uit de onderzoek-innovatie lijn en wat zijn facilitators, barrières en acties die ondernomen kunnen worden voor succesvolle implementatie van wetenschappelijke vindingen).

4. Wordt de output van innovatie-studies in de zorg en radiotherapie in het bijzonder gerapporteerd met hoge wetenschappelijke evidentie en in welke mate zijn 
geïmplementeerde innovaties in Nederlandse radiotherapie centra gebaseerd op wetenschappelijk bewijs.

5. Is het mogelijk om met een organisatorische innovatie tegelijkertijd zorgprocessen en onderzoek te verbeteren en is het mogelijk om hiervoor de onderzoeksopzet van een prospectieve klinische trial te gebruiken?

In hoofdstuk 2 is onderzocht wat innovatie in radiotherapie betekent en een instrument om de mate van innovatie te meten is ontwikkeld (onderzoeksvraag 1 ). De literatuur met betrekking tot innovatie is zeer uitgebreid. Vaak worden er veel uiteenlopende en soms vage definities gebruikt en is het niet duidelijk vanuit welk gezichtspunt innovatie wordt benaderd.

Mogelijke gezichtspunten betreffen 1) innovatie type (product, technologische, markt en organisatorische innovatie), 2) de radicaliteit van de innovatie (incrementeel of radicaal), 3) innovatie competentie (genereren van innovaties of het implementeren daarvan) en 4) het innovatieproces. Om de eerste onderzoeksvraag te beantwoorden, "Wat moet worden verstaan onder innovatie in de radiotherapie en hoe kan dit worden gemeten?", is een meetinstrument ontwikkeld dat alle relevante aspecten van innovatie in radiotherapie bestrijkt en inzicht kan geven in de innovatie implementatie prestatie. Op basis van een delphi onderzoeksdesign zijn experts op het vlak van radiotherapie en experts op het vlak van innovatie gevraagd te participeren in de ontwikkeling van het instrument. Het instrument onderscheidt de verschillende types innovatie en maakt het mogelijk daarbinnen specifieke innovaties te karakteriseren als radicaal dan wel incrementeel. Ook innovatie generatie en innovatie implementatie kan worden onderscheiden. In totaliteit zijn 13 indicatoren geïdentificeerd om innovatie te meten.

Samenvattend is in hoofdstuk 2 het begrip "innovatie" in radiotherapie beschreven en is een instrument ontwikkeld om innovatie te meten.

\section{Deel II: Innovaties die de kliniek wel en niet bereiken en de waarde van innovatie.}

In deel 2 hebben we onderzocht of er aanknopingspunten gevonden konden worden waarom bepaalde innovaties de kliniek bereiken en andere innovaties niet. $\mathrm{Er}$ is ook geprobeerd om meer inzicht te krijgen in de relatie tussen innovatie en output omdat dit duidelijk maakt hoe waardevol het is om een innovatie al dan niet te implementeren. (onderzoeksvragen 2, 3 en 4)

In hoofdstuk 3 is met behulp van het meetinstrument uit het vorige hoofdstuk de mate van innovatie in Nederlandse radiotherapiecentra onderzocht in de periode 2011-2013. Ook is onderzocht welke verschillen er bestaan tussen de centra (onderzoeksvraag 2). De studie maakte duidelijk dat de Nederlandse centra in grote mate innoveren: met 
name product, technologische en organisatorische innovaties. De 7 academische centra implementeren jaarlijks gemiddeld 13 innovaties (17-38 in 3 jaar). De 8 niet-academische centra gemiddeld 10 (14-75 in 3 jaar). Dit verschil is statistisch niet significant.

De overgrote meerderheid van innovaties bleken incrementele innovaties te zijn waarvoor vooral innovatie-implementatie competenties nodig zijn. Dit verklaart waarschijnlijk waarom er geen verschillen tussen academische en niet-academische centra zijn gevonden. Hoewel innovatie-generatie competenties waarschijnlijk meer aanwezig zijn in academische centra als gevolg van de onderzoekstaak, zijn innovatie-implementatie competenties dat niet per definitie.

Er werd geen relatie gevonden tussen innovatief werkgedrag van leden van de medische staf (artsen en fysici) en het aantal van geïmplementeerde innovaties.

De resultaten geven aan dat er ruimte is voor verbetering, met name voor centra met lage aantallen

Daarnaast bleek dat veel centra, onafhankelijk van elkaar, dezelfde innovaties hadden geïmplementeerd

In de discussie van hoofdstuk 3 is gespeculeerd over de vraag wat mogelijke oorzaken zouden kunnen zijn van de verschillen tussen centra. Hierbij kwamen onder andere aan de orde de vele factoren die de implementatie van innovatie beïnvloeden en het verschil tussen competenties op het vlak van innovatie-ontwikkeling en innovatie-implementatie.

Samengevat was er een grote variatie in het aantal innovaties per centrum. Veel centra bleken met implementatie van dezelfde innovaties bezig te zijn. De meeste innovaties waren incrementele innovaties.

In hoofdstuk 4 is het onderzoek opgenomen waarin is nagegaan in welke mate wetenschappelijke resultaten van het onderzoek van een radiotherapie kliniek zijn geïmplementeerd in die kliniek en welke wetenschappelijke vindingen nooit de kliniek hebben bereikt (onderzoeksvraag 3 ). In de literatuur is dit type onderzoek nog niet eerder gepubliceerd. Cijfers over de vaak genoemde research-implementatie kloof zijn vaak alleen gebaseerd op bijvoorbeeld de verhouding tussen gepubliceerd basaal onderzoek en gepubliceerd onderzoek over de integratie van bewezen interventies in de klinische praktijk, of op het aantal patiënten dat evidence-based zorg ontvangt, of op het percentage wetenschappelijke vindingen die in licentie worden gegeven. In hoofdstuk 4 is gebleken dat in een groot Nederlands radiotherapie centrum in 2015, 19\% van 234 studies die gepubliceerd waren in de periode 2008-2011, in de 
klinische praktijk waren geïmplementeerd, $6 \%$ in klinische trials en $24 \%$ in studies met patiëntmateriaal/data. Negatieve resultaten werden gevonden in enkel 2 studies waarschijnlijk als gevolg van "publication bias". Nationale studies en studies die nationale financiering hadden, werden in een hogere mate geïmplementeerd dan internationale studies en studies gefinancierd door bedrijven. De implementatietijd vanaf publicatie was 4 maanden voor klinisch onderzoek en 15 maanden voor technisch onderzoek. Bij 20/55 publicaties was het mogelijk om de datum te identificeren waarop een studie was voortgezet in de klinische setting. De implementatietijd voor preklinische studies was gemiddeld 1 maand $(n=4)$ en 19 maanden $(n=16)$ voor 16 technische studies. De belangrijkste facilitator voor implementatie was de sterkte van de evidentie. Workload en de complexiteit van de innovatie implementatie waren de belangrijke barrières die zijn gevonden.

Samenvattend is in een groot Nederlands radiotherapie centrum de efficiency van translationeel onderzoek gemeten en de omvang van het onderzoek vastgesteld dat nog niet was geïmplementeerd in de eigen kliniek. Dit vond plaats op de momenten die in de literatuur zijn beschreven als de twee potentiele weglek-situaties: 1. Van preklinisch naar "first in human" en 2. van klinische trial naar klinische routine. De belangrijkste facilitators en barrières werden geïnventariseerd en er werden op basis van literatuur mogelijke interventies aangedragen zoals deze zijn beschreven in de literatuur.

In hoofdstuk 5 (onderzoeksvraag 4) is de relatie tussen innovatie in de zorg/ radiotherapie en de daaruit resulterende output onderzocht op basis van een systematische literatuur review.

Hiermee werd beoogd een idee te krijgen over de vraag of innovaties die geïmplementeerd worden in de radiotherapie voor de implementatie voldoende wetenschappelijk zijn geëvalueerd. Output was omschreven als ofwel overleving, of bijwerkingen, of veiligheid, of service of efficiency of kosteneffectiviteit.

Via een literatuurreview konden 94 artikelen worden geïncludeerd van in totaal 1072 unieke publicaties. Statistisch significante resultaten met betrekking tot patiënt uitkomsten, service of veiligheid waren gerapporteerd in $65 \%$ van de artikelen. In tumor/technologie specifieke radiotherapie reviews was dit $76 \%$. Statistisch significante technologische resultaten waren er in $26 \%$ van de publicaties. Tenslotte waren er in $10 \%$ van de publicaties effecten van de innovatie op kosteneffectiviteit beschreven. In $36 \%$ van de studies was het effect op kosten/efficiëntie beschreven.

Er waren maar 13/94 organisatorische artikelen, waarvan, met betrekking tot sterkte van de evidentie, er 3/13 "level I" (23\%) en 7/13 "level V" (54\%) hadden. Bij de klinische 
artikelen was dit 38 keer "level I" (47\%) en 12 keer "level V" (15\%). Er was geen artikel dat op alle outputdimensies rapporteerde.

We concludeerden dat radiotherapie reviews met betrekking tot tumoren/technieken een redelijk goed inzicht geven in de effecten van innovatie op output met goede niveaus van evidentie. Verder dat het moeilijk is om conclusies te trekken over de impact van organisatorische innovaties omdat deze in de literatuur vaak niet zijn aangeduid als innovatie en/of een beperkte scope hebben.

De resultaten van deze review werden vergeleken met de geïmplementeerde innovaties in Nederlandse radiotherapie centra. In totaliteit waren in de periode 2011-2013 in de centra in minimaal 64-92\% (betrouwbaarheidsinterval 95\%) van de situaties innovaties goed geëvalueerd op data met betrekking tot patiënt uitkomsten voor de implementatie

Samenvattend werd in deze studie gevonden dat de output van innovatie nog niet altijd wordt gerapporteerd in wetenschappelijke literatuur op alle relevante output dimensies voordat de innovatie in de klinische praktijk wordt geïmplementeerd. Niettemin, de meerderheid van de behandelinnovaties in de Nederlandse radiotherapiecentra is wel goed geëvalueerd op patiënt gerelateerde outcome gegevens voordat de implementatie in de klinische praktijk plaatsvindt. Het was niet goed mogelijk om zicht te krijgen op de relatie tussen organisatorische innovaties en output.

\section{Deel III: evaluatie van een organisatorische evaluatie met de onderzoeksopzet van een prospectieve klinische trial.}

In deel III is onderzocht of het mogelijk is een organisatorische innovatie te implementeren op basis van een strikt onderzoeks-ontwerp dat bekend is bij clinici (onderzoeksvraag 5).

Meer specifiek is in hoofdstuk 6 het onderzoeks-ontwerp van een prospectieve klinische trial nagebootst met hypothese, steekproef calculatie, baseline metingen van geformuleerde eindpunten en herhaling van de metingen na 1 en 2 jaar. Het doel hiervan was drieledig: 1 . Het evalueren van een organisatorische innovatie, 2 . Het onderzoek naar organisatorische innovatie van wetenschappelijk bewijs voorzien, 3 . Het reduceren van scepsis bij sommige artsen met betrekking tot managementtheorieën met betrekking tot organisatorische innovatie.

De studie toonde dat een reorganisatieproces dat is opgezet als een prospectieve klinische trial mogelijk is. De betreffende opzet geeft medewerkers meer transparantie over problemen, oorzaken, interventies en effecten. In de kwalitatieve evaluatie werd 
het duidelijk dat deze benadering goed geaccepteerd wordt bij medische professionals (onderzoeksvraag 5)

\section{Deel IV algemene discussie en conclusies en aanbevelingen}

In hoofdstuk 7 is de algemene discussie van dit proefschrift opgenomen, alsmede de conclusies en aanbevelingen. Geconcludeerd wordt dat Nederlandse radiotherapie centra erg innovatief zijn maar dat verbeteringen wel nog mogelijk zijn omdat er grote verschillen zijn tussen centra; translatie van onderzoek in de klinische praktijk verder verbeterd kan worden; niet alle behandel en technologische innovaties wetenschappelijk worden geëvalueerd op relevante output dimensies; en soms ook niet op patiënt gerelateerde output data voor implementatie. Tenslotte hebben studies met betrekking tot organisatorische innovaties vaak een beperkte scope en geen sterke evidentie. Dit maakt evaluatie van innovaties voor implementatie moeilijk. Aanbevelingen om innovatie implementatie te versterken zijn beschreven, zoals bijvoorbeeld het registreren en benchmarken van de resultaten op innovatie indicatoren en het uitbouwen van de samenwerking op innovatie implementatie. Tenslotte is het belangrijk dat het management zorg draagt voor het juiste innovatieklimaat met betrekking tot managementstijl, organisatie contingenties en de innovatiestrategie. 

DANKWOORD 

Het is klaar! Naast mijn baan, mijn gezin, mijn familie, mijn commissariaten, mijn hobbies en "ruim" voor mijn pensioen (:) . De prijs was hoog. Indien ik dit toen had geweten, was ik waarschijnlijk niet gestart. Maar nu ben ik blij dat ik indertijd onwetend was. Ik heb geen spijt. Het was ook een mooi traject waar ik me vaak weer heerlijk student (en dus jong!) kon voelen.

Een dergelijk project, in deze fase van mijn leven met de vele activiteiten maar ook verplichtingen, is alleen mogelijk als je een heel goed ondersteuningsnetwerk om je heen hebt. En dat had ik. Heel erg veel dank is hier dan ook op zijn plaats voor heel veel mensen.

Allereerst is veel dank verschuldigd aan het promotieteam (Frits van Merode, Philippe Lambin en Liesbeth Boersma) en ook aan Andre Dekker. Beste Frits, jij was werkelijk een levende bibliotheek waar ik online toegang tot had! Alle relevante management literatuur en concepten, ook buiten je directe vakgebied, heb jij op het netvlies. Daarenboven was jij altijd bereid je drukke agenda vrij te maken om even te sparren. Ik heb het als zeer waardevol ervaren en we hebben afgesproken dat we daar gewoon mee doorgaan. Beste Philippe, jij bent een orginele en inventieve denker. Geen probleem is te groot voor jou. Je steeg regelmatig uit boven mijn onderzoeksuitvoering en reikte nieuwe concepten aan als ik weer eens even vastzat. Ook bij jou klopte ik nooit tevergeefs aan en je kwam altijd met verrassende inzichten over hoe verder te gaan. Dan Liesbeth, zonder jou zou ik het zeker niet hebben gered. Jij had mij veel meer te bieden dan alleen je intellectualiteit en je heldere, nuchtere visie op vraagstellingen. Ik liet jou altijd als laatste mijn teksten lezen omdat jij als geen ander de puntjes op de i kan zetten, oog hebt voor de importantie van structuur, alle formuleringen die niet worden ( $h$ )erkend door artsen er uit sloopt en zaken vereenvoudigt zodat ze duidelijk worden voor derden. Daarenboven had jij ook altijd hele praktische, goed werkende oplossingen voor problemen tijdens het onderzoek. Jouw steun was voor mij van onschatbare waarde. Heel veel dank! André, eigenlijk was je ook promotor. Zo heb je althans voor mij gefunctioneerd. Waar je ter wereld ook was, binnen no time had ik van jou antwoord op vragen en reviewde jij mijn artikelen. Jouw brede en innovatieve blik op zaken en je snelle sterke denkkracht hebben me enorm geholpen om het management perspectief aanspreekbaarder te maken voor mensen die daar van nature weinig affiniteit mee hebben.

Dan de overige co-auteurs: Dirk, Frank, Rachel, Mark, Geert, Cindy, Luc, Evelien, Joost, Bram. Ook veel dank voor jullie. Rachel en Luc, jullie noem ik nog even specifiek, ik heb jullie denk ik wel af en toe tot wanhoop gedreven als ik weer eens bepaalde analyses boven tafel moest krijgen of omdat toch iets weer net even anders moest. Als jullie me niet geholpen hadden was ik nog niet klaar geweest. Veel dank! Alle anderen ook veel dank voor jullie review, ondersteunend werk of adviezen. 
Ruud en Pascale, jullie dank ik zeer voor de adviezen rondom statistische bewerkingen en calculaties. Danny dank voor het nalezen van teksten en voor de opmaak van figuren. Sara voor het ondersteunend werk. Simone en Claudia, ik prijs me heel rijk dat jullie ons directiesecretariaat vormen. Ook jullie staan me overal bij en zijn geweldige ondersteuners.

Ook veel dank aan alle collega's van andere radiotherapiecentra die me belangenloos lijsten invulden, te woord stonden en zaken toestuurden.

De Raad van Toezicht dank ik dat ze mij de mogelijkheid hebben gegeven dit naast mijn werk te doen en voor alle steun tijdens de moeilijkere momenten op het werk.

Alle medewerkers van MAASTRO dank ik dat ze, elke dag opnieuw, MAASTRO een hele mooie organisatie laten zijn, waar met hart en ziel wordt gewerkt aan de zorg voor oncologische patiënten. Jullie creëren het klimaat waar ontwikkeling en vooruitgang centraal staan en waar zelfs een bestuurder de mogelijkheid heeft een PhD-traject te doen.

De leden van de leescommissie en de corona ook veel dank voor de bereidheid mijn proefschrift te beoordelen en een actieve rol te vervullen bij de verdediging. Ik voel me zeer vereerd dat jullie dit met jullie drukke agenda wilden doen.

Lieve Henk, Joost, Maartje en Frank. Ik heb jullie in de afgelopen jaren met zekerheid tekort gedaan. "Je luistert weer eens niet", "het is ongezellig want jij bent er niet of zit achter je bureau"," je bent prikkelbaar omdat het je weer eens tegenzit". Ik heb geprobeerd er altijd te zijn op momenten die ertoe deden. Ik realiseer me dat dit te weinig is. Ook momenten die er feitelijk niet toe doen zijn belangrijk in een gezinsleven. Toch hadden jullie wel begrip voor mijn ambities. Jullie wisten dat ik dit moest afmaken en dat zeiden jullie ook op de momenten dat ik dat nodig had. Heel veel dank daarvoor. Ik ga het goedmaken.

Lieve pap. Je kunt er net niet meer bij zijn. Ik heb er te lang over gedaan. Jij had er bij moeten zijn. Je hebt me altijd gestimuleerd het beste uit mezelf te halen en om te gaan voor een maximale prestatie. Ik had je gegund dat je had kunnen meemaken dat in ieder geval op dit punt je aanmoediging tot succes heeft geleid. Maar ook al ben je er niet fysiek, ik zie je gezicht, ik hoor je woorden en ze inspireren me nog steeds. Ik dank je voor alles. Lieve mam, ik ben super trots dat jij op 92-jarige leeftijd dit, voor mij belangrijke moment, kunt meemaken. Jij bent tot de dag van vandaag een moeder die er altijd voor me is, die nog steeds met veel liefde klusjes voor ons doet en die zorgzaam blijft. Sinds pap er niet meer is probeer ik ook door de week meer bij jou te zijn. Ik voel me zeer 
bevoorrecht dat ik tijdens al die momenten op 57 jarige leeftijd nog steeds de warmte van een betrokken moeder mag ervaren.

Tot slot ook dank aan vrienden en familie die met mijn geringe beschikbaarheid werden geconfronteerd en het daarmee moesten doen. Het is klaar nu. 

CURRICULUM VITAE 



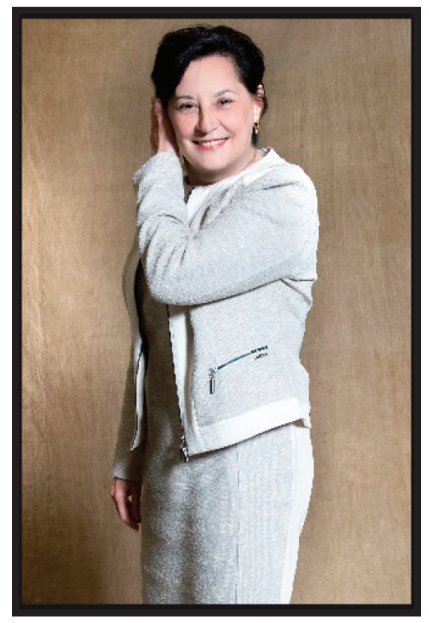

Maria Jacobs was born on 18 October 1959 in Ospel, the Netherlands. After finishing her pre-university education (VWO) in 1978 she took a higher vocational course in Human Resource Management in Eindhoven, which she completed in 1982.

Maria was subsequently appointed as a human resource manager at a psychiatric hospital in Boekel in that same year and, later on, at the general hospital in Sittard (Orbis Medical Centre). In 1989 she entered the three-year postgraduate programme in Business Administration in Maastricht, graduating cum laude. In 1994 she was promoted to the hospital management staff. In 2000 she completed an MSc degree in Business Administration at the Radboud University in Nijmegen, again graduating cum laude. She also completed a two-year postgraduate programme at the University of Leuven in the field of organisational development and process consultation. In 2003 she left the hospital in Sittard for the Maxima Medical Centre in Eindhoven. As a project manager there, she was tasked with establishing a new medical centre focused on elective hospital care. This project was so pioneering and successful that the Dutch minister of Public Health, personally opened the centre.

In early 2005 Maria Jacobs was asked to return to Orbis, which was involved in a largescale merger process. All homecare facilities in the entire western mining region were to become part of the Orbis Group and Maria was asked to lead the merger process. After the merger she was appointed director of the home and elderly care division within the Orbis group. One important task concerned the establishment of a joint venture with a commercial company (Vebego) while increasing quality of care and reducing costs, given that reimbursements for homecare were decreasing rapidly at the time. This project was completed successfully and the joint venture continues to work well. As the only large homecare organisation operating at that time, Orbis achieved a designation of 'A status' for care delivery and simultaneously saw annual returns increase by more than $25 \%$.

Per 1 May 2008 Maria was appointed to the board of directors in MAASTRO. In 2010 she started her PhD. The permanent tension between content and money, between freedom for the professional and the necessary restrictions in favour of a responsible management gave her the inspiration for her PHD. In 2015 she was appointed CEO of MAASTRO. Important projects during her tenure at MAASTRO have included the consolidation of MAASTRO's financial position in 2009 and 2010, the replacement of all equipment in 2011 and 2012, the foundation of a new satellite clinic in Venlo in 2012, 
the introduction of proton therapy in Maastricht (in preparation) and the introduction of several new management concepts. 
LIST OF PUBLICATIONS 



\section{Peer reviewed articles}

> Jacobs M, Boersma L, Dekker A, Hermanns E, Houben R, Govers M, et al. Organizational development trajectory of a large academic radiotherapy department set up similarly to a prospective clinical trial: the MAASTRO experience. Br J Radiol 2015:88:20140559.

> Jacobs M, Boersma L, Dekker A, Govers M, Lambin P, van Merode G. How to measure innovation in radiotherapy: an application of the Delphi method. Journal of Hospital Administration 2015:4(4) DOI: 10.5430/jha.v4n4p14

> Jacobs M, Boersma L, Merode FV, Dekker A, Verhaegen F, Linden L, et al. How efficient is translational research in radiation oncology? The example of a large Dutch academic radiation oncology department. Br J Radiol 2016; 89: 20160129.

> Jacobs M, Boersma L, Dekker A, Bosmans G, Van Merode F, Swart R, et al. What is the degree of innovation routinely implemented in Dutch radiotherapy centres? A multicentre cross-sectional study. Br J Radiol 2016; 89: 20160601.

> Jacobs M, Boersma L, Dekker A, Lambin P, de Russcher D, Swart R, Verhaegen F, Stultiens J, Ramaekers B \& van Merode G. What is the impact of innovation on output in health care with a special focus on treatment innovations in radiotherapy? A literature review. Submitted in: British Journal of Radiology.

> Lambin P, Zindler J, Vanneste B, van de Voorde L, Jacobs M, Eekers D, Peerlings J, Reymen B, Larue R, Deist T, de Jong E, Even A, Berlanga A, Roelofs E, Cheng Q, Carvalho S, Leijenaar R, Zegers $C$, van Limbergen E, Berbee $M$, van Elmpt W, Oberije C, Houben R, Dekker A, Boersma L, Verhaegen F, Bosmans G, Hoebers F, Smits K \& Walsh S. Modern clinical research: How rapid learning health care and cohort multiple randomised clinical trials complement traditional evidence based medicine, Acta Oncologica 2015:54:9, 1289-1300, DOI: 10.3109/0284186X.2015.1062136

> Lambin P, Zindler J, Vanneste B, Van de Voorde L, Eekers D, COmpter I, Panth K, Peerlings J, Larue R, Diest T, Jochems A, Lustberg T, van Soest J, de Jong E, Even A, Reymen B, Rekers N, van Gisbergen M, Roelifs E, Carvalho S, Leijenaar R, Zegers C, Jacobs $\mathbf{M}$, van Timmeren J, Brouwers $P$, Lal J, Dubois L, Yaromina A, van Limbergen E, Berbee M, van Elmpt W, Oberije C, Ramaekers B, Dekker A, Boersma L, Hoebers F, Smits K, Berlanga A and Wlalsh S. Decision support systems for personalized and participative radiation oncology. Advanced drugs delivery reviews 2017:109:131153. DOI: $10.1016 /$ j.addr.2016.01.006 
> Simons P, Backes H, Bergs J, Emans D, Johannesma M, Jacobs M, Marneffe W and Vandijck $D$. The effects of a lean transition on process times, patients and employees. International Journal of Health Care Quality Assurance 2017: Vol. 30 Iss 2 pp. 103 118 DOI: 10.1108/IJHCQA-08-2015-0106

\section{Book chapter}

> Backes $\mathrm{H}$ \& Jacobs $\mathbf{M}$. Lean in de Maastro Clinic: gestaag richting 'true North'. In: Benders J, van der Voort M \& Berden B. Lean denken en doen in de zorg. Acht verhalen uit de praktijk. Den Haag: Uitgeverij LEMMA; 2010: 35-42.

\section{International posters (presentation)}

> Jacobs M, Boersma L, Hermanns E, Smits K, Moorman S, Van Merode F, Lambin P. PO-0788: The reorganization of a large academic radiotherapy department set-up similar to a prospective clinical trial. Radiotherapy and Oncology, December 2014: 111:S55. DOI: 10.1016/S0167-8140(15)30906-3

> Soman R, Dekker A, Emans D, Jacobs M, Backes H \& van Merode F. EP-1425: Prediction of waiting time for lung cancer patients. Radiotherapy and Oncology, december 2014: 111:S131 DOI: http://dx.doi.org/10.1016/S0167-8140(15)31543-7

> Paulissen J, Offermann C, Houben R, van Ern E, Brouns M, Backes H, Boersma L, Vreuls G, Lemmen R, Dekker A, Lambin P, Jacobs M \& Smits K. PO-0783: Implementation of a trial outpatient clinic to improve participation and data collection in trials. April: 2016. DOI: 10.1016/S0167-8140(16)32033-3

> Jacobs, M, Dekker A, Boersma L, van Merode F, Bosmans G, Linden L, Simons P, Moorman S \& Lambin P. PV-0085: The level of innovations routinely implemented in Dutch radiotherapy centers: a cross-sectional study. April: 2016. https://user-swndwmf.cld.bz/ESTRO-35-Abstract-book3/62

> Jacobs, M, Boersma L, van Merode F, Dekker A, Verhaegen F, Linden L, Moorman S \& Lambin P. PV-0086: Clinical implementation of research within a radiotherapy department. A quality indicator? April: 2016. CN https://user-swndwmf.cld.bz/ESTRO-35-Abstract-book3/62 


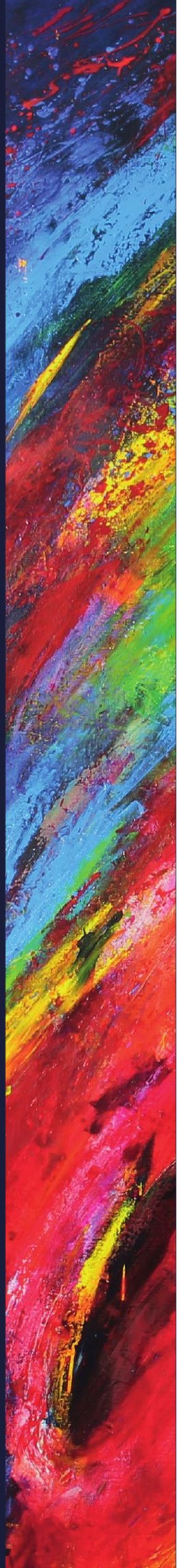